Portland State University

PDXScholar

TREC Final Reports

Transportation Research and Education Center

(TREC)

10-2009

\title{
Evaluating the Effectiveness of the Safety Investment Program (SIP) Policies for Oregon
}

Christopher M. Monsere

Portland State University, monsere@pdx.edu

Lisa Diercksen

Portland State University

Karen Dixon

Oregon State University

Michael Liebler

Oregon State University

Follow this and additional works at: https://pdxscholar.library.pdx.edu/trec_reports

Part of the Transportation Commons, Urban Studies Commons, and the Urban Studies and Planning Commons

Let us know how access to this document benefits you.

\section{Recommended Citation}

Christopher Monsere, Lisa Diercksen, Karen Dixon and Michael Liebler. Evaluating the Effectiveness of the Safety Investment Program (SIP) Policies for Oregon. OTREC-RR-10-11. Portland, OR: Transportation Research and Education Center (TREC), 2009. https://doi.org/10.15760/trec.69

This Report is brought to you for free and open access. It has been accepted for inclusion in TREC Final Reports by an authorized administrator of PDXScholar. Please contact us if we can make this document more accessible: pdxscholar@pdx.edu. 


\title{
EVALUATING THE EFFECTIVENESS OF
} THE SAFETY INVESTMENT PROGRAM (SIP) POLICIES FOR OREGON

\author{
Final Report
}

SPR 651 



\title{
EVALUATING THE EFFECTIVENESS OF THE SAFETY INVESTMENT PROGRAM (SIP) POLICIES FOR OREGON
}

\section{SPR 651}

\section{FINAL REPORT}

\author{
by \\ Christopher M. Monsere, Ph.D., P.E., Assistant Professor \\ Lisa Diercksen, Graduate Research Assistant \\ Portland State University \\ PO Box 751 \\ Portland OR 97207 \\ and \\ Karen Dixon Ph.D., P.E., Associate Professor \\ Michael Liebler, Graduate Research Assistant \\ School of Civil and Construction Engineering \\ Oregon State University \\ Corvallis, OR 97331 \\ for \\ Oregon Department of Transportation \\ Research Section \\ 200 Hawthorne SE, Suite B-240 \\ Salem OR 97310 \\ and \\ Federal Highway Administration \\ 400 Seventh Street, SW \\ Washington, DC 20590-0003
}


Page Intentionally Blank 


\begin{tabular}{|c|c|c|}
\hline $\begin{array}{l}\text { 1. Report No. } \\
\text { FHWA-OR-RD-10-05 }\end{array}$ & 2. Government Accession No. & 3. Recipient's Catalog No. \\
\hline \multicolumn{2}{|c|}{$\begin{array}{l}\text { 4. Title and Subtitle } \\
\text { Evaluating the Effectiveness of the Safety Investment Program (SIP) Policies } \\
\text { for Oregon }\end{array}$} & 6. Performing Organization Code \\
\hline $\begin{array}{l}\text { 7. Author(s) } \\
\text { Christopher M. Monsere, and Lisa Die } \\
\text { Karen Dixon, and Michael Liebler, Oı }\end{array}$ & $\begin{array}{l}\text { ercksen, Portland State University } \\
\text { regon State University }\end{array}$ & 8. Performing Organization Report No. \\
\hline 9. Performing Organization Name and Address & & $\begin{array}{l}\text { 10. Work Unit No. (TRAIS) } \\
\text { 11. Contract or Grant No. } \\
\text { SPR } 651\end{array}$ \\
\hline $\begin{array}{l}\text { 12. Sponsoring Agency Name and Address } \\
\text { Oregon Department of Transportation } \\
\text { Research Section } \\
200 \text { Hawthorne Ave. SE, Suite B-240 } \\
\text { Salem, Oregon 97301-5192 } \\
\text { Federal Highway Administration } \\
\text { 400 Seventh Street, SW } \\
\text { Washington, DC 20590-0003 }\end{array}$ & $\begin{array}{l}\text { Oregon Transportation Research } \\
\text { and Education Consortium (OTREC) } \\
\text { P.O. Box } 751 \\
\text { Portland, Oregon } 97207 \\
\text { and }\end{array}$ & $\begin{array}{l}\text { 13. Type of Report and Period Covered } \\
\text { 14. Sponsoring Agency Code }\end{array}$ \\
\hline
\end{tabular}

15. Supplementary Notes

16. Abstract

The Safety Investment Program (SIP) was originally called the Statewide Transportation Improvement Program Safety Investment Program (STIP-SIP). The concept of the program was first discussed in October 1997 and the program was adopted by the Oregon Transportation Commission in August 1998. The concept for the program grew out of a cost-effective approach to pavement preservation projects that set out to maximize the impact of money spent on highway safety, based on crash reduction factors. Safety projects were to be selected based on high crash locations as identified by the Safety Priority Index System (SPIS) and SIP Category ratings of five-mile sections. This research evaluated the SIP Policy from the perspective of: 1) an overall program for safety improvement projects, 2) a guiding policy when safety improvements are planned as part of other project work, and 3) a component integrated with the highway design procedures for resurfacing, restoration, or rehabilitation (3R) projects. The research included two levels of evaluation; the first evaluation was done as part of the systemic evaluation, while the second was a project-level evaluation. The systematic evaluation revealed that, in general, projects where safety funds were used resulted in a net decrease in total crashes as well as severe and fatal crashes; however, these benefits were not realized for all locations or all work types. The detailed review of the 24 mixed safety-preservation projects highlighted some of the challenges of successfully implementing the SIP Policy. It was clear that the SIP Policy has not been applied consistently to mixed projects. In particular, the variety of design and, to a lesser extent, the funding eligibility scores, highlight the variety of policy interpretations. The projectlevel evaluation concluded that the most important project element to improve safety performance was the specific identification of a safety problem. Recommendations were made on improved documentation procedures at the project level as well as strategies to improve overall policy compliance.

\begin{tabular}{l|l} 
17. Key Words & 18. Distribution Statement
\end{tabular}

Safety evaluation, safety management, pavement preservation, project management

19. Security Classification (of this report) 20. Security Classification (of this page) 21. No. of Pages
180 


\begin{tabular}{|c|c|c|c|c|c|c|c|c|c|}
\hline \multicolumn{10}{|c|}{ SI* (MODERN METRIC) CONVERSION FACTORS } \\
\hline \multicolumn{5}{|c|}{ APPROXIMATE CONVERSIONS TO SI UNITS } & \multicolumn{5}{|c|}{ APPROXIMATE CONVERSIONS FROM SI UNITS } \\
\hline Symbol & When You Know & Multiply By & To Find & Symbol & Symbol & When You Know & Multiply B & To Find & Symbol \\
\hline \multicolumn{5}{|c|}{ LENGTH } & \multicolumn{5}{|c|}{ LENGTH } \\
\hline in & inches & 25.4 & millimeters & $\mathrm{mm}$ & $\mathrm{mm}$ & millimeters & 0.039 & inches & in \\
\hline $\mathrm{ft}$ & feet & 0.305 & meters & $\mathrm{m}$ & $\mathrm{m}$ & meters & 3.28 & feet & $\mathrm{ft}$ \\
\hline yd & yards & 0.914 & meters & $\mathrm{m}$ & $\mathrm{m}$ & meters & 1.09 & yards & yd \\
\hline $\mathrm{mi}$ & miles & 1.61 & kilometers & $\mathrm{km}$ & $\mathrm{km}$ & kilometers & 0.621 & miles & $\mathrm{mi}$ \\
\hline \multicolumn{5}{|c|}{ AREA } & \multicolumn{5}{|c|}{ AREA } \\
\hline$i^{2}$ & square inches & 645.2 & millimeters squared & $\mathrm{mm}^{2}$ & $\mathrm{~mm}^{2}$ & millimeters squared & $\overline{0.0016}$ & square inches & $\mathrm{in}^{2}$ \\
\hline $\mathrm{ft}^{2}$ & square feet & 0.093 & meters squared & $\mathrm{m}^{2}$ & $\mathrm{~m}^{2}$ & meters squared & 10.764 & square feet & $\mathrm{ft}^{2}$ \\
\hline $\mathrm{yd}^{2}$ & square yards & 0.836 & meters squared & $\mathrm{m}^{2}$ & $\mathrm{~m}^{2}$ & meters squared & 1.196 & square yards & $\mathrm{yd}^{2}$ \\
\hline ac & acres & 0.405 & hectares & ha & ha & hectares & 2.47 & acres & ac \\
\hline $\mathrm{mi}^{2}$ & square miles & 2.59 & kilometers squared & $\mathrm{km}^{2}$ & $\mathrm{~km}^{2}$ & kilometers squared & 0.386 & square miles & $\mathrm{mi}^{2}$ \\
\hline \multicolumn{5}{|c|}{ VOLUME } & \multicolumn{5}{|c|}{ VOLUME } \\
\hline $\mathrm{fl} \mathrm{oz}$ & fluid ounces & 29.57 & milliliters & $\mathrm{ml}$ & $\mathrm{ml}$ & milliliters & 0.034 & fluid ounces & $\mathrm{fl} \mathrm{oz}$ \\
\hline gal & gallons & 3.785 & liters & $\mathrm{L}$ & $\mathrm{L}$ & liters & 0.264 & gallons & gal \\
\hline $\mathrm{ft}^{3}$ & cubic feet & 0.028 & meters cubed & $\mathrm{m}^{3}$ & $\mathrm{~m}^{3}$ & meters cubed & 35.315 & cubic feet & $\mathrm{ft}^{3}$ \\
\hline $\mathrm{yd}^{3}$ & cubic yards & 0.765 & meters cubed & $\mathrm{m}^{3}$ & $\mathrm{~m}^{3}$ & meters cubed & 1.308 & cubic yards & $y d^{3}$ \\
\hline \multicolumn{10}{|c|}{ NOTE: Volumes greater than $1000 \mathrm{~L}$ shall be shown in $\mathrm{m}^{3}$. } \\
\hline \multicolumn{5}{|c|}{ MASS } & \multicolumn{5}{|c|}{ MASS } \\
\hline $\mathrm{oz}$ & ounces & 28.35 & grams & g & g & grams & $\overline{0.035}$ & ounces & $\mathrm{oz}$ \\
\hline $\mathrm{lb}$ & pounds & 0.454 & kilograms & $\mathrm{kg}$ & $\mathrm{kg}$ & kilograms & 2.205 & pounds & $\mathrm{lb}$ \\
\hline $\mathrm{T}$ & short tons (2000 lb) & 0.907 & megagrams & $\mathrm{Mg}$ & $\mathrm{Mg}$ & megagrams & 1.102 & short tons (2000 lb) & $\mathrm{T}$ \\
\hline \multicolumn{5}{|c|}{ TEMPERATURE (exact) } & \multicolumn{5}{|c|}{ TEMPERATURE (exact) } \\
\hline${ }^{\circ} \mathrm{F}$ & Fahrenheit & $(\mathrm{F}-32) / 1.8$ & Celsius & ${ }^{\circ} \mathrm{C}$ & ${ }^{\circ} \mathrm{C}$ & Celsius & $1.8 \mathrm{C}+32$ & Fahrenheit & ${ }^{\circ} \mathrm{F}$ \\
\hline
\end{tabular}




\section{ACKNOWLEDGEMENTS}

The authors thank the Oregon Department of Transportation (ODOT), Federal Highway Administration (FHWA) for funding this research. The Oregon Transportation Research Consortium (OTREC) and Portland State University's Department of Civil and Environmental Engineering also supported this work. The Technical Advisory Committee has provided valuable input throughout the project, members of the committee include: Doug Bish, Tim Burks, Ed Fischer, Anne Holder, Christopher Henson, Liz Hunt, Joel McCarroll, Kathleen McConnell, Brian Paslay, and June Ross - ODOT; Nick Fortey - FHWA. In addition, staff of each region contributed the documents and provided a review of the projects including Sue Dagnese, Carrie Martin, Lloyd Bledsoe, Robert Sechler, Daniel Serpico, and Rich Heinemann, Norma Kearney provided all of the contractor data. Jill Scofield provided all of the STIP data. Many other ODOT staff provided assistance at various stages of the project.

\section{DISCLAIMER}

The contents of this report reflect the views of the authors, who are solely responsible for the facts and the accuracy of the material and information presented herein. This document is disseminated under the sponsorship of the U.S. Department of Transportation University Transportation Centers Program, Oregon Transportation Research Consortium, and the Oregon Department of Transportation in the interest of information exchange. The U.S. Government, Oregon Transportation Research Consortium, and the Oregon Department of Transportation assume no liability for the contents or use thereof. The contents do not necessarily reflect the official views of the U.S. Government Oregon Transportation Research Consortium, or the Oregon Department of Transportation. This report does not constitute a standard, specification, or regulation. 
Page Intentionally Blank 


\section{EVALUATING THE EFFECTIVENESS OF THE SAFETY INVESTMENT PROGRAM (SIP) POLICIES FOR OREGON}

\section{TABLE OF CONTENTS}

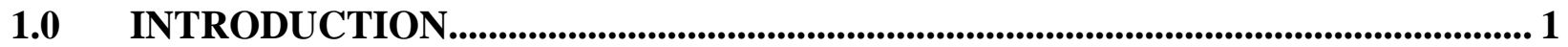

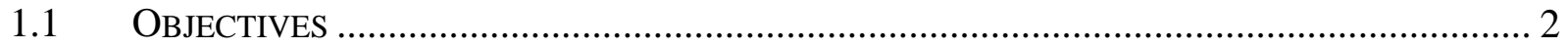

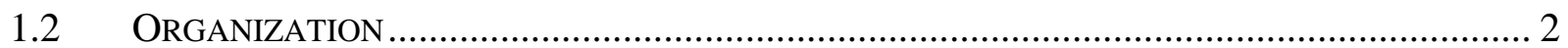

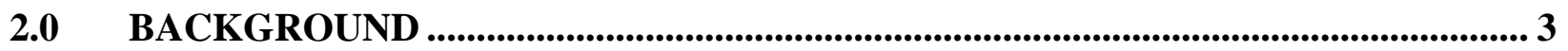

2.1 Safety InVestment Program (SIP) Policy .............................................................. 3

2.2 ODOT HIGHWAY DESIGN MANUAL ………………….............................................. 4

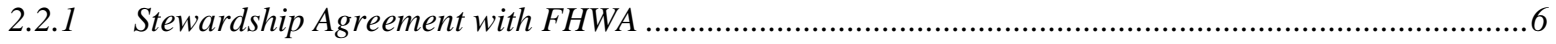

2.3 HighWAY SAFETY IMPROVEMENT PROGRAM (HSIP) ..................................................... 7

$3.0 \quad$ LITERATURE REVIEW ...................................................................................... 9

3.1 Historical PaVEMENT PRESERVATION Policies ......................................................... 9

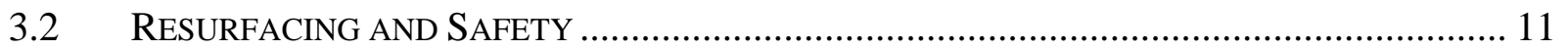

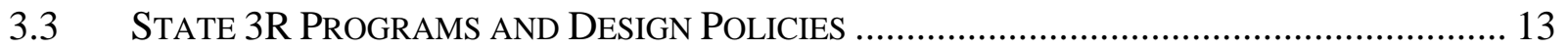

3.4 FUNDING ALLOCATION: SYSTEM OPTIMIZATION …………………………............... 17

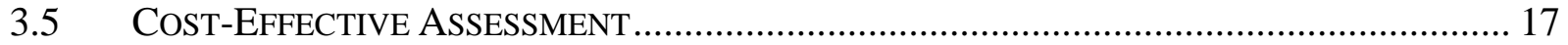

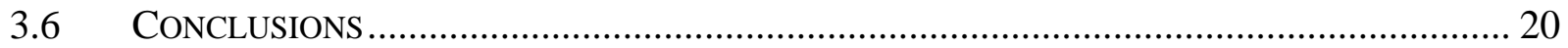

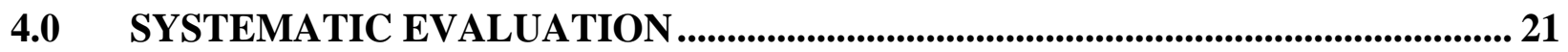

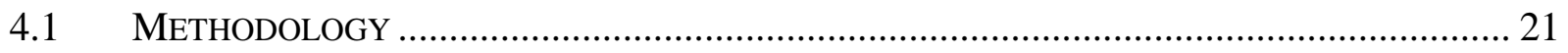

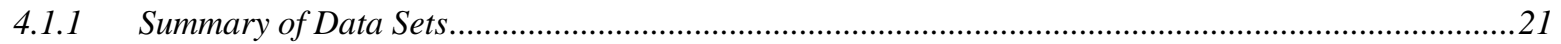

4.1.2 Approach for Relational Linking of Datasets ..................................................................................23

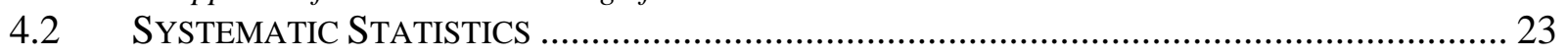

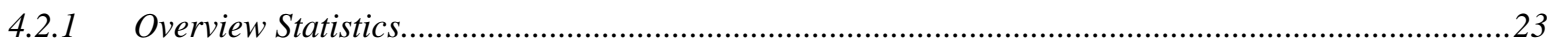

4.2.2 Example Detailed Statistics using Relational Dataset............................................................................28

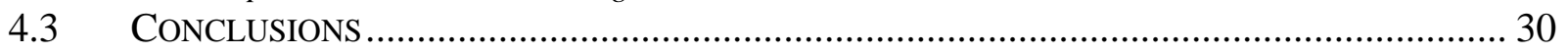

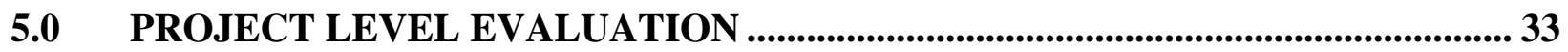

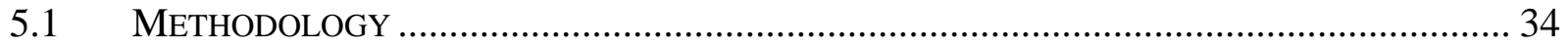

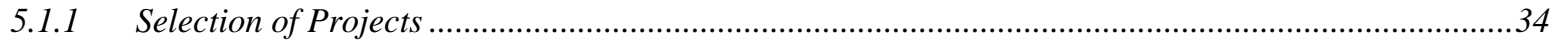

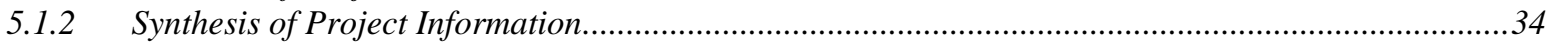

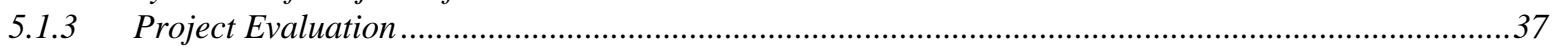

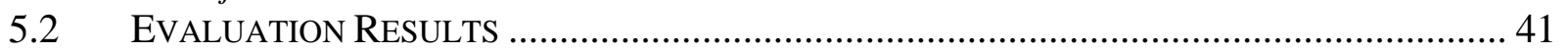

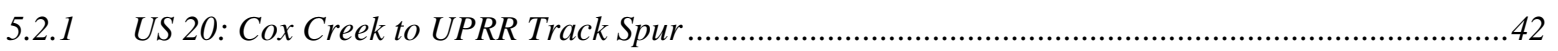

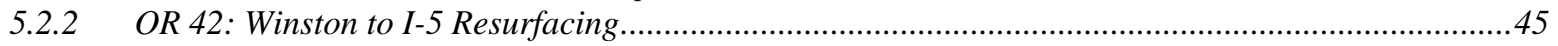

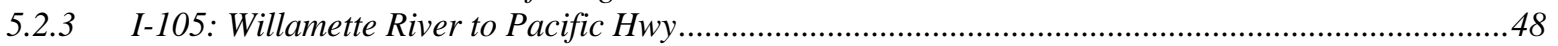

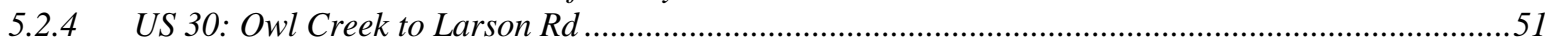

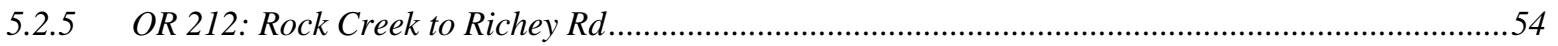

5.2.6 OR 10: Beaverton Tigard Hwy to Multnomah Co Line .................................................................58

5.2.7 OR 8: Quince St (Forest Grove) to District Boundary (Gaston) ....................................................6

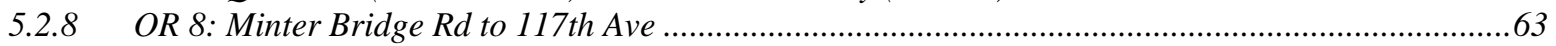

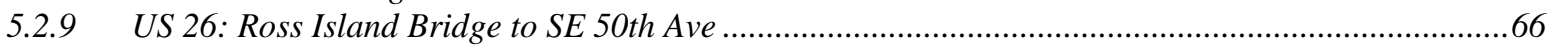


5.2.10 OR 6: Tillamook RR Overpass to Jordan Creek Bridge ..........................................................69

5.2.11 OR 22: Chemawa Rd to N Santiam Interchange..........................................................................

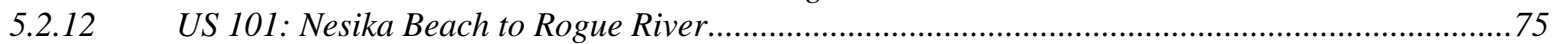

5.2.13 OR 126: Crooked River to Laughlin Rd (Prineville) ...............................................................78

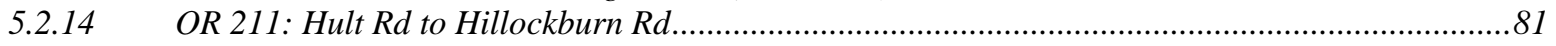

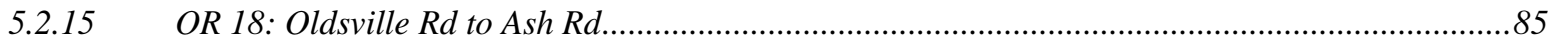

5.2.16 US 30: Bennett Rd to Laurel Ave ............................................................................................. 88

5.2.17 OR 35: Jct Hood River Hwy to Polallie Creek ...............................................................................91

5.2.18 OR 35: Long Prairie Rd to Odell Hwy .......................................................................................94

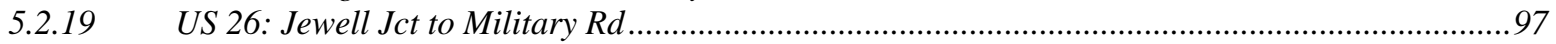

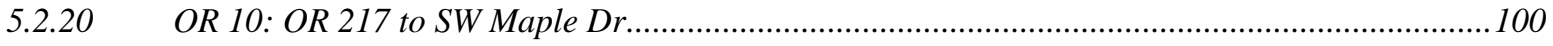

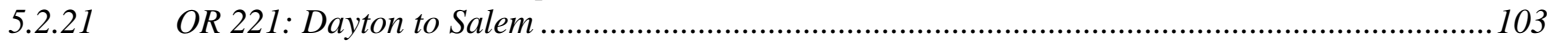

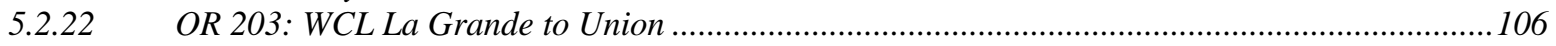

5.2.23 US 26: Lindsley Creek to Lower Nehalem Rd........................................................................109

5.2.24 US 20: Hampton to Glass Butte and Torkelson Rd.............................................................112

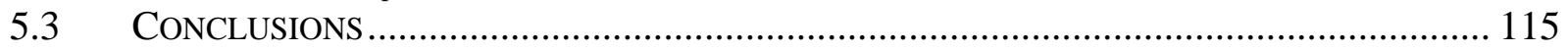

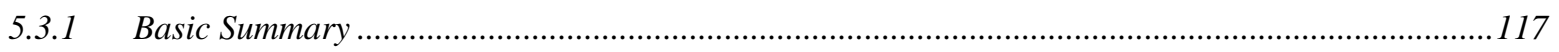

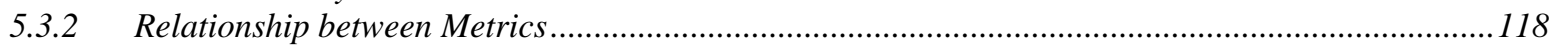

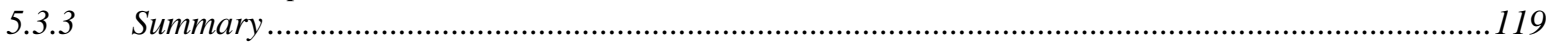

6.0 PERFORMANCE MEASURES.............................................................................. 121

6.1 EXISTING PERformance MEASURES .................................................................. 121

6.2 Potential PERformance Measures...................................................................... 123

7.0 CONCLUSIONS AND RECOMMENDATIONS............................................................. 127

$7.1 \quad$ CONCLUSIONS .................................................................................................... 127

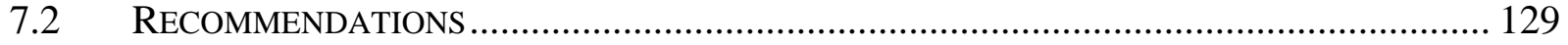

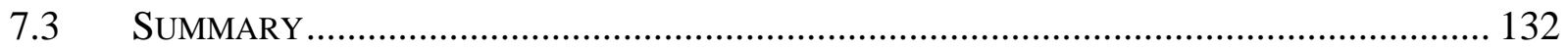

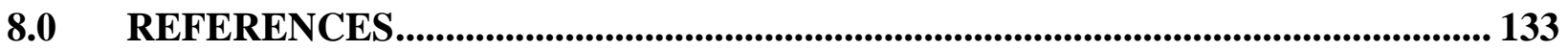

\section{APPENDICES}

Appendix A: Acronym List

Appendix B: OTC Meeting Minutes, August 1998

Appendix C: STIP Project Summaries

Appendix D: STIP Project Summaries

\section{LIST OF FIGURES}

Figure 2.1: Text from the ODOT Highway Design Manual...................................................................................

Figure 2.2: ODOT Highway Design Manual - Table 7-5: Mandatory Design Features..............................................6

Figure 4.1: Example GIS Buffer for a 2002-2005 STIP Project Site and Associated Crashes ...................................22

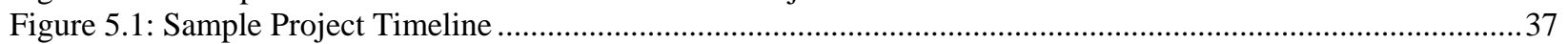

Figure 5.2: Conditions at Spicer Rd in 2002 (before) and added turn lanes in 2003 (after) ......................................43

Figure 5.3: Safety Performance, US 20-Cox Creek to UPRR Track Spur, Key No. 07101 ........................................45

Figure 5.4: Conditions in 2002 (before) and in 2004 (after) showing the addition of the right-turn lane at

“Kelly’s Corner” MP 75.72. OR-99 improvements not shown............................................................................46

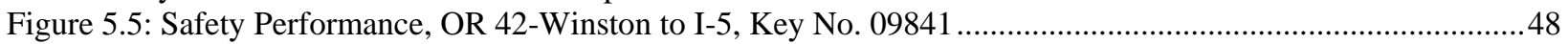

Figure 5.6: Conditions in 2004 (before) and 2006 (after) showing the additional auxiliary weaving lane .................49

Figure 5.7: Safety Performance, I-105 Willamette River to Pacific Hwy, Key No. 10349 ..........................................51 
Figure 5.8: Conditions in 2000 (before) and 2006 (after) showing guardrail and pavement markings at MP 49.10

Figure 5.9: Safety Performance, US 30-Owl Creek to Larson Rd, Key No. 10576 ................................................54

Figure 5.10: Conditions in 2001 (before) and 2002 (after) showing the preservation work at MP 4.93 and

the area near Royer Road (no median installed) .56

Figure 5.11: Safety Performance, OR 212-Rock Creek to Richey Rd, Key No. 10665 ..............................................57

Figure 5.12: Conditions in 2002 (before) and in 2007 (after) at MP 2.77 ...........................................................59

Figure 5.13: Project Scorecard, OR 10-Beaverton Tigard Hwy to Multnomah Co Line, Key No. 10666 ..................59

Figure 5.14: Safety Performance, OR 10-Beaverton Tigard Hwy to Multnomah Co Line, Key No. 10666...............60

Figure 5.15: Conditions in 2003 (before) and in 2006 (after) showing the upgraded guardrail at MP 19.45 ..............61

Figure 5.16: Safety Performance, OR 8-Quince St to District Boundary, Key No. 10679.........................................63

Figure 5.17: Conditions in 2002 (before) and in 2003 (after) showing the preservation work at MP 5.30 ................64

Figure 5.18: Safety Performance, OR 8-Minter Bridge Rd to $117^{\text {th }}$ Ave, Key No. 10680 .......................................66

Figure 5.19: Conditions in 2003 (before) and in 2006 (after) (2006) showing the overlay at MP 1.25 .....................67

Figure 5.20: Safety Performance, US 26-Ross Island Bridge to SE 50 ${ }^{\text {th }}$ Ave, Key No. 10731 .................................69

Figure 5.21: Flashing warning light at Wilson River Loop Road at MP 1.77 in 1998 and 2002.............................70

Figure 5.22: Safety Performance, OR 6-Tillamook RR Overpass to Jordan Creek Bridge, Key No. 10748 ................72

Figure 5.23: Conditions in 2004 (before) and in 2006 (after) showing the added safety lane extension at MP 7.98

Figure 5.24: Safety Performance, OR 22-Chemawa Rd to N Santiam Interchange, Key No. $10807 \ldots \ldots \ldots \ldots \ldots \ldots \ldots \ldots \ldots \ldots . . . . . . .75$

Figure 5.25: Conditions in 1998 (before) and 2001 (after) showing the preservation at MP 326.47 ..........................76

Figure 5.26: Safety Performance, US 101-Nesika Beach to Rogue River, Key No. 10817 .....................................78

Figure 5.27: Conditions in 2001 (before) and in 2004 (after) showing the traffic signal installation at OR

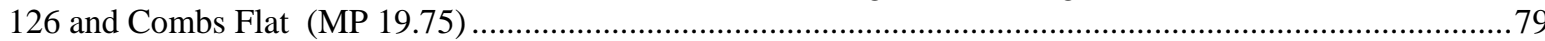

Figure 5.28: Safety Performance, OR 126-Crooked River to Laughlin Rd, Key No. 11072......................................81

Figure 5.29: Conditions in 2001 (before) and in 2004 (after) showing the added guardrail/upgraded culvert

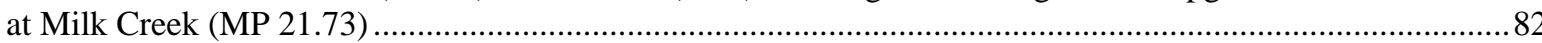

Figure 5.30: Conditions in 2001 (before) and in 2004 (after) showing the added guardrail/upgraded culvert

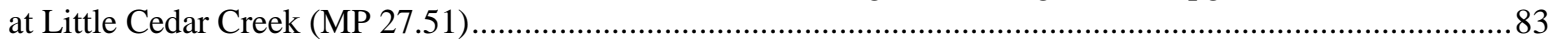

Figure 5.31: Safety Performance, OR 211-Hult Rd to Hillockburn Rd, Key No. 11125...........................................84

Figure 5.32: Conditions in 2004 (before) and in 2006 (after) showing the upgraded guardrail at MP 41.07 .............86

Figure 5.33: Safety Performance, OR 18-Oldsville Rd to Ash Rd, Key No. 11858.................................................87

Figure 5.34: Conditions in 2003 (before) and in 2005 (after) showing the preservation work at MP 23.14 ...............89

Figure 5.35: Safety Performance, US 30-Bennett Rd to Laurel Ave, Key No. 11938 ..............................................90

Figure 5.36: Conditions in 2004 (before) and in 2006 (after) showing the preservation work at MP 75.80 ...............92

Figure 5.37: Safety Performance, OR 35-Jct Hood River Hwy to Polallie Creek, Key No. 11939.............................93

Figure 5.38: Conditions in 2004 (before) and in 2006 (after) showing upgraded guardrail at MP 92.98...................95

Figure 5.39: Safety Performance, OR 35-Long Prairie Rd to Odell Hwy, Key No. 11940 .......................................96

Figure 5.40: Conditions in 2003 (before) and in 2007 (after) showing the upgraded guardrail at Bridge No.

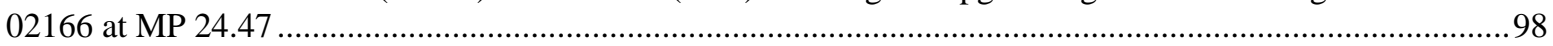

Figure 5.41: Safety Performance, US 26-Jewell Jct to Military Rd, Key No. 12856 ..............................................99

Figure 5.42: Conditions in 2002 (before) and in 2007 (after) showing construction at MP 0.98. Dual-left

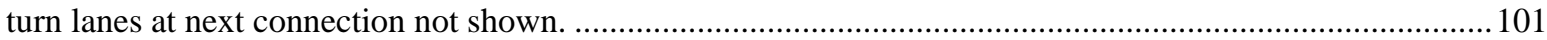

Figure 5.43: Safety Performance, OR 10- OR 217 to SW Maple Dr, Key No. 12905 .............................................102

Figure 5.44: Conditions in 2004 (before) and in 2007 (after) showing the upgraded guardrail ends at MP 0.75

Figure 5.45: Safety Performance, OR 221-Dayton to Salem, Key No. 13675 ....................................................105

Figure 5.46: Conditions in 2005 (before) and in 2008 (after) showing the upgraded and new guardrail at MP 15.60.

Figure 5.47: Safety Performance, OR 203-WCL La Grande to Union, Key No. 14127 ..........................................108

Figure 5.48: Conditions in 2004 (before) and in 2007 (after) showing the upgraded guardrail at Lindsley

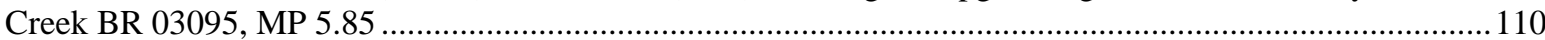

Figure 5.49: Conditions in 2004 and in 2007 (after) showing the Nehalem Road realignment at MP 19.72 ............110

Figure 5.50: Safety Performance, US 26-Lindsley Creek to Lower Nehalem Rd, Key No. 14172...........................112

Figure 5.51: Torkelson intersection MP 4.57 in 2006 and 2008......................................................................113

Figure 5.52: Conditions in 2006 and 2008 at MP 34.00 showing the addition of centerline rumblestrips................114 
Figure 5.53: Distribution of Evaluation Scores

\section{LIST OF TABLES}

Table 4.1: Summary by ODOT Region of Total Crashes for 2000 to 2003 STIP Projects ........................................24

Table 4.2: Summary by ODOT Region of Severe Crashes (Fatal \& Injury Type A) for 2000 to 2003 STIP

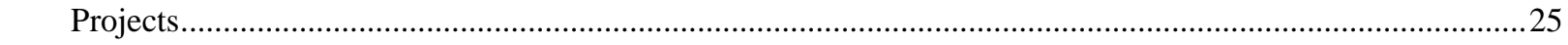

Table 4.3: Summary by Region of Total Crashes for 2002 to 2005 STIP Projects ..................................................26

Table 4.4: Summary by Region of Severe Crashes (Fatal \& Injury Type A) for 2002 to 2005 STIP Projects............26

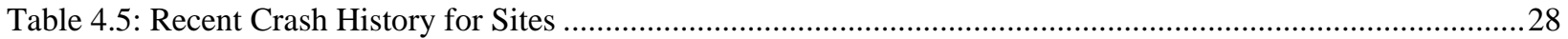

Table 4.6: Extended Severity Analysis for a Single Project (Key Number 11244) .................................................29

Table 4.7: Extended Analysis of Crash Type for a Single Project (Key Number 11244) .............................................30

Table 5.1: Number of projects selected from each region............................................................................................ 34

Table 5.2: Project Summary, US 20-Cox Creek to UPRR Track Spur, Key No. 07101 ..............................................43

Table 5.3: Project Scorecard, US 20-Cox Creek to UPRR Track Spur, Key No. 07101 .............................................44

Table 5.4: Project Summary, OR 42-Winston to I-5, Key No. 09841 ......................................................................46

Table 5.5: Project Scorecard, OR 42-Winston to I-5, Key No. 09841........................................................................47

Table 5.6: Project Summary, I-105 Willamette River to Pacific Hwy, Key No. 10349 ...............................................49

Table 5.7: Project Scorecard, I-105 Willamette River to Pacific Hwy, Key No. 10349..............................................50

Table 5.8: Project Summary, US 30-Owl Creek to Larson Rd, Key No. 10576........................................................52

Table 5.9: Project Scorecard, US 30-Owl Creek to Larson Rd, Key No. 10576 ...........................................................53

Table 5.10: Project Summary, OR 212-Rock Creek to Richey Rd, Key No. 10665 ...................................................55

Table 5.11: Project Scorecard, OR 212-Rock Creek to Richey Rd, Key No. 10665 .................................................57

Table 5.12: Project Summary, OR 10-Beaverton Tigard Hwy to Multnomah Co Line, Key No. 10666 .....................58

Table 5.13: Project Summary, OR 8-Quince St to District Boundary, Key No. 10679...............................................61

Table 5.14: Project Scorecard, OR 8-Quince St to District Boundary, Key No. 10679 ................................................62

Table 5.15: Project Summary, OR 8-Minter Bridge Rd to $117^{\text {th }}$ Ave, Key No. 10680 .............................................64

Table 5.16: Project Scorecard, OR 8-Minter Bridge Rd to $117^{\text {th }}$ Ave, Key No. 10680 …........................................65

Table 5.17: Project Summary, US 26-Ross Island Bridge to SE 50 $0^{\text {th }}$ Ave, Key No. 10731 .......................................67

Table 5.18: Project Scorecard, US 26-Ross Island Bridge to SE 50 ${ }^{\text {th }}$ Ave, Key No. 10731.....................................68

Table 5.19: Project Summary, OR 6-Tillamook RR Overpass to Jordan Creek Bridge, Key No. 10748.........................70

Table 5.20: Project Scorecard, OR 6-Tillamook RR Overpass to Jordan Creek Bridge, Key No. 10748 ......................71

Table 5.21: Project Summary, OR 22-Chemawa Rd to N Santiam Interchange, Key No. 10807 …...........................73

Table 5.22: Project Scorecard, OR 22-Chemawa Rd to N Santiam Interchange, Key No. 10807...............................74

Table 5.23: Project Summary, US 101-Nesika Beach to Rogue River, Key No. 10817 .............................................76

Table 5.24: Project Scorecard, US 101-Nesika Beach to Rogue River, Key No. 10817 ….........................................77

Table 5.25: Project Summary, OR 126-Crooked River to Laughlin Rd, Key No. 11072 .............................................79

Table 5.26: Project Scorecard, OR 126-Crooked River to Laughlin Rd, Key No. 11072 ...........................................80

Table 5.27: Project Summary, OR 211-Hult Rd to Hillockburn Rd, Key No. 11125..................................................82

Table 5.28: Project Scorecard, OR 211-Hult Rd to Hillockburn Rd, Key No. 11125 ....................................................84

Table 5.29: Project Summary, OR 18-Oldsville Rd to Ash Rd, Key No. 11858 .........................................................85

Table 5.30: Project Scorecard, OR 18-Oldsville Rd to Ash Rd, Key No. 11858 .......................................................87

Table 5.31: Project Summary, US 30-Bennett Rd to Laurel Ave, Key No. 11938......................................................8

Table 5.32: Project Scorecard, US 30-Bennett Rd to Laurel Ave, Key No. 11938 .....................................................90

Table 5.33: Project Summary, OR 35-Jct Hood River Hwy to Polallie Creek, Key No. 11939...................................91

Table 5.34: Project Scorecard, OR 35-Jct Hood River Hwy to Polallie Creek, Key No. 11939 ..................................93

Table 5.35: Project Summary, OR 35-Long Prairie Rd to Odell Hwy, Key No. 11940 …..........................................94

Table 5.36: Project Scorecard, OR 35-Long Prairie Rd to Odell Hwy, Key No. 11940 ............................................96

Table 5.37: Project Summary, US 26-Jewell Jct to Military Rd, Key No. 12856 .....................................................97

Table 5.38: Project Scorecard, US 26-Jewell Jct to Military Rd, Key No. 12856 ….......................................................99

Table 5.39: Project Summary, OR 10-OR 217 to SW Maple Dr, Key No. 12905 .....................................................100

Table 5.40: Project Scorecard, OR 10-OR 217 to SW Maple Dr, Key No. 12905 ...................................................102

Table 5.41: Project Summary, OR 221-Dayton to Salem, Key No. 13675 ...............................................................103

Table 5.42: Project Scorecard, OR 221-Dayton to Salem, Key No. 13675 ..............................................................105 
Table 5.43: Project Summary, OR 203-WCL La Grande to Union, Key No. 14127 ................................................106

Table 5.44: Project Scorecard, OR 203-WCL La Grande to Union, Key No. 14127 ..............................................108

Table 5.45: Project Summary, US 26-Lindsley Creek to Lower Nehalem Rd, Key No. 14172................................109

Table 5.46: Project Scorecard, US 26-Lindsley Creek to Lower Nehalem Rd, Key No. 14172 .............................111

Table 5.47: Project Summary, US 20-Hampton to Glass Butte and Torkelson Rd, Key No. 14189.........................113

Table 5.48: Project Scorecard, US 20-Hampton to Glass Butte and Torkelson Rd, Key No. 14189 ........................115

Table 5.49: SIP Project-level Evaluation Summary ……….................................................................................116 
Page Intentionally Blank 


\subsection{INTRODUCTION}

The improvement of highway infrastructure to enhance safety can be approached in one of four ways: 1) improve high-crash locations in a reactive manner based on observed crash patterns; 2) improve safety deficiencies as identified as part of other project work (usually associated with standards); 3) apply a countermeasure to all locations where it is likely to be cost-effective across an entire network (e.g. shoulder rumble strips on interstate highways); or 4) design safety improvements in all projects proactively using predictive methods and other tools. In nearly all states, reactive stand-alone safety improvements are the most common approach. Also common are safety improvements that are blended with other project work. This approach has been used most frequently on preservation projects. When used on these types of projects, careful considerations of the tradeoffs are necessary as the safety and preservation work efforts will generally have distinct program objectives.

In an attempt to formally address the push-pull between safety and preservation projects, the concept of the Safety Investment Program (SIP) was formulated. The Statewide Transportation Improvement Program - Safety Investment Program (STIP-SIP) was approved by the Oregon Transportation Commission (OTC) in August 1998 (see Appendix B). In approving the STIP Safety Investment Program, the OTC established the following policies: 1) invest in those segments or locations that have high levels of known fatal and serious injury crashes; and 2) invest in safety countermeasures that show a high benefit-to-cost ratio and target specific problems. The program was included in the 1999 Oregon Department of Transportation (ODOT) - Federal Highway Administration (FHWA) Stewardship Plan with the understanding that the approach be evaluated in the future. This research partially serves as that evaluation.

Since the inception of the program there has been some uncertainty as to whether SIP Policy encourages the most cost-effective use of limited resources. While substantial funds have been allocated through SIP since 1998, there currently is no system in place to track investments and results. In addition, the Highway Safety Improvement Program (HSIP) established in the most current Federal transportation authorization bill - Safe, Accountable, Flexible, Efficient Transportation Equity Act: A Legacy for Users (SAFETEA-LU) - requires states to conduct a strategic highway safety planning and results assessment.

This research project was undertaken by ODOT to conduct a comprehensive evaluation of the implementation of the SIP Policy. To a lesser extent the research also addressed concerns over whether SIP effectively sorts road segments requiring safety improvements and those where such improvements are not needed. In the program, roads are segmented into five-mile sections. These sections are categorized with a 1-5 rating based on the number of fatal or serious injury (injury A) crashes in a three-year period; with five (5) being the most crash-prone section. These ratings are assigned annually using the most recent three years of crash data. As originally proposed, stand-alone safety projects were to address the high-SIP five-mile sections. After some experience with the five-mile sections, guidance was changed indicate that stand-alone safety projects should address locations identified by the Department's network screening tool - the Safety Priority Index System (SPIS). However, the SIP segments remained a useful tool for 
preservation projects. As described in the ODOT Highway Design Manual, if a preservation project included a segment with a SIP category of 3, 4, or 5 additional safety features should be considered. These enhancements could be funded from the safety limitation. Preservation projects that did not contain a SIP segment with 3, 4, or 5 would focus on addressing mandatory safety features and pavement preservation.

\subsection{OBJECTIVES}

The primary objective of the research was to study the effectiveness of SIP Policy in meeting the goals and objectives of ODOT. Because the SIP Policy has two distinct applications, this research conducted two complementary research tasks to answer the objective. These tasks, documented in Chapter 4 and 5 respectively, and were:

- to assess the overall safety improvements for any STIP project that included safety funding; and

- to evaluate how effectively the policy has been implemented with respect to projects that involve a mix of safety and preservation work type, and recommending improvements, changes, or modifications to the existing policy.

\subsection{ORGANIZATION}

In addition to this introductory chapter, the report contains six chapters, whose content is briefly described below:

- Chapter 2: Background - Past and current policies as they relate to the SIP program were reviewed. This review served to inform the direction of the research and all subsequent chapters.

- Chapter 3: Literature Review -Current practices and published literature were reviewed for material that related to the project. The review primarily focused on resurfacing, restoration, and rehabilitation project process and how safety and preservation efforts are combined.

- Chapter 4: Systematic Evaluation - The systematic evaluation used crash data, geographic information systems (GIS) tools, and STIP data to evaluate the safety investment policy at a comprehensive level. All projects in the target STIP that were funded by safety funds were evaluated for before and after safety performance.

- Chapter 5: Project-Level Evaluation -To assess how effectively the SIP Policy had been applied in the mixed preservation/safety projects, a selection of projects, spanning multiple STIP years and regions were evaluated. The evaluation focused on detecting application of the policy in the scoping, design, and construction phases of the project.

- Chapter 6: Performance Measures - Potential performance measures are recommended.

- Chapter 7: Conclusions and Recommendations - Based on the information discovered as part of the above work, conclusions and recommendations are presented. 


\subsection{BACKGROUND}

This chapter presents a brief summary of ODOT policies that are related to the Safety Improvement Program (SIP) and that are relevant to the research. The SIP is referenced in a number of documents. In this research, the SIP Policy refers to the collective direction that these documents provide. The purpose of this chapter is to define the SIP Policy and describe how it relates to the Highway Design Manual and the current safety program. There have been substantial changes to the administration of the safety program since the research began and to give context to the research conclusions, the newly revised program is presented.

\subsection{SAFETY INVESTMENT PROGRAM (SIP) POLICY}

The Safety Investment Program (SIP) was originally called the Statewide Transportation Improvement Program - Safety Investment Program (STIP-SIP). The concept of the program was first discussed in October 1997 and the program was adopted by the Oregon Transportation Commission in August 1998. The SIP Policy was first implemented in the 2000-2003 STIP. The concept for the program grew out of a cost-effective approach to pavement preservation projects that set out to maximize the impact of money spent on highway safety, based on crash reduction factors. Safety projects were to be selected based on high crash locations as identified by the Safety Priority Index System (SPIS) and SIP Segment Rating (five-mile sections, described below). The SIP Policy also included a process for balancing safety and preservation goals by creating separate requirements for highway sections with minor crash severities and frequencies. The policies include the following (ODOT Highway Safety Program Guide 2007, pg 5)

The replacement of existing features on STIP projects (e.g., striping, guardrail, signing, rumble strips) in like kind shall not be funded from the Highway Safety Program. These existing features must be funded out of the project's program limitation (Modernization, Preservation, Bridge, etc.). The only exception is if the improvement is addressing a safety issue by enhancing the feature such as upgrading striping from paint to durable materials. The improvement must still show either a benefit/cost greater than 1.0, address a top 5\% SPIS site, or a SIP Category 4 or 5 segment.

The ODOT Highway Safety Program Guide provides a comprehensive description of the current SIP Policy and tools as an integral part of the process for programming highway safety projects. Five-mile sections of the state highway system are categorized by the number of fatal and severe injury crashes during a three period. The following is the stratification for SIP categories:

- Category 1: 0 (no) fatal or injury A (serious) crashes;

- Category 2: 1 to 2 fatal or injury A crashes;

- Category 3: 3 to 5 fatal or injury A crashes;

- Category 4: 6 to 9 fatal or injury A crashes;

- Category 5: 10 or more fatal or injury A crashes. 


\subsection{ODOT HIGHWAY DESIGN MANUAL}

The ODOT Highway Design Manual (HDM) provides design guidance for new highway construction, major reconstruction (4R), and resurfacing, restoration, or rehabilitation (3R) projects during project development. The current version is the 2003 edition, which replaced the 1997 edition. It is used for all projects that are located on state highways. National Highway System or Federal-aid projects on roadways that are under the jurisdiction of cities or counties use the 2001 AASHTO design standards or ODOT 3R design standards. State and local planners use the HDM to determine design requirements related to state highways in Transportation System Plans, Corridor Plans, and Refinement Plans. There are three design standards identified in the HDM and quoted below (ODOT Highway Design Manual 2003):

1. AASHTO Design Standards

These standards are contained in the 2001 AASHTO A Policy on Geometric Design of Highway and Streets (AASHTO 2001). This AASHTO publication is often referred to as the "Green Book" and is so referenced in this document. The design standards are specifically for use in the design of new construction and reconstruction projects for a variety of highway functional designs.

2. ODOT 4-R/New Design Standard

The ODOT 4-R/New standard is used for projects that are considered either reconstruction (4-R) or new construction. Reconstruction projects upgrade the facility to acceptable geometric standards. New construction projects include building new facilities or rebuilding existing facilities with major alignment changes. This standard provides design values for all areas of designs and most of them are within the value ranges of the 2001 AASHTO Green Book. In addition to the contents from 2001 AASHTO publication, ODOT 4-R/New Design Standard also contains some unique specific requirements that are not included in the AASHTO Green Book.

3. ODOT 3-R Design Standard.

The ODOT 3-R Design Standard provides guidance for projects that preserve and extend the service life of existing highways and enhance safety with cost-effective solutions. The general types of improvements include:

- Extending pavement life by at least 8 years,

- Safety enhancements,

- Minor widening,

- Improving vertical and horizontal alignments,

- Improving super elevation,

- Flattening side slopes, and

- Removing roadside hazards. 
Preservation projects are generally categorized as resurfacing, restoration, or rehabilitation (3R) projects. While the primary purpose of these projects is pavement preservation, appropriate safety countermeasures are generally incorporated where desirable. In the ODOT Highway Design Manual (HDM), the ODOT 3-R Design Standard provides guidance for 3-R projects based on the SIP Category (the five-mile sections ranked by number of fatal and severe injury crashes) within the project limits. As part of the stewardship agreement with FHWA, projects with low crash histories are focused primarily on pavement preservation activities and have a simplified project development process. The projects that have a higher accident history (i.e., SIP Category of 3, 4, or 5) have additional scoping and design requirements with an attempt to incorporate safety countermeasures. This is summarized in a screen-capture of the HDM shown in Figure 2.1:

\section{- 3-R Projects and STIP Safety Investment Program (SIP)}

Category 1 and 2 SIP projects are those with low accident histories. They receive abbreviated safety features fit the following description.

- "Pave mainly" is the focus.

- Mandatory Design Features are required.

- Low-cost mitigation measures are encouraged.

- Less scoping effort.

- Lower project development cost.

- More dollars go to pavement on the road. The goal is to have no more than $6 \%$ of the Pavement Preservation budget in each region focused on safety measures.

Category 3,4 , and 5 SIP projects are those that have a history of fatal or serious crashes and receive targeted safety features fit the following description.

- Safety countermeasures are examined for value in reducing prevalent crash types using the Countermeasure Analysis Tool (CAT).

- Mandatory Design Features are incorporated.

- Benefit/Cost $(\mathrm{B} / \mathrm{Cs})<0.8$ aren't put in project.

- Safety countermeasures with highest potential payback are incorporated in project.

- Safety countermeasures and features are funded out of each Region's Safety Budget.

Section 2.2 outlines the 3-R design process that should be used in development of all 3-R projects.

Figure 2.1: Text from the ODOT Highway Design Manual

As noted, all 3-R projects should include what are termed "Mandatory Design Features". These features are shown in Figure 2.2. 


\begin{tabular}{|l|l|}
\hline Geometric Deficiency & Mandatory Corrective Measure \\
\hline ADA/Sidewalk Ramps & $\begin{array}{l}\text { Ramps shall be added where } \\
\text { absent. }\end{array}$ \\
\hline Narrow Bridges/Deficient Rails & $\begin{array}{l}\text { Bridge rail retrofit or new bridge } \\
\text { rails; upgrade approach guardrail, } \\
\text { bridge connections and transitions } \\
\text { to current standards unless bridge } \\
\text { is scheduled for replacement. } \\
\text { Install Type } 3 \text { object markers and } \\
\text { post delineators. }\end{array}$ \\
\hline Existing Guardrail & $\begin{array}{l}\text { All non-standard terminals within } \\
\text { the clear zone shall be upgraded to } \\
\text { current standards. }\end{array}$ \\
$\begin{array}{l}\text { Runs less than } 18.5 \text { inches from } \\
\text { top of pavement to guardrail post } \\
\text { bolt shall be adjusted or replaced } \\
\text { to current standards. } \\
\text { Guardrail bridge connections shall } \\
\text { be upgraded if appropriate or } \\
\text { added if absent. }\end{array}$ \\
\hline
\end{tabular}

Figure 2.2: ODOT Highway Design Manual - Table 7-5: Mandatory Design Features

\subsubsection{Stewardship Agreement with FHWA}

The existing 1999 Stewardship Agreement is intended to guide the stewardship activities of both the FHWA and ODOT. The agreement establishes the review and approval of plans, specification, and engineering documents (PS\&Es), and discusses in more detail the effects of those selections. The plan also identifies the laws, regulations, and other requirements, both Federal and State, which apply to each type of project or activity. Note that this agreement is being renegotiated between ODOT and FHWA at the publication time of this report.

The role of the Safety Investment Program is described in the Appendix A of the Stewardship Agreement. It describes how the project development for 3R projects on Category 1 and 2 Safety Sections has been simplified. This simplified process was subject to much debate and FHWA provided very tentative support for this change. As part of their approval, it was implied that the application of the SIP would be evaluated in the future. While not the primary purpose of this research, this research can serve to partially answer this evaluation directive. 


\subsection{HIGHWAY SAFETY IMPROVEMENT PROGRAM (HSIP)}

While the focus of this evaluation is how the SIP policy was implemented under the programs and policies in place at the time, it is useful to have some context for the current program. Since the first implementation of the SIP, there have been continual changes in how the safety program has been administered at ODOT. The current safety program was established in the SAFETEALU, which established a new core Highway Safety Improvement Program (HSIP) for all states with separate funding for a total of \$5.1 billion for the years spanning 2006 to 2009 (FHWA 2005). The objective of the HSIP (like the SIP) is to reduce fatalities and serious injuries on public roads. HSIP provides flexibility for states to distribute funds to their most critical safety needs. States are also required to set performance-based goals, propose and implement potential countermeasures, evaluate the implementation results, and apply the information to set priorities for future improvement projects.

For stand-alone safety projects, the current ODOT Highway Safety Program Guide (2007) states, that for a project to be eligible for the use of safety funds, it must meet the following conditions:

- Be an eligible highway safety project.

- Have committed matching funds of $10 \%$ of the project cost (for federal funding).

- Be able to meet all applicable guidelines and standards for construction.

- Meet one of the following eligibility criteria:

o Positive Benefit/Cost (B/C) Ratio of 1.0 or greater;

o Top 5\% Safety Priority Index System (SPIS);

o Safety Investment Program (SIP) Category 4 or 5; or

o Justified by Risk Narrative.

Further, all projects submitted by the region for inclusion in the STIP are now reviewed by the Traffic-Roadway Section (TRS).

The SIP Policy described in the previous sections as it applies to pavement preservation projects (3R) is essentially the same with additional clarifications. The Guide prohibits the expenditure of safety funds on SIP Category 1 and 2 preservation projects and states that "existing features on STIP projects (e.g., striping, guardrail, signing, rumble strips) in like kind shall not be funded on SIP Category 3,4,5 projects” (emphasis from the Guide). 
Page Intentionally Blank 


\subsection{LITERATURE REVIEW}

The United States has allowed the use of Federal funds for resurfacing, restoration, and rehabilitation (3R) projects of federal-aid highways since 1976. Facing the limited funding and constant demands from safety improvements and pavement preservation, state transportation agencies are challenged as to how to balance the funding for safety improvements and pavement preservation projects. Besides the complexity of the entire decision making process, there are two essential questions for which the answers will assist state agencies in making decisions and achieving their goals of maximizing safety benefits:

- How should funding be allocated in the most cost-effective manner?

- How should the overall effectiveness of funding allocation results be evaluated?

To present previous policy changes and study results associated with these two questions and to demonstrate the issues of balancing pavement restoration and safety projects at the state level, this literature review identifies the related information from five areas:

- Historical pavement preservation policies,

- Resurfacing and safety,

- State resurfacing, restoration, and rehabilitation (3R) programs and design policies,

- Funding allocation, and

- Cost-effectiveness evaluation.

These five areas cover the historical federal and state policy changes, up-to-date study results on safety influences of road resurfacing, relationships of 3R programs and design policies, safety fund allocation approaches, and safety performance measurements as reviewed in the following sections.

\subsection{HISTORICAL PAVEMENT PRESERVATION POLICIES}

Historically, federal highway funds could only be used for new highway construction or complete reconstruction of existing highways. In 1976, the Federal-Aid Highway Act authorized states and local highway agencies to use federal funds on resurfacing, restoration, and rehabilitation projects for federal-aid highways. The Pavement Preservation Forum, led by FHWA in 1998, identified and emphasized the important role of pavement preservation in future highway programs. The federal policy and companion legislation has shifted the designation of highway fund expenditures from being directed solely towards new construction projects to cover a variety of projects including those that help maintain and provide serviceable conditions for existing road networks. The 3R program is intended not only to prolong the life cycle of the road network by scheduled roadway maintenance efforts, but also to improve roadway safety and traffic operation by incorporating geometric design improvements. While facing limited funding 
resources, highway agencies often must balance their funding decisions between these two competing needs.

As a result of this challenge, many agencies are unable to adequately consider pavement preservation projects during funding allocation and this limitation can result in an aging pavement infrastructure with reduced surface friction and diminished pavement quality. However, under many conditions, pavement repair projects may contribute to improved safety. The 1998 Pavement Preservation Forum suggested that the lack of reliable information and safety performance measures, which can be used to evaluate the impact on overall system performance of $3 \mathrm{R}$ projects, contributes to the dilemma of how to balance the deployment of safety strategies and pavement preservation priorities (FHWA 1998).

Special Report 214 (TRB 1987) presented an extensive evaluation of Federal 3R programs focusing on the role of safety improvements. Though this report is dated, many of the findings included in the report helped agencies craft their current rehabilitation projects. As an example, this 1987 report identified the following findings for state 3R practices:

- 3R design practices vary widely from agency to agency;

- 3R projects are initiated primarily to address pavement repair and rehabilitation needs;

- Federal-aid 3R projects frequently widen lanes and shoulders but seldom reconstruct sharp curves or replace bridges with narrow decks;

- Not enough is known about the safety gains that will occur after the geometry of existing highways is improved or other safety-oriented improvements are made; and

- Engineers who administer state traffic and safety programs seldom participate in the design of 3R projects.

Special Report 214 also provided recommendations for the following five categories:

- Safety-conscious design process

3R project designers should deliberately seek safety increasing opportunities for each project and provide sound safety and traffic engineering principles by applying the following steps: assess current conditions, determine project scope, document the design process, and review the design.

- Design practices for key highway features

The 3R design standard should help designers to determine whether an existing feature which does not meet AASHTO criteria should be upgraded with a 3R project. The numerical minimum 3R geometric design standards will help to distribute 3R program expenditures on more safety cost-effective geometric improvements.

- Other design procedures and assumptions

Since highway agencies may design 3R projects differently even under similar minimum 3R standards and similar project conditions, four procedures were proposed to encourage a more uniform application of 3R standards and a more consistent approach to safety, including: 
o Design traffic volume. Consider the design traffic volume by taking into account the expected performance period.

o Speed. Estimate actual running speed that is appropriate for the feature under consideration.

o Design values. Estimate the incremental safety cost-effectiveness of improvements that exceed the 3R minimum standard.

o Design exceptions. Explicitly address the expected safety consequences, cost and other impacts for an exception to a design standard.

- Planning and programming $3 R$ projects

Highway agencies select 3R projects primarily based on their pavement needs and seldom take into account their safety needs until preliminary design begins. Therefore, when selecting candidate 3R projects, agencies usually do not have the safety improvement implementation plan which can help to achieve optimal safety benefits with the most costeffective plan. The report recommended agencies consider safety needs at the early stage of the 3R-project decision making process.

- Safety research and training

The report also indicated that the decision maker often lacks a full understanding of safety consequences resulting from highway design decisions. As a result, additional resources should be devoted to long term safety research, training, and application efforts.

\subsection{RESURFACING AND SAFETY}

It has been commonly acknowledged that the roadway geometry design characteristics, roadside fixed objects, traffic control devices, driver behavior, and vehicle types have various impacts on roadway safety. However, as indicated in Special Report 214 (TRB 1987), the influences on crash rates of road surface condition characteristics remain unclear. This section discusses several research efforts and findings.

Cleveland (1987) determined that recently resurfaced rural roads experienced a small immediate increase in overall crashes (2\%). Meanwhile, there was an increase in overall crash severity with about $10 \%$ more injuries and fatalities per crash. However, crash results varied for dry pavement versus wet pavement following road resurfacing. Dry pavement crashes increased by $10 \%$ while wet pavement crashes decreased by a similar percentage. Urban resurfacing projects produced an average crash reduction at about $25 \%$ over the life time of the resurfaced pavement with a companion 25\% decrease in crash severity. Cleveland suggested the following reasons for these observations:

- Resurfacing improves both road smoothness and skid resistance, which will contribute to mitigating vehicle control related problems, especially on wet pavement.

- There is a mixed effect on crash severity as a result of resurfacing. While the higher speed observed after resurfacing will lead to more severe crashes, the improved pavement 
condition can reduce stopping distance which will contribute to a reduction in crash severity.

- Motorists drive faster and with less attention following road resurfacing. This change in driving behavior will lead to an increase in crashes (especially on dry pavement), where the benefit of resurfacing on dry pavement is not as obvious as the wet pavement benefits.

Agent et al. (2004) studied the trends of crash history and speed variation both before and after road resurfacing in Kentucky. These Kentucky researchers developed two major conclusions. First, the overall number of crashes did not decline after road resurfacing, though they did observe crash reductions for wet pavement. This is consistent with the findings by Cleveland (1987). Second, following resurfacing, the observed vehicle speeds did not change dramatically from those observed prior to resurfacing. This finding contradicts the study by Cleveland.

Based on these two studies, it is clear that improving the driving surface may have varying safety implications. While an improved pavement surface should provide greater friction and a safer driving surface, the improved driving surface may also enable increased travel speeds.

In 2001, the National Cooperative Highway Research Program (NCHRP) published Research Result Digest Number 255. This document titled "Impacts of Resurfacing Projects With and Without Additional Safety Improvements” found that there do not appear to be conclusive results revealing the relationship between crash occurrence following resurfacing and associated geometric improvements.

In the 2001 NCHRP study, the research team evaluated data collected from the states of Washington, California, Minnesota, New York, and Illinois. The effects on crashes following resurfacing projects varied between states and project scenarios. For example, for locations where they simply resurfaced the roads the average number of crashes were reduced by approximately $18 \%$ in Washington, while the average number of crashes increased by approximately 25\% in Minnesota. For locations where additional safety treatments were included with resurfacing projects, Washington observed little significant influence on crash reductions while Minnesota observed distinctive safety benefits. For both Minnesota and Washington, the study indicated that safety consistently improved as the pavement aged. The findings for the other states included in the study were inconsistent within each state, so the researchers could not arrive at specific conclusions regarding safety benefits of projects in these states.

Hauer et al. (1994) performed a statistical analysis evaluation for two types of resurfacing projects in New York State. One type, known as fast track projects, consisted of projects that involved only road resurfacing. The other type of project called Reconditioning and Preservation (R\&P) included resurfacing and roadside or road safety improvements. The research team determined that the fast track projects performed less well from a safety point of view than that observed for the R\&P projects. The safety initially declined in fast track projects, while the safety improved in R\&P projects. They also observed that the safety improved as the pavement aged for the first six to seven years of pavement life. 
Based on various studies and practical applications in transportation agencies of the United States and several other countries, Zimmerman and Larson (2005) suggested that a positive safety impact can be identified as an association of a pavement preservation program. For instance, the relatively smooth surface of roadways will reduce vehicle operating costs as well as crashes due to forestalled reactions of avoiding potholes and other surface irregularities in the pavement. This study did not address the influence on speed from the smooth surface on which inconsistent study results were found in previous studies (Cleveland 1987; NCHRP 2001; Agent 2004). Zimmerman and Larson did report that surface textures with increased friction could help reduce both wet and dry weather crashes. The previous studies did not show a strong connection between increased friction and crash rate reduction. However, this absence may be due to the limitation of data collection methodologies and data analysis capabilities. Based on the currently available technologies, Zimmerman and Larson recommended that agencies perform the road network evaluation including a data monitoring system to provide accurate pavement characteristic information on a regular basis. Items that this procedure would monitor include pavement macrotexture, microtexture, and roughness. A post-project result tracking system is very critical to properly evaluate the effectiveness of project investments and helps to make the corresponding adjustments in future project expenditures.

Overall, the Zimmerman and Larson study showed promising beneficial results by incorporating safety measures into pavement preservation programs. If agencies identify that the pavement surface condition contributes to crashes, then there is a very good chance of achieving the goal of reducing the number of crashes and improving road network conditions. Even though studies showed the possibility and effectiveness that pavement improvement activities can contribute to a reduction in crash occurrences, there is a lack of published research focusing on incorporating roadway safety management with pavement management and prevention management programs with pavement preservation programs in order to provide guidance and recommendations for agency practices.

\subsection{STATE 3R PROGRAMS AND DESIGN POLICIES}

The AASHTO Green Book provides the highway and street geometric design criteria for new construction and major reconstruction. In 1977, AASHTO published another design guide, the Geometric Design Guide for Resurfacing, Restoration, and Rehabilitation (RRR) of Highways and Streets (AASHTO 1977), to help agencies identify whether a geometric feature should be incorporated into $3 \mathrm{R}$ projects.

In recent years, several states have established their own formal 3R policies. In 2003, 36 state highway agencies participated in a survey conducted as part of NCHRP Project 17-9, "Safety Impacts of Resurfacing Projects With and Without Additional Safety Improvements" and ultimately published as NCHRP Report 486 (Harwood et al. 2003). Several of their survey results may be applicable to this research and are summarized as follows:

- Geometric Design Standards/Guidelines for 3R Projects

A total of 32 state agencies responded that they have specific geometric design standards or guidelines for $3 \mathrm{R}$ projects that are different from the design standards used for new construction. 
- Resurfacing Project Selection Process

Most states use pavement condition data which may be obtained from pavement management systems to identify the need for resurfacing. The survey responses indicate that most states do not include crash history when selecting roads to resurface.

- Process to Determine Needs for Additional Safety Improvements for Resurfacing Projects The survey results indicate a large variation between state procedures for determining the need for safety improvements. The following criteria were identified as considerations in the decision making process:
o Crash history/high crash locations,
o Condition of safety features,
o Cost-effectiveness analysis of improvements,
o Design criteria,
o Local demands/politics, and
o Skid testing.

- Established Procedures for Explicitly Considering Safety for Resurfacing Projects A majority of the states established procedures to consider safety explicitly for resurfacing projects. The procedures generally include a review of 5-year crash history to identify crash locations and causes, a review of high crash locations, and the identification of countermeasures.

- Policies and Procedures for Cost-Effectiveness Analysis of Improvement Alternatives Only 14 of 35 states have a formal policy or procedure for conducting cost-effectiveness analyses of alternative safety improvements in order to compare project construction costs and the potential of crash reduction. The cited adopted policies include the AASHTO Roadside Design Guide (1996), the ROADSIDE computer program accompanying the Design Guide, Special Report 214 (TRB 1987), and agency-specific procedures.

- Resource Allocation Tools

Only 11 of 26 states use resource allocation tools.

- Related State Research

Only nine of 26 states have conducted or sponsored research on the safety and/or operational effects associated with resurfacing. The state-sponsored topics include skid testing and before-and-after analyses.

- Post-resurfacing Evaluation

Only 10 of 34 states conducted post-project and operational evaluations of resurfacing projects with the following approaches:

o Before-and-after crash evaluation,

o Post-construction review as part of the engineering construction activity, and

o Surface friction analysis/skid testing.

Sanford et al. (1981) evaluated the cost and safety effectiveness of 3R improvements for 284miles of 2-lane rural highways in Illinois from 1978 to 1981. The research team performed 
safety and economic analyses based on the crash data collected for two years before and two years after safety improvements. The study showed significant crash rate reduction and crash severity rate reduction for Illinois 3R improvements for the projects with average annual daily traffic (AADT) above and below 3,000. The economic analysis reported that the 3R project expenditure exceeded the savings from the crash reduction. They concluded that the higher traffic volume locations associated with a better cost-effectiveness of 3R improvements benefit more than lower traffic volume locations. The researchers were not able to separate effects from improved geometric design elements and improved skid resistance.

Wisconsin DOT's pavement preservation strategy is established on the philosophy of optimizing the pavement performance to provide the highest quality service to road users under the limitation of available resources (Shober and Friedrichs 1998). This cause-based and customeroriented strategy can allocate funds in a more efficient way. Instead of treating the existing symptoms of the roadway pavement, treating the worst first, or following a pre-scheduled maintenance time table, Wisconsin DOT's pavement preservation strategy focuses on diagnosing the causes and addressing the root problems of symptoms of distress. The treatment selection process includes consideration of the highway functional classification, ability to treat all the pavement problems, initial costs, life cycle costs, cost-benefit analysis, age, and expected life of the pavement.

Tighe et al. (2001) examined road safety factors, such as shoulder design, pavement surface, pavement safety measurement criteria, and how these factors could be broadly incorporated into an asset management system and specifically into a pavement management system. The study occurred in Ontario and Alberta, Canada. The research team proposed a systematic approach to coordinate pavement maintenance and rehabilitation programs with road safety improvement. The study findings include:

- Pavement characteristics were strongly correlated with road safety;

- Data integrity, especially the location referencing, was identified as the critical factor for successfully incorporating safety management into pavement management; and

- A dedicated Safety Management System can provide valuable information, such as high incident locations, inventory, performance, deficiencies, priorities, skid properties, roughness, and shoulder widths.

A report published by FHWA (Mahoney et al. 2006) summarized a scan of state practices that incorporated safety into resurfacing and restoration projects. This scanning study included the states of New York, Colorado, Washington, Pennsylvania, Utah, and Iowa. The FHWA selected these six states because they were known to have strong state programs for integrating safety improvements in pavement projects. Since a scanning study does not include empirical analysis, the report does not arrive at any specific safety conclusions but rather provides a summary of good practices for incorporating safety into candidate pavement resurfacing projects.

The New York DOT has three resurfacing project categories that represent the various levels of improvement. These categories are further defined as resurfacing projects (1R); resurfacing or restoration projects that include some minor supplemental work (2R); and resurfacing, restoration, and rehabilitation projects that include overlays greater than 1.5 inches (freeway and 
non-freeway; 3R). The New York DOT uses a variety of factors including pavement needs, safety record, scope of improvement, right-of-way requirements, impacts, and controversy to determine exactly which improvement program applies. The scanning tour summary did not identify specific information regarding actual project selection procedures, but did indicate that the DOT's regional offices were responsible for specific project development.

The State of Colorado uses a formalized set of procedures that must be applied to all resurfacing projects with pavement overlays greater than 1.5 inches. Included in these procedures is their $3 \mathrm{R}$ safety analysis that uses safety performance functions to evaluate and predict corridor safety based on traffic exposure and crash history. Funding decisions are jointly developed by their central office's Safety and Traffic Engineering Branch and the specific design team from their regional office.

In the State of Washington, safety improvement funds are not typically authorized for resurfacing projects; however, preservation projects are expected to routinely incorporate basic safety enhancements. Pennsylvania has a similar approach for resurfacing projects.

Utah uses three different guidelines to evaluate candidate resurfacing projects. One of these guidelines outlines the process for operational safety reviews. These reviews are developed by the Utah DOT's central office and include a physical assessment of the location as well as a crash history evaluation. Ultimately, safety recommendations are then based on cost-benefit analysis.

The State of Iowa defines a resurfacing project for state highways as those with approximately 4inch overlays and an expected service life of 20 years. The Iowa DOT district offices are responsible for 3R projects and consider the following candidate safety countermeasures in their assessment:

- Improve horizontal curve superelevation;

- Where right-of-way is available, extend small culverts for more clear zone;

- Upgrade the bridge approach and guardrail;

- Add paved shoulders and shoulder rumble strips;

- Incorporate offset turn lanes at intersections;

- Flatten slopes near driveway entrances;

- Construct safety dikes at locations directly opposite to T-intersections;

- Removed fixed objects from clear zones;

- Place chevron signs at sharp horizontal curves; and

- Upgrade warning sign sheeting to florescent-yellow.

On National Highway System routes, Iowa decision makers also consider widening narrow travel lanes, upgrading shoulder treatments, and converting 4-lane undivided urban roads to 3lane facilities as candidate safety countermeasures. 
All six states regularly include the installation or upgrade of traffic control devices in their resurfacing projects. These traffic control devices may include longitudinal rumble strips, curve delineation, pavement marking, reflective pavement markers, median barrier delineation, signs, and signal upgrades. All six states also frequently include roadside safety improvements in their resurfacing projects. In general, a key element in project identification is pavement condition and it is generally weighted heavier than the safety record (as is typical for a stand-alone safety project).

\subsection{FUNDING ALLOCATION: SYSTEM OPTIMIZATION}

Harwood et al. (2003), as part of an NCHRP study, developed a systematic software to evaluate the trade-offs between expenditures for resurfacing and safety improvements and to evaluate alternatives of safety improvements where pavement resurfacing decisions have been made. The software, Resurfacing Safety Resource Allocation Program (RSRAP) estimates the benefits of various combinations of improvement alternatives for a specified set of projects in a region and maximizes the overall benefits in order to allocate the funding with system-wide optimal safety results given a user-defined budget constraint. The RSRAP will help agencies to choose sites with improvement needs from a system-wide point of view instead of from individual sites. In addition to the systemized site selection, the program also provides recommendations as to whether the site needs only pavement resurfacing or resurfacing combined with certain types of safety improvements.

Grile et al. (2005) compared funding allocation results of safety improvements selection on 3R projects given various budget constraints between the currently used Oregon DOT method and the RSRAP. One of the major differences between the Oregon DOT method and RSRAP is that while Oregon DOT evaluates each project separately, the RSRAP method provides systematic optimization results on all projects in a region or statewide.

At the time the paper was written, Oregon DOT attempted to spend no more than $25 \%$ of its safety budget supplementing preservation projects (Grile et al. 2005). However, both the Oregon DOT approach and RSRAP produced the total estimated costs of preservation projects with less than $25 \%$ of the safety budget for the study sites in the Oregon DOT Region 2 . Grile et al. (2005) further indicated that the $25 \%$ target has not always been consistently followed by the various regions within the DOT. The comparison results indicated that the RSRAP allocated more safety funds on preservation projects than the funds identified using the Oregon DOT method. Grile et al. indicated that the analysis results may cast some doubts on the effectiveness of using the $25 \%$ safety budget for preservation projects. The study also concluded that the RSRAP could be suitable for Oregon DOT as a systematic optimization tool to select various safety improvements on 3R projects.

\subsection{COST-EFFECTIVE ASSESSMENT}

Programs like the Oregon SIP or the Federal HSIP distribute funds for safety improvement projects that are intended to produce a significant reduction in the number of traffic fatalities or serious injuries on public roads. For an agency to assure that the expenditure of safety funds is appropriate, it is important to assess the benefits resulting from these planned expenditures. 
Since a large variety of potential safety-related improvements can include items such as guardrail, tree removal, or shoulder improvements, assessment strategies should also evaluate the specific countermeasure options to assure that funds are spent in the most cost effective and beneficial manner.

In the recently submitted series of Strategic Highway Safety Plans (SHSPs) many states proposed future application of a crash-based before-and-after study for assessment of safety improvements. At this time, few states actually adhere to the assessment requirements outlined in the SAFETEA-LU legislation; however, they are aware of the importance of this issue and are actively developing assessment plans for future performance evaluations.

The before-and-after crash study generally requires approximately six years of crash data. This data includes three years of information prior to the implementation of the proposed improvement and approximately three years after the completion of the proposed improvement (FHWA 2006; VTrans 2005; Utah DOT 2006; Virginia DOT 2006). Two common assessment methods are introduced in the following section: the crash-based method and the benefit-cost ratio method.

\section{Crash-Based Method}

The crash-based method is one of the proposed safety improvement effectiveness evaluation methods used by state agencies. Based on crash and traffic volume data for a period of at least six years, the crash variation can be measured as a change in percentage and then used as the performance value to determine the effectiveness of safety improvement projects. The crashbased method is presented by the following equation (VTrans 2005):

$$
c r=\left[\frac{N_{\text {Before }}-N_{\text {After }} \times \frac{A D T_{a}}{A D T_{b}}}{N_{\text {Before }}}\right] \times 100
$$

Where:

$$
\begin{aligned}
& c r=\text { percentage of crash reduction, } \\
& N_{\text {Before }}=\text { the number of crashes before improvement implementation, } \\
& N_{A f t e r}=\text { the number of crashes after improvement implementation, } \\
& A D T_{a}=\text { the average daily traffic before improvement implementation, and } \\
& A D T_{b}=\text { the average daily traffic after improvement implementation, }
\end{aligned}
$$

This formula does not take into account crash severity. A crash reduction factor (CRF) can be calculated based on accumulated data for a variety of potential improvements to estimate their likely impacts on safety. The CRFs then become critical input information into the benefit-cost $(\mathrm{B} / \mathrm{C})$ ratio calculation for proposed projects. For example, the Utah DOT is planning to establish a CRF database for various types of improvements and similar information associated with their projects. Currently, they rely on CRFs assembled by other states or the FHWA (Utah 
DOT 2006). Crash reduction factors developed for other jurisdictions may not accurately reflect the actual condition in Utah.

\section{Benefit-Cost Ratio (B/C)}

The B/C method has been used by most States as an estimated performance measure for proposed safety improvement strategies. This method can also be used to evaluate the effectiveness of a completed project; however, this use to date has been limited.

\section{- $\quad$ Benefit}

The actual benefits can be calculated based on the anticipated cost savings occurring as a result of reduced crashes following the implementation of the safety improvement countermeasures. The financial benefit can be calculated using a variety of methods. The Colorado DOT (2005) has proposed calculating anticipated financial benefit using a method that includes crash severity. The equation for this anticipated annual financial benefit is represented by the following:

$$
\mathrm{B}=[(\mathrm{PDO})(\mathrm{a})+(\mathrm{INJ})(\mathrm{b})+(\mathrm{FAT})(\mathrm{c})]
$$

Where:

$$
\begin{aligned}
& \text { B = annual benefit (dollars), } \\
& \text { PDO = the number of property damage only crash, } \\
& \text { INJ = the number of injury producing crashes, } \\
& \text { FAT = the number of fatality producing crashes, } \\
& \text { a = the cost per PDO crash, } \\
& \text { b = the cost per INJ crash, and } \\
& \text { c = the cost per FAT crash. }
\end{aligned}
$$

Another approach is a crash type based method used by the Illinois DOT to estimate the B/C ratio for proposed projects (Illinois DOT 2006). The benefit can be estimated by multiplying the number of reduced crashes for different crash types and safety improvement strategies by the average annual cost rate for the corresponding crash type. The average costs are estimated using historic crash data and the appropriate National Safety Council costs for each year. The crashes also can be evaluated on a person level using the number of persons injured or deceased (Utah DOT 2006). The average cost can then be estimated based on the historic data and required adjustments resulting from other identified critical sources such as the FHWA crash cost (FHWA 1994).

\section{- $\quad$ Cost}

The cost generally used for the $\mathrm{B} / \mathrm{C}$ base costs is the actual cost of the completed project plus the annual maintenance costs. This combination of initial and continuing costs provides an accurate baseline for contrasting benefits to total costs. The calculation of costs, however, vary among states with some states simply using initial construction costs. 
A B/C ratio with a value greater than 1.0 represents that the benefit outweighs the associated cost for the corresponding safety improvement project. A higher B/C ratio represents a higher effectiveness of the safety improvements.

In addition to the technical methodologies that are necessary for evaluating whether safety funds are spent wisely and effectively, the safety improvement program for many States also influences the systematic policy making process for safety improvements.

\subsection{CONCLUSIONS}

The balance of safety and pavement preservation projects has been the focus of previous studies. The published literature included information about historical pavement preservation projects, the perceived relationships between resurface and safety, a variety of state rehabilitation and design policies, various funding allocation strategies, and methods for assessing costeffectiveness of improvements. Given the amount of funds invested in pavement rehabilitation with inclusive or separate safety projects, there was a limited amount of research available for review. This highlights the need for future research in this area.

Though the results are mixed, at least six states have developed programs that require integration of safety elements into their pavement preservation projects. The methods for the states varied but each state policy addressed safety as a key element of the preservation project. In some instances, safety money could be spent in a limited manner on resurfacing while other states restricted the use of these funds to specific targeted safety enhancements that exclude pavement.

At this time, there are limited evaluation methodologies for completed safety improvement projects. The literature included several observations associated with improvement projects and safety. These include the following:

- Smooth roads (free of pot holes) will reduce vehicle operation costs and crashes;

- Improved surface texture will increase friction and reduce wet and dry weather crashes;

- Projects that include safety enhancements as part of rehabilitation efforts result in improved safety when compared to resurfacing projects only.

The use of before-after crash reduction studies as well as benefit/cost analysis are the two most frequently cited approaches to assessing the effectiveness of safety improvements; however, many states are in the early stages of implementing these strategies.

It is clear from the literature that there is a substantial requirement fueled by recent federal legislation that state agencies need to develop defendable assessment strategies for their safety improvement projects. Unfortunately at this time, the available assessment strategies are in their infant stages and need to mature over the coming years. 


\subsection{SYSTEMATIC EVALUATION}

The investment of safety funds can be determined based on a variety of metrics, but agencies often do not perform long-term assessments of safety benefits on projects after they are completed. In Oregon, a four-year Statewide Transportation Improvement Program (STIP) determines candidate improvement projects including the funding sources for these projects.

In an effort to identify perceived safety benefits of systematic improvements, the research team compiled an extensive database that incorporated 12 years of crash data, geospatial information, and STIP projects specifics for improvement efforts where safety funds were identified as a source of funding. This chapter summarizes the methods used for this systematic assessment, summary statistics for sample STIPs (with emphasis on the 2000 to 2003 and the 2002 to 2005 STIP), and additional project-specific evaluation options that are available using a similar robust data set for transportation improvement projects.

\subsection{METHODOLOGY}

\subsubsection{Summary of Data Sets}

The Oregon Department of Transportation (ODOT) has several data sources available for tracking project cost and performance. Included in these sources are the STIP project summary lists, crash data for Oregon state highways, and geospatial data captured in GIS databases. Each of these data sources can be used to help systematically evaluate transportation improvement projects.

\subsubsection{STIP Data Records}

The candidate improvements included in the STIP include information about the project location (highway number, beginning milepoint, and ending milepoint), the type of work activity, the project schedule, and the cost summary, including funding sources. Many STIP projects have multiple funding sources. When safety funds were included as one of these sources, the research team performed general summary statistics to determine if measurable safety improvements resulted from the expenditure these funds.

The research team acquired information for the 1998 to 2001, 2000 to 2003, 2002 to 2005, 2004 to 2007, and 2006 to 2009 STIP projects. It was found that, in many cases, a project identified in one STIP summary also appeared on the subsequent STIP, due either to the intentional two-year STIP overlap, the presence of fourth year advisory projects in the STIP, project delays, or similar circumstances such as contract negotiation delays and adjusted project scope resulting in schedule modifications. For the systematic research effort, the research team selected the 2000 to 2003 and the 2002 to 2005 STIP for evaluation. These target years were identified to assess the before and after crash statistics. The use of these two STIP summaries permitted safety assessment for a 
minimum of five years before construction and two or more years after construction for the majority of the identified projects. To further evaluate the safety improvements, the research team incorporated crash data as indicated in the following section.

\subsubsection{Crash Data}

The research team acquired 12 years of ODOT crash data (1995 to 2006) and compiled it with STIP records to create a robust data set that could be easily queried for a variety of analysis options. By doing this, the research team was able to determine the frequency and severity of crashes before construction and compare them to those that occurred in the year following construction. In addition, this comparison permits the assessment of crash types. For example, someone assessing a location where exclusive left-turn lanes were constructed at a signalized intersection would expect to observe a reduction in rearend crashes following construction. The linkage of the crash data with the STIP information permits this comparison as well as numerous similar candidate assessments.

\subsubsection{GIS Database}

The research team used ArcMap to visually identify the crash data for the limits of each STIP project. This use of the GIS software enabled the research team to develop additional merged datasets and assess projects that included buffer zones. For example, Figure 4.1 shows one 2002-2005 STIP site (location intentionally excluded) and demonstrates how a 150-foot buffer can be used to help identify the minor street intersection crashes. The buffer is assigned to the centerline vectors as identified in both the GIS drawing file and the companion database. When one centerline is excluded (as indicated by the lack of buffer in the figure for one turn movement) this indicates that the database has some incomplete data. This type of intersection configuration issue is very common to GIS and so should be considered as one limitation when using this approach. The example graphic depicts the location of the crashes that occurred within the buffer region during the 12-year study period from 1995 to 2006. This summary information could then be compiled for post-safety assessments on a variety of projects where safety funding is included.

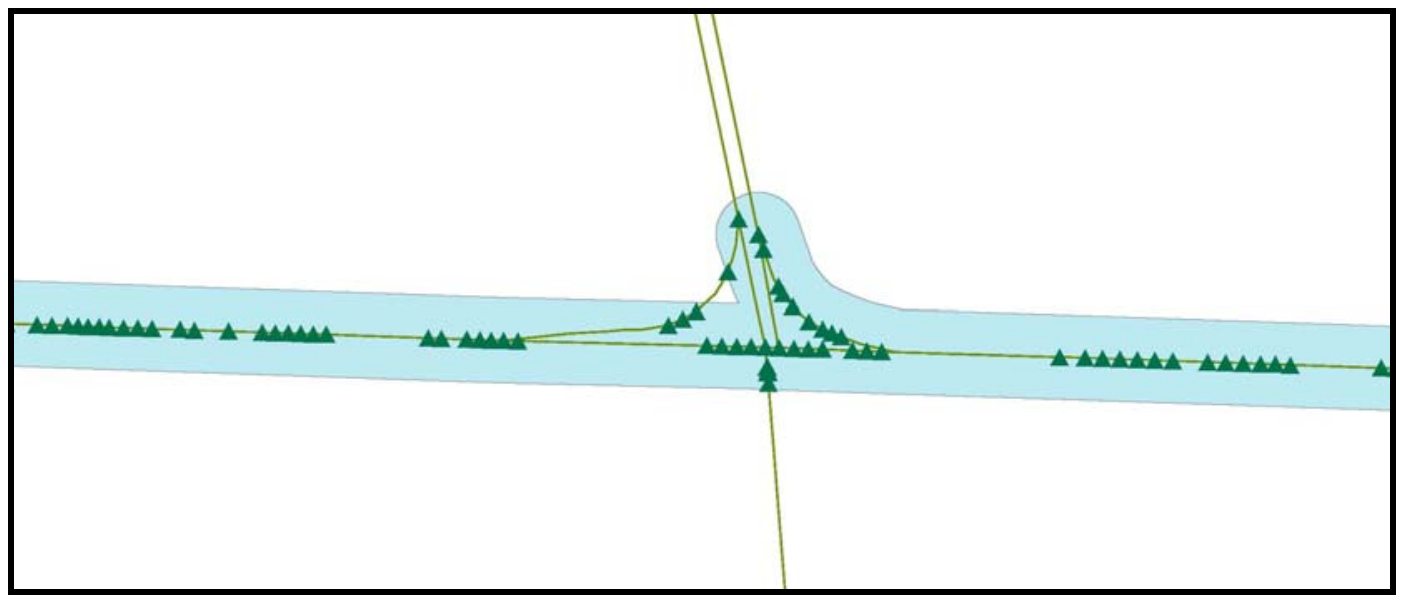

Figure 4.1: Example GIS Buffer for a 2002-2005 STIP Project Site and Associated Crashes 


\subsubsection{Approach for Relational Linking of Datasets}

The manual use of the three critical datasets (STIP project information, 12-year crash data, and geospatial data) is particularly challenging; however, in an effort to reduce the database size the research team compiled datasets with truncated crash information that excluded sites not associated with STIP projects. This reduced dataset was then linked in a relational database so as to enable straightforward systematic analysis. This linked database can be used to demonstrate potential project-level analysis that could be performed when ultimately assessing the specific safety benefits of an improvement project. The systematic statistics included in the following section demonstrate how this relational database can be used to evaluate a variety of system-level safety metrics.

One limitation of working with large static databases is that the depth of available analysis is directly constrained by the database content and quality. For example, the identified STIP project includes beginning and ending milepoint indications as project boundary definitions. A corridor may have safety enhancements along only a portion of the site, but at the systematic analysis level these internal boundaries are not known because that level of detail is restricted to the project-level files and not included in the STIP database. As a result, total crashes for STIP projects can only be identified for the overall project limits. If a corridor is very long and the safety enhancement is restricted to one location within the overall project, this analysis of crashes over the project length may underestimate the overall influence of the focused safety improvement.

\subsection{SYSTEMATIC STATISTICS}

\subsubsection{Overview Statistics}

As previously indicated, the research team evaluated systematic safety statistics for two STIP summaries and their associated crashes. Since the two STIP periods included in this analysis were 2000 to 2003 and 2002 to 2005, there were several projects included on both project summaries. In general, if the construction year did not change from one STIP summary to the next and the project length (based on beginning and ending milepoint values) remained the same, the crash evaluation for a project proved to be the same. Since the STIP summary includes expected projects, occasionally the same project key number provided moderately different safety statistics when changes in construction year or project limits occurred between the two reports. Due to the complexity of evaluating the various safety statistics at a systematic level, this summary assessment includes average crash frequency before and after construction as well as the total reduction in crashes demonstrated by the project. In some instances, the number of crashes actually increased following construction. A site that demonstrated this trend may not always have a problem but merits closer inspection to determine crash types and severity. The detailed statistics section (Section 4.2.2) demonstrates how these project level statistics can be generated from the relational dataset for additional consideration. 


\subsubsection{2000 to 2003 STIP Systematic Assessment}

An assessment of safety benefits can include many potential metrics, but a simple indication of relative safety improvements is the observed reduction in the number of crashes per year. Since the funding source can be depicted based on a specific type of work activity, Table 4.1 provides summary data for the five ODOT regions using the primary work type. For regions with many STIP projects, the use of a percent reduction in total crashes may be misleading if one specific project demonstrated disproportionate safety benefits. Thus Table 4.1 also includes a summary of the number of projects that actually demonstrated a reduction in crashes as well as projects that resulted in a net increase in crashes or exhibited no change in annual crashes.

Many funding decisions are based on reduction in severe or fatal injury crashes, so Table 4.2 depicts summary data, based on primary type of work activity, for the five ODOT regions. This table also depicts the actual number for fatal plus injury type A (severe injury) crashes associated with each project.

The research team incorporated the 2000 to 2003 STIP projects that included safety funding into a relational database and calculated the reduction in crashes per year. This summary table (see Table C.1: 2000 to 2003 STIP Safety Summary) is included in the appendix of this report. In the appendix and subsequent tables, a negative reduction in crashes actually can be interpreted as an increase in the number of crashes per year following construction.

Table 4.1: Summary by ODOT Region of Total Crashes for 2000 to 2003 STIP Projects

\begin{tabular}{c|c|c|c|c|c|c|c|c|c}
\hline $\begin{array}{c}\text { ODOT } \\
\text { Region }\end{array}$ & $\begin{array}{c}\text { Number } \\
\text { of } \\
\text { Projects }\end{array}$ & $\begin{array}{c}\text { Desc. of } \\
\text { Primary } \\
\text { Worktype }\end{array}$ & $\begin{array}{c}\text { Avg Before } \\
\text { Total } \\
\text { Crashes } \\
\text { per Year }\end{array}$ & $\begin{array}{c}\text { Tvg After } \\
\text { Total } \\
\text { Crashes } \\
\text { per Year }\end{array}$ & $\begin{array}{c}\text { Avg } \\
\text { Reduction } \\
\text { in Total } \\
\text { Crashes }\end{array}$ & $\begin{array}{c}\text { \% } \\
\text { Reduction } \\
\text { in Total } \\
\text { Crashes }\end{array}$ & $\begin{array}{c}\text { Projects } \\
\text { with } \\
\text { Reduction } \\
\text { in Total } \\
\text { Crashes }\end{array}$ & $\begin{array}{c}\text { Projects } \\
\text { with } \\
\text { Increase } \\
\text { in Total } \\
\text { Crashes }\end{array}$ & $\begin{array}{c}\text { Projects } \\
\text { with No } \\
\text { Change } \\
\text { in Total } \\
\text { Crashes }\end{array}$ \\
\hline \multirow{2}{*}{1} & 9 & PRESRV & 125.4 & 106.4 & 19.0 & $15.2 \%$ & 7 & 2 & 0 \\
\hline \multirow{2}{*}{2} & 23 & SAFETY & 44.3 & 39.4 & 4.9 & $11.0 \%$ & 17 & 3 & 3 \\
\hline & 1 & MODERN & 4.1 & 2.3 & 1.8 & $43.4 \%$ & 1 & 0 & 0 \\
\hline \multirow{2}{*}{3} & 4 & PRESRV & 78.9 & 70.2 & 8.7 & $11.1 \%$ & 2 & 2 & 0 \\
\hline & 16 & SAFETY & 2.7 & 2.0 & 0.7 & $25.6 \%$ & 10 & 5 & 1 \\
\hline & 1 & OPERAT & 36.8 & 0.5 & 36.3 & $98.6 \%$ & 1 & 0 & 0 \\
\hline & 1 & PRESRV & 3.0 & 5.5 & $(2.5)$ & $-83.3 \%$ & 0 & 1 & 0 \\
\hline 5 & 1 & SAFETY & 12.7 & 16.0 & $(3.3)$ & $-26.4 \%$ & 3 & 5 & 0 \\
\hline
\end{tabular}


Table 4.2: Summary by ODOT Region of Severe Crashes (Fatal \& Injury Type A) for 2000 to 2003 STIP Projects

\begin{tabular}{|c|c|c|c|c|c|c|c|c|c|}
\hline $\begin{array}{l}\text { ODOT } \\
\text { Region }\end{array}$ & $\begin{array}{c}\text { Number } \\
\text { of } \\
\text { Projects }\end{array}$ & $\begin{array}{c}\text { Desc. of } \\
\text { Primary } \\
\text { Worktype }\end{array}$ & $\begin{array}{c}\text { Avg Before } \\
\text { Severe } \\
\text { Crashes } \\
\text { per Year }\end{array}$ & $\begin{array}{c}\text { Avg After } \\
\text { Severe } \\
\text { Crashes } \\
\text { per Year }\end{array}$ & \begin{tabular}{|c|} 
Avg \\
Reduction \\
in Severe \\
Crashes
\end{tabular} & \begin{tabular}{|c|}
$\%$ \\
Reduction \\
in Severe \\
Crashes
\end{tabular} & \begin{tabular}{|c|} 
Projects \\
with \\
Reduction \\
in Severe \\
Crashes \\
\end{tabular} & \begin{tabular}{|c|} 
Projects \\
with \\
Increase \\
in Severe \\
Crashes \\
\end{tabular} & $\begin{array}{c}\text { Projects } \\
\text { with No } \\
\text { Change } \\
\text { in Severe } \\
\text { Crashes } \\
\end{array}$ \\
\hline \multirow{2}{*}{1} & 9 & PRESRV & 3.5 & 2.8 & 0.7 & $20.2 \%$ & 7 & 2 & 0 \\
\hline & 23 & SAFETY & 1.3 & 0.9 & 0.3 & $26.9 \%$ & 12 & 5 & 6 \\
\hline \multirow{3}{*}{2} & 1 & MODERN & 1.1 & 0.3 & 0.8 & $70.4 \%$ & 1 & 0 & 0 \\
\hline & 4 & PRESRV & 3.0 & 2.4 & 0.6 & $19.4 \%$ & 2 & 2 & 0 \\
\hline & 16 & SAFETY & 0.2 & 0.2 & 0.0 & $6.2 \%$ & 6 & 6 & 4 \\
\hline \multirow{3}{*}{3} & 1 & OPERAT & 0.8 & 0.0 & 0.8 & $100.0 \%$ & 1 & 0 & 0 \\
\hline & 1 & PRESRV & 0.2 & 0.7 & $(0.5)$ & $-233.3 \%$ & 0 & 1 & 0 \\
\hline & 8 & SAFETY & 1.7 & 1.9 & $(0.3)$ & $-17.2 \%$ & 3 & 5 & 0 \\
\hline \multirow{3}{*}{4} & 1 & MODERN & 1.0 & 1.0 & 0.0 & $0.0 \%$ & 1 & 0 & 0 \\
\hline & 1 & PRESRV & 1.7 & 0.6 & 1.1 & $64.0 \%$ & 1 & 0 & 0 \\
\hline & 7 & SAFETY & 0.8 & 0.3 & 0.5 & $58.8 \%$ & 5 & 1 & 1 \\
\hline 5 & 10 & SAFETY & 0.5 & 0.3 & 0.2 & $37.6 \%$ & 5 & 1 & 4 \\
\hline
\end{tabular}

As depicted in Table 4.1, four of the ODOT Regions (1, 2, 3, and 4) had STIP projects where the primary work type was Preservation. For Regions 1, 2, and 4 the Preservation projects resulted in an overall reduction in crashes ranging from $11.1 \%$ to $15.9 \%$, though Region 4 only had one project that met this criteria. The only Preservation project included in Region 3 resulted in an increase in crashes following construction. Table 4.2 shows severe crashes per year for the Preservation projects in Regions 1, 2, 3, and 4 and that the observed reduction in these severe crashes follows a trend similar to that of total crashes as depicted in Table 4.1. The reduction in severe or fatal crashes for Regions 1, 2 , and 4 ranged from $19.4 \%$ up to $64.0 \%$.

Similarly, Safety projects for all regions except Region 3 experienced a reduction in both total crashes (8.6\% to $25.6 \%$ ) as well as severe or fatal crashes (6.2\% to 58.5\%). Region 3 , however, included eight Safety projects, of which only three demonstrated a reduction in total crashes as well as severe and fatal crashes.

\subsubsection{2002 to 2005 STIP Systematic Assessment}

The research team next performed the systematic safety assessment described in Section 4.2.1.1 for the 2002 to 2005 STIP projects.

Table 4.3 provides summary data for the ODOT regions, primary work type, and percent reduction in total crashes for the 2002 to 2005 STIP projects where safety was included as one source of funding. As shown in Table 4.3 and Table 4.4, only three ODOT regions used safety funds on projects where Preservation was the primary work type (Regions 1, 2, and 4). The Preservation projects resulted in a percent reduction in total crashes ranging from $2.2 \%$ up to $11.5 \%$. The nine Preservation projects in Region 1 resulted in a $4.4 \%$ reduction in severe or fatal crashes and the one Preservation project in Region 4 resulted in a 52.3\% severe or fatal crash reduction. Alternatively, the seven 
Preservation projects in Region 2 had mixed results with an overall increase of $5.0 \%$ in severe crashes. This equated to a reduction for three sites, an increase for three sites, and no substantive change for one site.

Table 4.3: Summary by Region of Total Crashes for 2002 to 2005 STIP Projects

\begin{tabular}{|c|c|c|c|c|c|c|c|c|c|}
\hline $\begin{array}{l}\text { ODOT } \\
\text { Region }\end{array}$ & $\begin{array}{c}\begin{array}{c}\text { Number } \\
\text { of } \\
\text { Projects }\end{array} \\
\end{array}$ & \begin{tabular}{|c|} 
Desc. of \\
Primary \\
Worktype
\end{tabular} & \begin{tabular}{|c|} 
Avg \\
Before \\
Total \\
Crashes \\
per Year \\
\end{tabular} & \begin{tabular}{|c|} 
Avg After \\
Total \\
Crashes \\
per Year \\
\end{tabular} & $\begin{array}{c}\text { Avg } \\
\text { Reduction } \\
\text { in Total } \\
\text { Crashes } \\
\end{array}$ & \begin{tabular}{|c|}
$\%$ \\
Reduction \\
in Total \\
Crashes \\
\end{tabular} & 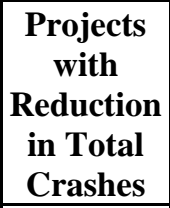 & $\begin{array}{l}\text { Projects } \\
\text { with } \\
\text { Increase } \\
\text { in Total } \\
\text { Crashes } \\
\end{array}$ & $\begin{array}{c}\text { Projects } \\
\text { with No } \\
\text { Change in } \\
\text { Total } \\
\text { Crashes } \\
\end{array}$ \\
\hline \multirow{3}{*}{1} & 1 & BRIDGE & 6.4 & 2.0 & 4.4 & $68.6 \%$ & 1 & 0 & 0 \\
\hline & $9^{*}$ & PRESRV & 80.3 & 72.1 & 8.2 & $10.2 \%$ & 5 & 4 & 0 \\
\hline & $33^{*}$ & SAFETY & 25.4 & 17.9 & 7.5 & $29.7 \%$ & 24 & 5 & 4 \\
\hline \multirow{2}{*}{2} & 7 & PRESRV & 87.0 & 85.1 & 1.9 & $2.2 \%$ & 2 & 4 & 1 \\
\hline & 32 & SAFETY & 6.9 & 5.4 & 1.6 & $22.6 \%$ & 21 & 6 & 5 \\
\hline \multirow{2}{*}{3} & 3 & MODERN & 7.8 & 11.2 & (3.4) & $-43.5 \%$ & 1 & 2 & 0 \\
\hline & 6 & SAFETY & 10.1 & 11.1 & (1.1) & $-10.4 \%$ & 1 & 1 & 4 \\
\hline \multirow{3}{*}{4} & 1 & PRESRV & 37.9 & 33.5 & 4.4 & $11.5 \%$ & 1 & 0 & 0 \\
\hline & 10 & SAFETY & 4.1 & 3.5 & 0.6 & $15.4 \%$ & 4 & 3 & 3 \\
\hline & 1 & SALMON & 1.6 & 1.0 & 0.6 & $38.5 \%$ & 1 & 0 & 0 \\
\hline 5 & 9 & SAFETY & 2.6 & 2.1 & 0.5 & $18.6 \%$ & 5 & 2 & 2 \\
\hline
\end{tabular}

*For Region 1, 12 PRESRV sites and 34 SAFETY sites included, but due to the proposed construction date adequate "After" crash data is not available. Similarly, the one OP-SSI project in ODOT Region 2 is not shown due to lack of "After" crash data.

Table 4.4: Summary by Region of Severe Crashes (Fatal \& Injury Type A) for 2002 to 2005 STIP Projects

\begin{tabular}{|c|c|c|c|c|c|c|c|c|c|}
\hline $\begin{array}{l}\text { ODOT } \\
\text { Region }\end{array}$ & $\begin{array}{l}\text { Number } \\
\text { of } \\
\text { Projects }\end{array}$ & $\begin{array}{c}\text { Desc. of } \\
\text { Primary } \\
\text { Worktype }\end{array}$ & $\begin{array}{c}\text { Avg } \\
\text { Before } \\
\text { Severe } \\
\text { Crashes } \\
\text { per Year }\end{array}$ & \begin{tabular}{|c} 
Avg After \\
Severe \\
Crashes \\
per Year
\end{tabular} & $\begin{array}{c}\text { Avg } \\
\text { Reduction } \\
\text { in Severe } \\
\text { Crashes }\end{array}$ & $\begin{array}{c}\% \\
\text { Reduction } \\
\text { in Severe } \\
\text { Crashes }\end{array}$ & \begin{tabular}{|c|} 
Projects \\
with \\
Reduction \\
in Severe \\
Crashes \\
\end{tabular} & \begin{tabular}{|c|} 
Projects \\
with \\
Increase \\
in Severe \\
Crashes \\
\end{tabular} & $\begin{array}{l}\text { Projects } \\
\text { with No } \\
\text { Change in } \\
\text { Severe } \\
\text { Crashes } \\
\end{array}$ \\
\hline \multirow{3}{*}{1} & 1 & BRIDGE & 0.4 & 0.3 & 0.0 & $11.1 \%$ & 1 & 0 & 0 \\
\hline & 9 & PRESRV & 2.7 & 2.6 & 0.1 & $4.4 \%$ & 5 & 4 & 0 \\
\hline & 33 & SAFETY & 0.8 & 0.4 & 0.3 & $42.3 \%$ & 21 & 5 & 7 \\
\hline \multirow{2}{*}{2} & 7 & PRESRV & 4.0 & 4.2 & $(0.2)$ & $-5.0 \%$ & 3 & 3 & 1 \\
\hline & 32 & SAFETY & 0.4 & 0.1 & 0.2 & $64.1 \%$ & 17 & 3 & 12 \\
\hline \multirow{2}{*}{3} & 3 & MODERN & 0.5 & 1.0 & $(0.6)$ & $-126.6 \%$ & 1 & 2 & 0 \\
\hline & 6 & SAFETY & 1.2 & 1.5 & $(0.3)$ & $-29.2 \%$ & 1 & 1 & 4 \\
\hline \multirow{3}{*}{4} & 1 & PRESRV & 1.6 & 0.8 & 0.8 & $52.3 \%$ & 1 & 0 & 0 \\
\hline & 10 & SAFETY & 0.4 & 0.1 & 0.3 & $77.0 \%$ & 4 & 1 & 5 \\
\hline & 1 & SALMON & 0.3 & 0.0 & 0.3 & $100.0 \%$ & 1 & 0 & 0 \\
\hline 5 & 9 & SAFETY & 0.3 & 0.2 & 0.0 & $7.4 \%$ & 2 & 1 & 6 \\
\hline
\end{tabular}

For projects with Safety as the primary work type, only Region 3 experienced an overall increase or no-change in total crashes (see Table 4.3) as well as severe or fatal crashes (see Table 4.4). For the six safety projects in Region 3 there was one site with a reduction 
in total crashes as well as in fatal or severe crashes, one site with an increase in total crashes as well as in fatal or severe crashes, and four sites where there were no changes in crashes. The four sites with no changes in the number of crashes did not have crashes at the sites before or after the improvement project. For Regions 1, 2, 4, and 5 the percent reduction in total crashes due to safety projects ranged from $18.6 \%$ for Region 5 to $29.7 \%$ for Region 1. For severe or fatal crashes, the percent reduction for Safety projects (per Table 4.4 ) ranged from $7.4 \%$ to $77.0 \%$ for these four regions.

The comprehensive results for the 2002 to 2005 STIP are included in Appendix C in Table C.2 of this report.

\subsubsection{Comparison of STIP Assessments}

The observed changes in crashes as demonstrated in Table 4.1, Table 4.2, Table 4.3, and Table 4.4 demonstrate that safety and preservation projects generally resulted in a reduced number of total crashes for all regions except for Region 3. In ODOT Region 3, there was consistently an increase in the number of crashes following construction. There is no clear indication why Region 3 projects were associated with an increase in crashes. For some of these Region 3 projects, Safety funding was designated for locations that did not have a documented history of crashes during the study period so any subsequent crashes would result in a perceived substantial increase in the number of annual crashes because even one crash following construction would appear to dramatically increase crashes (by 100\%) over zero previous crashes.

As shown in Table 4.5, several of the STIP projects occurred at sites without a recent documented crash history. The specific projects can be identified in Table C.1 and Table C.2. Frequently the sites without recent crashes coincided with a primary work type designated as Safety. For example, for the 2000 to 2003 STIP there were three Region 1 and three Region 5 sites that experienced an average of zero crashes per year prior to the Safety project. In these same Regions, there were not any severe or fatal crashes prior to the project at six and four sites respectively, so three additional sites in Region 1 and one additional site in Region 5 had only minor crashes prior to the safety enhancements. For the 2000 to 2003 STIP period, ODOT Region 3 was the only region that used safety funds at all sites with a recent documented crash history. For the 2002 to 2005 STIP period, only Region 5 used Safety funds at all sites with a recent documented crash history. 
Table 4.5: Recent Crash History for Sites

\begin{tabular}{|c|c|c|c|c|c|c|c|c|c|}
\hline \multirow[b]{3}{*}{$\begin{array}{l}\text { ODOT } \\
\text { Region }\end{array}$} & \multirow[b]{3}{*}{$\begin{array}{c}\text { Desc. of } \\
\text { Primary } \\
\text { Worktype }\end{array}$} & \multicolumn{4}{|c|}{2000 to 2003 STIP } & \multicolumn{4}{|c|}{2002 to 2005 STIP } \\
\hline & & \multicolumn{2}{|c|}{ Total Crashes } & \multicolumn{2}{|c|}{ Severe Crashes } & \multicolumn{2}{|c|}{ Total Crashes } & \multicolumn{2}{|c|}{ Severe Crashes } \\
\hline & & 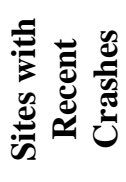 & 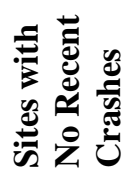 & 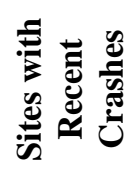 & 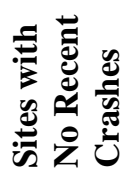 & 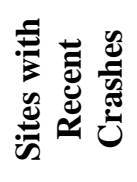 & 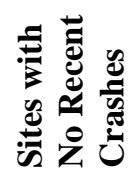 & 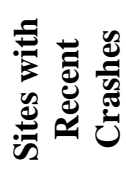 & 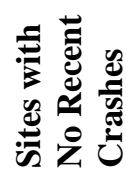 \\
\hline \multirow{3}{*}{1} & BRIDGE & -- & -- & -- & -- & 1 & 0 & 1 & 0 \\
\hline & PRESRV & 9 & 0 & 9 & 0 & 12 & 0 & 12 & 0 \\
\hline & SAFETY & 20 & 3 & 17 & 6 & 29 & 5 & 27 & 7 \\
\hline \multirow{4}{*}{2} & MODERN & 1 & 0 & 1 & 0 & -- & -- & -- & -- \\
\hline & OP-SSI & -- & -- & -- & -- & 1 & 0 & 1 & 0 \\
\hline & PRESRV & 4 & 0 & 3 & 1 & 6 & 1 & 6 & 1 \\
\hline & SAFETY & 15 & 1 & 10 & 6 & 28 & 4 & 20 & 12 \\
\hline \multirow{4}{*}{3} & MODERN & -- & -- & -- & -- & 3 & 0 & 3 & 0 \\
\hline & OPERAT & 1 & 0 & 1 & 0 & -- & -- & -- & -- \\
\hline & PRESRV & 1 & 0 & 1 & 0 & -- & -- & -- & -- \\
\hline & SAFETY & 8 & 0 & 8 & 0 & 2 & 4 & 2 & 4 \\
\hline \multirow{4}{*}{4} & MODERN & 1 & 0 & 1 & 0 & -- & -- & -- & -- \\
\hline & PRESRV & 1 & 0 & 1 & 0 & 1 & 0 & 1 & 0 \\
\hline & SAFETY & 6 & 1 & 6 & 1 & 7 & 3 & 4 & 6 \\
\hline & SALMON & -- & -- & -- & -- & 1 & 0 & 1 & 0 \\
\hline 5 & SAFETY & 7 & 3 & 6 & 4 & 7 & 0 & 3 & 0 \\
\hline
\end{tabular}

\subsubsection{Example Detailed Statistics using Relational Dataset}

Upon examination of individual STIP project reduction in crashes as depicted in Appendix C, Table C.1 and Table C.2, it is apparent that occasionally the number of crashes actually increased following construction of the project. When identified, the relational database can be further utilized to quickly evaluate project specific conditions. For example, an overall increase in the number of crashes may be expected if the goal of the improvement was to reduce the number of fatalities or injuries at the recognized expense of a possible increase in minor crash types. This supplemental assessment can be demonstrated using an example project.

In the 2002 to 2005 STIP, project key number 11244, located in ODOT Region 2, resulted in an actual increase in annual crashes. Prior to construction, this location experienced approximately three crashes per year, whereas following construction the number of crashes increased to 4.25 crashes per year (see Table C.2 in the report appendix). The specific project description indicated that the highway was realigned at this location and a left-turn refuge constructed to improve safety. As shown in Table 4.6, the specific injury information (in varying levels of detail) can be extracted for each year. For this location there were two fatal crashes in a seven year period prior to the 2002 construction year. Following construction, two fatal crashes occurred within a period of four years resulting in an increase in the average annual fatal crashes. In fact, injury crashes were the only observed severity level where the number of associated crashes were actually reduced. 
Table 4.6: Extended Severity Analysis for a Single Project (Key Number 11244)

\begin{tabular}{|c|c|c|c|c|}
\hline \multicolumn{5}{|c|}{$\begin{array}{l}\text { Project Description: } \\
\text { Construct Left Turn Refuge and Realign Highway (Construction Year 2002) }\end{array}$} \\
\hline \multirow[b]{2}{*}{ Year } & \multicolumn{4}{|c|}{ General Severity Category } \\
\hline & $\begin{array}{l}\text { Number of Fatal } \\
\text { Crashes }\end{array}$ & $\begin{array}{l}\text { Number of Injury } \\
\text { Crashes }\end{array}$ & \begin{tabular}{|c|} 
Number of Property \\
Damage Only Crashes
\end{tabular} & Total \\
\hline 1995 & 1 & 1 & \begin{tabular}{|c|}
0 \\
\end{tabular} & 2 \\
\hline 1996 & 0 & 2 & 2 & 4 \\
\hline 1997 & 1 & 2 & 0 & 3 \\
\hline 1998 & 0 & 3 & 1 & 4 \\
\hline 1999 & 0 & 0 & 1 & 1 \\
\hline 2000 & 0 & 2 & 1 & 3 \\
\hline 2001 & 0 & 3 & 1 & 4 \\
\hline 2002 & 0 & 1 & 0 & 1 \\
\hline 2003 & 0 & 1 & 3 & 4 \\
\hline 2004 & 1 & 3 & 2 & 6 \\
\hline 2005 & 1 & 1 & 1 & 3 \\
\hline 2006 & 0 & 2 & 2 & 4 \\
\hline Total: & 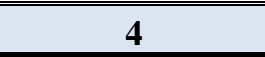 & 21 & 14 & 39 \\
\hline \multicolumn{5}{|l|}{ Summary Statistics: } \\
\hline Before -- Total (7 years) & 2 & 13 & 6 & 21 \\
\hline $\begin{array}{l}\text { Before -- Crashes per } \\
\text { Year }\end{array}$ & 0.3 & 1.9 & 0.9 & 3.0 \\
\hline After - Total (4 years) & 2 & 7 & 8 & 17 \\
\hline After - Crashes per Year & 0.5 & 1.8 & 2.0 & 4.3 \\
\hline $\begin{array}{l}\text { Reduction in Severity } \\
\text { (crashes per year) }\end{array}$ & $(0.2)$ & 0.1 & $(1.1)$ & $(1.3)$ \\
\hline Percent Reduction & $-75.0 \%$ & $5.8 \%$ & $-133.3 \%$ & $-41.7 \%$ \\
\hline
\end{tabular}

Table 4.7 further depicts how the relational database can be used evaluate the specific collision type. Based on the project description, the expenditure of safety funds for a highway realignment and left-turn refuge can be expected to reduce the number of rear-end crashes (by separating through traffic from left-turning traffic). This enhancement can also be expected to help reduce the number of turning crashes. By inspection of Table 4.7 the only collision types that actually experienced a reduction in crashes were fixed object crashes and opposing sideswipe crashes, not the expected crash reductions. Though these summary statistics do not answer the question as to why the expected crash reductions did not occur at this site, they can then be used by the agency to identify additional sources of potential safety hazards at the location. For example, a reduction in fixed object crashes and opposing sideswipe crashes may help indicate that one initial problem at this site could potentially be narrow lane width or unclear pavement marking. The site enhancements may inadvertently have corrected these alternative problems without directly addressing the more prominent angle and turn crashes. This type of analysis creates the ability to generate statistics so that a cursory analysis of the data can be performed before determining if additional site analysis is required. This type of data can be assembled to enable more comprehensive assessments of atypical project results. 
Table 4.7: Extended Analysis of Crash Type for a Single Project (Key Number 11244)

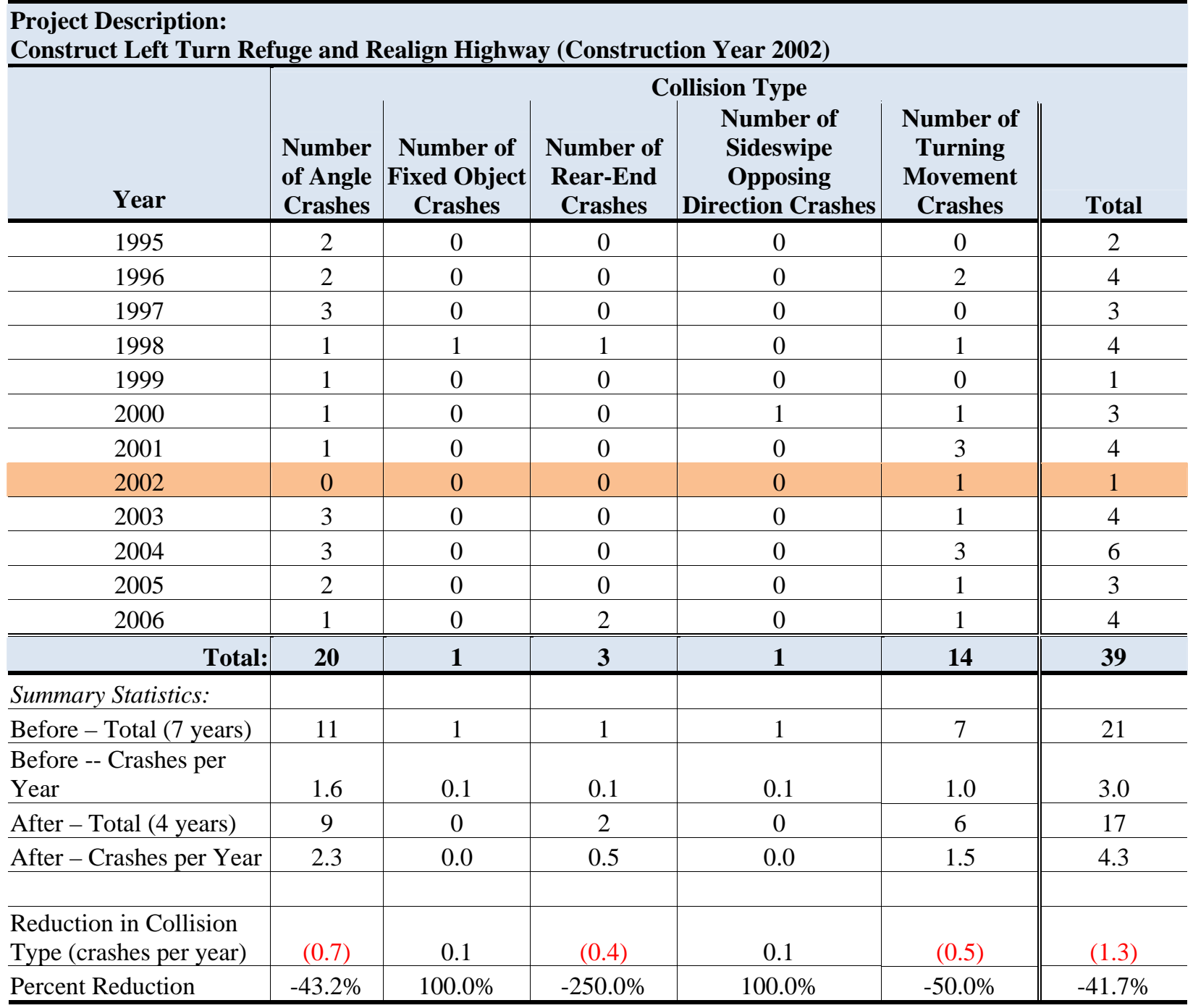

\subsection{CONCLUSIONS}

The systematic analysis demonstrates that, overall, the expenditure of safety funds have resulted in a reduction in total crashes and a similar trend in crash reductions for severe and fatal injury crashes. This information is depicted in Tables 4.1, 4.2, 4.3, and 4.4. In addition, Tables C.1 and C.2 depict crash trends for individual STIP projects. This analysis method also demonstrates that a systematic assessment of safety improvements following construction projects can provide insight into the types of projects that provide the most significant crash reductions. In some locations, for example, safety funds were utilized on projects that did not have documented crash histories and so the increase in the number of crashes is not necessarily indicative of the effects of the road enhancement but rather the selection of projects where safety funding is targeted. 
Table 4.5 demonstrates the number of sites where there was not a recent documented crash history but for which the use of safety funds were authorized.

The systematic analysis encompassed two consecutive STIP summaries and safety trends observed were consistent for both STIP periods. The additional use of the relational database that combined the STIP and crash history as developed for this assessment can also be used for evaluating individual project trends to determine changes in crash type, crash severity, or similar statistics.

The primary goal for this research effort for the systematic analysis of the safety projects was to evaluate if safety funds are being expended in a manner that results in improved safety conditions. Overall, this analysis demonstrated that safety funds are resulting in general total crash reductions. In addition, these projects also generally reduced severe and fatal crashes. The analysis also demonstrated that historic crash information can be merged with STIP project information so as to assess the effectiveness of the expenditure of safety funds for specific locations or types of improvements. This analysis could be one component in the decision process for determining the funding of future projects. 
Page Intentionally Blank 


\subsection{PROJECT LEVEL EVALUATION}

The previous chapter focused on all projects programmed in the STIP with "Safety" identified as one of the work types. In this chapter, a sample of constructed projects was selected for a comprehensive review with respect to the SIP Policy. The sample was constrained to projects whose primary work types (as identified in the STIP) were preservation and safety. A few projects also contained other work types (e.g. bridge, operations, bicycle/pedestrian) and are noted in the project summary. These projects were chosen to study the interactions between safety improvements and pavement preservation activities as they relate to the SIP Policy. This review included the entire project development process from scoping through to construction.

To accomplish this task, the research team first completed a pilot study. Fourteen pilot projects were selected that included work types of preservation only, safety only, and mixed preservation and safety projects. The projects were located in Regions 1, 2 and 4. For each project, project prospectus, as-constructed plans, design exceptions and contractor payments were obtained. In addition, photographs were taken from ODOT's Digital Video Log (DVL) to assess conditions before and after the projects were constructed. Following the results of this phase of the study, and with input from the TAC, a larger sample of 24 projects was selected from all of ODOT's regions. The evaluation results from the 24 projects are reported in this chapter.

It should clearly be noted that this evaluation exercise was not an attempt to audit project designs, project management, or safety countermeasure selection. The research team attempted to construct an accurate picture of each project's development and implementation from the available project records. While the records that were obtained are readily available, they do not fully document the project development process. This process is dynamic; the research has considered a static snapshot that was the best available characterization of the project. While it would have been possible (for some projects) to obtain qualitative or anecdotal input from the project team leader or lead designer, the research team took the approach of only gathering readily available data from various ODOT sources such as the project control system, asconstructed plans, design exceptions, crash data, STIP records, and contractor payment records. One important synergy of this approach is that it directly informed the recommendations given about performance measurement in the conclusions chapter (since data availability was a key driver). It also minimized bias that might have been introduced by relying on a more informal documentation procedure.

This chapter first documents the methodology used to select projects, the types of data collected, and the project evaluation procedures. Four metrics for each project were selected for evaluation. The scoring criteria are then presented. Then, concise summaries of each project are presented. The chapter concludes with the interpretation of these results. 


\subsection{METHODOLOGY}

\subsubsection{Selection of Projects}

Projects were selected from the Statewide Transportation Improvement Program (STIP), which is Oregon's four-year transportation capital improvement program. It is the document that identifies the funding for and scheduling of transportation projects and programs. It includes projects on the federal, state, city, and county transportation systems, multimodal projects (highway, passenger rail, freight, public transit, bicycle and pedestrian), and projects in National Parks and National Forests, and on Indian tribal lands. The STIP document is dynamic.

Amendments and modifications are frequently completed and any version can be considered only a current snapshot. For the purposes of this research, the final approved STIPs for each four-year cycle were obtained from ODOT.

The original design for the research was to select approximately 20-30 projects in a stratifiedrandom sample. The stratification was to be by ODOT Region to ensure that projects were selected (randomly) from each region in a proportional amount to the overall percentage of projects in each region. Forty-eight mixed preservation and safety projects were filtered from the STIP files (years 2000-2003, 2002-2005, 2004-2007, and 2006-2009). Of these, 31 projects were constructed. Project files were then requested for these projects. Though listed in the STIP, it was discovered that seven projects were dropped from the project development efforts or had construction date delayed and were not yet constructed, leaving 24 projects. At this point a random sample of projects from all regions was unlikely. Thus, all 24 available projects were selected for the full evaluation.

The number of projects selected from each region is shown in Table 5.1. A summary table of all projects (with details) is shown in Appendix D.

Table 5.1: Number of projects selected from each region.

\begin{tabular}{ccccc}
\hline Region & All Mixed STIP Projects & Constructed STIP Projects \\
\hline 1 & 28 & $58.3 \%$ & 12 & $50.0 \%$ \\
\hline 2 & 12 & $25.0 \%$ & 7 & $29.2 \%$ \\
\hline 3 & 3 & $6.3 \%$ & 2 & $8.3 \%$ \\
\hline 4 & 4 & $8.3 \%$ & 2 & $8.3 \%$ \\
\hline 5 & 1 & $2.1 \%$ & 1 & $4.2 \%$ \\
\hline Total & 48 & $100.0 \%$ & 24 & $100.0 \%$ \\
\hline
\end{tabular}

\subsubsection{Synthesis of Project Information}

After selecting the projects to review, information for each project was requested from the Region's traffic engineer (or appropriate staff). The data collected for each project included the project prospectus, as-constructed plans, design exceptions and contractor payments. In addition, photographs were taken from ODOT's Digital Video Log (DVL) to assess conditions before and after the projects were constructed. Finally, crash data and traffic volumes were obtained for each project to assess safety performance. 


\subsubsection{Prospectus}

The project prospectus was the key document for the evaluation. The prospectus is produced during the project development process and maintained throughout the project life (though there is no assurance that each project is updated systematically). The prospectus includes project details (region, state highway, beginning and ending mile points) and cost estimates (including construction, right-of-way, and preliminary engineering). Most importantly for this evaluation, the prospectus includes a brief description of the identified problem and proposed solution. These descriptions varied substantially in detail from project to project. On some prospectuses the narrative detailed the safety deficiencies and proposed solutions, while others listed "safety improvements as required" or no mention of safety at all.

\subsubsection{STIP Record Entry}

In addition to much of the information already provided on the project prospectus, the STIP record entry also identified the percent of each work type planned for the project. These work types were associated with fund codes of the various STIP project types. They represented the amount of the total project funded by each work type. For example, if a project was identified as $10 \%$ safety work type, $10 \%$ of the project's construction cost would be allocated to the region's safety limitation. It was assumed that the percent work type identified in the STIP record was accurate.

\subsubsection{Project Scope Year}

In order to evaluate the project retrospectively the scope year needed to be determined. The scope year would determine which SIP category was available for use in project development decisions. Unfortunately, the scope year was not systematically recorded in the documents obtained and had to be estimated. To estimate the scope year, the year the project prospectus was completed was used for the scope year. If this was missing or the STIP approval date was earlier, the STIP approval date was used for the scope year.

\subsubsection{As-Constructed Plans}

For each project, electronic versions of the as-constructed plans were obtained. Detailed locations of guardrail placement, turning refuges, and other safety items could be confirmed. If necessary, these plans were used to estimate the cost of the safety improvements by extracting the bid-item quantities.

\subsubsection{Digital Video Log}

The digital video log (DVL) was a valuable resource for reviewing and confirming asconstructed safety elements. For each project, before and after construction photos were reviewed. Relevant examples are included for each project. 


\subsubsection{Design Exceptions}

In the project development process, it is not uncommon for a project to require design exceptions for design elements that do not meet minimum design standards. For all selected projects, any filed design exceptions were obtained. These exceptions were cross referenced with the original scope of the project to verify the safety improvements that were scoped were designed. If no design exceptions were on file, it was assumed none existed.

\subsubsection{Contractor Payments}

For each project, a request for the final itemization of the bid payments to the contractor was made. These documents were obtained in hard-copy format. To analyze these documents, all bid items from the contractor payments were entered into a Microsoft Excel spreadsheet by the standard categories in the contractor payments (e.g. mobilization, traffic control, roadwork, surfaces, etc.). Based on the description available for each project, the expenditures for each work-type were estimated. This process is described in Section 3.3.

\subsubsection{Safety Investment Program Segment Categories}

The SIP segment category is critical for this evaluation since it determines what elements of the SIP Policy should have applied to the project. The SIP categorizes each five-mile segment of each state highway based on the total number of fatal and injury type 'A' (most serious) crashes. The categories range from 1 (zero fatal and injury A crashes in three years) to 5 (10 or more fatal and injury A crashes in three years). The maximum SIP category within the project limits was deemed to be the project's SIP category. Because the scope year was estimated, the research team assembled all available SIP category data for each project. In the project evaluation summary table, only the scope year SIP category is given. However, as will be described in the scoring criteria all SIP category data were considered. SIP Category data were available for 1999 (1996-1998 crash data) through 2006 (2003-2005 crash data). All SIP category data for each project are given in Appendix D, Table D.2.

\subsubsection{Safety Priority Index System}

Another key indicator of safety problems at particular locations is the Safety Priority Index System (SPIS) score. This score (maximum value is 100) is based on the previous three years of crash data and considers crash frequency (25\%), crash rate (25\%), and crash severity (50\%) in 0.10 mile sections. To become a SPIS site, three or more crashes (or one fatal crash) must have occurred at the same location in the previous three years. A “Top 10\%” cutoff value is produced each year. For each project, any Top 15\% SPIS sites are listed. The SPIS score is useful for identifying spot crash locations. In the project evaluation, only the scope year SPIS score is given. 


\subsubsection{Project Evaluation}

The following evaluation metrics were use to review each project:

1. Consistency of application of the SIP Policy to project Funding eligibility;

2. Consistency of application of the SIP Policy to Design elements;

3. Comparison of the planned and actual safety-related Expenditures; and

4. Safety performance.

The following subsections describe the various steps in each evaluation metric, the required data elements, and the criteria. Each evaluation metric was given a Likert item rating from 1-5 based on the criteria explained below. Given the dynamic nature of project development, flexible scoring criteria were established.

It is worth restating that this evaluation exercise was not an attempt to audit project designs, project management, or safety countermeasure selection. Project development is a dynamic process. The challenges in a post-analysis are presented graphically in Figure 5.1 which shows the project development process that is being evaluated. The evaluations metrics for each project are conducted at different times, these include:

- the scope year,

- when the project design takes place (between the scope and construction year),

- the construction year, and

- three years before and after the project construction for safety performance.

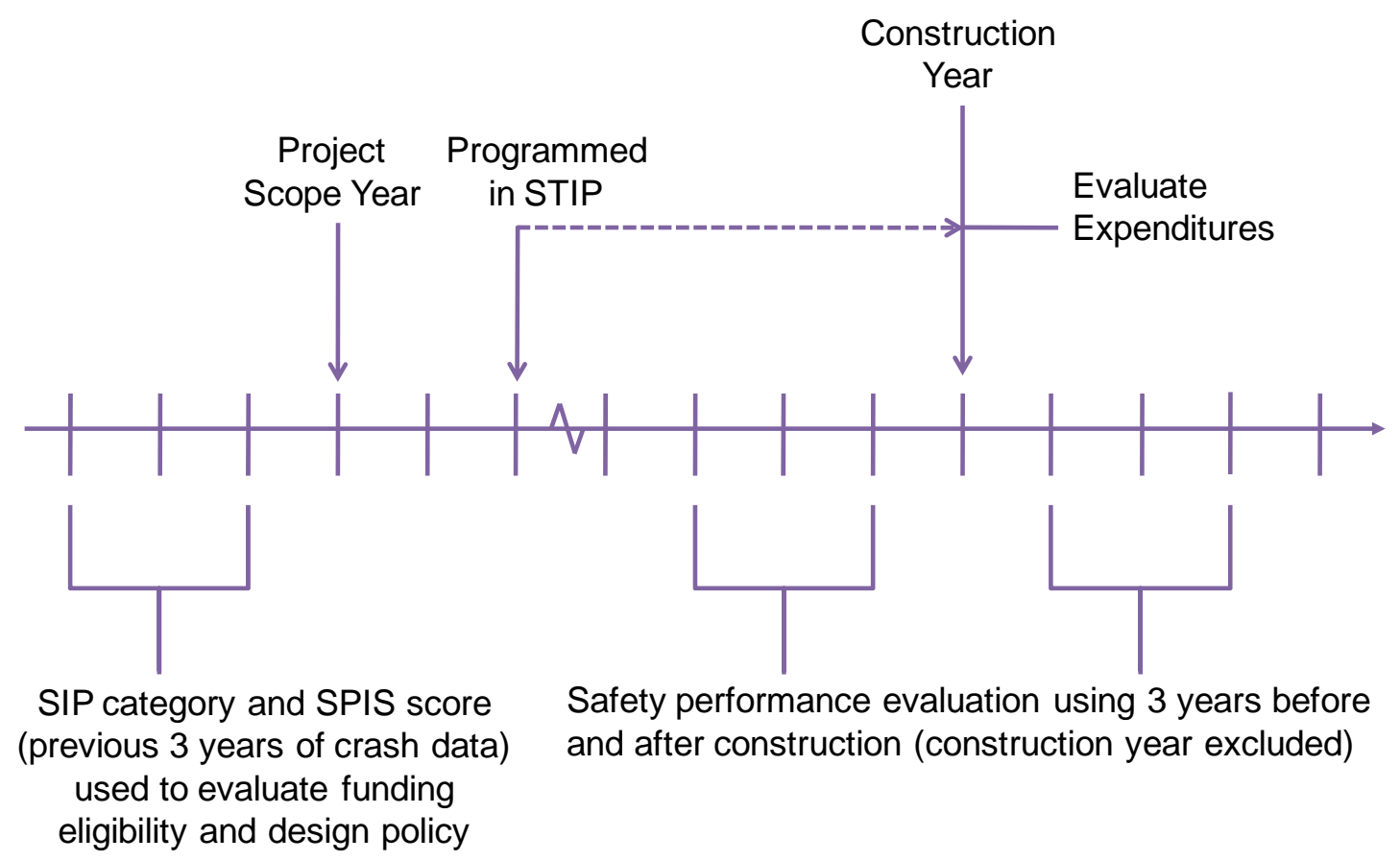

Figure 5.1: Sample Project Timeline 


\subsubsection{Consistency of Application of the SIP Policy to Project Funding Eligibility}

The first evaluation metric for each project is straightforward. For mixed preservation and safety projects to be considered eligible for safety funding under the SIP Policy, a SIP category of 3,4 , or 5 is required. The SIP segment category for the estimated scope year was used. Because of the uncertainty of the project scope year, adjacent years' SIP category were considered. The following scale was assigned (note no scores of 2 or 4 were given):

- For the estimated scope year, if the project contained a SIP category of 3, 4, or 5, it received a score of 1 . If it did not, adjacent years SIP data were considered. If other years contained a SIP category 3 or greater, the project was still scored a 1.

- If the project contained a SIP category of 1 or 2 for the estimated scope year but the adjacent SIP data fluctuated between 2 and 3, then the project received a score of 3 .

- If the project contained a SIP category of 1 or 2 in the scope year and all other years, it received a score of 5 .

\subsubsection{Consistency of Application of the SIP Policy to Design Elements}

The consistency of application of the SIP Policy to design elements also depends on the SIP category for each project. On mixed preservation and safety projects with a SIP 3, 4, or 5 category, the SIP Policy states only safety enhancements are eligible for safety funds. Mandatory design features (see Figure 2.2) are not eligible. Evaluation of this metric was largely dependent on what safety improvements were identified in the description provided in project narrative. Because the project prospectuses are not all completed to the same level of detail, the research team reviewed all project files (as-built drawings, pre- and post-construction digital video log, design exceptions) to see if any safety improvements (mandatory or enhancements) were constructed. Note no scores of 3 were given. The following criteria were established:

- If the project prospectus clearly defined the safety deficiencies and the proposed improvements were considered "enhancements," then the project received a score of 1 .

- If the project prospectus did not define the safety deficiencies, but review of the project files identified safety improvements that were "enhancements," the project received a score of 2 .

- If the project prospectus did define the safety deficiencies but a review of the project files identified safety improvements that were mandatory corrective features, the project received a score of 4 .

- If the project prospectus did not define the safety deficiencies, and the project file did not show evidence of safety improvements having been identified, the project received a score of 5. 


\subsubsection{Comparison of the Planned to Estimated Actual Safety Expenditures}

The third metric was a comparison of the planned (as stated in the STIP record) allocation of work type costs to the actual constructed costs. Evaluating this metric required the research team to assemble the project definition and determine which elements were intended to be funded by the safety limitation. For well-documented projects, the safety elements were easily determined from the description (e.g. installing a left-turn refuge). For less well-documented projects, as-built construction plans, design exceptions and before and after digital video logs were used to determine the safety elements.

Once the particular safety elements were known, the bid items from the contractor payments data were either coded as a safety, preservation, or shared item. Shared costs were defined as those that generally applied to the entire project and could not easily be assigned to either preservation or safety work items. These typically included mobilization, traffic control, right of way (ROW) development, and engineering bid items. It was assumed that these shared costs would have the same work type split as the total safety and preservation mix. This assumption can in some cases be weak, since it is possible that the safety work type (e.g., guardrail) required more mobilization than the preservation work items.

In cases where the safety element was not easily extracted by a single bid item (i.e. a leftturn refuge) the research team estimated the bid-item quantities from the as-built construction plans and bid-item cost shown in the contractor payments. For example, the quantities of paving material, fill, and other work items for adding a left-turn refuge could be estimated from the as-built plans. This estimate for the left-turn refuge would be added to the safety expenditures and subtracted from the preservation expenditures. The method used to estimate safety expenditures has considerable room for error. Where improvement was substantial (such as realigning an intersection) it was engineering judgment as to which costs were assigned to "safety" and which were assigned to "preservation."

After all bid items had been assigned, the estimated safety and preservation expenditures were compared to the planned estimates from the STIP record. If the safety elements required right-of-way (ROW), any ROW costs in the prospectus were noted and considered in the project scoring (though not explicitly shown in the actual vs. planned expenditure).

Finally, the estimated project construction costs from the STIP were compared to estimated actual construction costs. If there was substantial difference, it was noted. The concern was that projects that had been significantly reduced or expanded in scope may have also changed the amount of safety funds in the project (but not updated in the STIP records). 
The criteria were as follows:

- If the preservation and safety mixture from the STIP closely matched the tabulated bid items from the contractor payments, the project received a score of 1.

- If the preservation and safety mixture from the STIP did not closely match the tabulated bid items from the contractor payments, but the safety improvements scoped were implemented, the project received a score of 3.

- If the safety funds allocated were not spent on safety improvements identified, or if there was no evidence that safety funds were being used towards any safety improvements, the project received a score of 5.

It should be noted that this metric was evaluated independent of the previous criteria. For example, if safety elements did not meet the design policy, but were identified in the project narrative as the safety elements, the expenditures were tabulated. Stated another way, a project did not necessarily fail this criteria if it was determined that only mandatory design elements were funded with safety funds. The intent of scoring this metric was to identify if what was intended to be spent on safety was spent. However, in regards to the SIP Policy, the design and expenditures metrics must be considered together. Projects that receive poor design metric scores fail to meet SIP Policy. A good expenditure metric score does not change that fact.

\subsubsection{Evaluation of Safety Performance}

The purpose of the safety evaluation metric in the project-level evaluation was to establish the change in safety performance for each project. There are many inherent difficulties in evaluating a change in safety performance - even with such detailed project information. Given that the change in safety performance was to be translated into a Likert scale (1-5) rating, a general assessment was considered sufficient to measure safety performance.

For each project, crashes within the project limits for three years before and three years after the identified construction year were extracted from the state crash database. The construction year was not included. These crash counts were summarized by total, fatal and injury type 'A' severities, injury ' $\mathrm{B}$ ' and ' $\mathrm{C}$ ' severities, and property damage only. Both the percentage change and change in count were used to evaluate the project's safety performance. Fatal and injury A crash counts were used because they relate to the SIP Policy objectives to reduce the number of fatal and severe injury crashes. This crash count was tabulated for the entire project work limits. If the project narrative or elements specified a specific crash type or location, these were identified as target crashes. These crash counts were extracted for only the limits of the improvement (e.g. a left-turn enhancement, or a weaving lane). In cases where the project was constructed in 2006, only one year of after crash data were available; these projects were not given safety performance scores. 
In addition, an average daily traffic (ADT) value for the milepoint nearest the site was collected for each year from the ODOT highway volume tables in order to establish an exposure trend.

The criteria were established as follows:

- If fatal and injury A crashes or target crashes decreased by more than $15 \%$ and exposure was considered, the project received a score of 1.

- If fatal and injury A crashes or target crashes stayed approximately the same, the project received a score of 3 .

- If fatal and injury A crashes or target crashes increased by more than $15 \%$ and considered exposure, the project received a score of 5 .

\subsection{EVALUATION RESULTS}

The methodology described in the previous section was applied to selected projects. Projects are presented in ascending key number order in a concise three page snapshot. The format for each project is identical. It includes:

- A narrative in the "Description" section that gives a general description of the project.

- A Project Summary table that includes all data about the project. The table includes:

o Key Number - the unique number that identifies the project in the STIP.

o Contract Number - the unique number that identifies that project construction contract.

o Region - one of the five ODOT regions where the project was constructed.

o Funding - the work types and percentages as identified in the STIP documents.

o Highway - the internal ODOT highway number

o $\mathrm{MP}$ - the milepost limits of the project.

o Construction Year - the year the project was constructed.

o Estimated scope year - the estimated year the project was scoped.

o SIP Category - the maximum SIP Category for the estimated scope year reported within the project limits.

o SPIS score - the maximum SPIS score for the estimated scope year reported within the project limits.

o ODOT Problem - a short description of the identified problem taken directly from the project prospectus.

o ODOT Proposed Solution - a short description of the proposed solution taken directly from the project prospectus. Safety related items are italicized.

o Design Exceptions - the location, extent and type of any design exceptions that were filed for the project.

o Constructed Safety Improvements - the research team's interpretation of what safety improvements were constructed. 
o Target Crashes - the research team's assessment if the constructed safety improvements directly addressed a specific crash type or cost. The type and milepost range is given.

o Prospectus Costs - as identified in the prospectus, the cost (in 1000s) for preliminary engineering (PE), right-of-way (ROW) and construction (CON) costs.

o STIP Costs - as identified in the STIP, the cost (in 1000s) for preliminary engineering (PE), right-of-way (ROW) and construction (CON) costs.

- A set of figures showing significant before and after photographs of the safety improvements

- A narrative in the “Evaluation” section that explains how each metric's score was assigned.

- A Project Scorecard table which presents the score for each metric and brief note explaining the score. In the row labeled "Expenditures", this table also presents the total construction costs, the safety amount, and the splits by work type. This is presented for both the STIP record (same as "STIP Costs" in Project Summary table) and the estimated as-built costs.

- A Safety Performance figure that consists of five plots labeled A-E.

o Plot A (All Crashes, By Severity) shows the frequencies for crashes by severity (fatal and injury A, injury B and C, and property damage only) for each year. Three years of before data are always presented, followed by the construction year and the after data. At the time of this report, 2007 was the most recent crash data available.

o Plot B (Average Daily Traffic) shows average daily traffic. The vertical grey dotted line indicates the project's construction year.

o Plot C (Target Crashes) shows the frequency of the target crashes. These target crashes are those identified in the Project Summary table by type and milepost range. If no target crashes were identified, this plot is blank. The vertical grey dotted line indicates the project's construction year.

o Plots D (Percent Change) and E (Count Change) are shown for volume, target crashes, property damage only, injury B and C, and fatal and injury A crashes. The note below the $x$-axis for plots $\mathrm{D}$ and $\mathrm{E}$ state how many years were used in the before-after analysis.

\subsubsection{US 20: Cox Creek to UPRR Track Spur}

\subsubsection{Description}

This 10.8 mile preservation project on US 20 (Santiam Highway) was constructed in 2002 and contained a segment with a SIP category 5. A summary of the entire project from the project prospectus and STIP project files is shown in Table 5.2. The project area was mostly rural and was located in Region 2. A 7\% safety work type was identified in the STIP and prospectus. The problem statement did not define the safety deficiencies but explicitly described the proposed safety solutions. The constructed safety improvements were the addition of left and right-turn lanes at Spicer Road. This was 
considered an enhancement. Target crashes were identified as turning and rear-end crashes at Spicer Road (MP 9.82). Before and after photos from the digital video log are shown in Figure 5.2.

Table 5.2: Project Summary, US 20-Cox Creek to UPRR Track Spur, Key No. 07101

\begin{tabular}{|c|c|c|c|c|c|}
\hline $\begin{array}{l}\text { Key No. } \\
\text { Contract No. }\end{array}$ & $\begin{array}{l}07101 \\
12654\end{array}$ & Region & 2 & Funding & $\begin{array}{l}\text { Preservation } 84 \% \\
\text { Safety } 7 \% \\
\text { Bridge } 9 \%\end{array}$ \\
\hline Highway & 016 Santiam & MP & $2-12.8$ & $\begin{array}{l}\text { Construction } \\
\text { Year }\end{array}$ & 2002 \\
\hline $\begin{array}{l}\text { Estimated } \\
\text { Scope Year }\end{array}$ & 1999 & $\begin{array}{l}\text { SIP } \\
\text { Category } \\
1996-1998\end{array}$ & 5 & $\begin{array}{l}\text { SPIS Score } \\
1996-1998\end{array}$ & $\begin{array}{l}\text { Max: 65.91, MP } \\
6.46,95-100 \%\end{array}$ \\
\hline $\begin{array}{l}\text { ODOT } \\
\text { Problem }\end{array}$ & \multicolumn{5}{|c|}{$\begin{array}{l}\text { Deteriorated and rutted roadway surface. Accident sites. Burkhart Creek bridge has } \\
\text { scour problems, excessive deflection in girders, and low load capacity. }\end{array}$} \\
\hline $\begin{array}{l}\text { ODOT } \\
\text { Proposed } \\
\text { Solution }\end{array}$ & \multicolumn{5}{|c|}{$\begin{array}{l}\text { 3R Preservation project. Overlay the highway with } 100 \mathrm{~mm} \text { AC (50mm "B" mix base } \\
\text { course and 50mm "F" mix wearing course), construct a new structure at Burkhart } \\
\text { Creek and widen the structure at Truax Creek, construct a left turn refuge between } \\
\text { Harber and Engel Roads, construct left turn refuges and right turn deceleration lanes } \\
\text { at Spicer Road (HEP Funding), and installing guardrail at four box culvert locations, } \\
\text { and extend one box culvert. }\end{array}$} \\
\hline $\begin{array}{l}\text { Design } \\
\text { Exceptions }\end{array}$ & \multicolumn{5}{|c|}{$\begin{array}{l}\text { Shoulder widths at Burkhart Creek Bridge MP } 3.92 \text { and Truax Creek Bridge at MP } \\
4.69 \text { (construct at } 1.8 \mathrm{~m} \text { ) }\end{array}$} \\
\hline $\begin{array}{l}\text { Constructed } \\
\text { Safety } \\
\text { Improvements }\end{array}$ & \multicolumn{3}{|c|}{$\begin{array}{l}\text { Added a left-turn and right-turn lane at Spicer } \\
\text { Road }\end{array}$} & $\begin{array}{l}\text { Target } \\
\text { Crashes }\end{array}$ & \begin{tabular}{l|l} 
Angle and \\
Rear End @ \\
Spicer Rd (MP \\
9.82) \\
\end{tabular} \\
\hline \multirow{4}{*}{$\begin{array}{l}\text { Prospectus } \\
\text { Costs (000's) }\end{array}$} & \multirow{4}{*}{$\begin{array}{l}\text { PE } \\
\text { ROW } \\
\text { CON } \\
\text { TOTAL }\end{array}$} & $\$ 370$ & \multirow{4}{*}{$\begin{array}{l}\text { STIP Costs } \\
\text { (000's) }\end{array}$} & \multirow{4}{*}{$\begin{array}{l}\text { PE } \\
\text { ROW } \\
\text { CON } \\
\text { TOTAL }\end{array}$} & $\$ 379$ \\
\hline & & $\$ 320$ & & & $\$ 200$ \\
\hline & & $\$ 4,898$ & & & $\$ 4,932$ \\
\hline & & $\$ 5,588$ & & & $\$ 5,511$ \\
\hline
\end{tabular}

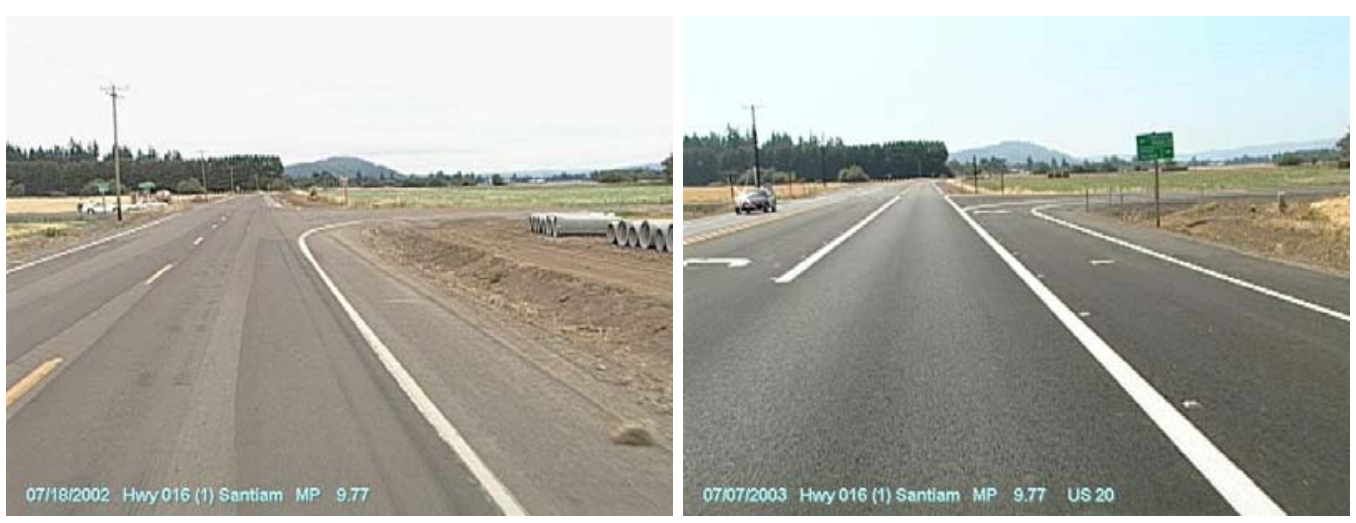

Figure 5.2: Conditions at Spicer Rd in 2002 (before) and added turn lanes in 2003 (after)

\subsubsection{Evaluation}

The project scored well in all evaluation metrics, which are summarized in Table 5.3. The project included a segment with a SIP category of 5. The addition of turning lanes at 
Spicer Road was considered an enhancement. Thus the project funding eligibility score was 1 and the design score was 1 . The project also earned a 1 for the expenditures metric. As shown in Table 5.3, a 7\% use of STIP safety funding was planned. In the as-built data it was estimated that the left-turn refuge and right-turn deceleration lane cost $\$ 386,000$ (including the share of $\$ 1.03$ million in shared costs that included mobilization, traffic control, and right-of-way development). The construction cost of the turning lanes was developed by applying rough quantity estimates from the construction plans for asphalt and bases. The actual safety expenditures were $8 \%$ of the construction costs - which matches the STIP allocation.

Safety was improved within the project limits following construction. The addition of left-turn and right-turn lanes on rural highways generally address turning and rear-end crashes. These were identified as the target crashes in the vicinity of Spicer Road. Improvement was found in these crashes. Comparing the three-year before and after periods over the project limits, target crashes decreased from 4 to 1 at the Spicer Road intersection. Over the entire project limits, fatal and injury A crashes decreased from a total of 14 to 4, a decrease of 10 crashes (-71\%). The primary fatal and injury A crash types that decreased were turn, rear, and head-on collisions. These decreases were possibly related to the improvements in the roadway width by the addition of a left-turn refuge between Harber and Engel (not funded by safety) and other improvements. Traffic volume declined over the seven year period most likely from a count adjustment. Considering this evidence, the project was given a performance score of 1 .

Table 5.3: Project Scorecard, US 20-Cox Creek to UPRR Track Spur, Key No. 07101

\begin{tabular}{|c|c|c|c|c|c|c|c|}
\hline Metric & Score & \multicolumn{6}{|l|}{ Note } \\
\hline $\begin{array}{l}\text { Funding } \\
\text { Eligibility }\end{array}$ & 1 & \multicolumn{6}{|c|}{$\begin{array}{l}\text { The project contained a SIP segment with category of } 5 \text { and was eligible for } \\
\text { safety funds. }\end{array}$} \\
\hline Design & 1 & \multicolumn{6}{|c|}{$\begin{array}{l}\text { The safety problem statement did not define the safety deficiencies but explicitly } \\
\text { described the proposed safety solutions. The safety improvements (adding } \\
\text { turning lanes at Spicer Road) were enhancements. }\end{array}$} \\
\hline \multirow[t]{4}{*}{ Expenditures } & 1 & \multicolumn{6}{|c|}{$\begin{array}{l}\text { The identified safety enhancements accounted for } 8 \% \text { of project construction } \\
\text { costs; } 7 \% \text { was planned. The costs are summarized (in 1,000s): }\end{array}$} \\
\hline & & & Total & Other & Other \% & Safety & Safety \% \\
\hline & & STIP & $\$ 4,932$ & $\$ 4,587$ & $93 \%$ & $\$ 345$ & $7 \%$ \\
\hline & & As-Built & $\$ 4,730$ & $\$ 4,344$ & $92 \%$ & $\$ 386$ & $8 \%$ \\
\hline Performance & 1 & \multicolumn{6}{|c|}{$\begin{array}{l}\text { The project identified a particular safety problem at Spicer Road. Percentage and } \\
\text { count changes for the target crashes }(-75 \%,-3) \text { and fatal and injury A crashes } \\
(-71 \%,-10) \text { indicated an improvement in safety. }\end{array}$} \\
\hline
\end{tabular}



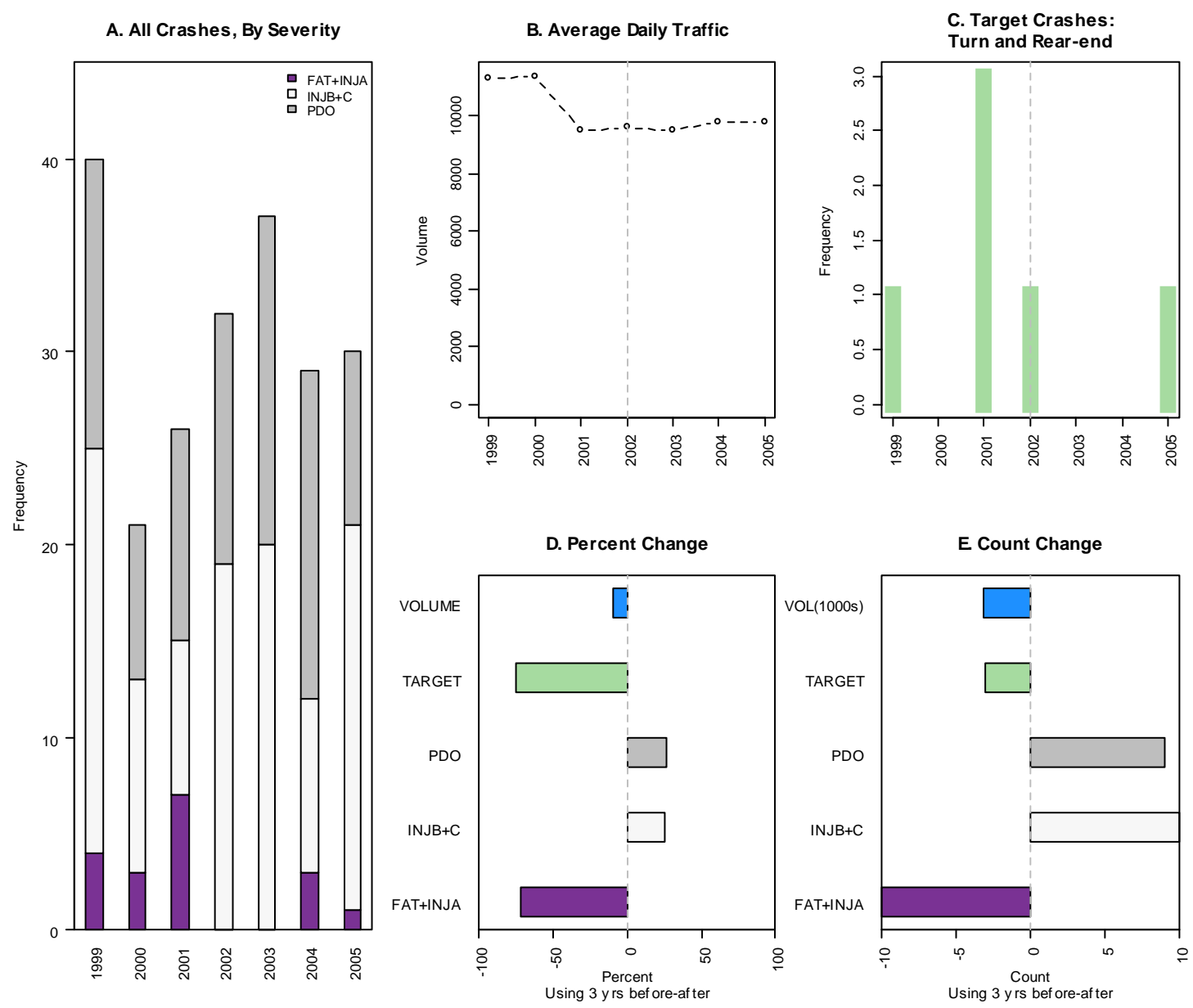

Figure 5.3: Safety Performance, US 20-Cox Creek to UPRR Track Spur, Key No. 07101

\subsubsection{OR 42: Winston to I-5 Resurfacing}

\subsubsection{Description}

This 4.0 mile preservation project, located on the OR 42 (Coos Bay-Roseburg Highway) was constructed in 2002. A summary of the entire project from the project prospectus and STIP project files is shown in Table 5.4. The project area was of both rural and urban character and was located in Region 3. A 30\% safety work type was identified in the STIP and prospectus. The project limits contained a segment with a SIP category of 4 . The project narrative did not define the safety deficiencies, however, some safety solutions were proposed. After reviewing the as-built plans and digital video logs, it was determined that the constructed safety improvements included upgraded guardrails, installation of a right-turn lane and signal modifications at Kelly's Corner (OR 42 and Carnes/Roberts), and installation of a WB right-turn lane at the OR 42/99 intersection. These were considered as enhancements. Before and after photos from the video log are 
shown in Figure 5.4. In addition, the overhead advance flashing beacons (be prepared to stop when lights flash) and signs were removed based on undesirable driver behavior.

Table 5.4: Project Summary, OR 42-Winston to I-5, Key No. 09841

\begin{tabular}{|c|c|c|c|c|c|}
\hline $\begin{array}{l}\text { Key No. } \\
\text { Contract No. }\end{array}$ & $\begin{array}{l}09841 \\
12867\end{array}$ & Region & 3 & Funding & $\begin{array}{l}\text { Preservation } 44 \% \\
\text { Safety } 30 \% \\
\text { Operations } 26 \% \\
\end{array}$ \\
\hline Highway & $\begin{array}{l}035 \text { Coos } \\
\text { Bay-Roseburg }\end{array}$ & MP & 73.2-77.2 & $\begin{array}{l}\text { Construction } \\
\text { Year }\end{array}$ & 2002 \\
\hline $\begin{array}{l}\text { Estimated } \\
\text { Scope Year }\end{array}$ & 1999 & $\begin{array}{l}\text { SIP } \\
\text { Category } \\
\text { 1996-1998 }\end{array}$ & 4 & $\begin{array}{l}\text { SPIS Score } \\
1996-1998\end{array}$ & $\begin{array}{l}\text { Max: } 77.6, \mathrm{MP} \\
75.63,90-95 \%\end{array}$ \\
\hline $\begin{array}{l}\text { ODOT } \\
\text { Problem }\end{array}$ & \multicolumn{5}{|c|}{$\begin{array}{l}\text { The asphalt concrete surface is deteriorating and is considered "fair" in the } 1998 \\
\text { pavement condition report. The overall index is 61.1. The guardrail and bridge } \\
\text { connections do not meet current standards. }\end{array}$} \\
\hline $\begin{array}{l}\text { ODOT } \\
\text { Proposed } \\
\text { Solution }\end{array}$ & \multicolumn{5}{|c|}{$\begin{array}{l}\text { Grind full width and overlay (including section of Hwy } 99 \text { south of the Hwy 99/42 } \\
\text { intersection in Winston). Replace guardrail and bridge connections where necessary. } \\
\text { Improve geometry (install right-turn lanes/signals) at Kelly's Corner (Hwy } 42 \text { and } \\
\text { Carnes/Roberts). Install WB right-turn lane at Hwy 42/99 intersection in Winston. } \\
\text { Construct pedestrian refuges in downtown Winston. Resurface multi-use path } \\
\text { adjacent to Hwy } 42 \text { between Winston and Green. Close Winston Section Road's } \\
\text { entrance to Hwy } 42 \text {. }\end{array}$} \\
\hline $\begin{array}{l}\text { Design } \\
\text { Exceptions }\end{array}$ & \multicolumn{5}{|c|}{$\begin{array}{l}\text { Lane Width: “C2”35+849 - “C2”36+083. Shoulder Width: “C2”37+605 - } \\
\text { "C2”37+774 Eastbound Bridge and “C2”41+179 - “C2”41+236 Bridge over } \\
\text { Interstate 5. Bridge Width: “C2”37+605 - “C2”37+774 Eastbound Bridge over the } \\
\text { South Umpqua River. Sidewalk Width: “C1”45+611 - “C2”36+042 Lt. }\end{array}$} \\
\hline $\begin{array}{l}\text { Constructed } \\
\text { Safety } \\
\text { Improvements }\end{array}$ & \multicolumn{3}{|c|}{$\begin{array}{l}\text { Upgrade existing guardrail, right turning lanes at } \\
\text { Kelly's Corner and OR } 99\end{array}$} & $\begin{array}{l}\text { Target } \\
\text { Crashes }\end{array}$ & \begin{tabular}{l|l} 
Turning and \\
rear end at \\
Kelly’s Corner \\
and OR-99 \\
(MPs 75.72 \\
and 76.22) \\
\end{tabular} \\
\hline \multirow{4}{*}{$\begin{array}{l}\text { Prospectus } \\
\text { Costs (000's) }\end{array}$} & \multirow{4}{*}{$\begin{array}{l}\text { PE } \\
\text { ROW } \\
\text { CON } \\
\text { TOTAL }\end{array}$} & $\$ 349$ & \multirow{4}{*}{$\begin{array}{l}\text { STIP Costs } \\
\text { (000's) }\end{array}$} & \multirow{4}{*}{$\begin{array}{l}\text { PE } \\
\text { ROW } \\
\text { CON } \\
\text { TOTAL }\end{array}$} & $\$ 349$ \\
\hline & & $\$ 50$ & & & $\$ 50$ \\
\hline & & $\$ 2,493$ & & & $\$ 2,533$ \\
\hline & & $\$ 2,892$ & & & $\$ 2,932$ \\
\hline
\end{tabular}
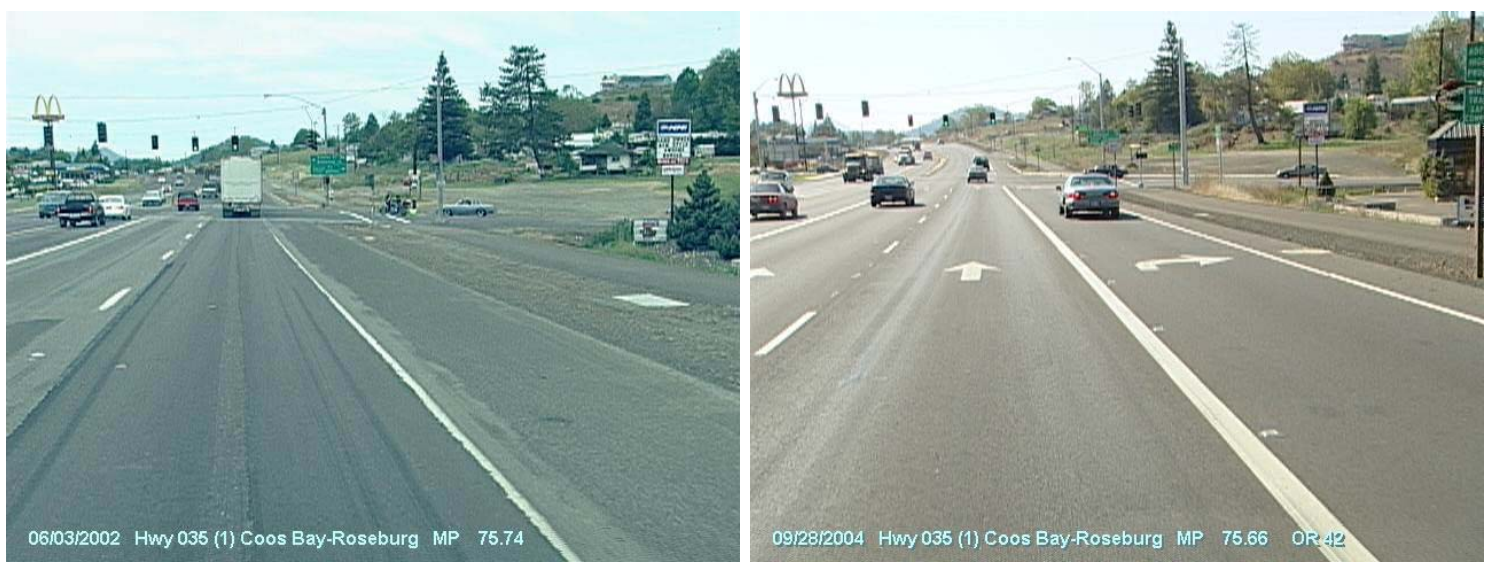

Figure 5.4: Conditions in 2002 (before) and in 2004 (after) showing the addition of the right-turn lane at "Kelly's Corner" MP 75.72. OR-99 improvements not shown. 


\subsubsection{Evaluation}

The project was evaluated according to the criteria in each metric and the results are summarized in Table 5.5. The project included a segment with a SIP category of 4 . While the project narrative did not define the safety deficiencies, the addition of the right-turn lanes was considered an enhancement. This earned the project a funding eligibility score of 1 and a design score of 2. The cost to install a right-turn lane at Kelly's Corner (OR 42 and Carnes/Roberts) and to install a WB right-turn lane at OR 42/99 intersection was estimated from the construction plans at $\$ 489,000$ (including the shared costs). Other safety-related items included guardrail Type 2a and 3, guardrail anchors, end pieces, transitions, connections and terminals; and right-turn lanes. These expenditures totaled $14 \%$ of the construction costs; the STIP planned that $30 \%$ of the project cost would be safety funding. However, there was some uncertainty about the continuity of the project scope since the estimate in the STIP and prospectus differed from the actual constructed costs (\$2.5M to $\$ 3.4 \mathrm{M})$. Considering these data, the project was given an expenditure score of 3 .

The safety performance following the completion of the project was mixed. Over the project limits, fatal and injury A crashes decreased from a total of 7 to $2(-60 \%)$ in the project work limits, while traffic volume increased 7\% over the same period. The addition of right-turn lanes on rural highways generally address turning and rear-end crashes. These were identified as the target crashes in the vicinity of the improvements. Target crashes, however, increased from 21 to 24 at the intersections. Because of the decrease in fatal and injury A crashes, the project was give a performance score of 2.

Table 5.5: Project Scorecard, OR 42-Winston to I-5, Key No. 09841

\begin{tabular}{|c|c|c|c|c|c|c|c|}
\hline Metric & Score & \multicolumn{6}{|l|}{ Note } \\
\hline $\begin{array}{l}\text { Funding } \\
\text { Eligibility }\end{array}$ & 1 & \multicolumn{6}{|c|}{$\begin{array}{l}\text { The project contained a segment with a SIP Category } 4 \text { and was eligible for } \\
\text { safety funds. }\end{array}$} \\
\hline Design & 2 & \multicolumn{6}{|c|}{$\begin{array}{l}\text { The project did not define the safety deficiencies. While upgrading the existing } \\
\text { guardrail was a mandatory item, the addition of right-turn lanes at Kelly's } \\
\text { Corner and Hwy } 99 \text { were considered to be safety enhancements. }\end{array}$} \\
\hline \multirow[t]{4}{*}{ Expenditures } & 3 & \multicolumn{6}{|c|}{$\begin{array}{l}\text { The identified safety enhancements accounted for } 14 \% \text { of project construction } \\
\text { costs; } 30 \% \text { was planned. The costs are summarized (in 1,000s): }\end{array}$} \\
\hline & & & Total & Other & Other \% & Safety & Safety \% \\
\hline & & STIP & $\$ 2,533$ & $\$ 1,773$ & $70 \%$ & $\$ 760$ & $30 \%$ \\
\hline & & As-Built & $\$ 3,437$ & $\$ 2,948$ & $86 \%$ & $\$ 489$ & $14 \%$ \\
\hline Performance & 2 & \multicolumn{6}{|c|}{$\begin{array}{l}\text { Target crashes (rear-end and turning near Kelly’s corner and OR 99) increased } \\
\text { from } 21 \text { to } 24(14 \%) \text {. However, fatal and injury A crashes over the entire project } \\
\text { limits decreased } 60 \% \text { from a total of } 7 \text { to } 2 \text {. }\end{array}$} \\
\hline
\end{tabular}




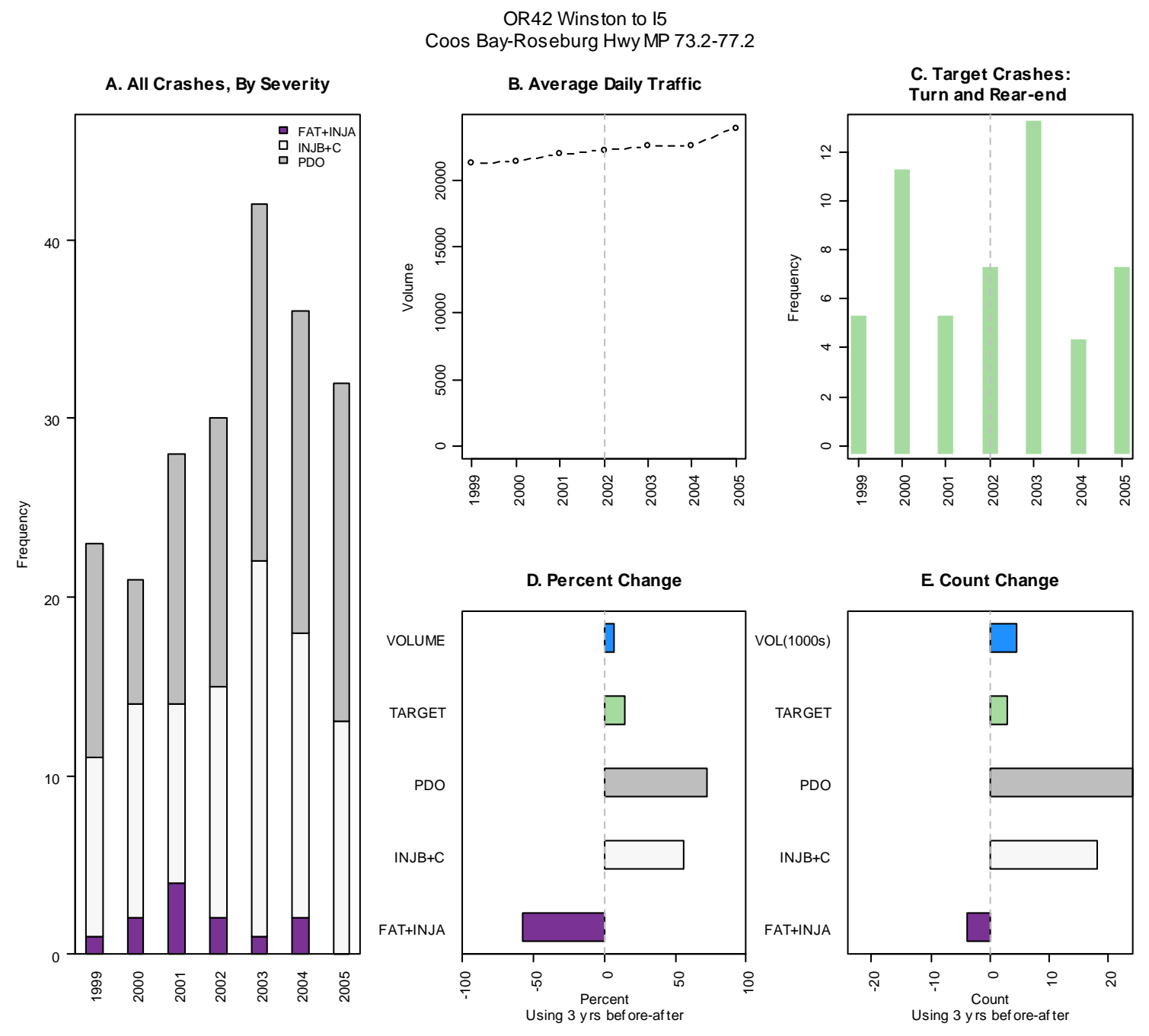

Figure 5.5: Safety Performance, OR 42-Winston to I-5, Key No. 09841

\subsubsection{I-105: Willamette River to Pacific Hwy}

\subsubsection{Description}

This 3.06 mile preservation project on I-105 (Eugene-Springfield Highway) was constructed in 2005. A summary of the entire project from the project prospectus and STIP project files is shown in Table 5.6. The project area was of mostly urban freeway character and was located in Region 2. A 15\% safety work type was identified in the STIP and prospectus. The project limits contained a segment with a SIP category of 3. The project prospectus defined the safety deficiencies (heavy weaving) as well as the proposed safety solutions. After reviewing the as-built plans and digital video logs the constructed safety improvements included the addition of auxiliary lanes between the Coburg Road and from Delta Hwy interchanges, and the upgrade of existing guardrails and median barriers. These were considered to be a mix of enhancements and mandatory 
corrective measures. Before and after photos from the digital video log are shown in Figure 5.6. Target crashes were identified as rear-end and sideswipe crashes in the vicinity of the additional lanes (MP 1.21-1.53 and 2.35-3.09).

Table 5.6: Project Summary, I-105 Willamette River to Pacific Hwy, Key No. 10349

\begin{tabular}{|c|c|c|c|c|c|}
\hline $\begin{array}{l}\text { Key No. } \\
\text { Contract No. }\end{array}$ & $\begin{array}{l}10349 \\
13061 \\
\end{array}$ & Region & 2 & Funding & $\begin{array}{l}\text { Preservation } 85 \% \\
\text { Safety } 15 \%\end{array}$ \\
\hline Highway & $\begin{array}{l}227 \text { Eugene- } \\
\text { Springfield }\end{array}$ & MP & 0.89-3.95 & $\begin{array}{l}\text { Construction } \\
\text { Year }\end{array}$ & 2005 \\
\hline $\begin{array}{l}\text { Estimated } \\
\text { Scope Year }\end{array}$ & 2000 & $\begin{array}{l}\text { SIP } \\
\text { Category } \\
1997-1999\end{array}$ & 3 & $\begin{array}{l}\text { SPIS Score } \\
1997-1999\end{array}$ & $\begin{array}{l}\text { Max: 51.27, MP } \\
2.34,90-95 \%\end{array}$ \\
\hline $\begin{array}{l}\text { ODOT } \\
\text { Problem }\end{array}$ & \multicolumn{5}{|c|}{$\begin{array}{l}\text { The PCCP has lifted panels and numerous maintenance repairs at the joints. The } \\
\text { current pavement rating is in the bottom end of "fair" category and meets the } \\
\text { qualifications for a preservation project. Heavy weave movements during peak hours } \\
\text { is causing accidents and lower LOS at interchanges. }\end{array}$} \\
\hline $\begin{array}{l}\text { ODOT } \\
\text { Proposed } \\
\text { Solution }\end{array}$ & \multicolumn{5}{|c|}{$\begin{array}{l}\text { Remove the concrete panels and replace with aggregate and AC. Replace existing } \\
\text { guardrail and concrete median barrier. Build auxiliary lanes from I-105 to Coburg } \\
\text { Road (EB and WB) and from Delta Hwy to Country Club Road (EB and WB). }\end{array}$} \\
\hline $\begin{array}{l}\text { Design } \\
\text { Exceptions }\end{array}$ & \multicolumn{5}{|c|}{$\begin{array}{l}\text { Reduced inside and outside shoulder width at structures. The shoulder width are } \\
\text { below standard and some will be further narrowed because of bridge rail safety } \\
\text { retrofit. Reduced inside roadway shoulder width: The existing inside shoulders are } \\
0.97 \mathrm{~m} \text { wide and no additional widening is being proposed. }\end{array}$} \\
\hline $\begin{array}{l}\text { Constructed } \\
\text { Safety } \\
\text { Improvements }\end{array}$ & \multicolumn{3}{|c|}{ Addition of auxiliary lanes between interchanges } & $\begin{array}{l}\text { Target } \\
\text { Crashes }\end{array}$ & \begin{tabular}{|l|} 
Rear end and \\
sideswipe (MP \\
$1.21-1.53$ and \\
$2.35-3.09)$ \\
\end{tabular} \\
\hline \multirow{4}{*}{$\begin{array}{l}\text { Prospectus } \\
\text { Costs (000's) }\end{array}$} & \multirow{4}{*}{$\begin{array}{l}\text { PE } \\
\text { ROW } \\
\text { CON } \\
\text { TOTAL }\end{array}$} & $\$ 495$ & \multirow{4}{*}{$\begin{array}{l}\text { STIP Costs } \\
\text { (000's) }\end{array}$} & \multirow{4}{*}{$\begin{array}{l}\text { PE } \\
\text { ROW } \\
\text { CON } \\
\text { TOTAL }\end{array}$} & $\$ 505$ \\
\hline & & $\$ 10$ & & & \\
\hline & & $\$ 15,919$ & & & $\$ 14,519$ \\
\hline & & $\$ 16,424$ & & & $\$ 15,024$ \\
\hline
\end{tabular}
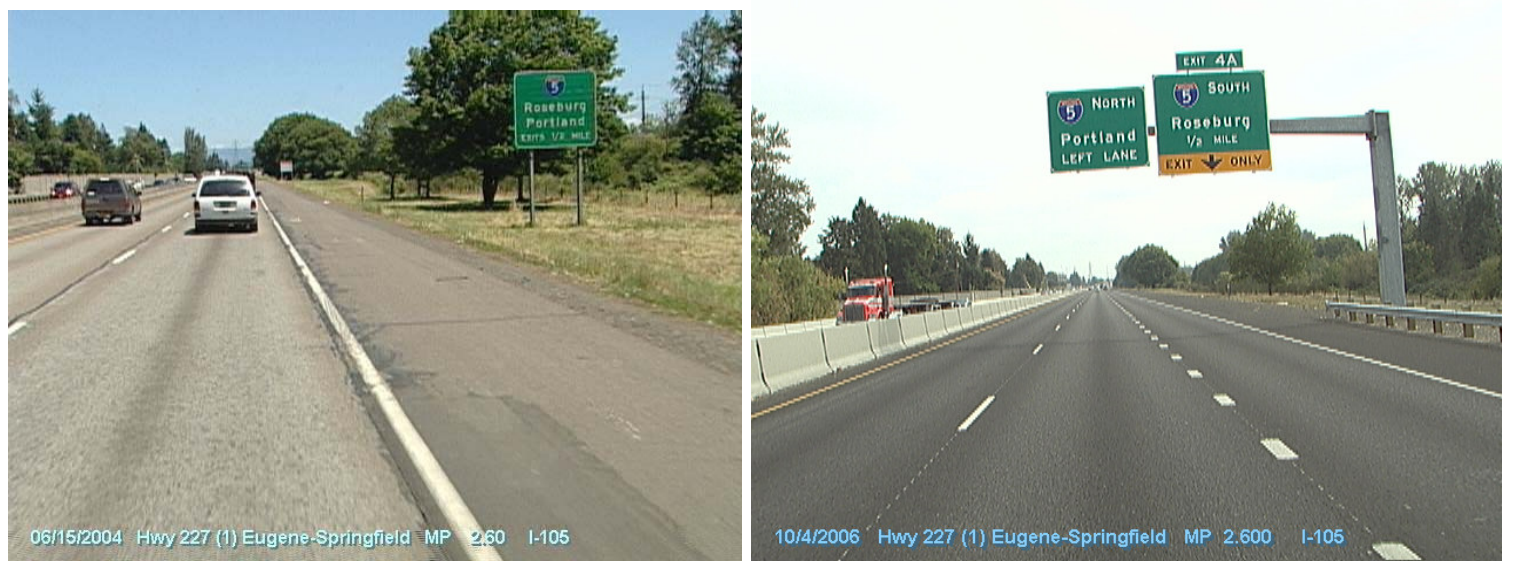

Figure 5.6: Conditions in 2004 (before) and 2006 (after) showing the additional auxiliary weaving lane 


\subsubsection{Evaluation}

The project was evaluated according to the criteria for each metric and the results are summarized in Table 5.7. The project included a segment with a SIP category of 3 , earning the project a funding eligibility score of 1 . The upgrade of existing guardrails was a mandatory corrective measure, but the added auxiliary lanes were considered enhancements, resulting in a design score of 2 . Analysis of the project expenditures showed the estimated safety costs to be approximately $\$ 1.23$ million. These safety items included the added auxiliary lanes and the guardrail, concrete medians, stone embankments, and the retaining wall within the auxiliary lane construction mileage. These expenditures totaled $14 \%$ of the construction costs. The STIP planned a $15 \%$ use of safety funding. From the analysis, it appeared that the allocated safety funds were spent on safety items. Thus, the project was given an expenditure score of 1 .

In this evaluation, it appeared that safety was not improved. The target crashes (rear-end and sideswipe-overtaking crashes) increased by a total of 10 , when compared to two years before to after (+43\%). Over the same period, traffic volumes increased $7 \%$. Fatal and injury A crashes also increased from 0 to 2 . However, considering the entire 6 years (as shown in Figure 5.7) the increase did not appear to be substantial (average of one per year). Given this evidence, the project was given a performance score of 3.

Table 5.7: Project Scorecard, I-105 Willamette River to Pacific Hwy, Key No. 10349

\begin{tabular}{|c|c|c|c|c|c|c|c|}
\hline Metric & Score & \multicolumn{6}{|l|}{ Note } \\
\hline $\begin{array}{l}\text { Funding } \\
\text { Eligibility }\end{array}$ & 1 & \multicolumn{6}{|c|}{$\begin{array}{l}\text { The project contained a segment with a SIP Category } 3 \text { and was eligible for } \\
\text { safety funds. }\end{array}$} \\
\hline Design & 2 & \multicolumn{6}{|c|}{$\begin{array}{l}\text { The project defined the safety deficiencies and the proposed safety solutions. } \\
\text { The auxiliary lanes were intended to improve the heavy weaving however, the } \\
\text { upgrade of existing guardrails and median barriers were mandatory corrective } \\
\text { measures. }\end{array}$} \\
\hline \multirow[t]{4}{*}{ Expenditures } & \multirow[t]{4}{*}{1} & \multicolumn{6}{|c|}{$\begin{array}{l}\text { The identified safety enhancements accounted for } 14 \% \text { of project construction } \\
\text { costs; } 15 \% \text { was planned. The costs are summarized (in 1,000s): }\end{array}$} \\
\hline & & & Total & Other & Other \% & Safety & Safety \% \\
\hline & & STIP & $\$ 14,519$ & $\$ 12,341$ & $85 \%$ & $\$ 2,178$ & $15 \%$ \\
\hline & & As-Built & $\$ 16,253$ & $\$ 14,019$ & $86 \%$ & $\$ 2,234$ & $14 \%$ \\
\hline Performance & 3 & \multicolumn{6}{|c|}{$\begin{array}{l}\text { Target crashes (rear-end and sideswipe) increased in the vicinity of the } \\
\text { interchanges where the additional weaving lanes were added. }\end{array}$} \\
\hline
\end{tabular}




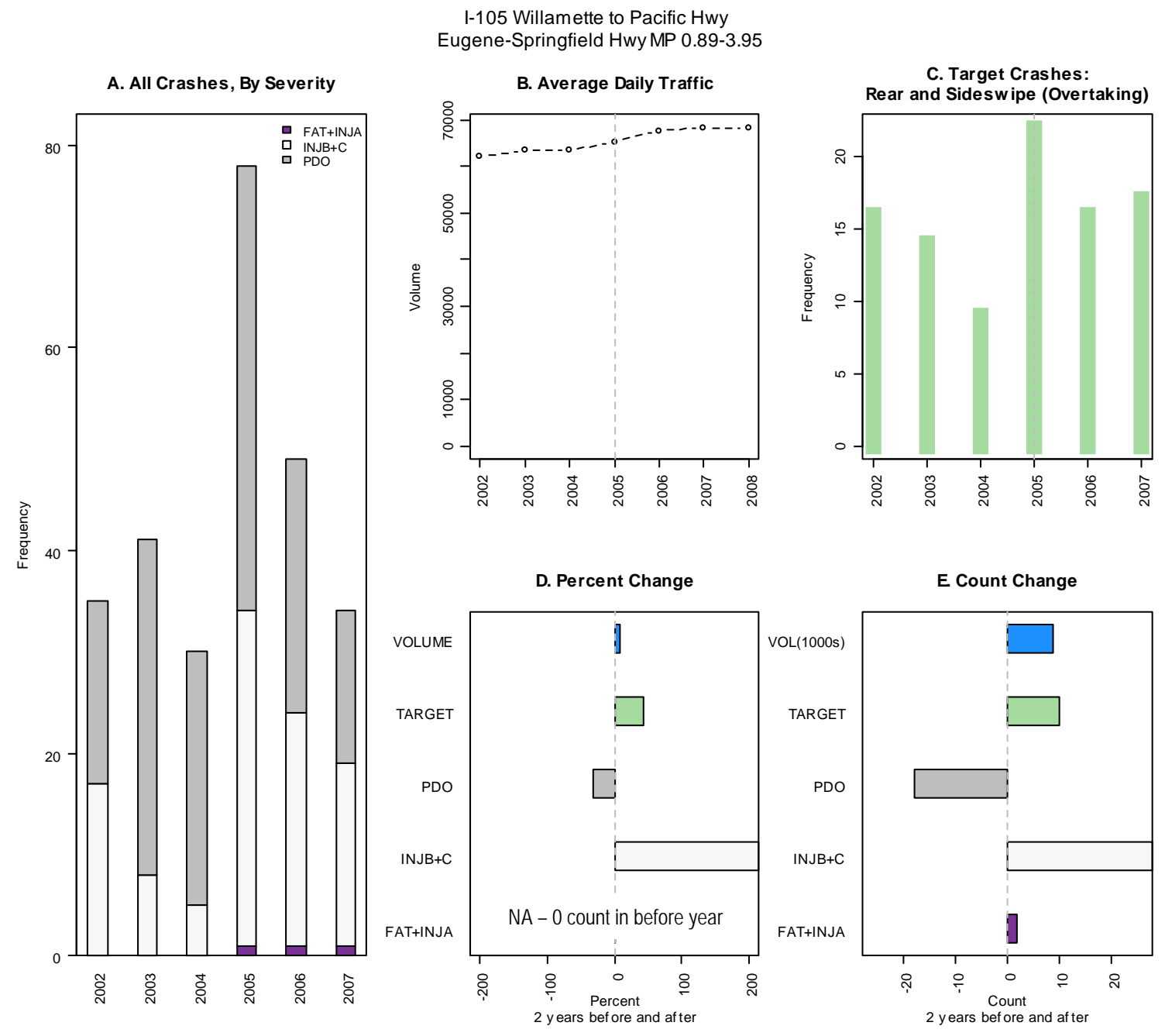

Figure 5.7: Safety Performance, I-105 Willamette River to Pacific Hwy, Key No. 10349

\subsubsection{US 30: Owl Creek to Larson Rd}

\subsubsection{Description}

This 3.7 mile preservation project on US 30 (Lower Columbia River Highway) was constructed in 2001. A summary of the entire project from the project prospectus and STIP project files is shown in Table 5.8. The project area was of mostly urban character and was located in Region 1. A 39\% safety work type was identified in the STIP and prospectus. The project limits contained a segment with a SIP category of 2 . The project narrative did not define the safety deficiencies, but some optional safety solutions were proposed. A review of the as-built plans and digital video logs indicated that the constructed safety improvements included shoulder widening, drainage modifications, guardrail construction, barrier adjustment, and durable striping. These were considered enhancements. Based on the constructed safety improvements, target crashes were 
identified to be lane departure crashes over the entire project limits. A photo from the digital video log taken after construction is shown in Figure 5.8.

Table 5.8: Project Summary, US 30-Owl Creek to Larson Rd, Key No. 10576

\begin{tabular}{|c|c|c|c|c|c|}
\hline $\begin{array}{l}\text { Key No. } \\
\text { Contract No. }\end{array}$ & $\begin{array}{l}10576 \\
12542 \\
\end{array}$ & Region & 1 & Funding & $\begin{array}{l}\text { Preservation 61\% } \\
\text { Safety 39\% }\end{array}$ \\
\hline Highway & $\begin{array}{l}\text { 002W Lower } \\
\text { Columbia } \\
\text { River }\end{array}$ & MP & $46.5-50.2$ & $\begin{array}{l}\text { Construction } \\
\text { Year }\end{array}$ & 2001 \\
\hline $\begin{array}{l}\text { Estimated } \\
\text { Scope Year }\end{array}$ & 1999 & $\begin{array}{l}\text { SIP } \\
\text { Category } \\
1996-1998 \\
\end{array}$ & 2 & $\begin{array}{l}\text { SPIS Score } \\
1996-1998\end{array}$ & $\begin{array}{l}\text { Max:47.68, MP } \\
48.32-48.47,85- \\
90 \%\end{array}$ \\
\hline $\begin{array}{l}\text { ODOT } \\
\text { Problem }\end{array}$ & \multicolumn{5}{|c|}{$\begin{array}{l}\text { Pavement is cracking, rutting, and showing signs of localized base failure. Much of } \\
\text { the shoulder and median is of substandard width, overlay will require reconstruction } \\
\text { of curb and sidewalk ramps. }\end{array}$} \\
\hline $\begin{array}{l}\text { ODOT } \\
\text { Proposed } \\
\text { Solution }\end{array}$ & \multicolumn{5}{|c|}{$\begin{array}{l}\text { Proposed preservation work includes inlay and overlay the existing pavement } \\
\text { through the section, including the Longview Bridge Interchange, and performance of } \\
\text { ancillary work such as base corrections, signal loop replacement, drainage curbs, etc., } \\
\text { where required. Optional safety work being proposed consists of shoulder widening, } \\
\text { drainage modifications, guardrail construction, barrier adjustment, and durable } \\
\text { striping. }\end{array}$} \\
\hline $\begin{array}{l}\text { Design } \\
\text { Exceptions }\end{array}$ & \multicolumn{5}{|c|}{$\begin{array}{l}\text { Placing pedestrian activator posts at the back of existing guardrail and keeping } \\
\text { existing positions of the signal cable support poles at MP } 48.387 \text { and } 48.243 \text {. } \\
\text { Shoulder widths from 47.72-47.78. Narrow shoulders for MP 47.91-48.16. }\end{array}$} \\
\hline $\begin{array}{l}\text { Constructed } \\
\text { Safety } \\
\text { Improvements }\end{array}$ & \multicolumn{3}{|c|}{$\begin{array}{l}\text { Upgrade existing guardrail, durable striping } \\
\text { pavement markings, shoulder widening, } \\
\text { drainage modifications }\end{array}$} & $\begin{array}{l}\text { Target } \\
\text { Crashes }\end{array}$ & $\begin{array}{l}\text { Lane departure } \\
\text { (fixed object, non- } \\
\text { collision, head-on, } \\
\text { sideswipe) }\end{array}$ \\
\hline \multirow{4}{*}{$\begin{array}{l}\text { Prospectus } \\
\text { Costs (000's) }\end{array}$} & \multirow{4}{*}{$\begin{array}{l}\text { PE } \\
\text { ROW } \\
\text { CON } \\
\text { TOTAL }\end{array}$} & $\$ 547$ & \multirow{4}{*}{$\begin{array}{l}\text { STIP Costs } \\
\text { (000's) }\end{array}$} & \multirow{4}{*}{$\begin{array}{l}\text { PE } \\
\text { ROW } \\
\text { CON } \\
\text { TOTAL }\end{array}$} & \begin{tabular}{|l|l|}
$\$ 883$ \\
\end{tabular} \\
\hline & & & & & \\
\hline & & $\$ 5,646$ & & & $\$ 5,631$ \\
\hline & & $\$ 6,193$ & & & $\$ 6,514$ \\
\hline
\end{tabular}
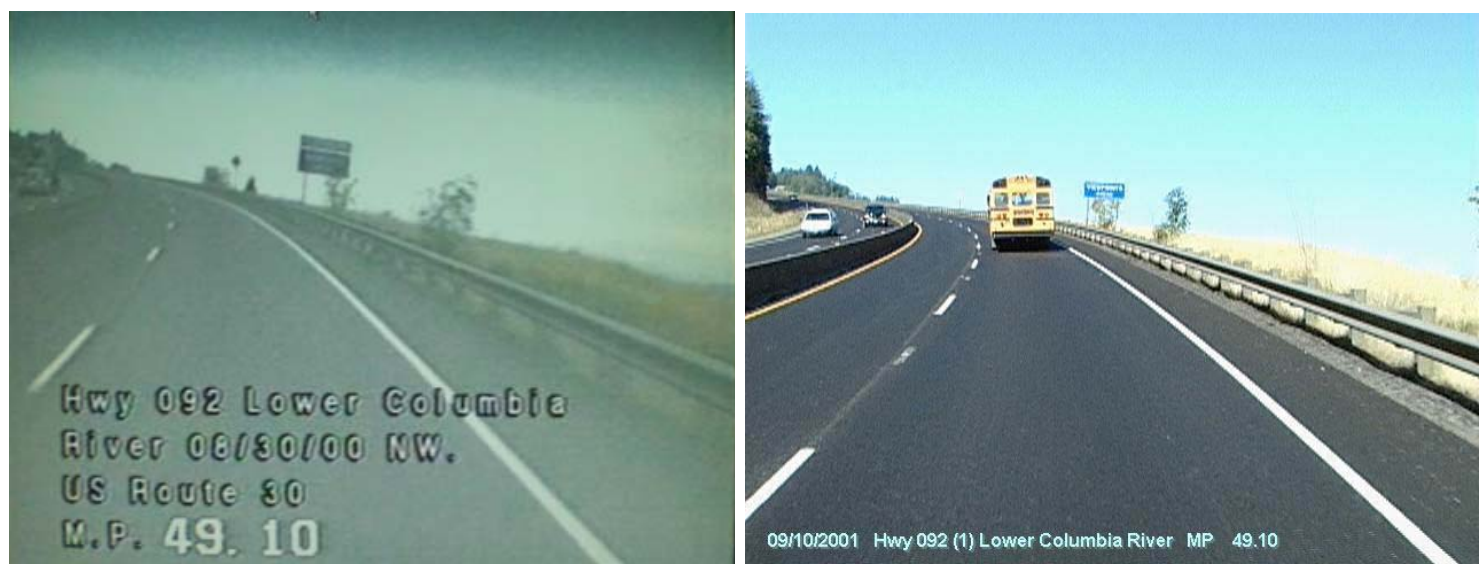

Figure 5.8: Conditions in 2000 (before) and 2006 (after) showing guardrail and pavement markings at MP 49.10 


\subsubsection{Evaluation}

The project was evaluated according to the criteria in each metric and the results are summarized in Table 5.9. For the estimated scope year, the project contained a segment with SIP category of 2. All years prior to construction did not contain a SIP category 3 or 4. According to the criteria, this earned the project a funding eligibility score of 5 . The upgrade of existing guardrail, durable striping pavement markings, shoulder widening, and drainage modifications were considered enhancements, resulting in a design score of 2. In analyzing the project expenditures, safety costs totaled $\$ 208,000$, which included guardrail Type 2a; guardrail anchors, end pieces and terminals; concrete inlets; asphalt shoulders; and durable striping. The safety expenditures were $17 \%$ of the construction costs, while the STIP planned a 39\% use of safety funding. From the analysis, it appeared that not all of the allocated safety funds were spent. However, the estimated costs from the STIP and prospectus differed substantially from the actual constructed costs $(\$ 5.6 \mathrm{M}$ to $\$ 1.7 \mathrm{M}$ ). The reason for this discrepancy was not identified but was likely to due to reductions in the project after it was first scoped. Thus, the project was given an expenditure score of 3.

The safety performance on the project was mixed. Target crashes (lane departure crashes over the entire project limits) decreased by 7 crashes (33\%) over the project limits. Fatal and injury A crashes increased by 1 (50\%) while traffic volumes decreased over the evaluation period. While the percentage increase in the fatal and injury A crashes was high, the count increase (1) was minor. Because of the decrease in target crashes, the project was given a safety performance score of 2 .

Table 5.9: Project Scorecard, US 30-Owl Creek to Larson Rd, Key No. 10576

\begin{tabular}{|c|c|c|c|c|c|c|c|}
\hline Metric & Score & \multicolumn{6}{|l|}{ Note } \\
\hline $\begin{array}{l}\text { Funding } \\
\text { Eligibility }\end{array}$ & 5 & \multicolumn{6}{|c|}{$\begin{array}{l}\text { The project contained a segment with SIP category of } 2 \text { for all years prior to } \\
\text { construction. }\end{array}$} \\
\hline Design & 2 & \multicolumn{6}{|c|}{$\begin{array}{l}\text { The project did not define the safety deficiencies. However, constructed safety } \\
\text { improvements were enhancements. }\end{array}$} \\
\hline \multirow[t]{4}{*}{ Expenditures } & \multirow[t]{4}{*}{3} & \multicolumn{6}{|c|}{$\begin{array}{l}\text { The identified safety enhancements accounted for } 15 \% \text { of project construction } \\
\text { costs; } 39 \% \text { was planned. The costs are summarized (in 1,000s): }\end{array}$} \\
\hline & & & Total & Other & Other \% & Safety & Safety \% \\
\hline & & STIP & $\$ 5,631$ & $\$ 3,435$ & $61 \%$ & $\$ 2,196$ & $39 \%$ \\
\hline & & As-Built & $\$ 1,655$ & $\$ 1,369$ & $83 \%$ & $\$ 286$ & $17 \%$ \\
\hline Performance & 2 & \multicolumn{6}{|c|}{$\begin{array}{l}\text { Target crashes (lane departure crashes) decreased by } 7 \text { crashes (33\%) over the } \\
\text { project limits. Fatal and injury A crashes increased by } 1 \text {. }\end{array}$} \\
\hline
\end{tabular}




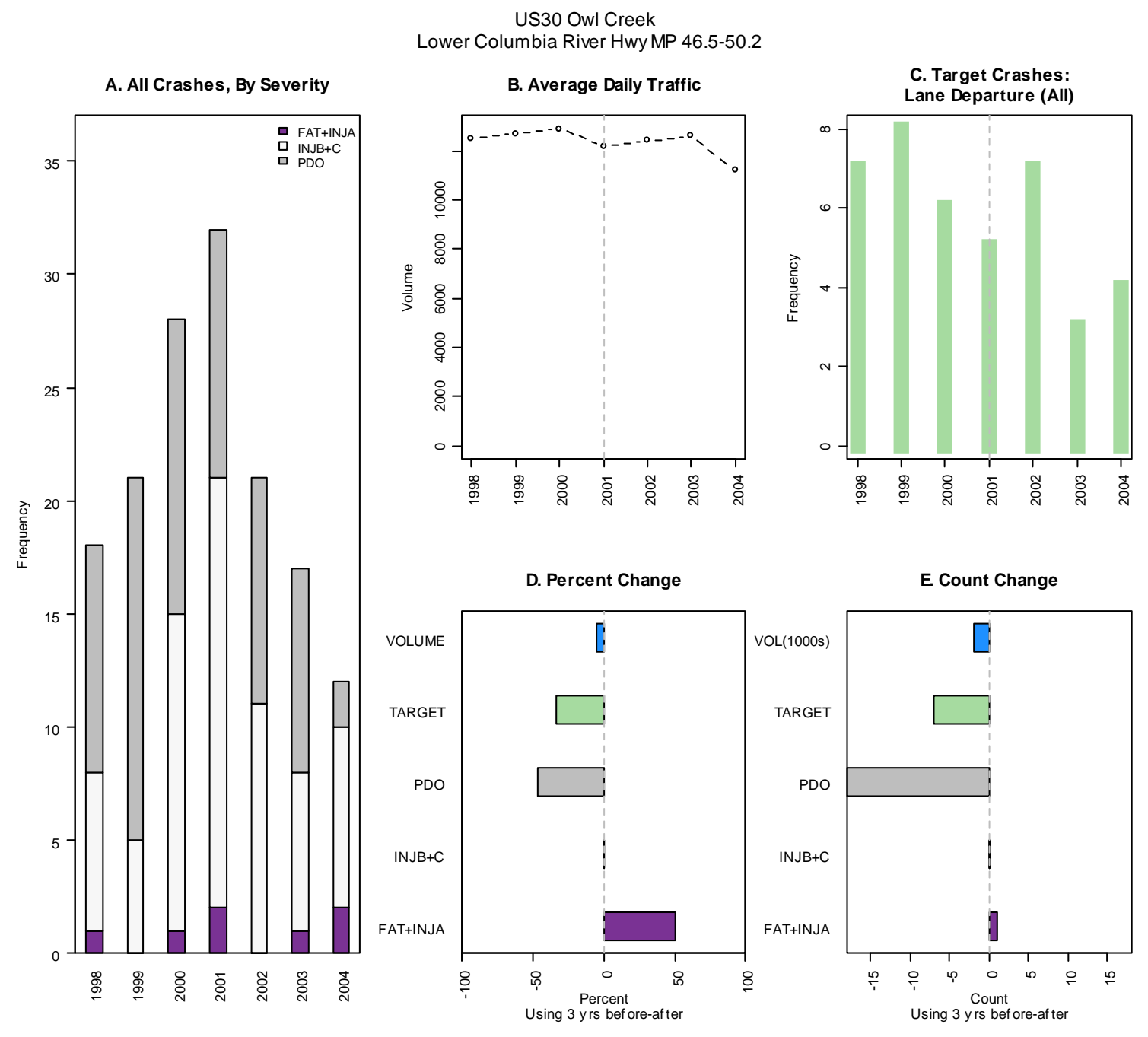

Figure 5.9: Safety Performance, US 30-Owl Creek to Larson Rd, Key No. 10576

\subsubsection{OR 212: Rock Creek to Richey Rd}

\subsubsection{Description}

This 6.9 mile preservation project on the OR 212 (Clackamas-Boring Highway) was constructed in 2001. A summary of the entire project from the project prospectus and STIP project files is shown in Table 5.10. The project area was of both rural and urban character and was located in Region 1. A 44\% safety work type was identified in the STIP and prospectus. The project limits contained a segment with a SIP category of 3. The project narrative defined the safety deficiencies and proposed safety solutions; however, it was not clear what, if any, target crashes were being addressed. As such, none were considered. After reviewing the as-built plans and digital video logs the constructed safety improvements included guardrail repair and shoulder repair. The traversable median from identified in the proposed solution from Royer Road to $242^{\text {nd }}$ was not 
constructed. Instead, the existing left turn lane was preserved. Before and after photos from the digital video log are shown in Figure 5.10.

Table 5.10: Project Summary, OR 212-Rock Creek to Richey Rd, Key No. 10665

\begin{tabular}{|c|c|c|c|c|c|}
\hline $\begin{array}{l}\text { Key No. } \\
\text { Contract No. }\end{array}$ & $\begin{array}{l}10665 \\
12826\end{array}$ & Region & 1 & Funding & $\begin{array}{l}\text { Preservation } 54 \% \\
\text { Safety } 44 \% \\
\text { Bike/Ped } 2 \%\end{array}$ \\
\hline Highway & $\begin{array}{l}174 \\
\text { Clackamas- } \\
\text { Boring }\end{array}$ & MP & $0-6.9$ & $\begin{array}{l}\text { Construction } \\
\text { Year }\end{array}$ & 2001 \\
\hline $\begin{array}{l}\text { Estimated } \\
\text { Scope Year }\end{array}$ & 2000 & $\begin{array}{l}\text { SIP } \\
\text { Category } \\
\text { 1997-1999 }\end{array}$ & 3 & $\begin{array}{l}\text { SPIS Score } \\
1997-1999\end{array}$ & $\begin{array}{l}\text { Max: 60.51, MP } \\
0.79-0.82,90- \\
95 \%\end{array}$ \\
\hline $\begin{array}{l}\text { ODOT } \\
\text { Problem }\end{array}$ & \multicolumn{5}{|c|}{$\begin{array}{l}\text { The pavement in this section is deteriorating. Much of the section (Rock Creek to } \\
242^{\text {nd }} \text { ) has narrow shoulders and non-traversable ditches and/or side slopes. There is } \\
\text { need for a continuous left turn median between Royer Road and } 242^{\text {nd }} \text {. Numerous } \\
\text { roadside obstructions (mailboxes, utility poles, etc.) exist throughout the section. } \\
\text { Many of the signs need replacement. Many culverts are in need of repair or cleaning } \\
\text { and there are priority fish culverts located within the project limits. }\end{array}$} \\
\hline $\begin{array}{l}\text { ODOT } \\
\text { Proposed } \\
\text { Solution }\end{array}$ & \multicolumn{5}{|c|}{$\begin{array}{l}\text { Level ruts and overlay the entire surface. Replace shoulder rock and stabilize with } \\
\text { oil. Construct new curbs within Damascus. Repair guardrail at several locations. } \\
\text { Replace the culvert at Wyeast, extend the culvert and improve ditch drainage at North } \\
\text { Ct. Improve ditches, shoulders, and provide traversable median from Royer Rd. as } \\
\text { appropriate. Provide low cost mitigations for horizontal and vertical deficiencies and } \\
\text { provide a water quality facility at Royer Rd. Safety items total }(\$ 2,169 \mathrm{k}) \text { is greater } \\
\text { than } 6 \% \text { of the total project cost. Horizontal and vertical exceptions will be required. }\end{array}$} \\
\hline $\begin{array}{l}\text { Design } \\
\text { Exceptions }\end{array}$ & \multicolumn{5}{|c|}{$\begin{array}{l}\text { Shoulder width less than } 1.8 \mathrm{~m} \text { from MP } 0.03 \text { to } 2.5 \text {. Median turn lane less than } 4.8 \mathrm{~m} \\
\text { from MP } 2.5 \text { to } 4.69 \text {. Shy distance of } 0.6 \mathrm{~m} \text { at selected concrete curb and barrier } \\
\text { locations. }\end{array}$} \\
\hline $\begin{array}{l}\text { Constructed } \\
\text { Safety } \\
\text { Improvements }\end{array}$ & \multicolumn{3}{|c|}{$\begin{array}{l}\text { Upgraded existing guardrail, added shoulder } \\
\text { width }\end{array}$} & $\begin{array}{l}\text { Target } \\
\text { Crashes }\end{array}$ & None \\
\hline \multirow{4}{*}{$\begin{array}{l}\text { Prospectus } \\
\text { Costs (000's) }\end{array}$} & \multirow{4}{*}{$\begin{array}{l}\text { PE } \\
\text { ROW } \\
\text { CON } \\
\text { TOTAL }\end{array}$} & $\$ 456$ & \multirow{4}{*}{$\begin{array}{l}\text { STIP Costs } \\
\text { (000's) }\end{array}$} & \multirow{4}{*}{$\begin{array}{l}\text { PE } \\
\text { ROW } \\
\text { CON } \\
\text { TOTAL }\end{array}$} & $\$ 403$ \\
\hline & & $\$ 626$ & & & $\$ 702$ \\
\hline & & $\$ 4,209$ & & & $\$ 4,452$ \\
\hline & & $\$ 5,291$ & & & $\$ 5,557$ \\
\hline
\end{tabular}
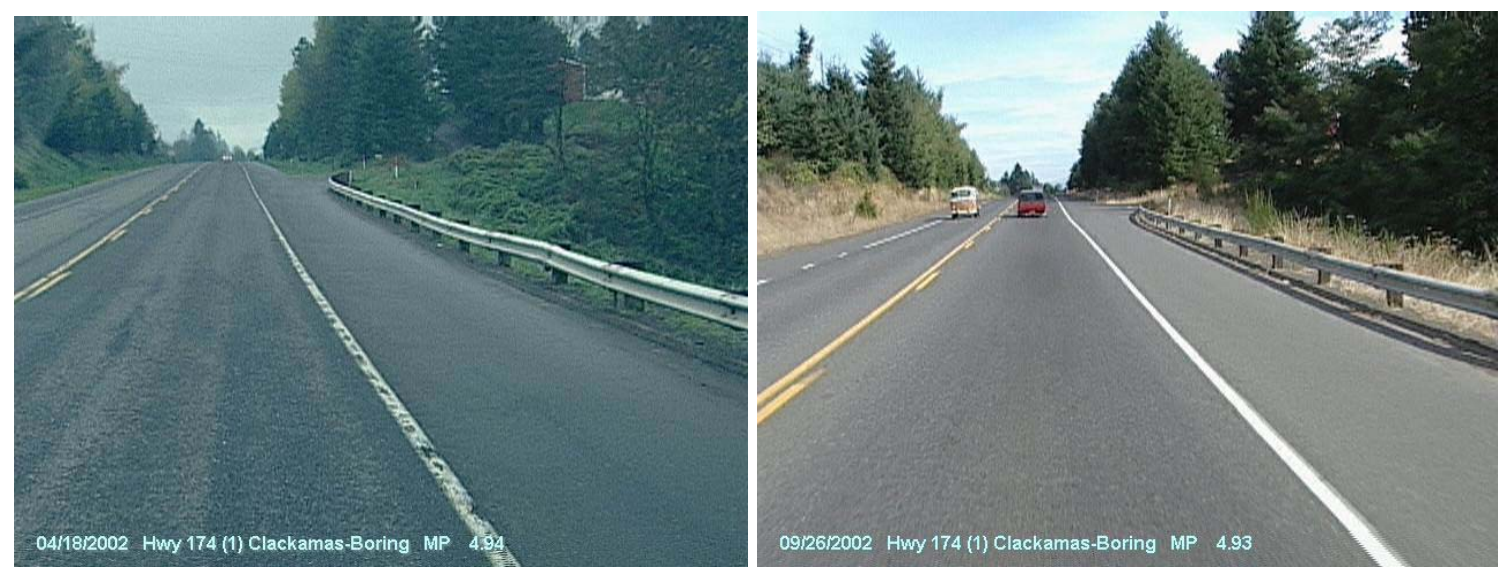

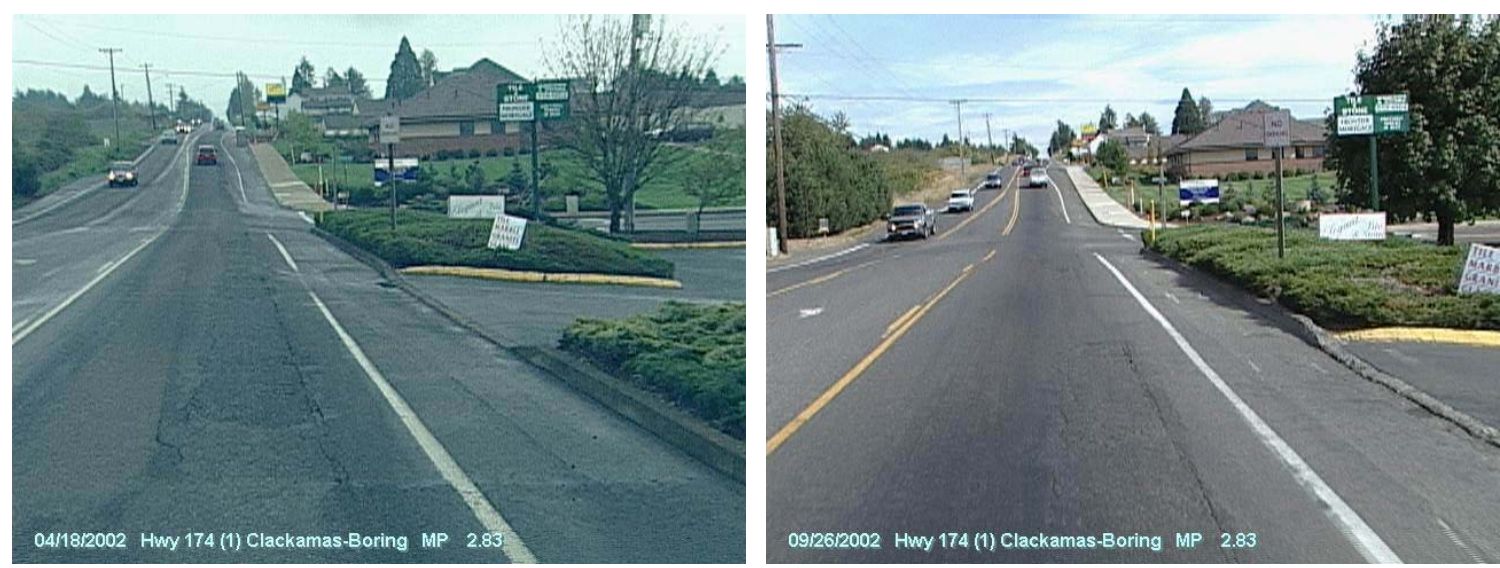

Figure 5.10: Conditions in 2001 (before) and 2002 (after) showing the preservation work at MP 4.93 and the area near Royer Road (no median installed)

\subsubsection{Evaluation}

The project was evaluated according to the criteria for each metric and the results are summarized in Table 5.11. The project included a segment with a SIP category of 3 and the safety deficiencies and the proposed safety improvements were defined as enhancements, earning the project a funding eligibility score of 1 and a design score of 1 . In analyzing the project expenditures, safety costs $(\$ 128,000)$ included guardrail Type 2a, 3 , guardrail anchors and end pieces, transitions, and added shoulder width. The safety expenditures totaled $5 \%$ of the construction costs. The STIP planned a $44 \%$ use of safety funding. From the analysis, it appears that not all of the allocated safety funds were spent. Thus, the project was given an expenditure score of 5 . The estimated costs from the STIP and prospectus compare well with the actual constructed costs ( $\$ 4.5 \mathrm{M}$ to $\$ 4.8 \mathrm{M})$. In addition, there was $\$ 702 \mathrm{~K}$ in ROW costs according to the project prospectus. Some of these ROW costs may have been incurred from the shoulder widening from MP 2.854.69, which added to the safety costs.

The safety within the project limits was not improved from the before to after periods. An additional 8 fatal and injury A crashes occurred in the three-year after period. These additional crashes were rear-end (3), angle (2), fixed-object (2), non-collision (1) and sideswipe (1). (there was one less "other"). There was a decrease of (1) crash in the other category. The volume data indicate that volumes decreased (but this may be a correction adjustment by the traffic monitoring staff). The relationship between the project work elements and the decreased safety is not clear from the information available. It is possible that the modifications have resulted in higher operating speeds. Considering all of the evidence, the project was given a safety performance score of 5 . 
Table 5.11: Project Scorecard, OR 212-Rock Creek to Richey Rd, Key No. 10665

\begin{tabular}{|c|c|c|c|c|c|c|c|}
\hline Metric & Score & \multicolumn{6}{|l|}{ Note } \\
\hline $\begin{array}{l}\text { Funding } \\
\text { Eligibility }\end{array}$ & 1 & \multicolumn{6}{|c|}{$\begin{array}{l}\text { The project contained a SIP segment with category of } 3 \text { and was eligible for } \\
\text { safety funds. }\end{array}$} \\
\hline Design & 1 & \multicolumn{6}{|c|}{$\begin{array}{l}\text { The project defined the safety deficiencies and the constructed safety } \\
\text { improvements were enhancements. }\end{array}$} \\
\hline \multirow[t]{4}{*}{ Expenditures } & \multirow[t]{4}{*}{5} & \multicolumn{6}{|c|}{$\begin{array}{l}\text { The identified safety enhancements accounted for } 5 \% \text { of project construction } \\
\text { costs; } 44 \% \text { was planned. The costs are summarized (in 1,000s): }\end{array}$} \\
\hline & & & Total & Other & Other \% & Safety & Safety \% \\
\hline & & STIP & $\$ 4,452$ & $\$ 2,493$ & $56 \%$ & $\$ 1,958$ & $44 \%$ \\
\hline & & As-Built & $\$ 4,773$ & $\$ 4,524$ & $95 \%$ & $\$ 249$ & $5 \%$ \\
\hline Performance & 5 & \multicolumn{6}{|c|}{$\begin{array}{l}\text { There were no target crashes identified for the project. Fatal and injury A } \\
\text { crashes increased from } 3 \text { to } 11 \text { in the before to after periods }\end{array}$} \\
\hline
\end{tabular}

OR212 Rock Creek Clackamas-Boring Hwy MP 0-6.9

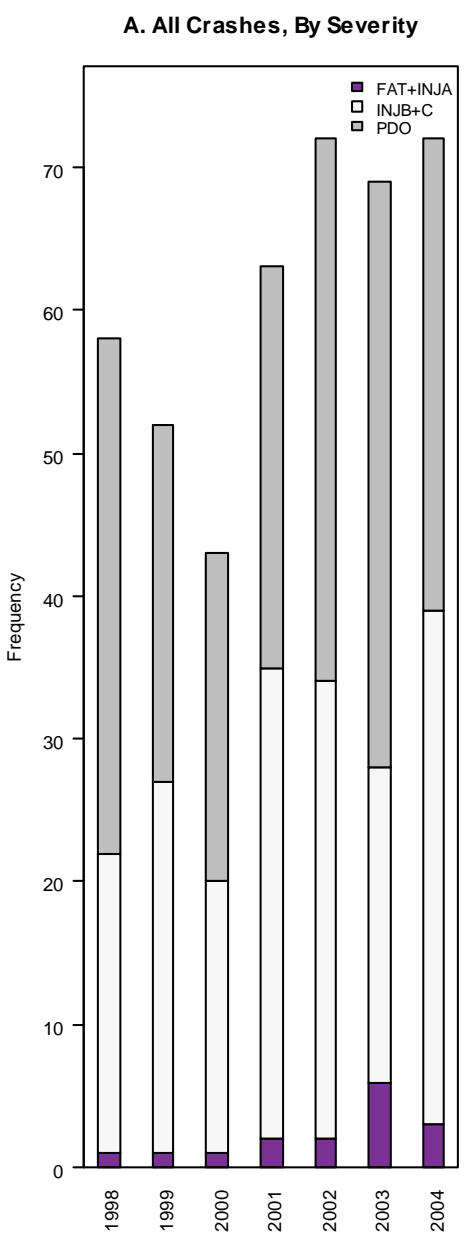

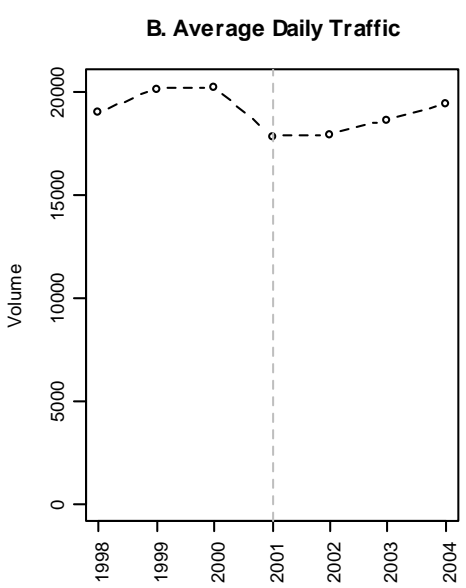
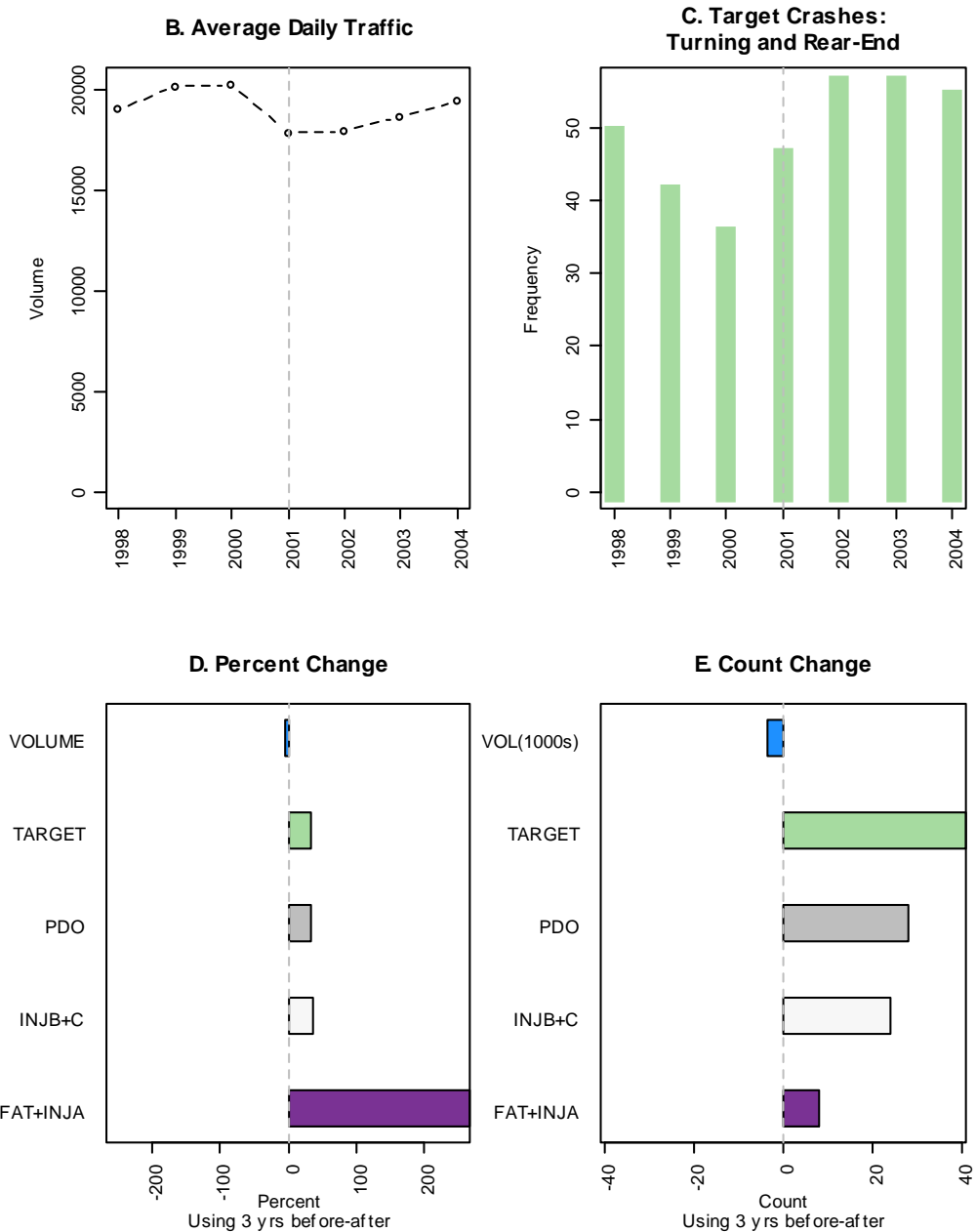

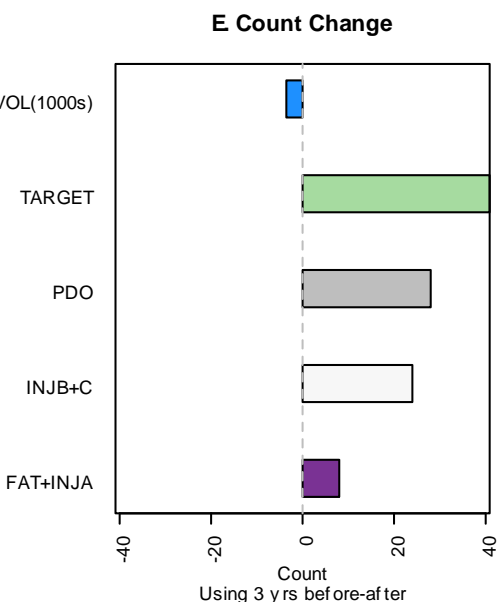

Figure 5.11: Safety Performance, OR 212-Rock Creek to Richey Rd, Key No. 10665 


\subsubsection{OR 10: Beaverton Tigard Hwy to Multnomah Co Line}

\subsubsection{Description}

This 2.44 mile preservation project on OR 10 (Beaverton-Hillsdale Highway) was constructed in 2001. A summary of the entire project, from the project prospectus and STIP project files is shown in Table 5.12. The project area was of mostly urban character and was located in Region 1. A 22\% safety work type was identified in the STIP and prospectus. The project limits contained a segment with a SIP category of 5 . The project narrative did not define the safety deficiencies or proposed safety solutions. A review of the as-built plans and digital video logs indicated that no constructed safety improvements were identified. Before and after photos from the digital video log are shown in Figure 5.12.

Table 5.12: Project Summary, OR 10-Beaverton Tigard Hwy to Multnomah Co Line, Key No. 10666

\begin{tabular}{|c|c|c|c|c|c|}
\hline Key No. Contract No. & $\begin{array}{l}10666 \\
12906\end{array}$ & Region & 1 & Funding & $\begin{array}{l}\text { Preservation } \\
73 \% \\
\text { Safety 22\% } \\
\text { Bike/Ped 5\% }\end{array}$ \\
\hline Highway & $\begin{array}{l}040 \\
\text { Beaverton- } \\
\text { Hillsdale }\end{array}$ & MP & $\begin{array}{l}0.97- \\
3.41\end{array}$ & $\begin{array}{l}\text { Construction } \\
\text { Year }\end{array}$ & 2001 \\
\hline Estimated Scope Year & 2000 & $\begin{array}{l}\text { SIP } \\
\text { Category } \\
\text { 1997-1999 }\end{array}$ & 5 & $\begin{array}{l}\text { SPIS Score } \\
1997-1999\end{array}$ & $\begin{array}{l}\text { Max: 85.47, } \\
\text { MP 0.97, 95- } \\
100 \%\end{array}$ \\
\hline $\begin{array}{l}\text { ODOT } \\
\text { Problem }\end{array}$ & \multicolumn{5}{|c|}{$\begin{array}{l}\text { The existing pavement condition is rated poor due to extensive fatigue } \\
\text { cracking and rutting. The outer travel lanes are measurably worse than } \\
\text { the inner travel lanes, but all lanes (including the continuous center turn } \\
\text { lane) exhibit substantial pavement deformation. The concrete curb is } \\
\text { generally in acceptable condition except where previous overlays have } \\
\text { reduced curb exposure. To provide and/or restore adequate drainage no } \\
\text { further loss of curb exposure can be tolerated. Accordingly, a straight } \\
\text { inlay/overlay of the outer lanes is not acceptable. Curb replacement to } \\
\text { increase height is not feasible given the developed abutting properties. }\end{array}$} \\
\hline $\begin{array}{l}\text { ODOT } \\
\text { Proposed Solution }\end{array}$ & \multicolumn{5}{|c|}{$\begin{array}{l}\text { This project will grind and inlay the travel lanes }(75 \mathrm{~mm}) \text { and center } \\
\text { turn lane }(50 \mathrm{~mm}) \text {. Sidewalk and pedestrian ramp improvements will be } \\
\text { constructed. }\end{array}$} \\
\hline Design Exceptions & \multicolumn{5}{|c|}{$\begin{array}{l}\text { Allowance of finished grade curb exposure to be between 4" and 6” } \\
\text { (throughout most of the project). Standard shoulder width needed for } \\
\text { this project is } 1.8 \mathrm{~m} \text {. }\end{array}$} \\
\hline $\begin{array}{l}\text { Constructed Safety } \\
\text { Improvements }\end{array}$ & \multicolumn{3}{|c|}{ None identified } & $\begin{array}{l}\text { Target } \\
\text { Crashes }\end{array}$ & $\begin{array}{l}\text { None } \\
\text { identified }\end{array}$ \\
\hline \multirow{4}{*}{ Prospectus Costs (000's) } & & $\$ 449$ & \multirow{4}{*}{$\begin{array}{l}\text { STIP } \\
\text { Costs } \\
\text { (000's) }\end{array}$} & \multirow{4}{*}{\begin{tabular}{l|l} 
PE \\
ROW \\
CON \\
TOTAL
\end{tabular}} & \begin{tabular}{l|l}
$\$ 653$ \\
\end{tabular} \\
\hline & ROW & $\$ 385$ & & & $\$ 81$ \\
\hline & CON & $\$ 2,341$ & & & $\$ 2,900$ \\
\hline & TOTAL & $\$ 3,175$ & & & $\$ 3,634$ \\
\hline
\end{tabular}



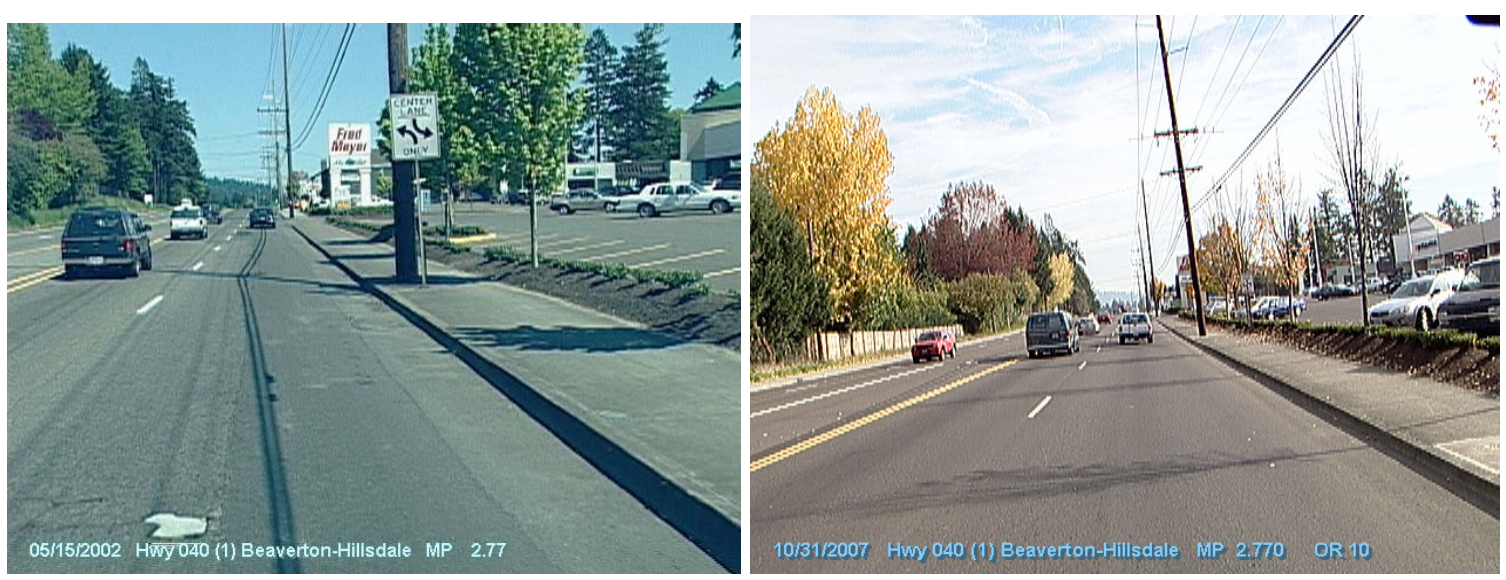

Figure 5.12: Conditions in 2002 (before) and in 2007 (after) at MP 2.77

\subsubsection{Evaluation}

The project was evaluated according to the criteria for each metric and the results are summarized in Figure 5.13. The project included a segment with a SIP category of 5; therefore received a funding eligibility score of 1 . However, there were no safety deficiencies or solutions proposed, resulting in a design score of 5 . In analyzing the project expenditures, no safety work was identified. The estimated costs compared well with actual constructed costs ( $\$ 2.9 \mathrm{M}$ to $\$ 3.3 \mathrm{M})$. The STIP planned a 22\% use of safety funding. From the analysis, it appears that no safety funds were spent. Thus, the project was given an expenditure score of 5.

The safety-related data are summarized in Figure 5.14A-E. No target crashes were identified within the project limits. There was a small decrease of fatal and injury A crashes from 8 to 7 (a 12\% decrease). However, the data indicated that the volume count also decreased over the evaluation period by approximately $11 \%$. Overall, it was estimated that safety on the project was essentially unchanged. The project was given a safety performance score of 3 .

Figure 5.13: Project Scorecard, OR 10-Beaverton Tigard Hwy to Multnomah Co Line, Key No. 10666

\begin{tabular}{|c|c|c|c|c|c|c|c|}
\hline Metric & Score & \multicolumn{6}{|l|}{ Note } \\
\hline $\begin{array}{l}\text { Funding } \\
\text { Eligibility }\end{array}$ & 1 & \multicolumn{6}{|c|}{$\begin{array}{l}\text { The project contained a SIP segment with category of } 5 \text { and was eligible for } \\
\text { safety funds. }\end{array}$} \\
\hline Design & 5 & \multicolumn{6}{|c|}{$\begin{array}{l}\text { The project did not define the safety deficiencies or proposed safety } \\
\text { improvements. }\end{array}$} \\
\hline \multirow[t]{3}{*}{ Expenditures } & \multirow[t]{3}{*}{5} & \multicolumn{6}{|c|}{$\begin{array}{l}\text { There were no identified safety items; 22\% was planned. The costs are } \\
\text { summarized (in 1,000s): }\end{array}$} \\
\hline & & STIP & 2,900 & $\$ 2,262$ & $78 \%$ & $\$ 638$ & $22 \%$ \\
\hline & & As-Built & $\$ 3,311$ & $\$ 3,311$ & $100 \%$ & 0 & $0 \%$ \\
\hline Performance & 3 & \multicolumn{6}{|c|}{$\begin{array}{l}\text { No target crashes were identified. The fatal and injury A crashes decreased by } \\
\text { from } 8 \text { to } 7(-12 \%) \text {. Considering the drop in exposure, safety was essentially } \\
\text { unchanged. }\end{array}$} \\
\hline
\end{tabular}


OR10 Beaverton Tigard to MCL

Beaverton-Hills dale Hwy MP 0.97-3.41
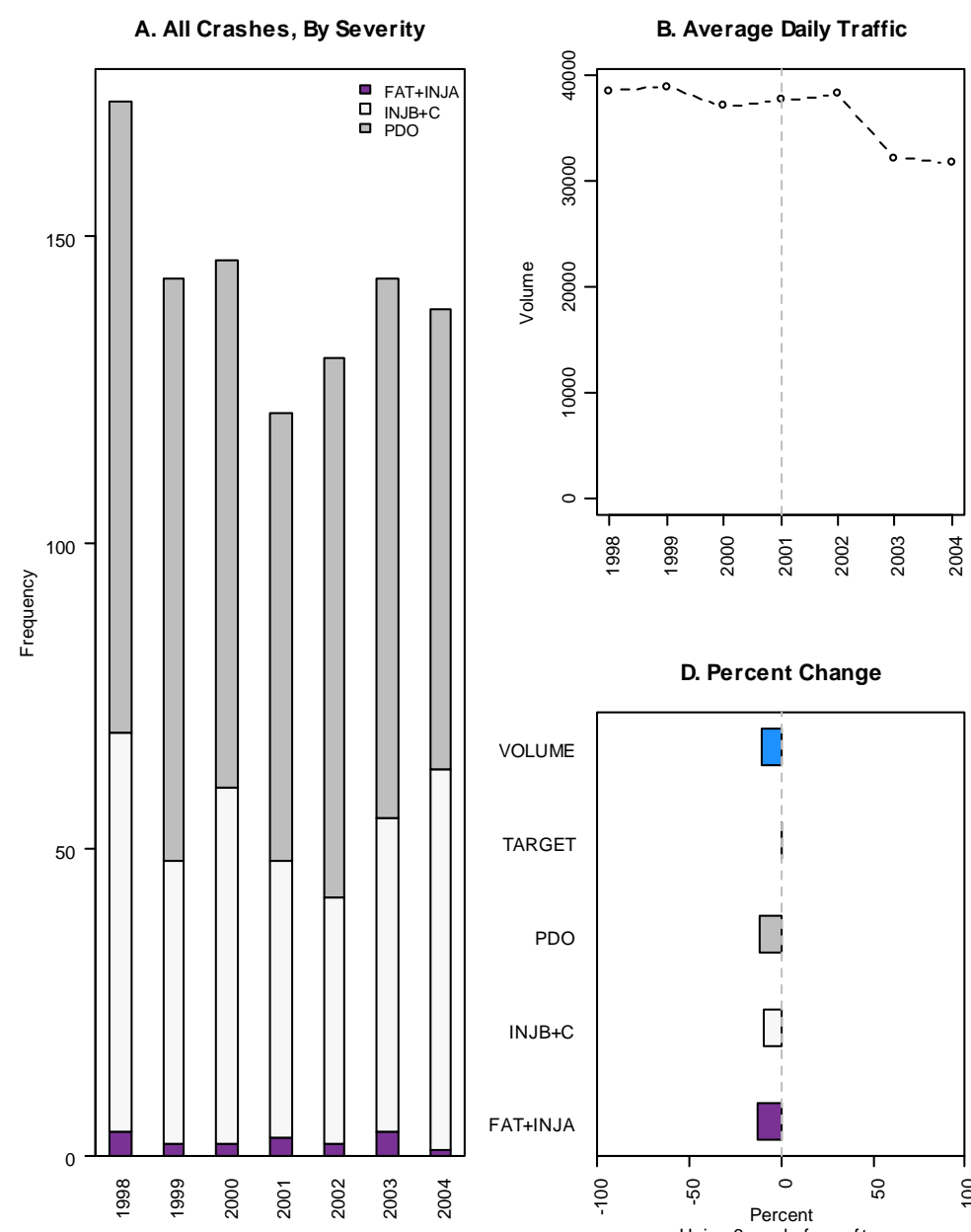

C. Target Crashes:

None

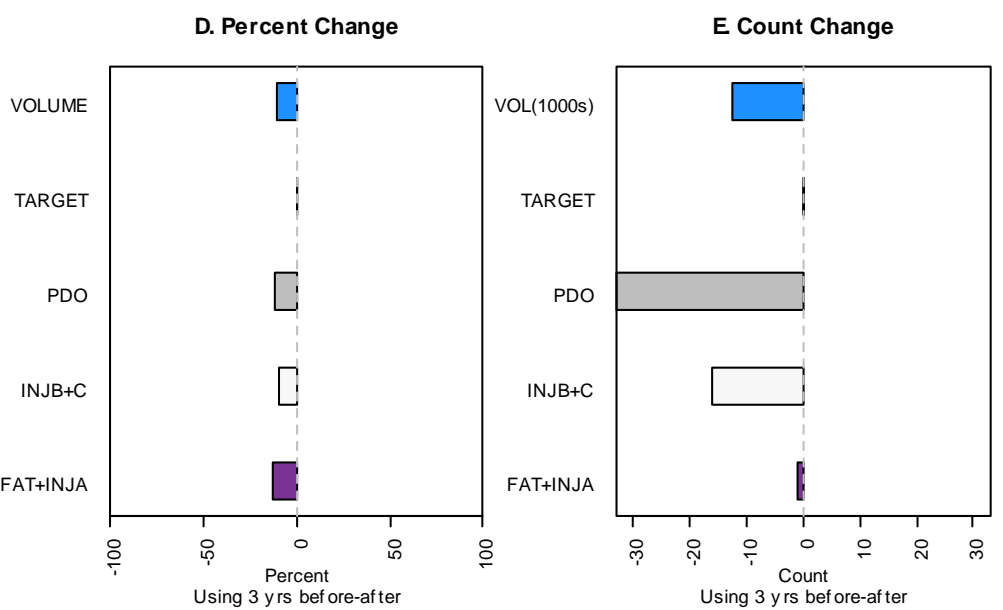

Figure 5.14: Safety Performance, OR 10-Beaverton Tigard Hwy to Multnomah Co Line, Key No. 10666

\subsubsection{OR 8: Quince St (Forest Grove) to District Boundary (Gaston)}

\subsubsection{1}

Description

This 8.63 mile preservation project on the OR 8 (Tualatin Valley Highway) was constructed in 2001. A summary of the entire project from the project prospectus and STIP project files is shown in Table 5.13. The project area was of mostly rural character and was located in Region 1. A 10\% safety work type was identified in the STIP and prospectus. The project limits contain a segment with a SIP category of 5 . The project did not define the safety deficiencies and the proposed safety solutions were vague. After reviewing the as-built plans and digital video logs the constructed safety improvements 
include upgrading existing guardrails. These were considered mandatory corrective measures. Before and after photos from the digital video log are shown in Figure 5.15.

Table 5.13: Project Summary, OR 8-Quince St to District Boundary, Key No. 10679

\begin{tabular}{|c|c|c|c|c|c|}
\hline $\begin{array}{l}\text { Key No. } \\
\text { Contract No. }\end{array}$ & $\begin{array}{l}10679 \\
13001 \\
\end{array}$ & Region & 1 & Funding & $\begin{array}{l}\text { Preservation } 90 \% \\
\text { Safety } 10 \%\end{array}$ \\
\hline Highway & $\begin{array}{l}029 \text { Tualatin } \\
\text { Valley }\end{array}$ & MP & $17.88-26.51$ & $\begin{array}{l}\text { Construction } \\
\text { Year } \\
\end{array}$ & 2004 \\
\hline $\begin{array}{l}\text { Estimated } \\
\text { Scope Year }\end{array}$ & 2001 & $\begin{array}{l}\text { SIP } \\
\text { Category } \\
1998-2000\end{array}$ & 5 & $\begin{array}{l}\text { SPIS Score } \\
1998-2000\end{array}$ & $\begin{array}{l}\text { No SPIS scores in } \\
\text { the Top } 15 \%\end{array}$ \\
\hline $\begin{array}{l}\text { ODOT } \\
\text { Problem }\end{array}$ & \multicolumn{5}{|c|}{$\begin{array}{l}\text { The pavement of this important regional highway is exhibiting fatigue cracking, } \\
\text { shrinkage cracking, and wheel path rutting. Portions of this section are already rated } \\
\text { poor. Ongoing development in Washington and Yamhill Counties will measurably } \\
\text { increase traffic volume within the next several years. } 1999 \text { pavement rating listed as } \\
\text { poor. }\end{array}$} \\
\hline $\begin{array}{l}\text { ODOT } \\
\text { Proposed } \\
\text { Solution }\end{array}$ & \multicolumn{5}{|c|}{$\begin{array}{l}\text { Based on the preliminary evaluation by the Pavement Design Section a } 50 \mathrm{~mm} \text { inlay } \\
\text { and } 100 \mathrm{~mm} \text { overlay is proposed to add structural capacity and eliminate the existing } \\
\text { deformation. Complete safety upgrades as required. }\end{array}$} \\
\hline $\begin{array}{l}\text { Design } \\
\text { Exceptions }\end{array}$ & \multicolumn{5}{|c|}{$\begin{array}{l}\text { Median width: Sta. } 11+622 \text { to Sta } 13+025 \text {. Right turn lanes: various locations } \\
\text { throughout project. Shoulder width: various locations. Sidewalk width: Sta. } 4+875 \text { to } \\
\text { Sta. } 5+084 \text {. }\end{array}$} \\
\hline $\begin{array}{l}\text { Constructed } \\
\text { Safety } \\
\text { Improvements }\end{array}$ & \multicolumn{3}{|c|}{ Upgrade existing guardrail } & $\begin{array}{l}\text { Target } \\
\text { Crashes }\end{array}$ & None identified \\
\hline \multirow{4}{*}{$\begin{array}{l}\text { Prospectus } \\
\text { Costs (000's) }\end{array}$} & \multirow{4}{*}{$\begin{array}{l}\text { PE } \\
\text { ROW } \\
\text { CON } \\
\text { TOTAL }\end{array}$} & $\$ 370$ & \multirow{4}{*}{$\begin{array}{l}\text { STIP Costs } \\
\text { (000's) }\end{array}$} & \multirow{4}{*}{$\begin{array}{l}\text { PE } \\
\text { ROW } \\
\text { CON } \\
\text { TOTAL }\end{array}$} & $\$ 370$ \\
\hline & & & & & $\$ 56$ \\
\hline & & $\$ 5,791$ & & & $\$ 6,735$ \\
\hline & & $\$ 6,161$ & & & $\$ 7,161$ \\
\hline
\end{tabular}
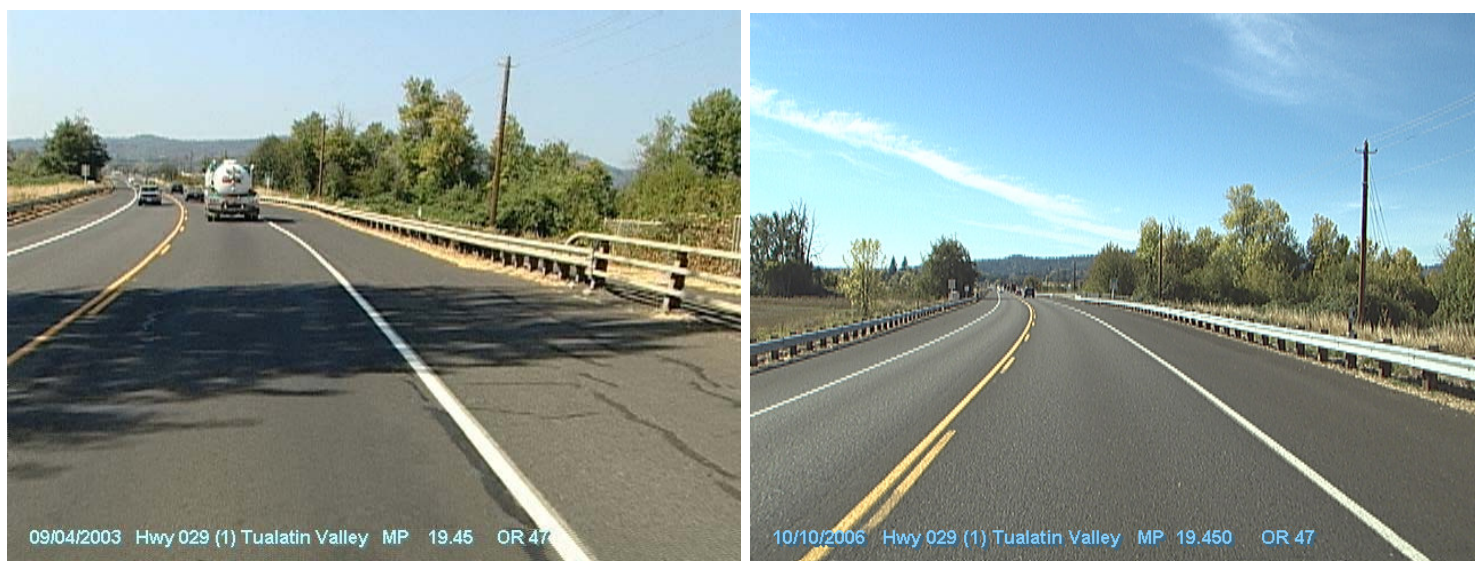

Figure 5.15: Conditions in 2003 (before) and in 2006 (after) showing the upgraded guardrail at MP 19.45

\subsubsection{Evaluation}

The project was evaluated according to the criteria for each metric and the results are summarized in Table 5.14. The project included a segment with SIP category 5, earning 
the project a funding eligibility score of 1 . The upgrade of existing guardrails was a mandatory corrective measure, resulting in a design score of 4. Analysis of the project expenditures showed that the safety items included guardrail Type 2a, 3, guardrail connections, transitions, and removal/reinstallation of Type 2 guardrail and totaled $\$ 229,000$. These expenditures totaled $10 \%$ of the construction costs. The STIP planned a $10 \%$ use of safety funding. It appears the safety funds allocated were spent on safety items even though they were mandatory items. Of note, the estimated costs from the STIP and prospectus differ substantially from the actual constructed costs ( $\$ 6.7 \mathrm{M}$ to $\$ 2.9 \mathrm{M})$ indicating that the project changed in scope over the development process. The project was given an expenditure score of 1 . The safety-related data for the project are summarized in Figure 5.16A-E. No target crashes were identified for the project. Over the project limits for the three years before to after, fatal and injury A crashes increased from 8 to 11 (+38\%). The project was given a safety performance score of 5 .

Table 5.14: Project Scorecard, OR 8-Quince St to District Boundary, Key No. 10679

\begin{tabular}{|c|c|c|c|c|c|c|c|}
\hline Metric & Score & \multicolumn{6}{|l|}{ Note } \\
\hline $\begin{array}{l}\text { Funding } \\
\text { Eligibility }\end{array}$ & 1 & \multicolumn{6}{|c|}{$\begin{array}{l}\text { The project contained a SIP segment with category of } 5 \text { and was eligible for } \\
\text { safety funds. }\end{array}$} \\
\hline Design & 4 & \multicolumn{6}{|c|}{$\begin{array}{l}\text { The project did not define the safety deficiencies and the proposed safety } \\
\text { solutions were vague. The constructed safety improvements (upgrading existing } \\
\text { guardrails) were mandatory corrective measures. }\end{array}$} \\
\hline \multirow[t]{4}{*}{ Expenditures } & 1 & \multicolumn{6}{|c|}{$\begin{array}{l}\text { The identified safety work accounted for } 10 \% \text { of project construction costs; } 10 \% \\
\text { was planned. The costs are summarized (in 1,000s): }\end{array}$} \\
\hline & & & Total & Other & Other \% & Safety & Safety \% \\
\hline & & STIP & $\$ 6,735$ & $\$ 6,061$ & $90 \%$ & $\$ 673$ & $10 \%$ \\
\hline & & As-Built & $\$ 2,879$ & $\$ 2,593$ & $90 \%$ & $\$ 286$ & $10 \%$ \\
\hline Performance & 5 & \multicolumn{6}{|c|}{$\begin{array}{l}\text { No target crashes were identified. The fatal and injury A crashes increased by } 3 \\
\text { from } 8 \text { to } 11(+38 \%) \text {. }\end{array}$} \\
\hline
\end{tabular}




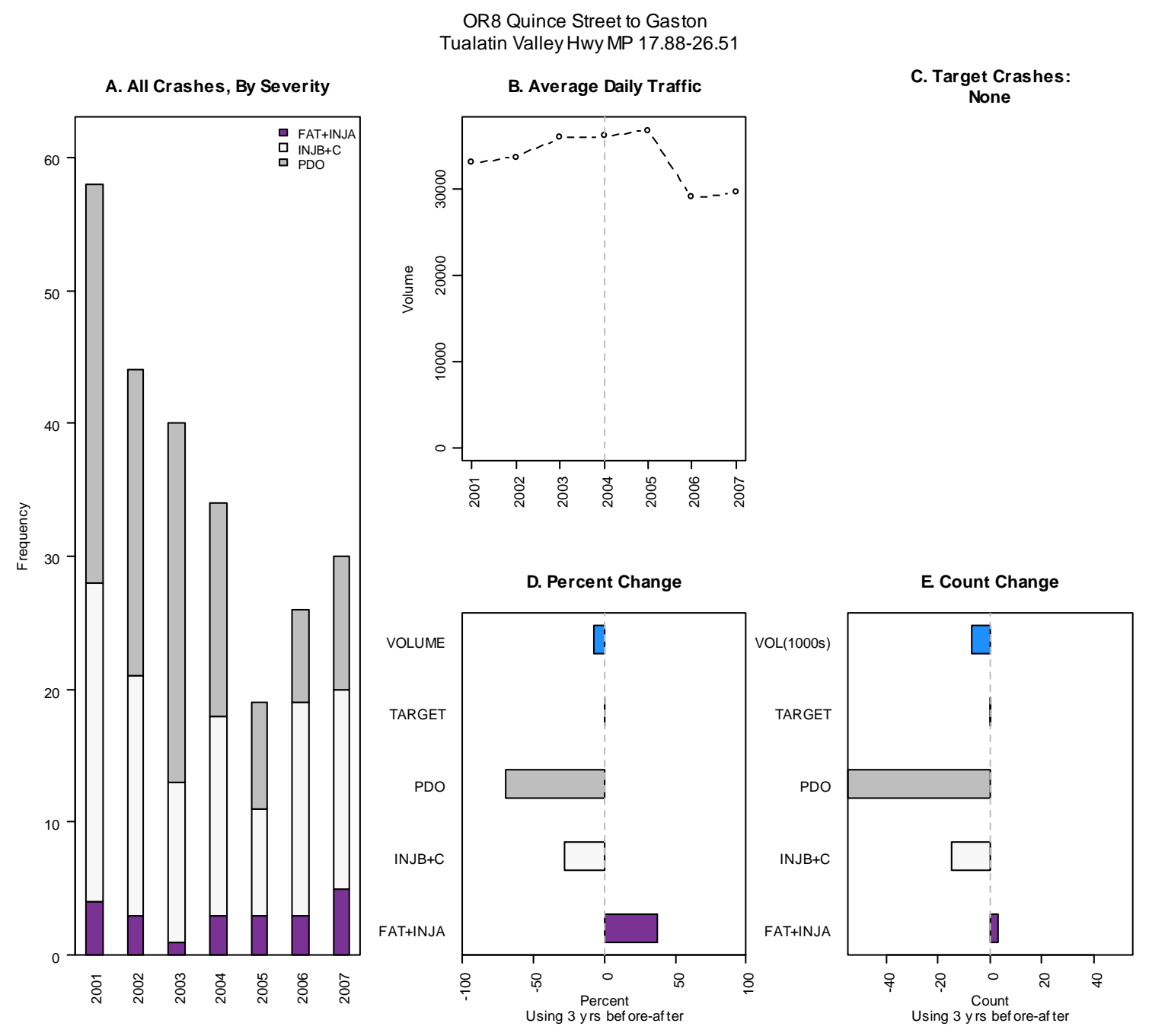

Figure 5.16: Safety Performance, OR 8-Quince St to District Boundary, Key No. 10679

\subsubsection{OR 8: Minter Bridge Rd to 117th Ave}

\subsubsection{Description}

This 8.1 mile preservation project on the OR 8 (Tualatin Valley Highway) was constructed in 2002. A summary of the entire project from the project prospectus and STIP project files is shown in Table 5.15. The project area was of mostly urban character and was located in Region 1. A 13\% safety work type was identified in the STIP and prospectus. The project limits contained a segment with a SIP category of 5. The project did not define the safety deficiencies and the proposed safety solutions were vague. After reviewing the as-built plans and digital video logs it was determined that the constructed safety improvements included upgrading existing guardrails. These were considered mandatory corrective measures. The project also included durable markings. Since lane 
departures were not identified as a safety issue, these were not considered enhancements. Before and after photos from the digital video log are shown in Figure 5.17.

Table 5.15: Project Summary, OR 8-Minter Bridge Rd to $117^{\text {th }}$ Ave, Key No. 10680

\begin{tabular}{|c|c|c|c|c|c|}
\hline $\begin{array}{l}\text { Key No. } \\
\text { Contract No. }\end{array}$ & $\begin{array}{l}10680 \\
12791\end{array}$ & Region & 1 & Funding & $\begin{array}{l}\text { Preservation } 79 \% \\
\text { Safety } 13 \% \\
\text { Bike/Ped } 8 \%\end{array}$ \\
\hline Highway & $\begin{array}{l}029 \text { Tualatin } \\
\text { Valley }\end{array}$ & MP & $4.05-11.28$ & $\begin{array}{l}\text { Construction } \\
\text { Year }\end{array}$ & 2002 \\
\hline $\begin{array}{l}\text { Estimated } \\
\text { Scope Year }\end{array}$ & 2000 & $\begin{array}{l}\text { SIP } \\
\text { Category } \\
\text { 1997-1999 } \\
\end{array}$ & 5 & $\begin{array}{l}\text { SPIS Score } \\
1997-1999\end{array}$ & $\begin{array}{l}\text { Max: 86.68, MP } \\
4.51,95-100 \%\end{array}$ \\
\hline $\begin{array}{l}\text { ODOT } \\
\text { Problem }\end{array}$ & \multicolumn{5}{|c|}{$\begin{array}{l}\text { This largely urban section displays two distinct pavement problems. The first } 3.9 \mathrm{~km} \\
\text { have extensive fatigue and moderate alligator cracking, wheel path deformation and } \\
\text { turn lane shoving. The remaining } 9.1 \mathrm{~km} \text { has extensive bleeding resulting in a very } \\
\text { poor friction factor. Moderate rutting and shoving exists in turn lanes. The section } \\
\text { has sidewalk throughout much of its length. The existing walk is narrow, lacks } \\
\text { connectivity, and exhibits numerous ADA obstacles, with non-conforming sidewalk } \\
\text { ramps and driveways. The existing sidewalk also lacks connectivity. }\end{array}$} \\
\hline $\begin{array}{l}\text { ODOT } \\
\text { Proposed } \\
\text { Solution }\end{array}$ & \multicolumn{5}{|c|}{$\begin{array}{l}\text { A } 75 \mathrm{~mm} \text { grind/inlay of the travel lanes is proposed to remove the pavement } \\
\text { deformation. Turn lanes areas exhibiting deformation will also be ground/inlayed. } \\
\text { Between } 117^{\text {th }} \text { Ave and Hocken Ave, the outer } 2.4 \mathrm{~m} \text { of road surface in each direction } \\
\text { will be reconstructed to correct base and subgrade deficiencies. R/W and cost issues } \\
\text { dictate that exceptions be obtained for most of the section's ADA deficiencies. A } \\
\text { figure amounting to } 1 \% \text { of the total cost of the roadway items is included in the } \\
\text { estimate to cover ADA upgrades. Additional pedestrian improvements (primarily } \\
\text { sidewalk infill) will be funded from the Bike/Pedestrian (ped) program. Complete } \\
\text { safety upgrades as required. Some signal upgrade work may be required. }\end{array}$} \\
\hline $\begin{array}{l}\text { Design } \\
\text { Exceptions }\end{array}$ & \multicolumn{5}{|c|}{$\begin{array}{l}\text { Median width: East end of project in the City of Beaverton, Sta. } 11+662 \text { to Sta. } \\
13+025 \text {. Right turn lanes: Various locations throughout project section. Shoulders: } \\
\text { Various locations. Sidewalk: Sta. } 4+875 \text { to Sta. } 5+084 \text {. }\end{array}$} \\
\hline $\begin{array}{l}\text { Constructed } \\
\text { Safety } \\
\text { Improvements }\end{array}$ & \multicolumn{3}{|c|}{$\begin{array}{l}\text { Upgraded guardrail, durable pavement } \\
\text { markings }\end{array}$} & $\begin{array}{l}\text { Target } \\
\text { Crashes }\end{array}$ & None identified \\
\hline \multirow{4}{*}{$\begin{array}{l}\text { Prospectus } \\
\text { Costs (000's) }\end{array}$} & \multirow{4}{*}{$\begin{array}{l}\text { PE } \\
\text { ROW } \\
\text { CON } \\
\text { TOTAL }\end{array}$} & \multirow[t]{2}{*}{$\$ 512$} & \multirow{4}{*}{$\begin{array}{l}\text { STIP Costs } \\
\text { (000's) }\end{array}$} & \multirow{4}{*}{$\begin{array}{l}\text { PE } \\
\text { ROW } \\
\text { CON } \\
\text { TOTAL }\end{array}$} & $\$ 504$ \\
\hline & & & & & \\
\hline & & $\$ 5,898$ & & & $\$ 5,909$ \\
\hline & & $\$ 6,410$ & & & $\$ 6,413$ \\
\hline
\end{tabular}
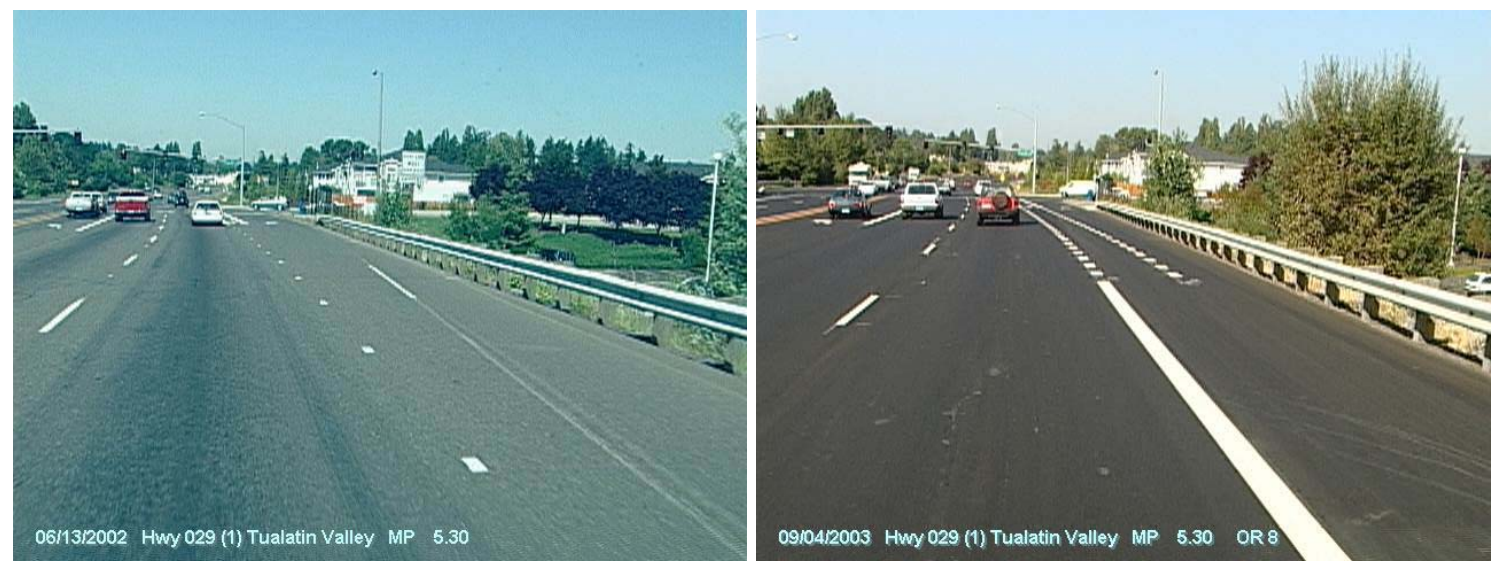

Figure 5.17: Conditions in 2002 (before) and in 2003 (after) showing the preservation work at MP 5.30 


\subsubsection{Evaluation}

The project was evaluated according to the criteria for each metric and the results are summarized in Table 5.16. The project included a segment with a SIP category of 5, earning the project a funding eligibility score of 1 . The upgrade of existing guardrails was a mandatory corrective measure, resulting in a design score of 4 . The safety related items included guardrail Type 2a, 3, guardrail connections, and transitions. The project also included durable markings. These expenditures totaled $\$ 819,000$ (durable markings were $\$ 592,000$ ) which was $12 \%$ of the construction costs. The STIP planned a $13 \%$ use of safety funding. Thus, the project was given an expenditure score of 1 .

The safety-related data for the project are summarized in Figure 5.18A-E. No target crashes were identified for the project. Over the project limits for the three years before to after, fatal and injury A crashes decreased from 24 to 15 (-38\%). The largest reduction in fatal and injury A crashes was in rear-end (-4) turning (-3), and pedestrian (-3). The project narrative indicated: safety upgrades as required, potential signal upgrades that may be required (as-built plans did not indicate any modifications), and pedestrian enhancements to be paid out of the bike-ped fund (one midblock crossing and new sidewalks found on the as-built plans). These improvements may have contributed to what appears to be an improvement in safety within the project limits. Primarily because of the decrease in fatal and injury A crashes, the project was given a safety performance score of 2.

Table 5.16: Project Scorecard, OR 8-Minter Bridge Rd to $117^{\text {th }}$ Ave, Key No. 10680

\begin{tabular}{|c|c|c|c|c|c|c|c|}
\hline Metric & Score & \multicolumn{6}{|l|}{ Note } \\
\hline $\begin{array}{l}\text { Funding } \\
\text { Eligibility }\end{array}$ & 1 & \multicolumn{6}{|c|}{$\begin{array}{l}\text { The project contained a segment with SIP category of } 5 \text { and was eligible for } \\
\text { safety funds. }\end{array}$} \\
\hline Design & 4 & \multicolumn{6}{|c|}{$\begin{array}{l}\text { The project did not define the safety deficiencies and the proposed safety } \\
\text { solutions were vague. The constructed safety improvements (upgrading existing } \\
\text { guardrails) were mandatory corrective measures. Durables were not considered } \\
\text { enhancements on this urban section. }\end{array}$} \\
\hline \multirow[t]{4}{*}{ Expenditures } & 1 & \multicolumn{6}{|c|}{$\begin{array}{l}\text { The identified safety enhancements accounted for }<1 \% \text { of project construction } \\
\text { costs; } 17 \% \text { was planned. The costs are summarized (in 1,000s): }\end{array}$} \\
\hline & & & Total & Other & Other \% & Safety & Safety \% \\
\hline & & STIP & $\$ 5,909$ & $\$ 5,140$ & $87 \%$ & $\$ 768$ & $13 \%$ \\
\hline & & As-Built & $\$ 6,874$ & $\$ 6,054$ & $88 \%$ & $\$ 819$ & $12 \%$ \\
\hline Performance & 2 & \multicolumn{6}{|c|}{$\begin{array}{l}\text { No target crashes were identified. However, fatal and injury A crashes decreased } \\
\text { from } 24 \text { to } 15(-38 \%) \text {. Exposure decreased approximately } 8 \% \text { over the same } \\
\text { period. }\end{array}$} \\
\hline
\end{tabular}




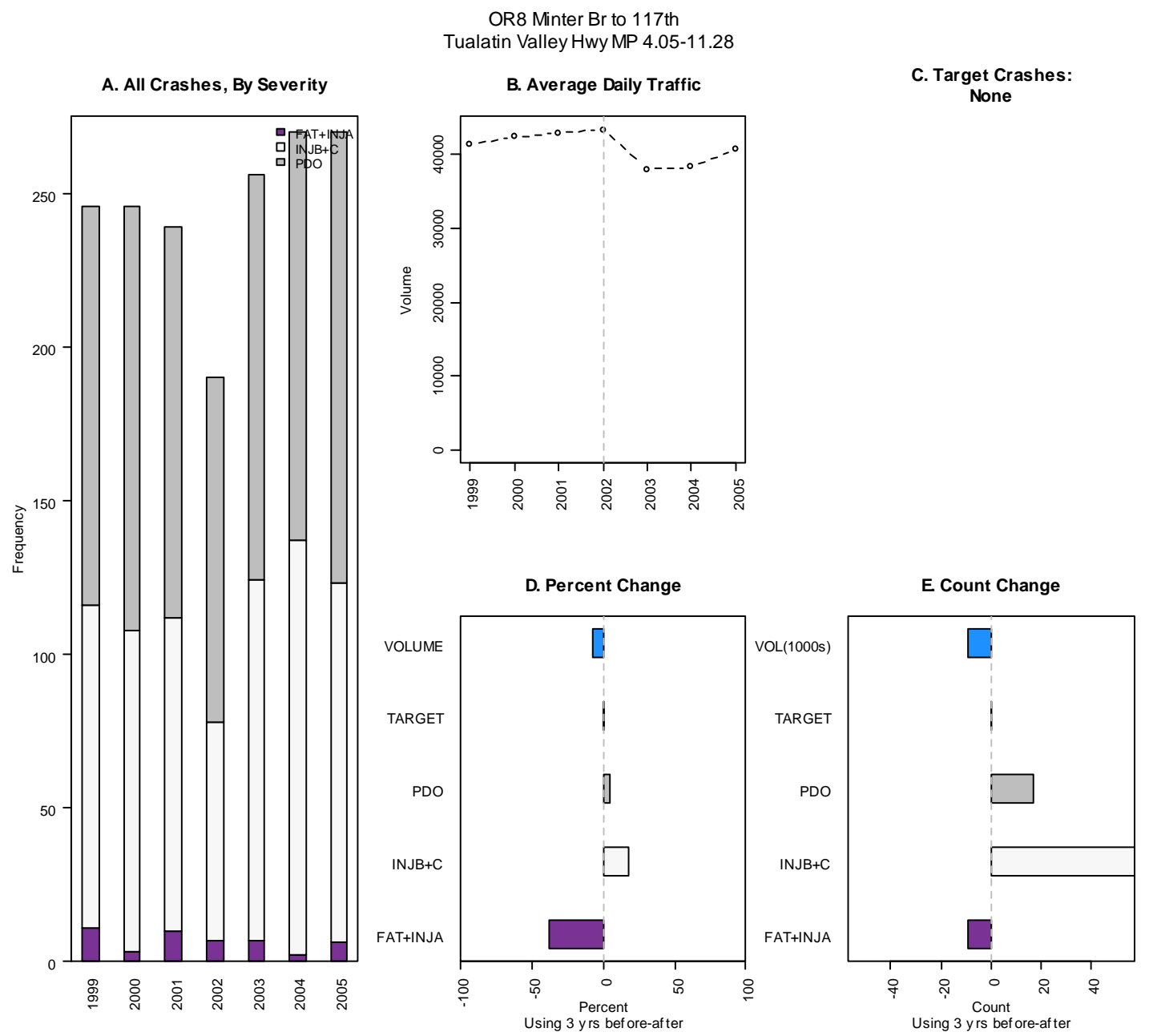

Figure 5.18: Safety Performance, OR 8-Minter Bridge Rd to $117^{\text {th }}$ Ave, Key No. 10680

\subsubsection{US 26: Ross Island Bridge to SE 50th Ave}

\subsubsection{1}

\section{Description}

This 2.44 mile preservation project on the US 26 (Mt. Hood Highway) was constructed in 2000. A summary of the entire project from the project prospectus and STIP project files is shown in Table 5.17. The project area was of urban character and was located in Region 1. A 7\% safety work type was identified in the STIP and prospectus. The project limits contained a segment with a SIP category of 5, however, the project did not define the safety deficiencies and the proposed safety solutions were vague. After reviewing the as-built plans and digital video logs it was found that minor access management (driveway closures and concrete islands) was identified as safety improvements. Before and after photos from the digital video log are shown in Figure 5.19. 
Table 5.17: Project Summary, US 26-Ross Island Bridge to SE 50 ${ }^{\text {th }}$ Ave, Key No. 10731

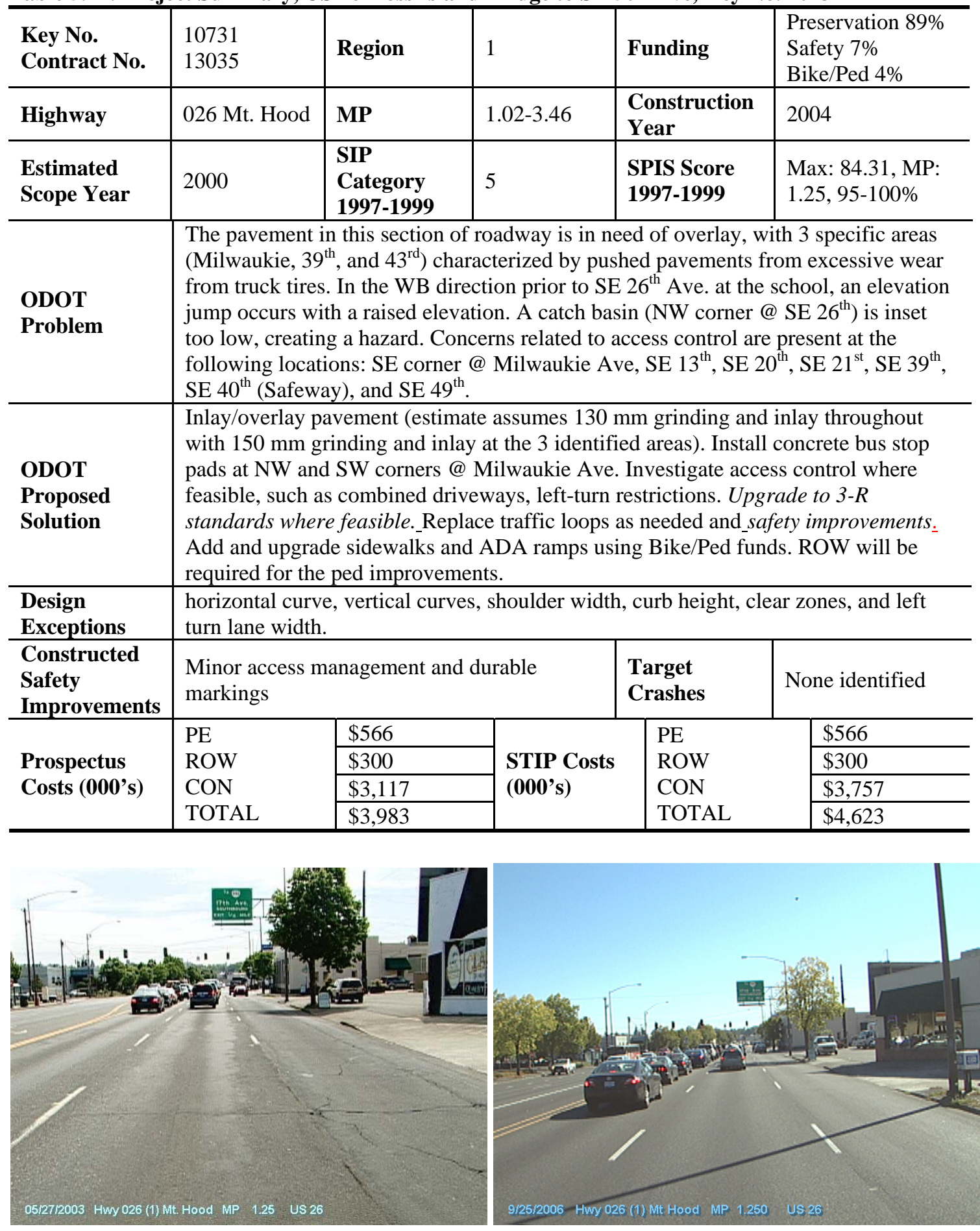

Figure 5.19: Conditions in 2003 (before) and in 2006 (after) (2006) showing the overlay at MP 1.25 


\subsubsection{Evaluation}

The project was evaluated according to the criteria for each metric and the results are summarized in Table 5.18. The project had a SIP segment category of 5 within the project limits, receiving a funding eligibility score of 1 . The project included minor driveway closures and concrete islands as safety improvements. Durable pavement marking were included in the project but these were not considered enhancements. This resulted in a design score of 2 . The STIP planned a $7 \%$ use of safety funding. Analysis of project expenditures indicated that construction of the concrete islands, driveway closures, and durable markings accounted for $7 \%$ of the expenditures. Thus, the project was given an expenditure score of 1.

The safety-related data for the project are summarized in Figure 5.20A-E. No target crashes were identified for the project. Over the project limits for the three years before to after, fatal and injury A crashes increased from 11 to 16 (45\%). The project narrative indicated safety improvements, access control, potential signal upgrades that may be required (as-built plans did not indicate any modifications), and pedestrian enhancements to be paid out of the bike-ped fund. Fatal and injury A crashes increased or were unchanged for all crash types. Minor injury and property crashes decreased over the same period as did traffic volume. Overall, because of the change in fatal and injury A crashes the project was given a safety performance score of 5 .

Table 5.18: Project Scorecard, US 26-Ross Island Bridge to SE 50 ${ }^{\text {th }}$ Ave, Key No. 10731

\begin{tabular}{|c|c|c|c|c|c|c|c|}
\hline Metric & Score & \multicolumn{6}{|l|}{ Note } \\
\hline $\begin{array}{l}\text { Funding } \\
\text { Eligibility }\end{array}$ & 1 & \multicolumn{6}{|c|}{$\begin{array}{l}\text { The project contained a segment with SIP category of } 5 \text { and was eligible for } \\
\text { safety funds. }\end{array}$} \\
\hline Design & 2 & \multicolumn{6}{|c|}{$\begin{array}{l}\text { The project included minor driveway closures and concrete islands as safety } \\
\text { improvements. Durable markings were included but not considered } \\
\text { enhancements. }\end{array}$} \\
\hline \multirow[t]{4}{*}{ Expenditures } & \multirow[t]{4}{*}{1} & \multicolumn{6}{|c|}{$\begin{array}{l}\text { The safety improvements identified accounted for } 7 \% \text {; } 7 \% \text { was planned. The } \\
\text { costs are summarized (in 1,000s): }\end{array}$} \\
\hline & & & Total & Other & Other \% & Safety & Safety \% \\
\hline & & STIP & $\$ 3,757$ & $\$ 3,494$ & $93 \%$ & $\$ 262$ & $7 \%$ \\
\hline & & As-Built & $\$ 3,213$ & $\$ 2,994$ & $93 \%$ & $\$ 219$ & $7 \%$ \\
\hline Performance & 5 & \multicolumn{6}{|c|}{$\begin{array}{l}\text { No target crashes were identified. Fatal and injury A crashes increased } 45 \% \\
\text { from } 11 \text { to } 16 \text { from the three year before to after periods. }\end{array}$} \\
\hline
\end{tabular}




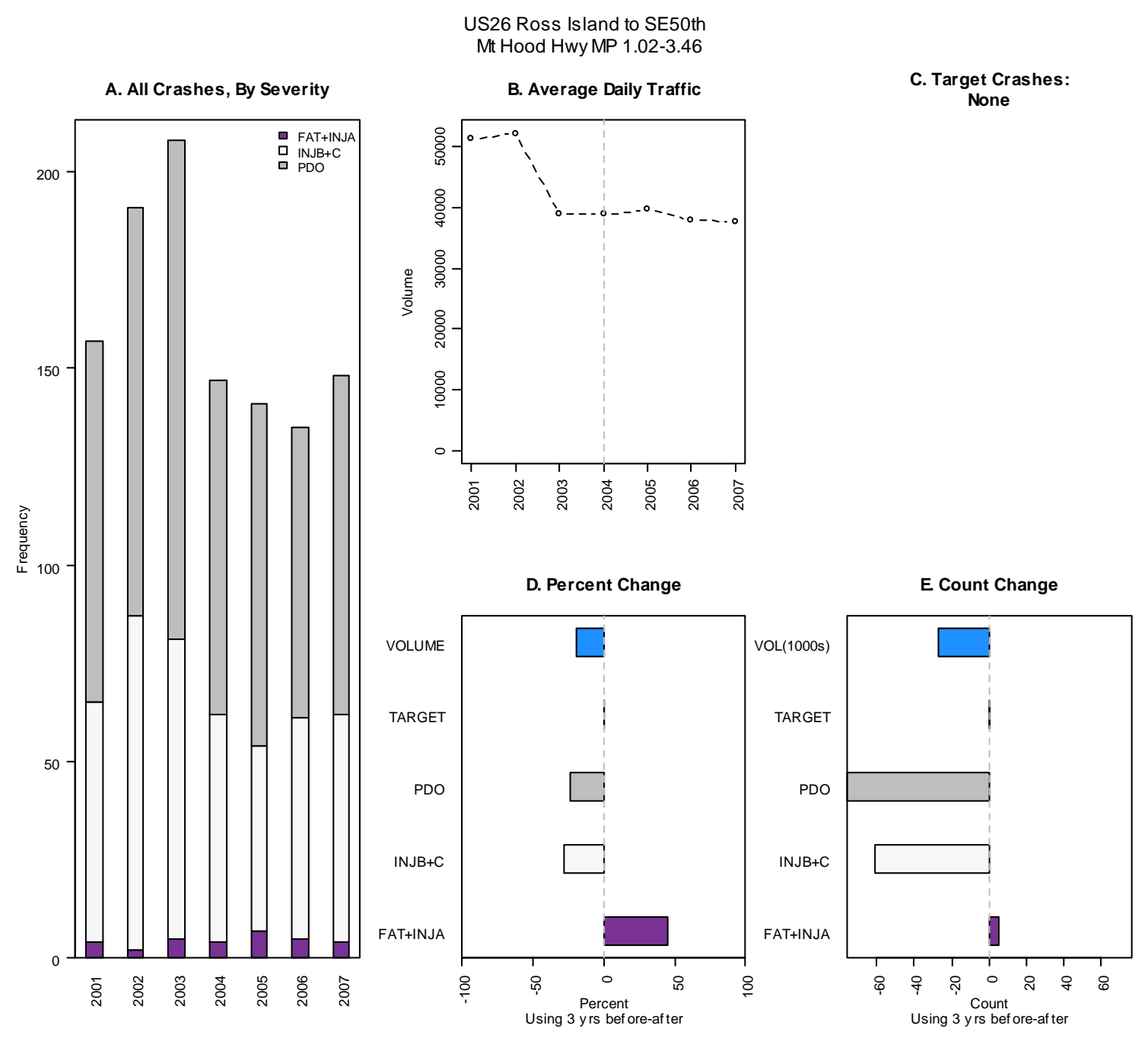

Figure 5.20: Safety Performance, US 26-Ross Island Bridge to SE 50 ${ }^{\text {th }}$ Ave, Key No. 10731

\subsubsection{OR 6: Tillamook RR Overpass to Jordan Creek Bridge}

\subsubsection{Description}

This 17.five-mile preservation project on the Wilson River Highway (OR 6) was constructed in 2002. A summary of the entire project, from the project prospectus and STIP project files, is shown in Table 5.19. The project area was of mostly rural character and was located in Region 2. A 2\% safety work type was identified in the STIP and prospectus. The project limits contained a segment with a SIP category of 2. The project narrative did not define the safety deficiencies and the proposed safety solution included the installation of flashing warning lights and signage. These were considered enhancements. Before and after photos from the digital video log are shown in Figure 5.21 . 
Table 5.19: Project Summary, OR 6-Tillamook RR Overpass to Jordan Creek Bridge, Key No. 10748

\begin{tabular}{|c|c|c|c|c|c|}
\hline $\begin{array}{l}\text { Key No. } \\
\text { Contract No. }\end{array}$ & $\begin{array}{l}10748 \\
12676\end{array}$ & Region & 2 & Funding & $\begin{array}{l}\text { Preservation 98\% } \\
\text { Safety 2\% }\end{array}$ \\
\hline Highway & $\begin{array}{l}\text { 037 Wilson } \\
\text { River }\end{array}$ & MP & $0.5-18$ & $\begin{array}{l}\text { Construction } \\
\text { Year }\end{array}$ & 2002 \\
\hline $\begin{array}{l}\text { Estimated } \\
\text { Scope Year }\end{array}$ & 2000 & $\begin{array}{l}\text { SIP } \\
\text { Category } \\
\text { 1997-1999 }\end{array}$ & 2 & $\begin{array}{l}\text { SPIS Score } \\
1997-1999\end{array}$ & $\begin{array}{l}\text { Max: 83.37, MP } \\
1.71-1.79,95- \\
100 \%\end{array}$ \\
\hline $\begin{array}{l}\text { ODOT } \\
\text { Problem }\end{array}$ & \multicolumn{5}{|c|}{$\begin{array}{l}\text { Deteriorating Pavement: Deep long cracks on the pavement along CL. Same type of } \\
\text { cracks can be seen along the fog line and edge of pavement. Pavement is rutting. }\end{array}$} \\
\hline $\begin{array}{l}\text { ODOT } \\
\text { Proposed } \\
\text { Solution }\end{array}$ & \multicolumn{5}{|c|}{$\begin{array}{l}\text { Preservation overlay. Upgrade, adjust, and add guardrail and replace failing culverts. } \\
2 \% \text { of the funding to go to Wilson River Loop Road to install flashing warning lights } \\
\text { and signage. }\end{array}$} \\
\hline $\begin{array}{l}\text { Design } \\
\text { Exceptions }\end{array}$ & \multicolumn{5}{|c|}{$\begin{array}{l}\text { Not providing guardrail installations for various RCBCs (Equipment/Cattlepasses) } \\
\text { near road approaches (various locations along section). }\end{array}$} \\
\hline $\begin{array}{l}\text { Constructed } \\
\text { Safety } \\
\text { Improvements }\end{array}$ & \multicolumn{3}{|c|}{ Flashing beacon at Wilson River Loop Road } & $\begin{array}{l}\text { Target } \\
\text { Crashes }\end{array}$ & None \\
\hline \multirow{4}{*}{$\begin{array}{l}\text { Prospectus } \\
\text { Costs (000's) }\end{array}$} & PE & $\$ 197$ & \multirow{4}{*}{$\begin{array}{l}\text { STIP Costs } \\
\text { (000's) }\end{array}$} & \multirow{4}{*}{$\begin{array}{l}\text { PE } \\
\text { ROW } \\
\text { CON } \\
\text { TOTAL }\end{array}$} & $\$ 197$ \\
\hline & ROW & & & & \\
\hline & CON & $\$ 2,316$ & & & $\$ 2,336$ \\
\hline & TOTAL & $\$ 2,513$ & & & $\$ 2,533$ \\
\hline
\end{tabular}

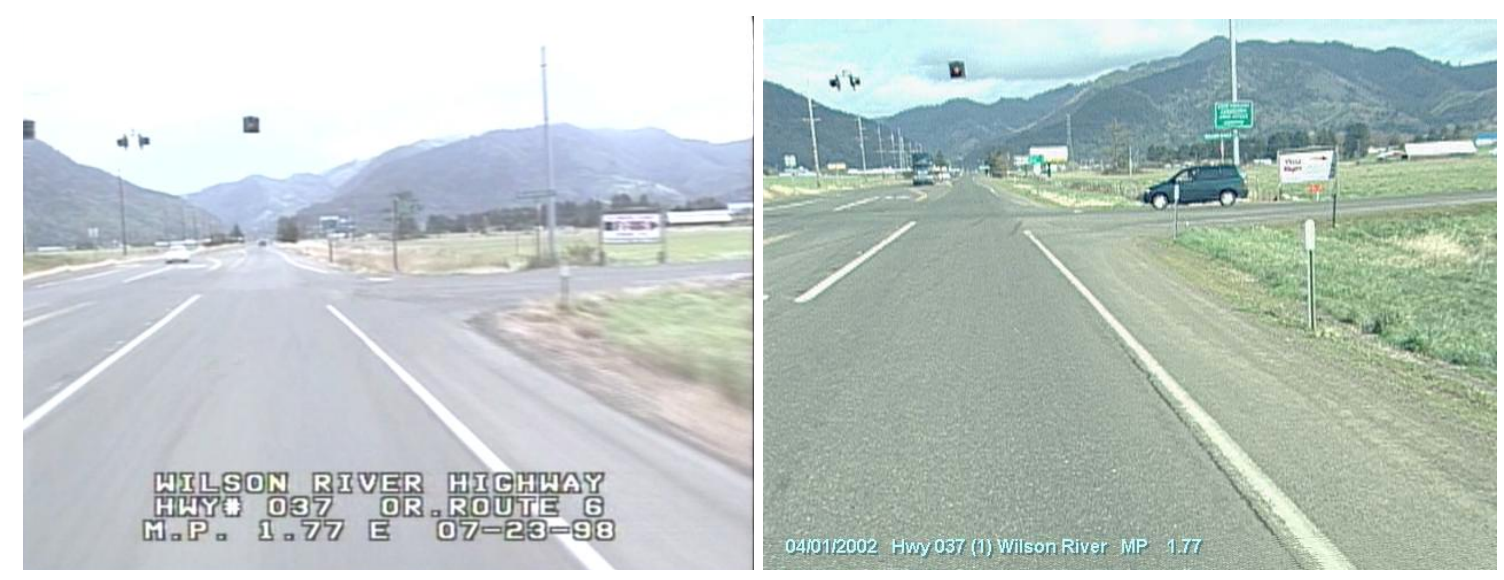

Figure 5.21: Flashing warning light at Wilson River Loop Road at MP 1.77 in 1998 and 2002

\subsubsection{Evaluation}

The project was evaluated according to the criteria for each metric and the results are summarized in Table 5.20. The project included a segment with a SIP category of 2 in the estimated scope year. However, the year after the estimated scope year and prior to construction contained a SIP category 3. Thus, the project was given a funding score of 3 . The project prospectus proposed installing a flashing beacon at Wilson River Loop Road, which was considered an enhancement. Therefore, the design score given was a 2 . There were no safety costs identified for this project. The STIP planned a $2 \%$ use of safety funding. However, after reviewing the construction plans and digital video logs, it 
appears that the flashing beacon was constructed prior to this project. This was an unusual circumstance and while it shows that the intent of the improvement was constructed it was not part of this project. The criteria used for all other projects require an expenditure score of 5 .

The safety-related data for the project are summarized in Figure 5.22A-E. No target crashes were identified for the project. The project narrative indicated installing a flashing beacon with the $2 \%$ of safety funds; however it appears from the DVL and asbuilt plans that this was installed prior to construction of the project. Fatal and injury $\mathrm{A}$ crashes decreased from 9 to 8 . There was a decrease of three fatal and injury A angle crashes and two sideswipe meeting crashes. Head-ons and turning crashes increased by two each. Minor injury and property crashes increased over the same period as well as traffic volume (+3\%). Overall, because fatal and injury A crashes did not change significantly the project was given a safety performance score of 3 .

Table 5.20: Project Scorecard, OR 6-Tillamook RR Overpass to Jordan Creek Bridge, Key No. 10748

\begin{tabular}{|c|c|c|c|c|c|c|c|}
\hline Metric & Score & \multicolumn{6}{|l|}{ Note } \\
\hline $\begin{array}{l}\text { Funding } \\
\text { Eligibility }\end{array}$ & 3 & \multicolumn{6}{|c|}{$\begin{array}{l}\text { The project contained a segment with a SIP category of } 2 \text { in the estimated scope } \\
\text { year. However, the year after the estimated scope year and prior to construction } \\
\text { contained a SIP category } 3 \text {. }\end{array}$} \\
\hline Design & 2 & \multicolumn{6}{|c|}{$\begin{array}{l}\text { The project did not define the safety deficiencies. The proposed safety } \\
\text { improvements (adding and upgrading existing guardrails and adding a flashing } \\
\text { beacon) were enhancements (but were not installed). }\end{array}$} \\
\hline \multirow[t]{4}{*}{ Expenditures } & 5 & \multicolumn{6}{|c|}{$\begin{array}{l}\text { There were no constructed safety improvements accounted for in the project } \\
\text { construction costs; } 2 \% \text { was planned. The costs are summarized (in 1,000s): }\end{array}$} \\
\hline & & & Total & Other & Other \% & Safety & Safety \% \\
\hline & & STIP & $\$ 2,336$ & $\$ 2,289$ & $98 \%$ & $\$ 47$ & $2 \%$ \\
\hline & & As-Built & $\$ 2,942$ & $\$ 2,942$ & $100 \%$ & $\$ 0$ & $0 \%$ \\
\hline Performance & 3 & \multicolumn{6}{|c|}{$\begin{array}{l}\text { No target crashes were identified and fatal and injury A crashes decreased by } 1 \text {. } \\
\text { Overall, safety of this project was unchanged. }\end{array}$} \\
\hline
\end{tabular}



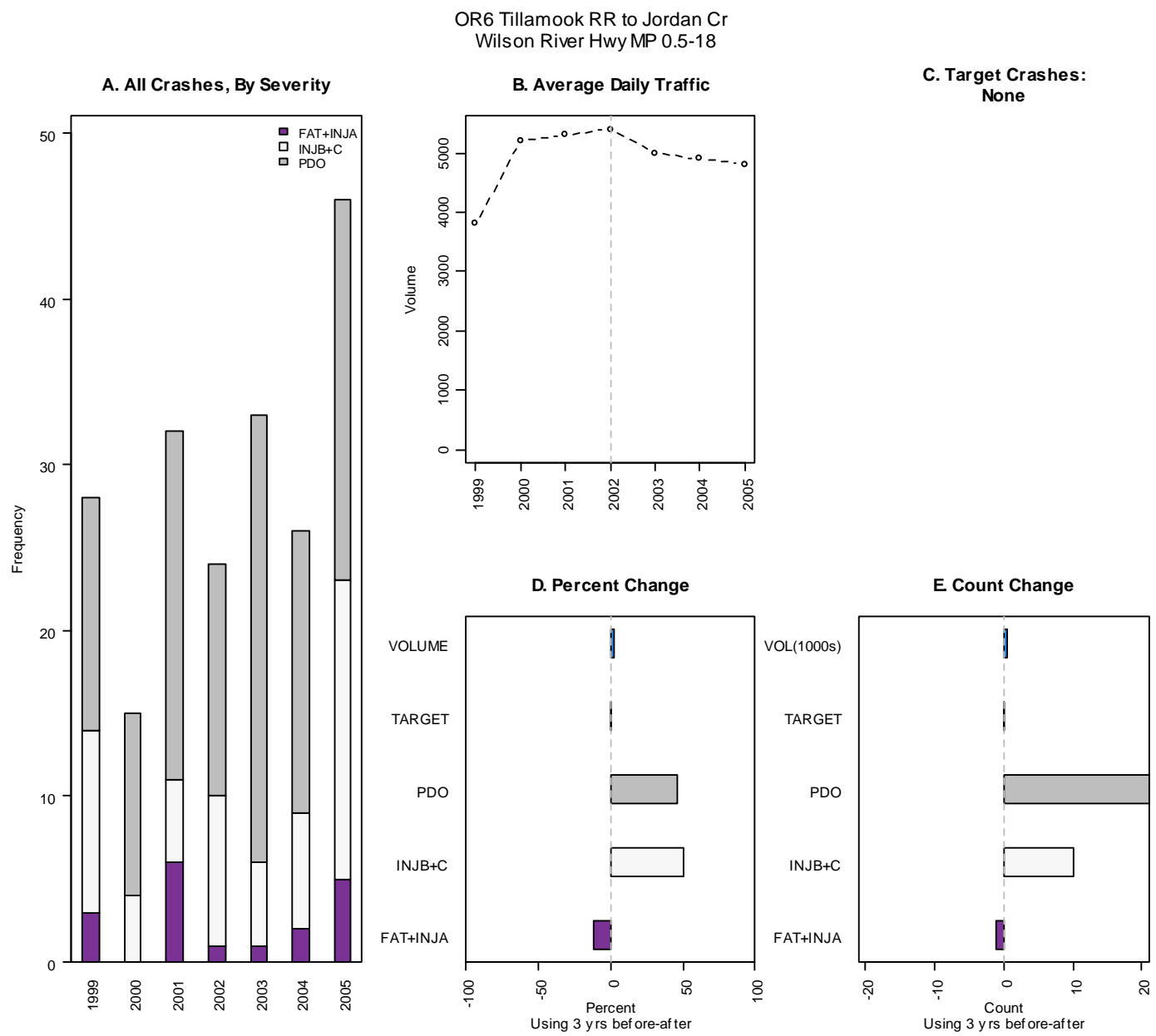

Figure 5.22: Safety Performance, OR 6-Tillamook RR Overpass to Jordan Creek Bridge, Key No. 10748

\subsubsection{R 22: Chemawa Rd to N Santiam Interchange}

\subsubsection{1 \\ Description}

This 8.32 mile preservation project on OR 22 (Salem Highway) was constructed in 2004. A summary of the entire project from the project prospectus and STIP project files is shown in Table 5.21. The project area was of mostly urban character and was located in Region 2. A $12 \%$ safety work type was identified in the STIP and prospectus. The project limits contained a segment with a SIP category of 4 . The project did not define the safety deficiencies. However, the proposed safety solutions were stated. After reviewing the as-built plans and digital video logs the constructed safety improvements included upgrading substandard approach guardrail and bridge railing, durable striping, and safety lane extensions. These were considered enhancements. The addition of the safety lane was assumed to target rear-end and sideswipe crashes from Airport to Mill Creek, EB only MP 7.92-8.46. Before and after photos from the digital video log are shown in Figure 5.23. 
Table 5.21: Project Summary, OR 22-Chemawa Rd to N Santiam Interchange, Key No. 10807

\begin{tabular}{|c|c|c|c|c|c|}
\hline $\begin{array}{l}\text { Key No. } \\
\text { Contract No. }\end{array}$ & $\begin{array}{l}10807 \\
12986\end{array}$ & Region & 2 & Funding & $\begin{array}{l}\text { Preservation } 85 \% \\
\text { Safety } 12 \% \\
\text { Bike/Ped } 3 \%\end{array}$ \\
\hline Highway & 072 Salem & MP & $0.14-8.46$ & $\begin{array}{l}\text { Construction } \\
\text { Year } \\
\end{array}$ & 2004 \\
\hline $\begin{array}{l}\text { Estimated } \\
\text { Scope Year }\end{array}$ & 2000 & $\begin{array}{l}\text { SIP } \\
\text { Category } \\
1997-1999 \\
\end{array}$ & 4 & $\begin{array}{l}\text { SPIS Score } \\
1997-1999\end{array}$ & $\begin{array}{l}\text { Max: 89.95, MP } \\
5.43,95-100 \%\end{array}$ \\
\hline $\begin{array}{l}\text { ODOT } \\
\text { Problem }\end{array}$ & \multicolumn{5}{|c|}{$\begin{array}{l}\text { Very extensive low and moderate with intermittent high severity fatigue cracking. } \\
\text { Extensive low severity transverse cracking, intermittent low and moderate } \\
\text { longitudinal cracking. Extensive blade patching with intermittent wheeltrack } \\
\text { patching. Low to moderate pavement rutting. Cement Treated Base (CTB) has some } \\
\text { failure, losing up to } 60 \% \text { of its strength. Approach guardrail and bridge railing } \\
\text { substandard on two structures. Opportunity for Safety (HEP), Operational, and } \\
\text { Pedestrian upgrades: Commercial/Division intersection, sidewalk bulb-outs, guide } \\
\text { signs and sign bridge. }\end{array}$} \\
\hline $\begin{array}{l}\text { ODOT } \\
\text { Proposed } \\
\text { Solution }\end{array}$ & \multicolumn{5}{|c|}{$\begin{array}{l}\text { Rehabilitate the pavement with } 75 \mathrm{~mm} \text { of AC overlay with } 50 \mathrm{~mm} \text { grind/inlay in } \\
\text { travel lanes from MP } 0.60 \text { to } 5.40 \text { and } 6.34 \text { to } 7.43 \text {. Overlay } 50 \mathrm{~mm} 7.43 \text { to } 8.46 \text {. } \\
\text { Estimated } 1800 \text { sq. meters of digout repairs required. Upgrade substandard approach } \\
\text { guardrail and bridge railing (using safety funds). Durable striping on skip-stripes } \\
\text { (using HEP funds). Construct sign bridge and guide signs approaching Commercial } \\
\text { on Trade and construct pedestrian bulb-outs on Ferry at intersections with } \\
\text { Commercial and High Streets. Construct safety lane extension from Airport Road to } \\
\text { Mill Creek Bridge EB only (safety funds). Add sidewalks on S. side (SWIS funds). } \\
\text { Extend median on Mission Street to just past Hawthorne intersection. }\end{array}$} \\
\hline $\begin{array}{l}\text { Design } \\
\text { Exceptions }\end{array}$ & \multicolumn{5}{|c|}{$\begin{array}{l}\text { Curb exposure and pavement cross slope (MP } 5.94 \text { and MP 6.10), shy distance (MP } \\
6.97 \text { and MP7.08), clear zone (throughout project). Pavement design life (Ferry Street } \\
\text { between Commercial and Church Street). }\end{array}$} \\
\hline $\begin{array}{l}\text { Constructed } \\
\text { Safety } \\
\text { Improvements }\end{array}$ & \multicolumn{3}{|c|}{$\begin{array}{l}\text { Upgrade substandard approach guardrail and } \\
\text { bridge railing, durable striping, and safety } \\
\text { lane extension }\end{array}$} & $\begin{array}{l}\text { Target } \\
\text { Crashes }\end{array}$ & $\begin{array}{l}\text { Rear end and } \\
\text { sideswipe, EB only } \\
\text { MP 7.92-8.46 }\end{array}$ \\
\hline \multirow{4}{*}{$\begin{array}{l}\text { Prospectus } \\
\text { Costs (000's) }\end{array}$} & \multirow{4}{*}{$\begin{array}{l}\text { PE } \\
\text { ROW } \\
\text { CON } \\
\text { TOTAL }\end{array}$} & $\$ 275$ & \multirow{4}{*}{$\begin{array}{l}\text { STIP Costs } \\
\text { (000's) }\end{array}$} & \multirow{4}{*}{$\begin{array}{l}\text { PE } \\
\text { ROW } \\
\text { CON } \\
\text { TOTAL }\end{array}$} & \begin{tabular}{l|l}
$\$ 275$ \\
\end{tabular} \\
\hline & & & & & \\
\hline & & $\$ 6,326$ & & & $\$ 7,886$ \\
\hline & & $\$ 6,601$ & & & $\$ 8,161$ \\
\hline
\end{tabular}

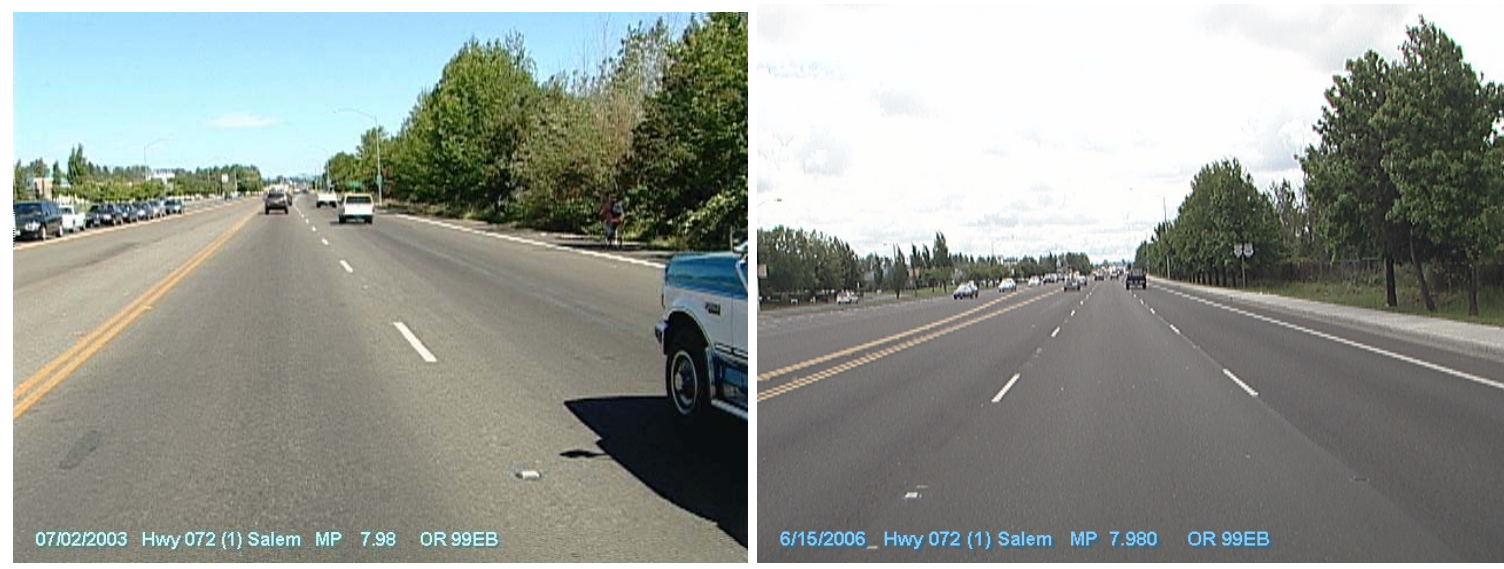

Figure 5.23: Conditions in 2004 (before) and in 2006 (after) showing the added safety lane extension at MP 7.98 


\subsubsection{Evaluation}

The project was evaluated according to the criteria for each metric and the results are summarized in Table 5.22. The project contained a SIP segment with category of 4 and was eligible for safety funds. Though the safety deficiencies were not stated, the proposed improvements (upgrade substandard approach guardrail and bridge railing, durable striping, and safety lane extension) were a mix of enhancements and mandatory corrective measures, resulting in a design score of 2 . The safety related items totaled $\$$ 365,000 and included guardrail, bridge railings, durable striping, and the safety lane extension costs. The calculated safety costs accounted for $11 \%$ of the construction costs and the STIP planned a $12 \%$ use of safety funding. Analysis of project expenditures indicated that the allocated safety funds were spent on safety items. The estimated costs from the STIP and prospectus differed substantially from the actual constructed costs (\$7.8M to $\$ 5.8 \mathrm{M})$. The reason for this decrease in scope was not identified but added some uncertainty to the continuity of the project documentation. Considering this evidence, the project was given an expenditure score of 1.

The safety-related data for the project are summarized in Figure 5.24 A-E. The addition of the safety lane was assumed to target rear-end and sideswipe crashes from Airport to Mill Creek, EB only MP 7.92-8.46. These crashes were reduced from 25 to 23, a $8 \%$ decrease. Over the entire project limits, fatal and injury A crashes were reduced 24\% (from 17 to 13). Considering that target crashes declined by $8 \%$ and fatal and injury $\mathrm{A}$ crashes declined by 24\%, the project was given a safety performance score of 1 .

Table 5.22: Project Scorecard, OR 22-Chemawa Rd to N Santiam Interchange, Key No. 10807

\begin{tabular}{|c|c|c|c|c|c|c|c|}
\hline Metric & Score & \multicolumn{6}{|l|}{ Note } \\
\hline $\begin{array}{l}\text { Funding } \\
\text { Eligibility }\end{array}$ & 1 & \multicolumn{6}{|c|}{$\begin{array}{l}\text { The project contained a segment with a SIP category of } 4 \text { and was eligible for } \\
\text { safety funds. }\end{array}$} \\
\hline Design & 2 & \multicolumn{6}{|c|}{$\begin{array}{l}\text { The project did not define the safety deficiencies. However, the proposed safety } \\
\text { solutions were stated. The safety improvements (upgrading substandard } \\
\text { approach guardrail and bridge railing, durable striping, and safety lane } \\
\text { extension) were a mix of mandatory corrective measures and enhancements. }\end{array}$} \\
\hline \multirow[t]{4}{*}{ Expenditures } & \multirow[t]{4}{*}{1} & \multicolumn{6}{|c|}{$\begin{array}{l}\text { The identified safety enhancements accounted for } 11 \% \text { of project construction } \\
\text { costs; } 12 \% \text { was planned. The costs are summarized (in 1,000s): }\end{array}$} \\
\hline & & & Total & Other & Other \% & Safety & Safety \% \\
\hline & & STIP & $\$ 7,886$ & $\$ 6,940$ & $88 \%$ & $\$ 946$ & $12 \%$ \\
\hline & & As-Built & & & & $\$ 656$ & $11 \%$ \\
\hline Performance & 1 & \multicolumn{6}{|c|}{$\begin{array}{l}\text { Target crashes decreased from } 25 \text { to } 23 \text {, a } 8 \% \text { decrease in the improvement } \\
\text { area, while over the entire project limits, fatal and injury A crashes were reduced } \\
24 \% \text { (from } 17 \text { to } 13 \text { ). }\end{array}$} \\
\hline
\end{tabular}




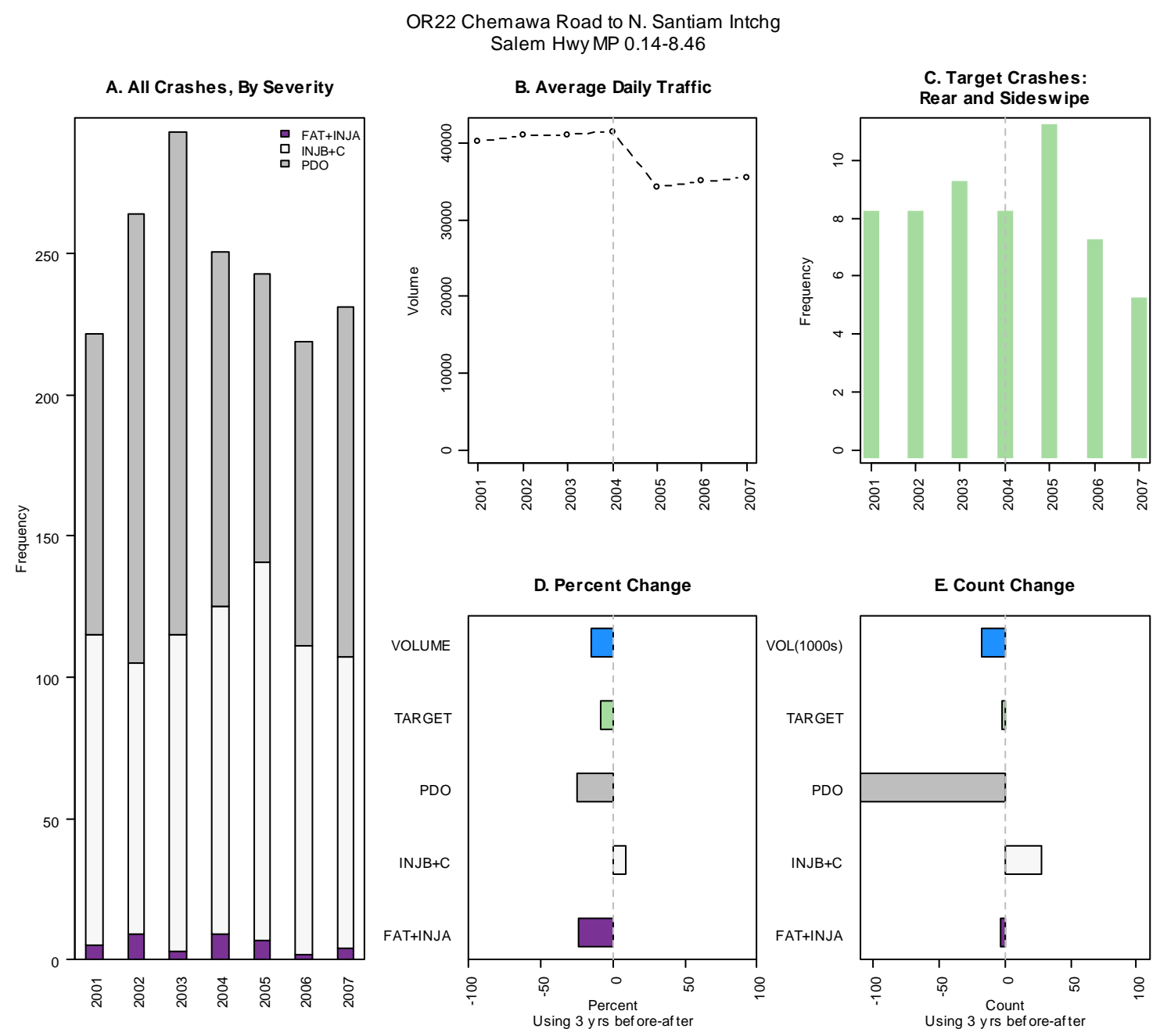

Figure 5.24: Safety Performance, OR 22-Chemawa Rd to N Santiam Interchange, Key No. 10807

\subsubsection{US 101: Nesika Beach to Rogue River}

\subsubsection{Description}

This 7.5 mile preservation project on US 101 (Oregon Coast Highway) was constructed in 2000. A summary of the entire project from the project prospectus and STIP project files is shown in Table 5.23. The project area was of mostly rural character and was located in Region 3. A 40\% safety work type was identified in the STIP and prospectus. The project limits contained a segment with a SIP category of 2 . The project did not define the safety deficiencies and the proposed safety solutions were vague. After reviewing the as-built plans and digital video logs it was found that the constructed safety improvements include upgrading existing guardrail and adding durable striping. The guardrail upgrades were considered mandatory corrective measures. The durable striping could be considered "enhancement” if justification for lane-departure crashes was given 
in the prospectus. A photo from after construction from the digital video log is shown in Figure 5.25.

Table 5.23: Project Summary, US 101-Nesika Beach to Rogue River, Key No. 10817

\begin{tabular}{|c|c|c|c|c|c|}
\hline $\begin{array}{l}\text { Key No. } \\
\text { Contract No. }\end{array}$ & $\begin{array}{l}10817 \\
12511 \\
\end{array}$ & Region & 3 & Funding & $\begin{array}{l}\text { Preservation } 60 \% \\
\text { Safety } 40 \%\end{array}$ \\
\hline Highway & $\begin{array}{l}009 \text { Oregon } \\
\text { Coast }\end{array}$ & MP & 320.4-327.9 & $\begin{array}{l}\text { Construction } \\
\text { Year }\end{array}$ & 2000 \\
\hline $\begin{array}{l}\text { Estimated } \\
\text { Scope Year }\end{array}$ & 1999 & $\begin{array}{l}\text { SIP } \\
\text { Category } \\
1996-1998 \\
\end{array}$ & 2 & $\begin{array}{l}\text { SPIS Score } \\
1996-1998\end{array}$ & $\begin{array}{l}\text { No SPIS scores in } \\
\text { the Top } 15 \%\end{array}$ \\
\hline $\begin{array}{l}\text { ODOT } \\
\text { Problem }\end{array}$ & \multicolumn{5}{|c|}{$\begin{array}{l}\text { Pavement surface deteriorated and considered “poor” in } 1009 \text { pavement condition } \\
\text { report. The overall Index of } 34.1 \text { within section. Existing guardrail doesn't meet } \\
\text { current standards (post spacing, bockouts, rail height). }\end{array}$} \\
\hline $\begin{array}{l}\text { ODOT } \\
\text { Proposed } \\
\text { Solution }\end{array}$ & \multicolumn{5}{|c|}{$\begin{array}{l}\text { Considerable congestion during tourist season at Nesika Beach Rd due to heavy RV } \\
\text { usage. Overlay existing pavement with 50mm Type B and 50mm Type F asphalt } \\
\text { concrete. Replace deficient guardrail and safety ends. Place durable stripe } \\
\text { delineation. (Build left turn channelization has been eliminated from project). }\end{array}$} \\
\hline $\begin{array}{l}\text { Design } \\
\text { Exceptions }\end{array}$ & \multicolumn{5}{|c|}{ None } \\
\hline $\begin{array}{l}\text { Constructed } \\
\text { Safety } \\
\text { Improvements }\end{array}$ & \multicolumn{3}{|c|}{$\begin{array}{l}\text { Upgrade existing guardrail, durable striping } \\
\text { pavement markings }\end{array}$} & $\begin{array}{l}\text { Target } \\
\text { Crashes }\end{array}$ & None identified \\
\hline \multirow{4}{*}{$\begin{array}{l}\text { Prospectus } \\
\text { Costs (000's) }\end{array}$} & \multirow{4}{*}{$\begin{array}{l}\text { PE } \\
\text { ROW } \\
\text { CON } \\
\text { TOTAL }\end{array}$} & $\$ 178$ & \multirow{4}{*}{$\begin{array}{l}\text { STIP Costs } \\
\text { (000's) }\end{array}$} & \multirow{4}{*}{$\begin{array}{l}\text { PE } \\
\text { ROW } \\
\text { CON } \\
\text { TOTAL }\end{array}$} & $\$ 178$ \\
\hline & & $\$ 10$ & & & $\$ 10$ \\
\hline & & $\$ 3,100$ & & & $\$ 3,100$ \\
\hline & & $\$ 3,288$ & & & $\$ 3,288$ \\
\hline
\end{tabular}
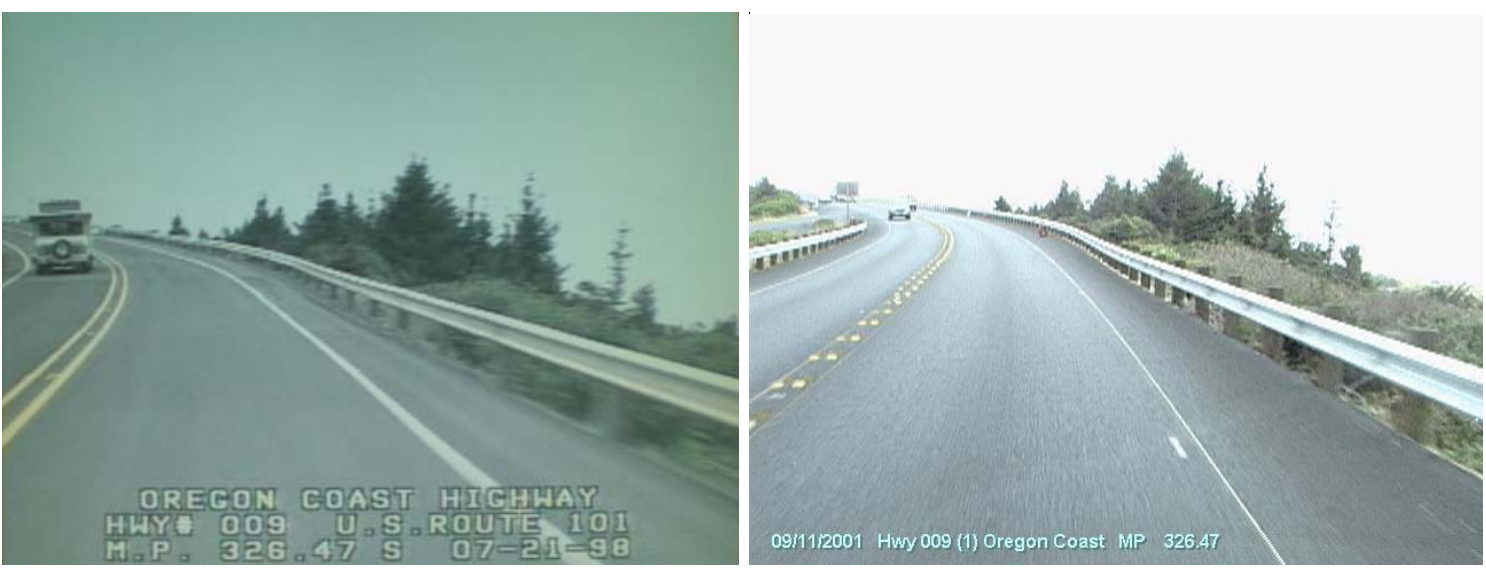

Figure 5.25: Conditions in 1998 (before) and 2001 (after) showing the preservation at MP 326.47

\subsubsection{Evaluation}

The project was evaluated according to the criteria for each metric and the results are summarized in Table 5.24. The project contained a SIP segment with a category of 2 for the estimated scope year. No years prior to construction contained a SIP category greater than 2. According to the criteria, this earned the project a funding eligibility score of 5 . The safety deficiencies and solutions were not defined and the constructed safety 
improvements were considered mandatory corrective measures; this resulted in a design score of 4 . Analysis of project expenditures indicated that the safety related items included guardrail Type 2a and 3; guardrail anchors, end pieces, transitions, and terminals; and durable striping totaling $\$ 327,000$. These expenditures totaled $20 \%$ of the construction costs; since the STIP planned a $40 \%$ use of safety funding, it appeared not all of the allocated safety funds were spent. Thus, the project was given an expenditure score of 3.

The safety-related data for the project are summarized in Figure 5.26A-E. Within the project limits there was not a substantial number of crashes. Total crashes increased from 5 to 18 in the before to after evaluation period. Fixed-object crashes were the most common which would support the addition of enhanced striping. However, fatal and injury A crashes increased from 1 to 4; all other crash severity types also increased. Overall, considering the increase in fatal and injury A crashes and the lack of improvement in any other crash area, the project was given a safety performance score of 5.

Table 5.24: Project Scorecard, US 101-Nesika Beach to Rogue River, Key No. 10817

\begin{tabular}{|c|c|c|c|c|c|c|c|}
\hline Metric & Score & \multicolumn{6}{|l|}{ Note } \\
\hline $\begin{array}{l}\text { Funding } \\
\text { Eligibility }\end{array}$ & 5 & \multicolumn{6}{|c|}{$\begin{array}{l}\text { The project contained a SIP segment with category of } 2 \text { for STIP years 1997- } \\
\text { 1999. No years prior to construction contained a category greater than } 2 \text {. }\end{array}$} \\
\hline Design & 4 & \multicolumn{6}{|c|}{$\begin{array}{l}\text { The project did not define the safety deficiencies and the proposed safety } \\
\text { solutions were vague. The constructed safety improvements (upgrading existing } \\
\text { guardrails) were mandatory corrective measures. The durable striping could be } \\
\text { considered “enhancement” if justification for lane-departure crashes was given } \\
\text { (it was not in the prospectus). }\end{array}$} \\
\hline \multirow[t]{4}{*}{ Expenditures } & 3 & \multicolumn{6}{|c|}{$\begin{array}{l}\text { The identified safety enhancements accounted for } 20 \% \text { of project construction } \\
\text { costs; } 40 \% \text { was planned. The costs are summarized (in 1,000s): }\end{array}$} \\
\hline & & & Total & Other & Other \% & Safety & Safety \% \\
\hline & & STIP & $\$ 3,100$ & $\$ 1,860$ & $60 \%$ & $\$ 1,240$ & $40 \%$ \\
\hline & & As-Built & $\$ 2,179$ & $\$ 1,749$ & $80 \%$ & $\$ 430$ & $20 \%$ \\
\hline Performance & 5 & \multicolumn{6}{|c|}{$\begin{array}{l}\text { No target crashes were identified. fatal and injury A crashes increased from } 1 \text { to } \\
4 \text {; all other severity types also increased as well. }\end{array}$} \\
\hline
\end{tabular}




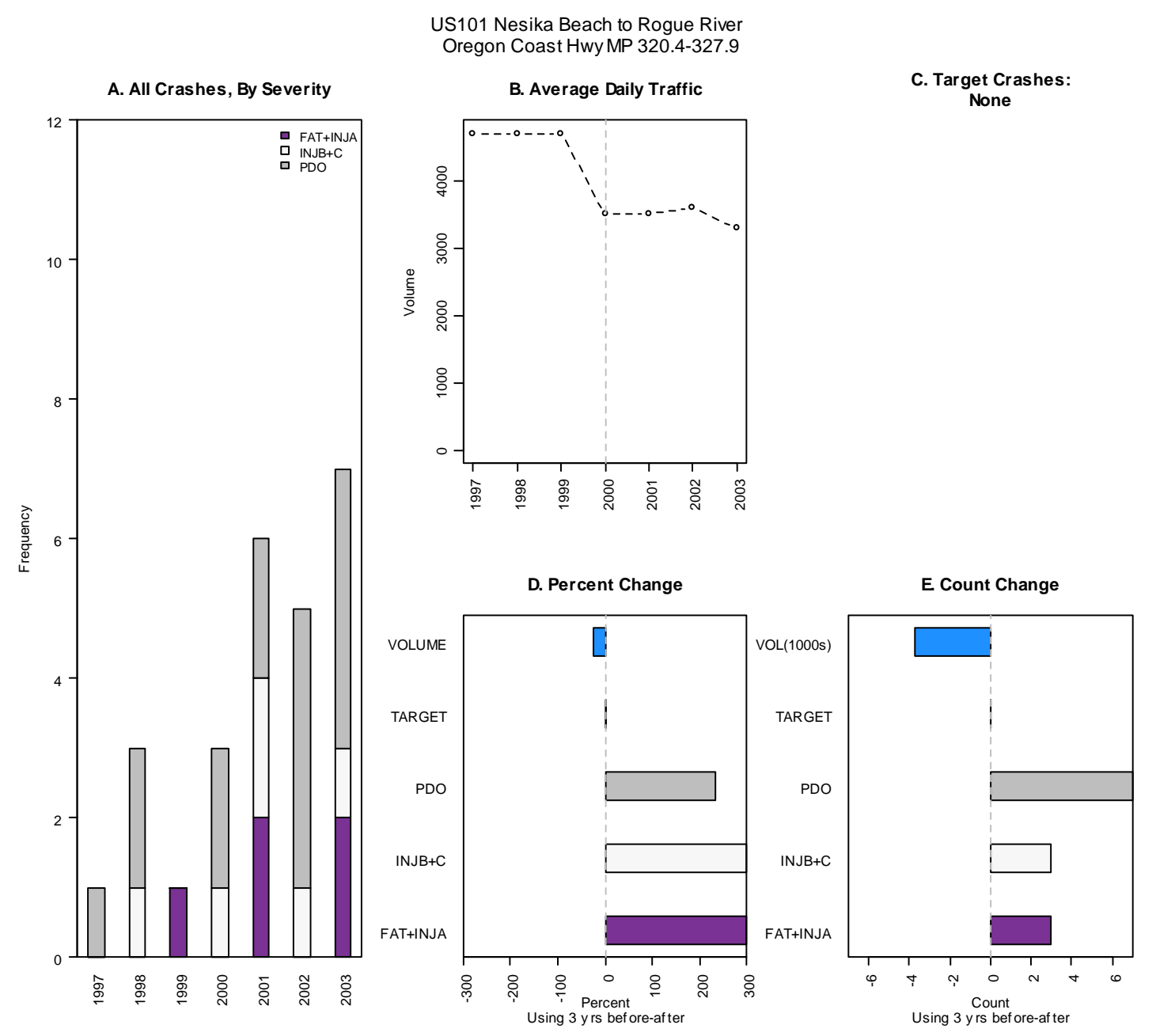

Figure 5.26: Safety Performance, US 101-Nesika Beach to Rogue River, Key No. 10817

\subsubsection{OR 126: Crooked River to Laughlin Rd (Prineville)}

\subsubsection{Description}

This 2.5 mile preservation project on OR 126 (Ochoco Highway) was constructed in 2002. A summary of the entire project from the project prospectus and STIP project files is shown in Table 5.25. The project area was of mostly urban character and was located in Region 4. An 18\% safety work type was identified in the STIP and prospectus. The project limits contained a segment with a SIP category of 4 and the project defined the safety deficiencies and the proposed safety solutions well. After reviewing the as-built plans and digital video logs it was determined that the constructed safety improvements included adding a traffic signal. This was considered an enhancement. Target crashes were identified as turning and angle crashes at the Combs Flat intersection at MP 19.75 (+-.05). Before and after photos from the digital video log are shown in Figure 5.27. 
Table 5.25: Project Summary, OR 126-Crooked River to Laughlin Rd, Key No. 11072

\begin{tabular}{|c|c|c|c|c|c|}
\hline $\begin{array}{l}\text { Key No. } \\
\text { Contract No. }\end{array}$ & $\begin{array}{l}11072 \\
12646\end{array}$ & Region & 4 & Funding & $\begin{array}{l}\text { Preservation 82\% } \\
\text { Safety } 18 \%\end{array}$ \\
\hline Highway & 041 Ochoco & MP & $18.00-20.50$ & $\begin{array}{l}\text { Construction } \\
\text { Year }\end{array}$ & 2002 \\
\hline $\begin{array}{l}\text { Estimated } \\
\text { Scope Year }\end{array}$ & 1999 & $\begin{array}{l}\text { SIP } \\
\text { Category } \\
\text { 1996-1998 }\end{array}$ & 4 & $\begin{array}{l}\text { SPIS Score } \\
1996-1998\end{array}$ & $\begin{array}{l}\text { Max: 59.05. MP } \\
19.66-19.76,90- \\
95 \%\end{array}$ \\
\hline $\begin{array}{l}\text { ODOT } \\
\text { Problem }\end{array}$ & \multicolumn{5}{|c|}{$\begin{array}{l}\text { The existing pavement on } 3^{\text {rd }} \text { Street (Hwy 26) is in poor condition and continues to } \\
\text { deteriorate. Fatigue, cracking, stripping, rutting and delamination are evident } \\
\text { throughout this section. There is a high accident rate at the Combs Flat intersection } \\
\text { due to increasing development along the Ochoco Highway and to the south along the } \\
\text { Paulina Highway. }\end{array}$} \\
\hline $\begin{array}{l}\text { ODOT } \\
\text { Proposed } \\
\text { Solution }\end{array}$ & \multicolumn{5}{|c|}{$\begin{array}{l}\text { The west end of the project starts at the east end of the Crooked River Bridge on Hwy } \\
126 \text { and at the intersection of Hwy } 26 \text { and } 6^{\text {th }} \text { Street. The east end of the project is at } \\
\text { the intersection of Laughlin Road and Hwy } 26 \text {. Center turn lane: } 40 \text { mm cold plane } \\
\text { pavement removal and } 40 \mathrm{~mm} \text { of level } 3,12.5 \mathrm{~mm} \text { dense JMAC Wearing Course } \\
\text { (lime treated). Travel lanes + } 0.6 \mathrm{~m}: 75 \mathrm{~mm} \text { of cold plane pavement removal and } \\
\text { inlay } 75 \mathrm{~mm} \text { of Level } 312.5 \text { dense HMAC wearing course (lime treated). } \\
\text { Intersection of Hwy } 41 \text { and Hwy 380: } 50 \mathrm{~mm} \text { of Level } 312.5 \mathrm{~mm} \text { dense HMAC } \\
\text { wearing course (lime treated, } 175 \mathrm{~mm} \text { of Level } 312.5 \mathrm{~mm} \text { dense HMAC Base } \\
\text { Course ( } 50 \mathrm{~mm}, 50 \mathrm{~mm}, 75 \mathrm{~mm} \text { lifts lime treated) } 350 \mathrm{~mm} \text { dense graded aggregate } \\
\text { base and subgrade geotextile. Install traffic signal and pedestrian facilities at } 41 / 380 \\
\text { intersection, add sidewalks and curb in front of Ochoco Plaza, and infill sidewalks } \\
\text { along } 41 \text { through town. }\end{array}$} \\
\hline $\begin{array}{l}\text { Design } \\
\text { Exceptions }\end{array}$ & \multicolumn{5}{|l|}{ None } \\
\hline $\begin{array}{l}\text { Constructed } \\
\text { Safety } \\
\text { Improvements }\end{array}$ & \multicolumn{3}{|c|}{ Install traffic signal at Highway $41 / 380$} & $\begin{array}{l}\text { Target } \\
\text { Crashes }\end{array}$ & $\begin{array}{l}\text { Turning and angle } \\
\text { at MP } 19.75(+- \\
.05)\end{array}$ \\
\hline \multirow{4}{*}{$\begin{array}{l}\text { Prospectus } \\
\text { Costs (000's) }\end{array}$} & $\mathrm{PE}$ & $\$ 127$ & \multirow{4}{*}{$\begin{array}{l}\text { STIP Costs } \\
\text { (000's) }\end{array}$} & \multirow{4}{*}{$\begin{array}{l}\text { PE } \\
\text { ROW } \\
\text { CON } \\
\text { TOTAL }\end{array}$} & $\$ 113$ \\
\hline & ROW & $\$ 51$ & & & $\$ 67$ \\
\hline & CON & $\$ 1,294$ & & & $\$ 1,488$ \\
\hline & TOTAL & $\$ 1,472$ & & & $\$ 1,668$ \\
\hline
\end{tabular}

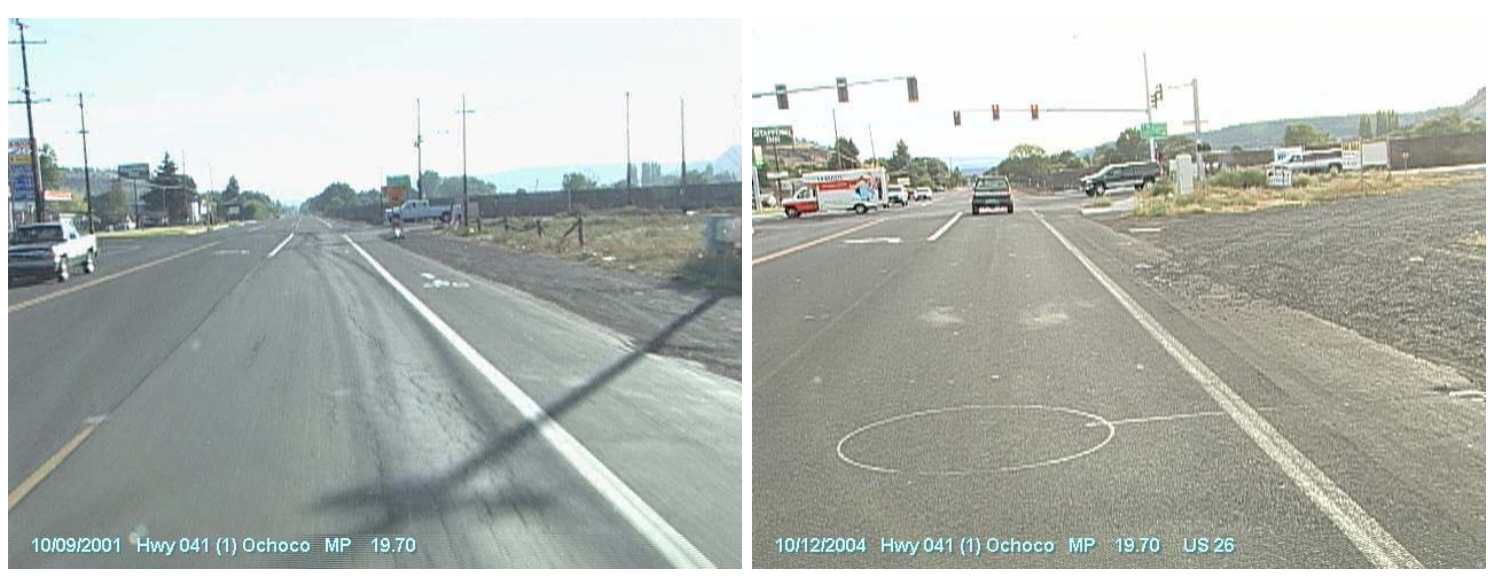

Figure 5.27: Conditions in 2001 (before) and in 2004 (after) showing the traffic signal installation at OR 126 and Combs Flat (MP 19.75) 


\subsubsection{Evaluation}

The project scored well in all four scoring metrics and the results are summarized in Table 5.26. The project included a segment with a SIP category of 4 and the addition of the traffic signal at OR 126 and Combs Flatwas considered an enhancement. Therefore, funding eligibility and design scores were given a 1 . Analysis of project expenditures indicated that safety costs for the traffic signal totaled $\$ 164,000$ (including shared costs), about $18 \%$ of construction costs. The STIP also planned an $18 \%$ use of safety funding. From the analysis, it appeared that the allocated safety funds were spent on the identified safety items. Thus, the project was given an expenditure score of 1 .

The safety-related data for the project are summarized in Figure 5.28A-E. At the intersection with Hwy 380, target crashes were identified as turning and angle crashes which are likely to be mitigated by a traffic signal. At this location, these crashes were reduced 33\%, from 6 to 4 in the three-year period before to after. Over the project limits, injury A crashes decreased from 3 to 2 (there were no fatal crashes). All other crash types and severities decreased (with the exception of pedestrian which increased from 2 to 5 all minor injury). Overall, it appeared that the project work resulted in improved safety. The project was given a safety performance score of 1 .

Table 5.26: Project Scorecard, OR 126-Crooked River to Laughlin Rd, Key No. 11072

\begin{tabular}{|c|c|c|c|c|c|c|c|}
\hline Metric & Score & \multicolumn{6}{|l|}{ Note } \\
\hline $\begin{array}{l}\text { Funding } \\
\text { Eligibility }\end{array}$ & 1 & \multicolumn{6}{|c|}{$\begin{array}{l}\text { The project contained a segment with a SIP category of } 4 \text { and was eligible for } \\
\text { safety funds. The SIP segment is from MP 15-20. }\end{array}$} \\
\hline Design & 1 & \multicolumn{6}{|c|}{$\begin{array}{l}\text { The project defined the safety deficiencies and the proposed safety solutions } \\
\text { well. The safety improvement (traffic signal installation) was an enhancement. }\end{array}$} \\
\hline \multirow[t]{4}{*}{ Expenditures } & 1 & \multicolumn{6}{|c|}{$\begin{array}{l}\text { The identified safety enhancements accounted for } 18 \% \text { of project construction } \\
\text { costs; } 18 \% \text { was planned. The costs are summarized (in } 1,000 \text { s): }\end{array}$} \\
\hline & & & Total & Other & Other \% & Safety & Safety \% \\
\hline & & STIP & $\$ 1,488$ & $\$ 1,220$ & $82 \%$ & $\$ 268$ & $18 \%$ \\
\hline & & As-Built & $\$ 910$ & $\$ 745$ & $82 \%$ & $\$ 164$ & $18 \%$ \\
\hline Performance & 1 & \multicolumn{6}{|c|}{$\begin{array}{l}\text { Target crashes were reduced } 33 \% \text { from } 6 \text { to } 4 \text { comparing the three-year before to } \\
\text { after periods. Over the project limits, injury A crashes decreased from } 3 \text { to } 2 \\
\text { (there were no fatal crashes). }\end{array}$} \\
\hline
\end{tabular}




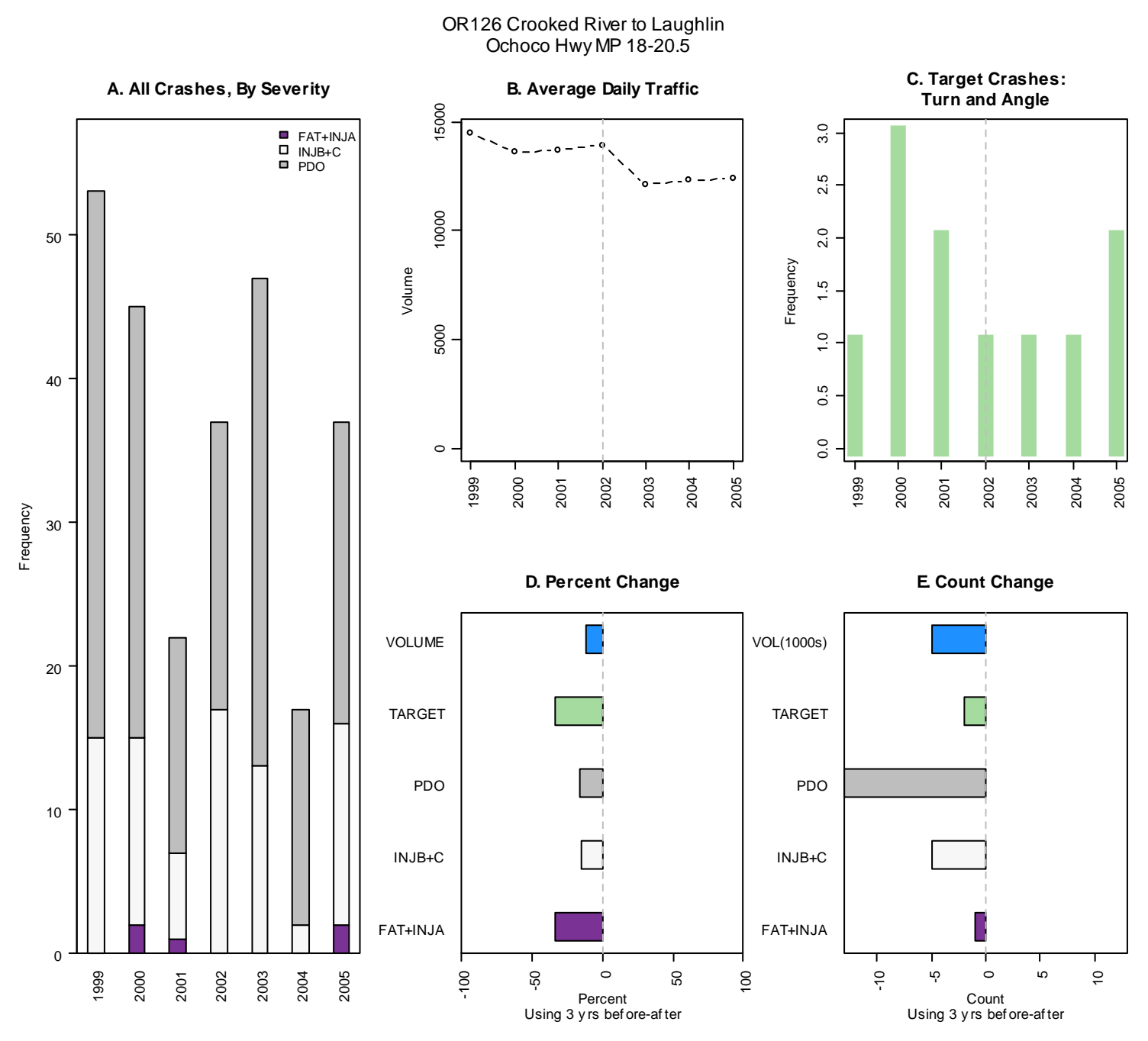

Figure 5.28: Safety Performance, OR 126-Crooked River to Laughlin Rd, Key No. 11072

\subsubsection{OR 211: Hult Rd to Hillockburn Rd}

\subsubsection{Description}

This 7.81 mile preservation project on OR 211 (Woodburn-Estacada Highway) was constructed in 2002. A summary of the entire project from the project prospectus and STIP project files is shown in Table 5.27. The project area was of mostly rural character and was located in Region 1. A 33\% safety work type was identified in the STIP and prospectus. The project limits contained a segment with a SIP category of 3. The project defined the safety deficiencies and the proposed safety solutions well. After reviewing the as-built plans and digital video logs the constructed safety improvements included adding and upgrading guardrails, upgrading culverts, adding durable markings, and adding shoulder width. These were considered enhancements. Before and after photos from the digital video log are shown in Figure 5.29 and Figure 5.30. 
Table 5.27: Project Summary, OR 211-Hult Rd to Hillockburn Rd, Key No. 11125

\begin{tabular}{|c|c|c|c|c|c|}
\hline $\begin{array}{l}\text { Key No. } \\
\text { Contract No. }\end{array}$ & $\begin{array}{l}11125 \\
12668\end{array}$ & Region & 1 & Funding & $\begin{array}{l}\text { Preservation 67\% } \\
\text { Safety 33\% }\end{array}$ \\
\hline Highway & $\begin{array}{l}161 \\
\text { Woodb } \\
\text { Estacad }\end{array}$ & MP & 20.89-28.70 & $\begin{array}{l}\text { Construction } \\
\text { Year }\end{array}$ & 2002 \\
\hline $\begin{array}{l}\text { Estimated } \\
\text { Scope Year }\end{array}$ & 2000 & $\begin{array}{l}\text { SIP } \\
\text { Category } \\
1997-1999 \\
\end{array}$ & 3 & $\begin{array}{l}\text { SPIS Score } \\
1997-1999\end{array}$ & $\begin{array}{l}\text { No SPIS scores in } \\
\text { the Top } 15 \%\end{array}$ \\
\hline $\begin{array}{l}\text { ODOT } \\
\text { Problem }\end{array}$ & \multicolumn{5}{|c|}{$\begin{array}{l}\text { The surfacing shows signs of fatigue cracking, moderate rutting, potholes and small } \\
\text { isolated areas of apparent structural failure. The culvert ends for the box culverts that } \\
\text { carry Milk Cr. and Little Cedar Cr. are located }<1 \mathrm{~m} \text { from the edge of pavement and } \\
\text { have been struck - one recently. These same culverts are potential obstructions to } \\
\text { fish passage. There are long sections without safety guardrail with numerous spots of } \\
\text { run-off-the-road evidence and without any shoulder; paved or otherwise. } \\
\text { Maintenance has documented the locations of several highway cross culverts that are } \\
\text { severely corroded and near failure. }\end{array}$} \\
\hline $\begin{array}{l}\text { ODOT } \\
\text { Proposed } \\
\text { Solution }\end{array}$ & \multicolumn{5}{|c|}{$\begin{array}{l}\text { Repave the existing surfacing according to the suggested pavements design. Extend } \\
\text { the box culvert ends as directed by the design engineer and include safety barrier or } \\
\text { guardrail across the top and culvert approaches. Install guardrail as directed by } \\
\text { design engineer based on the accident records and potential safety hazard. Construct } \\
\text { paved or gravel shoulder as directed by design engineer based on the accident } \\
\text { records and potential safety hazard. Replace highway cross culverts as directed by } \\
\text { the maintenance section. }\end{array}$} \\
\hline $\begin{array}{l}\text { Design } \\
\text { Exceptions }\end{array}$ & \multicolumn{5}{|c|}{$\begin{array}{l}\text { Shoulder width, horizontal curves \& superelevation, } 1.2 \text { m guardrail distance from } \\
\text { fogline @ bridge approaches, normal crown cross slope on Clear Creek bridge (MP } \\
\text { 27.33), curved bridge rail transition at SW end of clear creek bridge (MP 27.33). }\end{array}$} \\
\hline $\begin{array}{l}\text { Constructed } \\
\text { Safety } \\
\text { Improvements }\end{array}$ & \multicolumn{3}{|c|}{$\begin{array}{l}\text { Add and upgrade existing guardrail and } \\
\text { upgrade culverts, added shoulder width in } \\
\text { various locations, durable markings. }\end{array}$} & $\begin{array}{l}\text { Target } \\
\text { Crashes }\end{array}$ & $\begin{array}{l}\text { Lane departure } \\
\text { (off roadway) } \\
\text { entire project }\end{array}$ \\
\hline \multirow{4}{*}{$\begin{array}{l}\text { Prospectus } \\
\text { Costs (000's) }\end{array}$} & \multirow{4}{*}{$\begin{array}{l}\text { PE } \\
\text { ROW } \\
\text { CON } \\
\text { TOTAL }\end{array}$} & $\$ 180$ & \multirow{4}{*}{$\begin{array}{l}\text { STIP Costs } \\
\text { (000's) }\end{array}$} & \multirow{4}{*}{$\begin{array}{l}\text { PE } \\
\text { ROW } \\
\text { CON } \\
\text { TOTAL }\end{array}$} & \begin{tabular}{l|l} 
& $\$ 331$ \\
\end{tabular} \\
\hline & & & & & \\
\hline & & $\$ 2,5$ & & & $\$ 3,634$ \\
\hline & & $\$ 2,705$ & & & \\
\hline
\end{tabular}
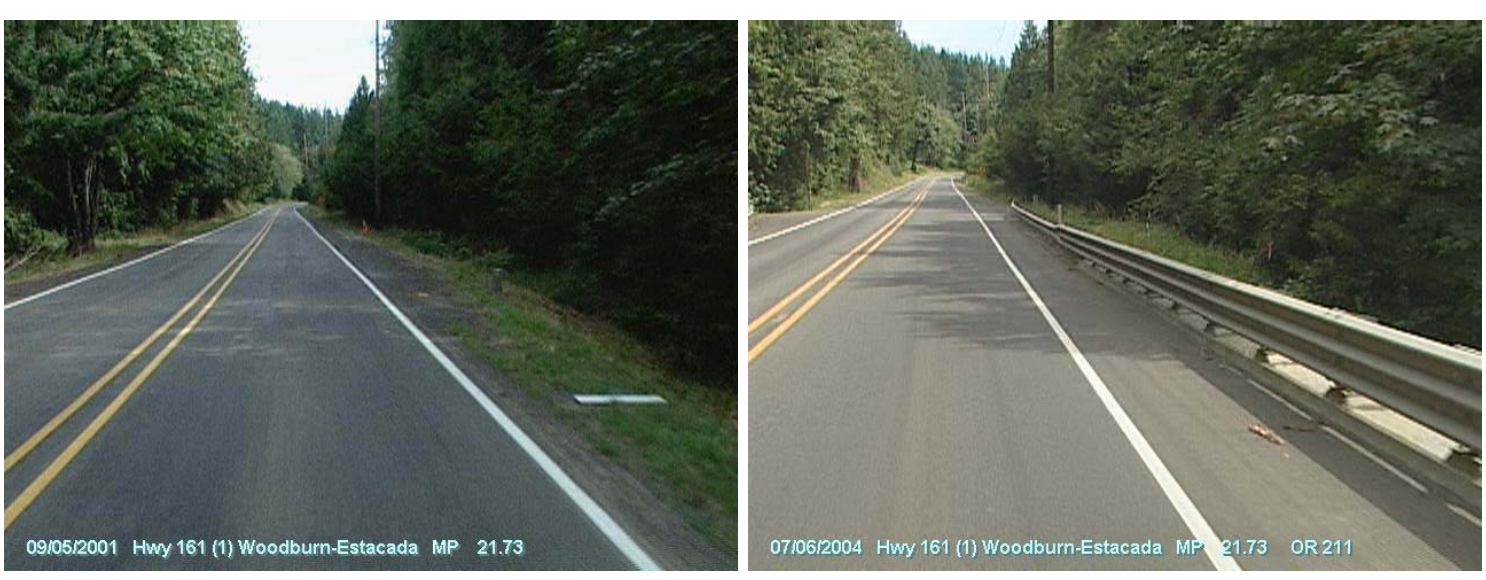

Figure 5.29: Conditions in 2001 (before) and in 2004 (after) showing the added guardrail/upgraded culvert at Milk Creek (MP 21.73) 

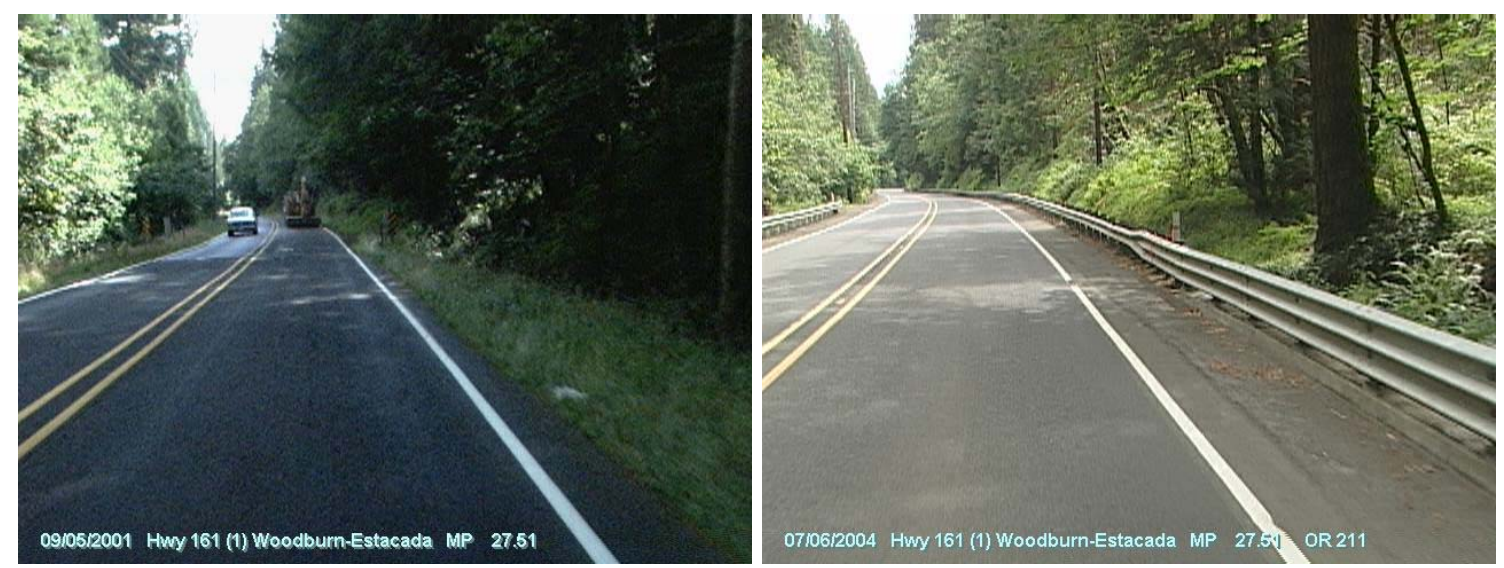

Figure 5.30: Conditions in 2001 (before) and in 2004 (after) showing the added guardrail/upgraded culvert at Little Cedar Creek (MP 27.51)

\subsubsection{Evaluation}

The project was evaluated and the results are summarized in Table 5.28. The project included a segment with a SIP category of 3 and the addition and upgrading of guardrail, durable striping, and culverts were considered enhancements. Therefore, the funding eligibility and design scores were given a score of 1 . The guardrail, culvert and shoulder widening work in these two areas totaled approximately $39 \%$ of the construction costs. The STIP planned a 33\% use of safety funding. Analysis of project expenditures indicated that the allocated safety funds were spent on safety items. Thus, the project was given an expenditure score of 1 .

The safety-related data for the project are summarized in Figure 5.31A-E. The addition of guardrail and improvements to the shoulder should improve lane departure (off-roadway) crashes. These were defined as the target crashes over the project limits. These crashes were reduced from 16 to $14(-13 \%)$. Additionally, over the project limits, fatal and injury A crashes decreased from 4 to 3 (-25\%). Exposure (volume) also decreased from the before to after periods. All crash severities also were reduced, with the exception of headon (increased from 1 to 2 ) and rear-end (1 to 3). Considering all metrics, it appears that the project work improved safety. The project was given a safety performance score of 1 . 
Table 5.28: Project Scorecard, OR 211-Hult Rd to Hillockburn Rd, Key No. 11125

\begin{tabular}{|c|c|c|c|c|c|c|c|}
\hline Metric & Score & \multicolumn{6}{|l|}{ Note } \\
\hline $\begin{array}{l}\text { Funding } \\
\text { Eligibility }\end{array}$ & 1 & \multicolumn{6}{|c|}{$\begin{array}{l}\text { The project contained a SIP segment with category of } 3 \text { and was eligible for } \\
\text { safety funds. }\end{array}$} \\
\hline Design & 1 & \multicolumn{6}{|c|}{$\begin{array}{l}\text { The project defined the safety deficiencies and the proposed safety solutions } \\
\text { well. The safety improvements (adding and upgrading guardrails and upgrading } \\
\text { culverts) were enhancements. }\end{array}$} \\
\hline \multirow[t]{4}{*}{ Expenditures } & 1 & \multicolumn{6}{|c|}{$\begin{array}{l}\text { The identified safety enhancements accounted for } 32 \% \text { of project construction } \\
\text { costs; } 33 \% \text { was planned. The costs are summarized (in 1,000s): }\end{array}$} \\
\hline & & & Total & Other & Other \% & Safety & Safety \% \\
\hline & & STIP & $\$ 3,634$ & $\$ 2,435$ & $67 \%$ & $\$ 1,199$ & $33 \%$ \\
\hline & & As-Built & $\$ 2,970$ & $\$ 1,816$ & $61 \%$ & $\$ 1,153$ & $39 \%$ \\
\hline Performance & 1 & \multicolumn{6}{|c|}{$\begin{array}{l}\text { Target crashes were identified as lane departure (off-roadway) for the project } \\
\text { limits. These crashes were reduced from } 16 \text { to } 14(-13 \%) \text {. Over the project } \\
\text { limits, fatal and injury A crashes decreased from } 4 \text { to } 3(-25 \%) \text {. }\end{array}$} \\
\hline
\end{tabular}

R211 Hult Rd to Hillockburn Woodburn-Estacada Hwy MP 20.89-28.7
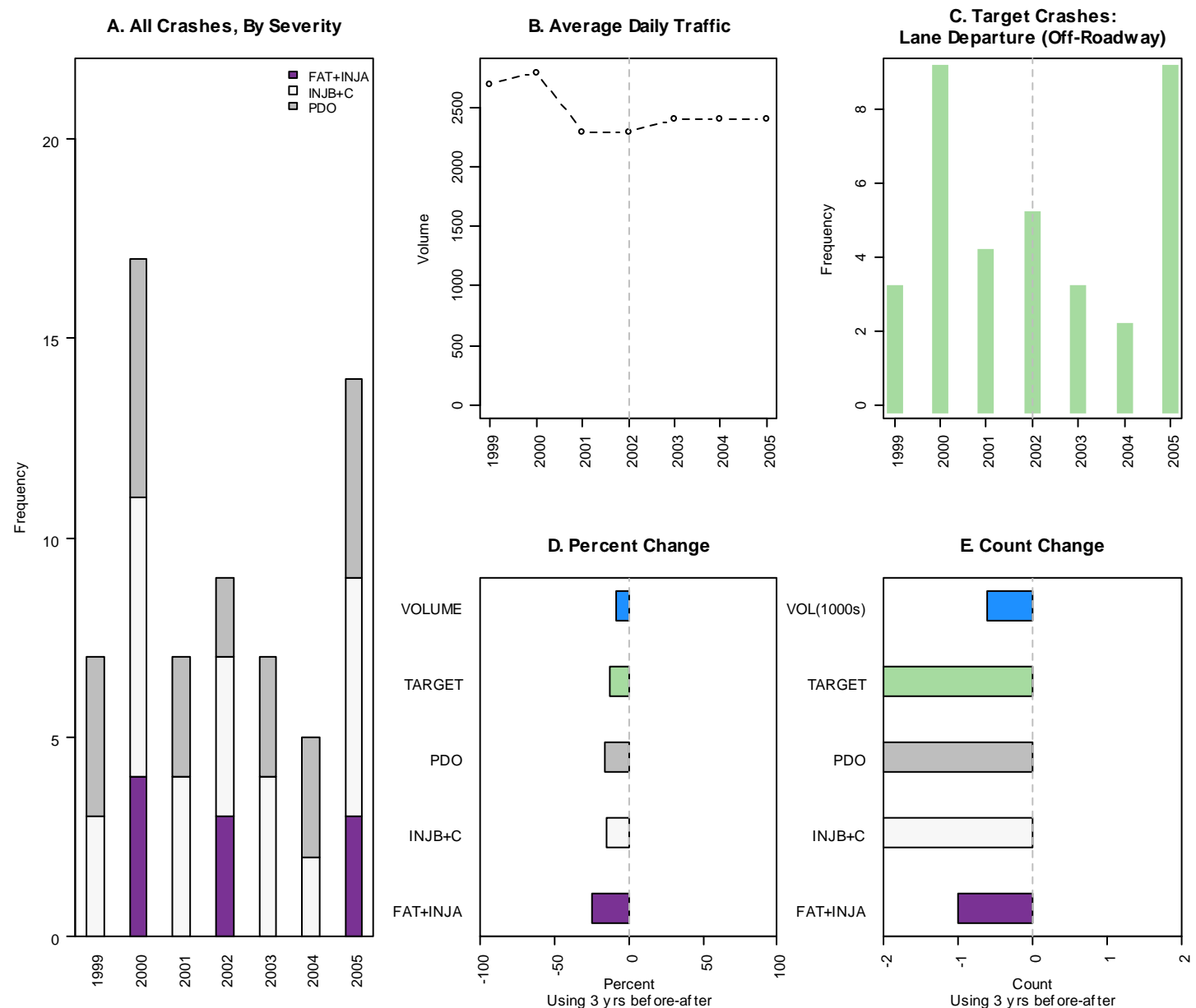

Figure 5.31: Safety Performance, OR 211-Hult Rd to Hillockburn Rd, Key No. 11125 


\subsubsection{OR 18: Oldsville Rd to Ash Rd}

\subsubsection{Description}

This 9.73 mile preservation project on OR 18 (Salmon River Highway) was constructed in 2005. A summary of the entire project from the project prospectus and STIP project files is shown in Table 5.29. The project area was of both rural and urban character and was located in Region 2. A 9\% safety work type was identified in the STIP and prospectus. The project limits contain a segment with a SIP category of 3 during the estimated scope year (note the prospectus indicates a SIP 4). The project defined the safety deficiencies and the proposed safety solutions. After reviewing the as-built plans and digital video logs, the constructed safety improvements included upgrading existing guardrails. These were considered mandatory corrective measures. No target crashes were identified. Before and after photos from the digital video log are shown in Figure 5.32 .

Table 5.29: Project Summary, OR 18-Oldsville Rd to Ash Rd, Key No. 11858

\begin{tabular}{|c|c|c|c|c|c|}
\hline $\begin{array}{l}\text { Key No. } \\
\text { Contract No. }\end{array}$ & $\begin{array}{l}11858 \\
13166 \\
\end{array}$ & Region & 2 & Funding & $\begin{array}{l}\text { Preservation 91\% } \\
\text { Safety 9\% }\end{array}$ \\
\hline Highway & $\begin{array}{l}\text { 039 Salmon } \\
\text { River }\end{array}$ & MP & $40.37-50.10$ & $\begin{array}{l}\text { Construction } \\
\text { Year }\end{array}$ & 2005 \\
\hline $\begin{array}{l}\text { Estimated } \\
\text { Scope Year }\end{array}$ & 2003 & $\begin{array}{l}\text { SIP } \\
\text { Category } \\
2000-2002\end{array}$ & 3 & $\begin{array}{l}\text { SPIS Score } \\
2000-2002\end{array}$ & $\begin{array}{l}\text { Max: 39.45, MP } \\
\text { 49.91, 85-90\% }\end{array}$ \\
\hline $\begin{array}{l}\text { ODOT } \\
\text { Problem }\end{array}$ & \multicolumn{5}{|c|}{$\begin{array}{l}\text { Pavement rating "moving to poor". Region paving priority ranking No. 6. Some } \\
\text { locations with substandard guardrail and guardrail connections need to be } \\
\text { upgraded. Most of the project limits are in highway sections with a SIP category of } 4 \text {. } \\
\text { Section from MP43.70 - MP } 45.85 \text { has severe cracking, pot holes and distortions } \\
\text { indicating structural failure. }\end{array}$} \\
\hline $\begin{array}{l}\text { ODOT } \\
\text { Proposed } \\
\text { Solution }\end{array}$ & \multicolumn{5}{|c|}{$\begin{array}{l}\text { MP 40.37-42.80: Resurface pavement per ODOT Pavement Section Design. The } \\
\text { work includes grinding in urban sections where necessary to maintain curb or barrier } \\
\text { height; upgrading guardrail where needed; and extending or removing cattlepass } \\
\text { structure (\# M025) at MP 43.75. Centerline and/or shoulder rumble strips shall be } \\
\text { installed where existing. There are two no work areas, MP 42.80-43.25 and MP } \\
\text { 43.78-45.89. }\end{array}$} \\
\hline $\begin{array}{l}\text { Design } \\
\text { Exceptions }\end{array}$ & \multicolumn{5}{|c|}{ None } \\
\hline $\begin{array}{l}\text { Constructed } \\
\text { Safety } \\
\text { Improvements }\end{array}$ & \multicolumn{3}{|c|}{ Upgrade existing guardrail } & $\begin{array}{l}\text { Target } \\
\text { Crashes }\end{array}$ & None identified \\
\hline \multirow{4}{*}{$\begin{array}{l}\text { Prospectus } \\
\text { Costs (000's) }\end{array}$} & $\mathrm{PE}$ & $\$ 421$ & \multirow{4}{*}{$\begin{array}{l}\text { STIP Costs } \\
\text { (000's) }\end{array}$} & \multirow{4}{*}{$\begin{array}{l}\text { PE } \\
\text { ROW } \\
\text { CON } \\
\text { TOTAL }\end{array}$} & $\$ 207$ \\
\hline & ROW & & & & $\$ 2$ \\
\hline & $\mathrm{CON}$ & $\$ 3,330$ & & & $\$ 3,490$ \\
\hline & TOTAL & $\$ 3,751$ & & & $\$ 3,699$ \\
\hline
\end{tabular}



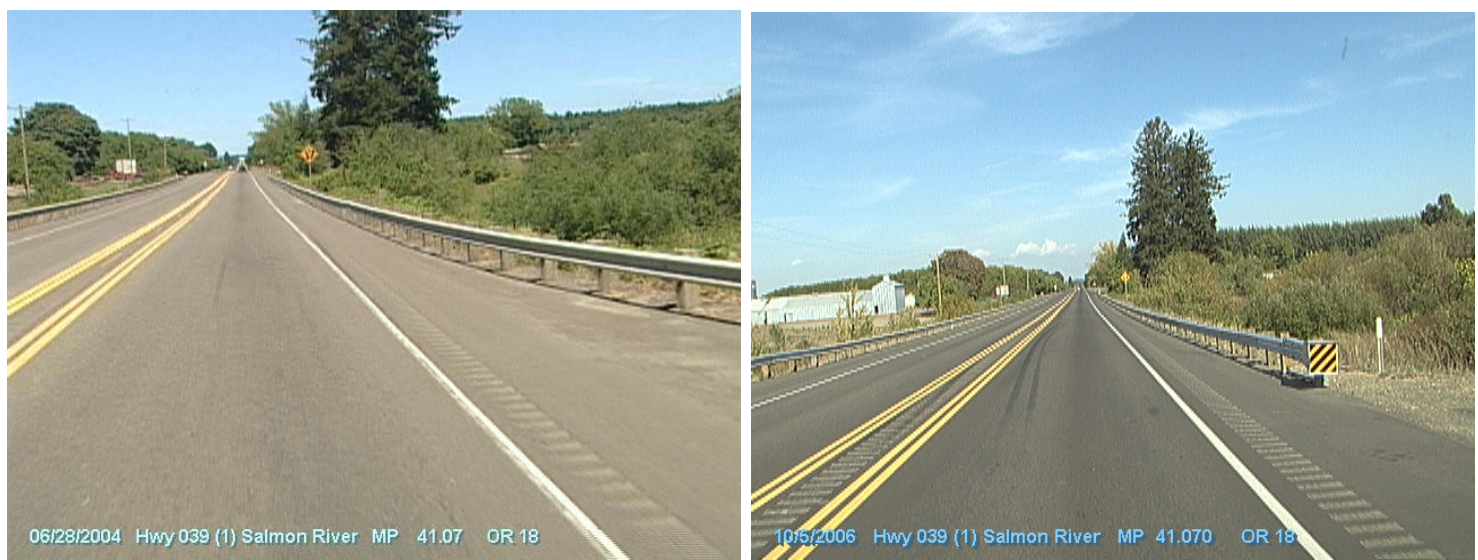

Figure 5.32: Conditions in 2004 (before) and in 2006 (after) showing the upgraded guardrail at MP 41.07

\subsubsection{Evaluation}

The project was evaluated and the results are summarized in Table 5.30. The project included a segment with a SIP category of 3, earning the project a funding eligibility score of 1 . The project defined the safety deficiencies and solutions; however the upgrade of existing guardrails was a mandatory corrective measure, resulting in a design score of 4.

In analyzing the project expenditures, the safety related items included upgrading existing guardrails, terminals and railings for a total of $\$ 73,000$. The actual safety costs constituted $5 \%$ of the construction costs, while the STIP planned a $9 \%$ use of safety funding. Analysis of project expenditures indicated that not all of the allocated safety funds were spent. Thus, the project was given an expenditure score of 3 . It should be noted that the estimated costs from the STIP and prospectus differed from the actual constructed costs ( $\$ 3.5 \mathrm{M}$ to $\$ 2.6 \mathrm{M})$.

The safety-related data for the project are summarized in Figure 5.33A-E. Based on the project description, no target crashes were identified. Over the project limits, in the two years before to after comparison period, fatal and injury A crashes were unchanged (5 in each period). Traffic volumes were also unchanged while other less severe crash types exhibited increases. However, since the fatal and injury A crashes were unchanged the project was given a safety performance score of 3 . 
Table 5.30: Project Scorecard, OR 18-Oldsville Rd to Ash Rd, Key No. 11858

\begin{tabular}{|c|c|c|c|c|c|c|c|}
\hline Metric & Score & \multicolumn{6}{|l|}{ Note } \\
\hline $\begin{array}{l}\text { Funding } \\
\text { Eligibility }\end{array}$ & 1 & \multicolumn{6}{|c|}{$\begin{array}{l}\text { The project contained a segment with a SIP Category of } 3 \text { and was eligible for } \\
\text { safety funds. }\end{array}$} \\
\hline Design & 4 & \multicolumn{6}{|c|}{$\begin{array}{l}\text { The project defined the safety deficiencies and the proposed safety solutions. } \\
\text { The safety improvements (upgrading guardrails and connections) are mandatory } \\
\text { corrective measures. }\end{array}$} \\
\hline \multirow[t]{4}{*}{ Expenditures } & \multirow[t]{4}{*}{3} & \multicolumn{6}{|c|}{$\begin{array}{l}\text { The identified safety enhancements accounted for } 5 \% \text { of project construction } \\
\text { costs; } 9 \% \text { was planned. The costs are summarized (in 1,000s): }\end{array}$} \\
\hline & & & Total & Other & Other \% & Safety & Safety \% \\
\hline & & STIP & $\$ 3,490$ & $\$ 3,176$ & $91 \%$ & $\$ 314$ & $9 \%$ \\
\hline & & As-Built & $\$ 2,572$ & $\$ 2,447$ & $95 \%$ & $\$ 126$ & $5 \%$ \\
\hline Performance & 3 & \multicolumn{6}{|c|}{$\begin{array}{l}\text { No target crashes were identified. Fatal and injury A crashes were unchanged ( } 5 \\
\text { in each two-year before and after period). }\end{array}$} \\
\hline
\end{tabular}

A. All Crashes, By Severity

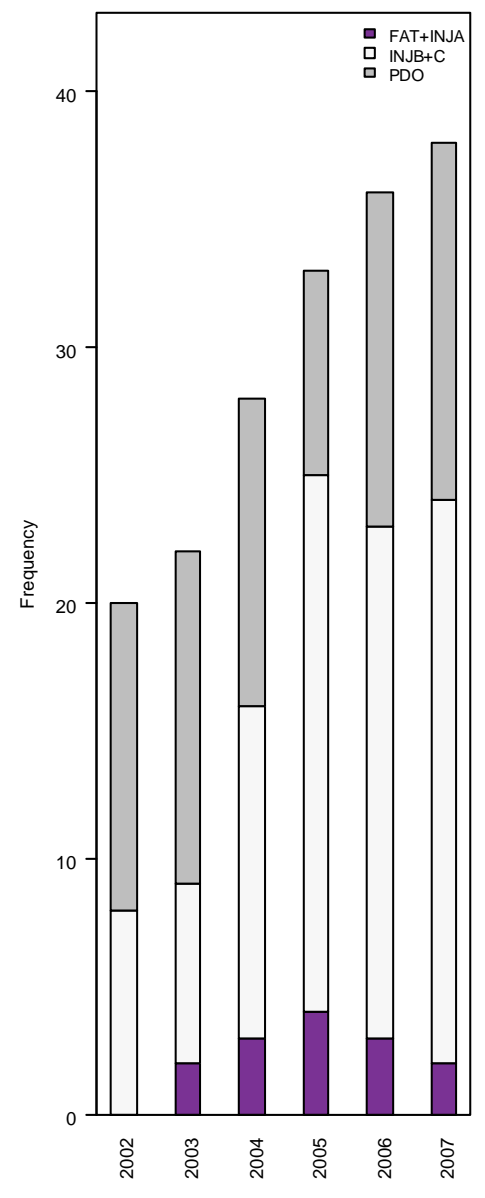

Salmon River Hwy MP 40.37-50.1

B. Average Daily Traffic

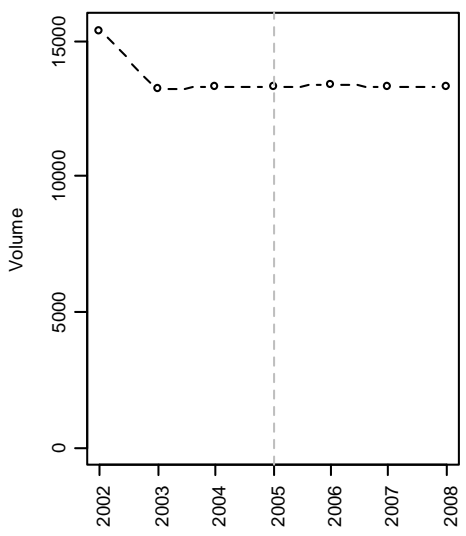

C. Target Crashes: None

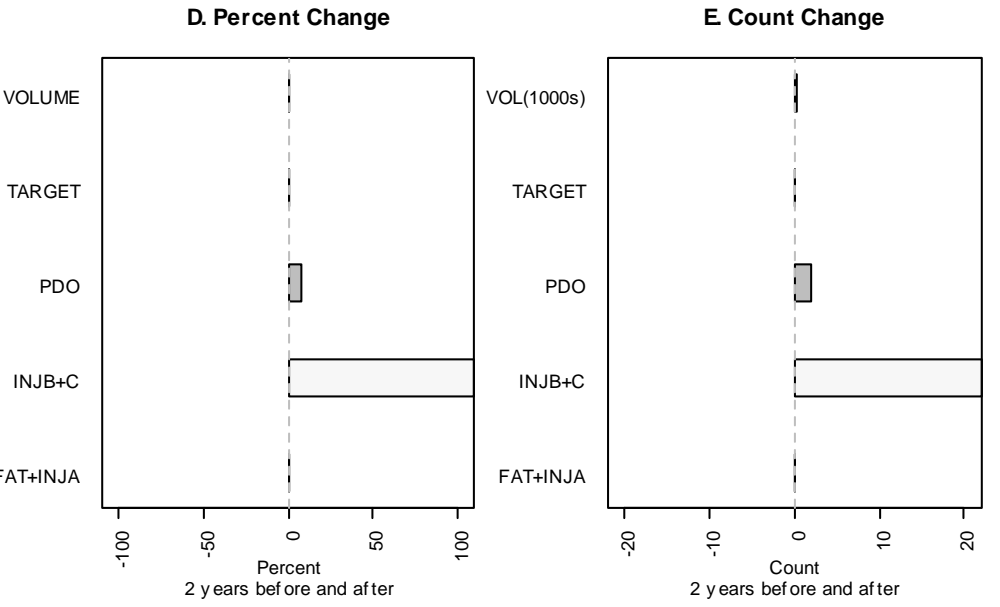

Figure 5.33: Safety Performance, OR 18-Oldsville Rd to Ash Rd, Key No. 11858 


\subsubsection{US 30: Bennett Rd to Laurel Ave}

\subsubsection{Description}

This 4.69 mile preservation project on US 30 (Lower Columbia River Highway) was constructed in 2004. A summary of the entire project from the project prospectus and STIP project files is shown in Table 5.31. The project area was of mostly rural character and was located in Region 1. A 19\% safety work type was identified in the STIP and prospectus. The project limits contained a segment with a SIP category of 4 . The project did not define the safety deficiencies and the proposed safety solutions were vague. After reviewing the as-built plans and digital video logs it was determined that the constructed safety improvements included upgrading existing guardrails, which were considered mandatory corrective measures. Before and after photos from the digital video log are shown in Figure 5.34.

Table 5.31: Project Summary, US 30-Bennett Rd to Laurel Ave, Key No. 11938

\begin{tabular}{|c|c|c|c|c|c|}
\hline $\begin{array}{l}\text { Key No. } \\
\text { Contract No. }\end{array}$ & $\begin{array}{l}11938 \\
12668 \\
\end{array}$ & Region & 1 & Funding & $\begin{array}{l}\text { Preservation } 81 \% \\
\text { Safety } 19 \%\end{array}$ \\
\hline Highway & $\begin{array}{l}\text { 092 Lower } \\
\text { Columbia } \\
\text { River }\end{array}$ & MP & 21.1-25.79 & $\begin{array}{l}\text { Construction } \\
\text { Year }\end{array}$ & 2004 \\
\hline $\begin{array}{l}\text { Estimated } \\
\text { Scope Year }\end{array}$ & 2001 & $\begin{array}{l}\text { SIP } \\
\text { Category } \\
1998-2000\end{array}$ & 4 & $\begin{array}{l}\text { SPIS Score } \\
1998-2000\end{array}$ & $\begin{array}{l}\text { Max:42.10, MP } \\
25.70-25.79,85- \\
90 \%\end{array}$ \\
\hline $\begin{array}{l}\text { ODOT } \\
\text { Problem }\end{array}$ & \multicolumn{5}{|c|}{$\begin{array}{l}\text { Pavement rating "moving to poor". The } 1999 \text { pavement rating was fair. Some surface } \\
\text { cracking is evident. It is expected that rutting and surface cracking will be more } \\
\text { prevalent by } 2005 \text {. }\end{array}$} \\
\hline $\begin{array}{l}\text { ODOT } \\
\text { Proposed } \\
\text { Solution }\end{array}$ & \multicolumn{5}{|c|}{$\begin{array}{l}50 \mathrm{~mm} \text { overlay with approximately } 100 \mathrm{~m} 2 \text { surface stabilization (200 mm HMAC } \\
\text { over } 250 \mathrm{~mm} \text { Aggregate Base). Replace waterproof membrane on two structures and } \\
\text { provide safety upgrades, as needed. Install durable striping including recessed } \\
\text { markers. Upgrade signing as needed. }\end{array}$} \\
\hline $\begin{array}{l}\text { Design } \\
\text { Exceptions }\end{array}$ & \multicolumn{5}{|c|}{ None } \\
\hline $\begin{array}{l}\text { Constructed } \\
\text { Safety } \\
\text { Improvements }\end{array}$ & \multicolumn{3}{|c|}{ Upgrade existing guardrail } & $\begin{array}{l}\text { Target } \\
\text { Crashes }\end{array}$ & None identified \\
\hline \multirow{4}{*}{$\begin{array}{l}\text { Prospectus } \\
\text { Costs (000's) }\end{array}$} & \multirow{4}{*}{$\begin{array}{l}\text { PE } \\
\text { ROW } \\
\text { CON } \\
\text { TOTAL }\end{array}$} & $\$ 283$ & \multirow{4}{*}{$\begin{array}{l}\text { STIP Cost } \\
\text { (000's) }\end{array}$} & \multirow{4}{*}{$\begin{array}{l}\text { PE } \\
\text { ROW } \\
\text { CON } \\
\text { TOTAL }\end{array}$} & $\$ 305$ \\
\hline & & $\$ 73$ & & & $\$ 82$ \\
\hline & & $\$ 2,828$ & & & $\$ 3,289$ \\
\hline & & $\$ 3,184$ & & & $\$ 3,676$ \\
\hline
\end{tabular}



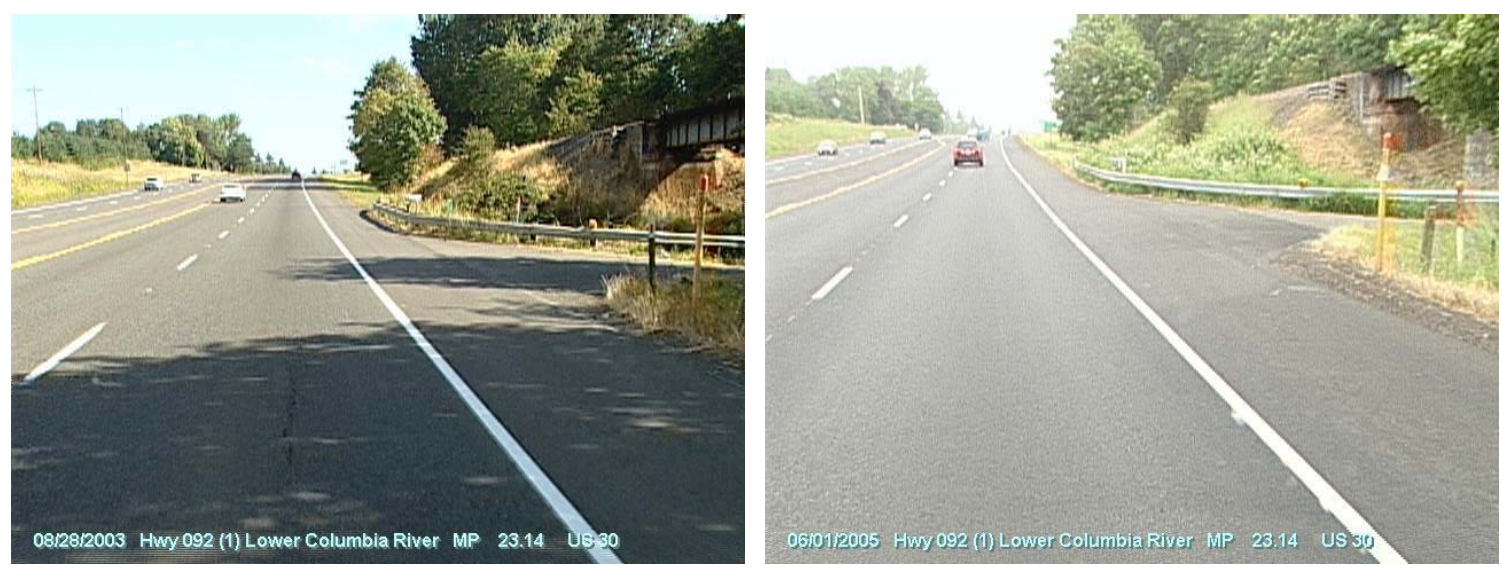

Figure 5.34: Conditions in 2003 (before) and in 2005 (after) showing the preservation work at MP 23.14

\subsubsection{Evaluation}

The project was evaluated according to the criteria for each metric and the results are summarized in Table 5.32. The project included a segment with a SIP category of 4 , earning the project a funding eligibility score of 1 . The upgrade of existing guardrails was a mandatory corrective measure, resulting in a design score of 4 . The project expenditures were analyzed and the safety related items included guardrails Type 2A, 3, 4 , guardrail transitions, and terminals which totaled $\$ 445,000$. The STIP planned a $19 \%$ use of safety funding and the actual safety costs only accounted for $9 \%$ of the construction costs. Analysis of project expenditures indicated that not all of the allocated safety funds were spent. Thus, the project was given an expenditure score of 3. It should be noted that the estimated costs from the STIP and prospectus differed from the actual constructed costs ( $\$ 3.3 \mathrm{M}$ to $\$ 2.1 \mathrm{M}$ ). The reason for this decrease in scope was not identified

The safety-related data for the project are summarized in Figure 5.35A-E. No target crashes were identified for the project. Over the project limits, fatal and injury A crashes increased $80 \%$ from 5 to 9 for the three-year before to after periods. Traffic volumes increased 2.5\% over the same period. Crashes of all other severities also increased. Based on these data, the project was given a safety performance score of 5 . 
Table 5.32: Project Scorecard, US 30-Bennett Rd to Laurel Ave, Key No. 11938

\begin{tabular}{|c|c|c|c|c|c|c|c|}
\hline Metric & Score & \multicolumn{6}{|l|}{ Note } \\
\hline $\begin{array}{l}\text { Funding } \\
\text { Eligibility }\end{array}$ & 1 & \multicolumn{6}{|c|}{$\begin{array}{l}\text { The project contained a segment with a SIP category of } 4 \text { and was eligible for } \\
\text { safety funds. }\end{array}$} \\
\hline Design & 4 & \multicolumn{6}{|c|}{$\begin{array}{l}\text { The project did not define the safety deficiencies and the proposed safety } \\
\text { solutions were vague. The constructed safety improvements (upgrading existing } \\
\text { guardrails) were mandatory corrective measures. }\end{array}$} \\
\hline \multirow[t]{4}{*}{ Expenditures } & 3 & \multicolumn{6}{|c|}{$\begin{array}{l}\text { The identified safety enhancements accounted for } 9 \% \text { of project construction } \\
\text { costs; } 19 \% \text { was planned. The costs are summarized (in 1,000s): }\end{array}$} \\
\hline & & & Total & Other & Other \% & Safety & Safety \% \\
\hline & & STIP & $\$ 3,289$ & $\$ 2,664$ & $81 \%$ & $\$ 625$ & $19 \%$ \\
\hline & & As-Built & $\$ 2,136$ & $\$ 1,946$ & $91 \%$ & $\$ 190$ & $9 \%$ \\
\hline Performance & 5 & \multicolumn{6}{|c|}{$\begin{array}{l}\text { No target crashes were identified for the project. Over the project limits, fatal } \\
\text { and injury A crashes increased } 80 \% \text { from } 5 \text { to } 9 \text { for the three-year before to after } \\
\text { periods. }\end{array}$} \\
\hline
\end{tabular}

US30 Bennett Rd to Laurel Ave

Lower Columbia River Hwy MP 21.1-25.79

A. All Crashes, By Severity

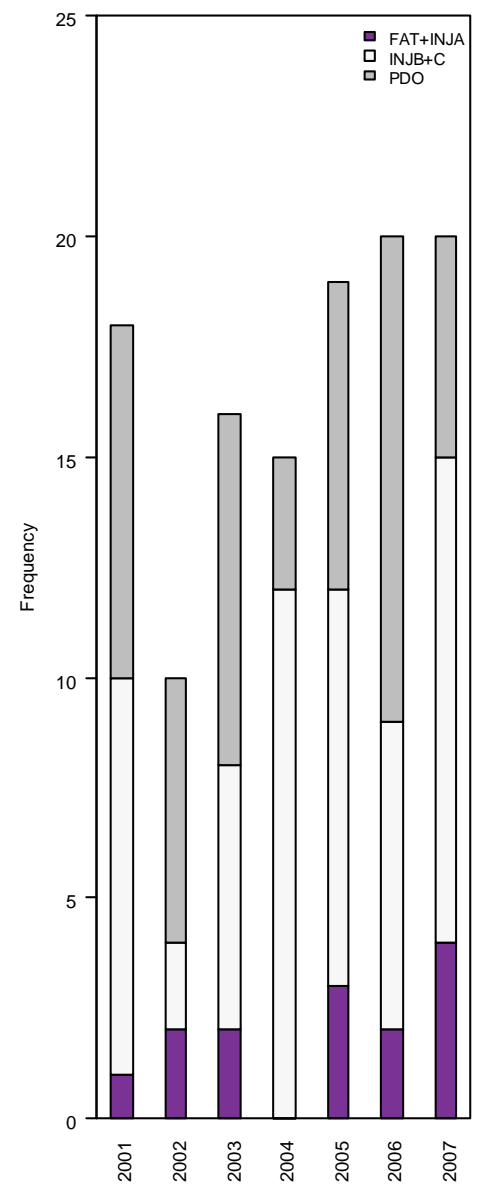

B. Average Daily Traffic

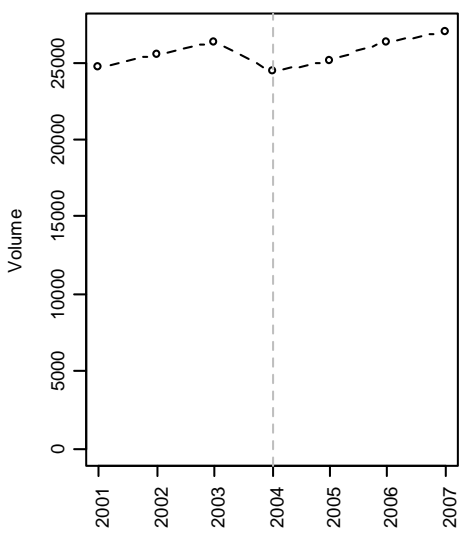

C. Target Crashes: None
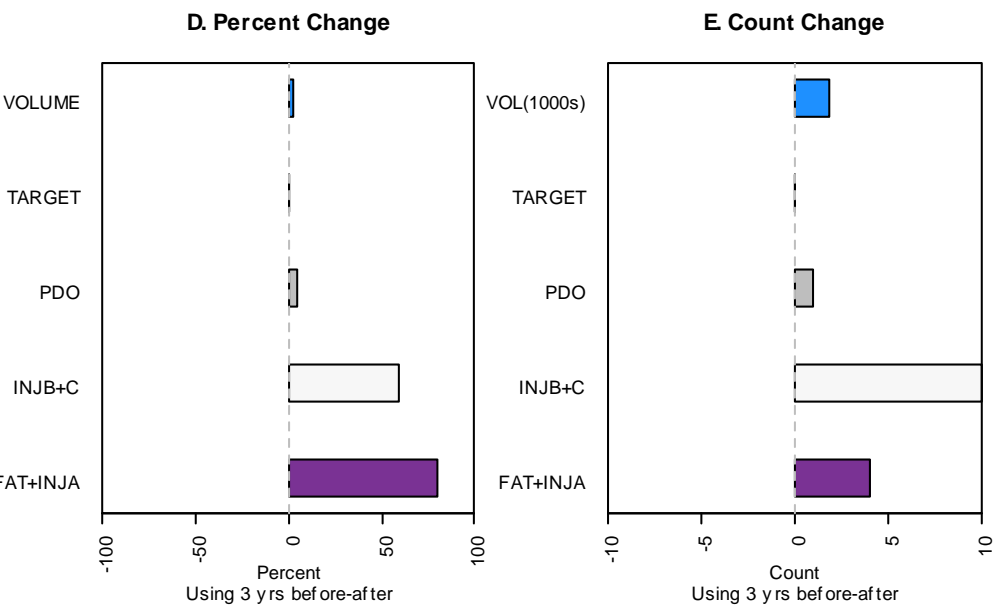

Figure 5.35: Safety Performance, US 30-Bennett Rd to Laurel Ave, Key No. 11938 


\subsubsection{OR 35: Jct Hood River Hwy to Polallie Creek}

\subsubsection{Description}

This 9.11 mile preservation project on OR 35 (Mt. Hood Highway) was constructed in 2005. A summary of the entire project from the project prospectus and STIP project files is shown in Table 5.33. The project area was of mostly rural character and was located in Region 1. A 24\% safety work type was identified in the STIP and prospectus. The project limits contained a segment with a SIP category of 3 . The prospectus mentions substandard and damaged guardrail but not specific safety problems. As such, no target crashes were identified. After reviewing the as-built plans and digital video logs the constructed safety improvements included upgrading existing guardrails. These were considered mandatory corrective measures. The project also contained durable markings. Since no lane departure problem was identified, these were not considered enhancements. Before and after photos from the digital video log are shown in Figure 5.36.

Table 5.33: Project Summary, OR 35-Jct Hood River Hwy to Polallie Creek, Key No. 11939

\begin{tabular}{|c|c|c|c|c|c|}
\hline $\begin{array}{l}\text { Key No. } \\
\text { Contract No. }\end{array}$ & $\begin{array}{l}11939 \\
13148\end{array}$ & Region & 1 & Funding & $\begin{array}{l}\text { Preservation } 76 \% \\
\text { Safety } 24 \%\end{array}$ \\
\hline Highway & 026 Mt. Hood & MP & 73.79-84.93 & $\begin{array}{l}\text { Construction } \\
\text { Year }\end{array}$ & 2005 \\
\hline $\begin{array}{l}\text { Estimated } \\
\text { Scope Year }\end{array}$ & 2002 & $\begin{array}{l}\text { SIP } \\
\text { Category } \\
1999-2001 \\
\end{array}$ & 3 & $\begin{array}{l}\text { SPIS Score } \\
1999-2001\end{array}$ & $\begin{array}{l}\text { Max: 45.88, MP } \\
74.94-75,85-90 \%\end{array}$ \\
\hline $\begin{array}{l}\text { ODOT } \\
\text { Problem }\end{array}$ & \multicolumn{5}{|c|}{$\begin{array}{l}\text { The pavement rating will be moving to poor by } 2005 \text {. The } 1999 \text { pavement rating was } \\
\text { fair. Note: This section contains an equation milepost at MP } 82.62 \text { that reduces the } \\
\text { length } 2.03 \text { miles. The highway crosses East Fork Hood River. Roadway runoff from } \\
\text { structures may contribute to reduced water quality. Below standard guardrail ends } \\
\text { and bridge connections. Some sections of guardrail are below the minimum height } \\
\text { and are damaged. }\end{array}$} \\
\hline $\begin{array}{l}\text { ODOT } \\
\text { Proposed } \\
\text { Solution }\end{array}$ & \multicolumn{5}{|c|}{$\begin{array}{l}\text { MP } 73.79 \text { to MP } 76 \text { and MP } 79.5 \text { to MP 84.93: } 50 \text { mm overlay, crack seal transverse } \\
\text { cracks. MP } 76.0 \text { to MP 79.5: } 75 \text { mm overlay, crack seal transverse cracks. Provide } \\
\text { water quality enhancements on structure if cost effective. Repair and upgrade all } \\
\text { guardrails and signs as required. }\end{array}$} \\
\hline $\begin{array}{l}\text { Design } \\
\text { Exceptions }\end{array}$ & \multicolumn{5}{|c|}{$\begin{array}{l}\text { 2' shoulders and waive the 2' shy distance next to guardrail. The minimum shoulder } \\
\text { width for this rural arterial is 3'. MP 82.62-84.93. }\end{array}$} \\
\hline $\begin{array}{l}\text { Constructed } \\
\text { Safety } \\
\text { Improvements }\end{array}$ & \multicolumn{3}{|c|}{$\begin{array}{l}\text { Upgrade existing guardrail; add durable } \\
\text { markings, }\end{array}$} & $\begin{array}{l}\text { Target } \\
\text { Crashes }\end{array}$ & None identified \\
\hline \multirow{4}{*}{$\begin{array}{l}\text { Prospectus } \\
\text { Costs (000's) }\end{array}$} & \multirow{4}{*}{$\begin{array}{l}\text { PE } \\
\text { ROW } \\
\text { CON } \\
\text { TOTAL }\end{array}$} & $\$ 366$ & \multirow{4}{*}{$\begin{array}{l}\text { STIP Cost } \\
\text { (000's) }\end{array}$} & \multirow{4}{*}{$\begin{array}{l}\text { PE } \\
\text { ROW } \\
\text { CON } \\
\text { TOTAL }\end{array}$} & $\$ 428$ \\
\hline & & & & & $\$ 58$ \\
\hline & & $\$ 3,665$ & & & $\$ 4,519$ \\
\hline & & $\$ 4,021$ & & & $\$ 5,005$ \\
\hline
\end{tabular}



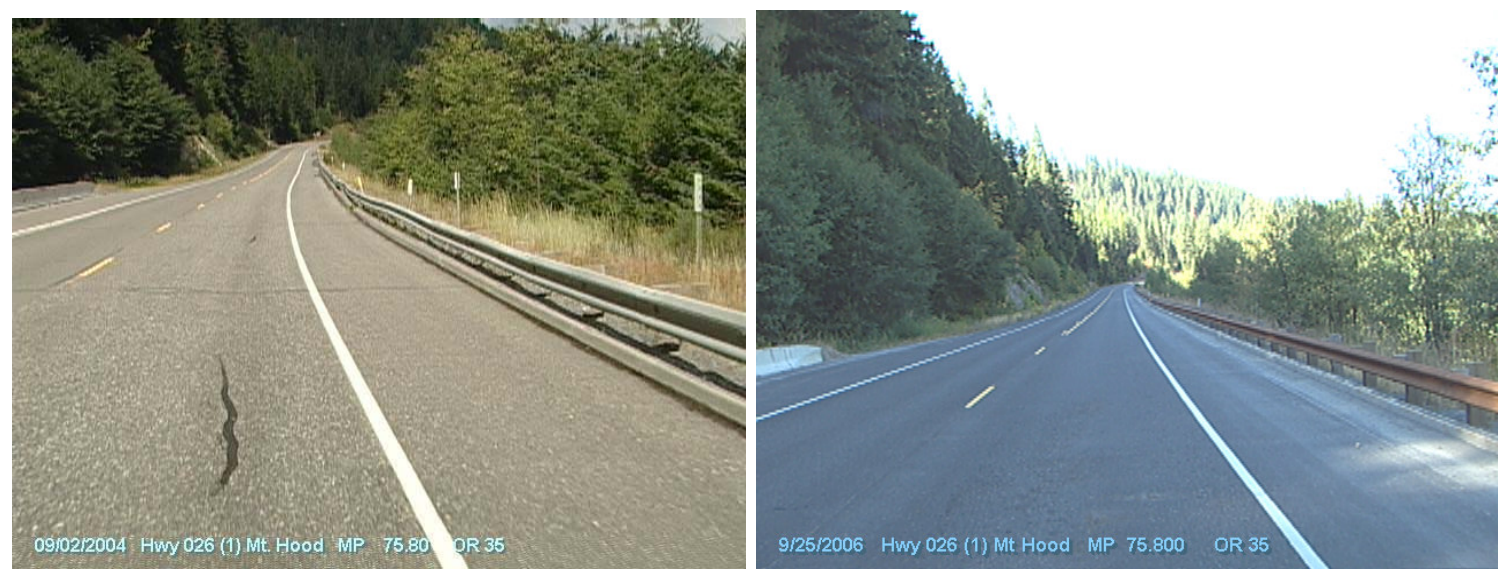

Figure 5.36: Conditions in 2004 (before) and in 2006 (after) showing the preservation work at MP 75.80

\subsubsection{Evaluation}

The project was evaluated according to the criteria for each metric and the results are summarized in Table 5.34. The project did include a segment with a SIP category of 3 in the estimated scope year. However, none of the adjacent years contained a segment with a SIP category of 3 (as shown in Table D.2 in the appendix). This project was unique in this respect. Therefore, rather than score the project a 1 by the strict criteria, the project was given a funding score of 3 to reflect that there was a possibility that the project did not meet the SIP criteria. The upgrade of existing guardrails was a mandatory corrective measure, resulting in a design score of 4 .

Analysis of project expenditures indicated that the safety related items included guardrail Type 2a; guardrail anchors, transitions, and terminals; removal and salvage of guardrail; durable markings, and beam rail retrofit. These expenditures totaled $28 \%$ of the construction costs, comparable to the STIP planned safety funding of $24 \%$. Thus, the project was given an expenditure score of 1 .

The safety-related data for the project are summarized in Figure 5.37A-E. No target crashes were identified. Fatal and injury A crashes increased from 1 to 2 (100\%) over the two-year before-after period (the third year was unavailable since the project was constructed in 2005). Traffic volumes declined. Total crashes decreased from 15 to 12; injury $\mathrm{B}$ and $\mathrm{C}$ and property damage only crashes also decreased. The project was given a safety performance score of 3 . (Note that $100 \%$ increase in the fatal and injury A crashes was only a count increase of 1.) 
Table 5.34: Project Scorecard, OR 35-Jct Hood River Hwy to Polallie Creek, Key No. 11939

\begin{tabular}{|c|c|c|c|c|c|c|c|}
\hline Metric & Score & \multicolumn{6}{|l|}{ Note } \\
\hline $\begin{array}{l}\text { Funding } \\
\text { Eligibility }\end{array}$ & 3 & \multicolumn{6}{|c|}{$\begin{array}{l}\text { The project contained a SIP segment with category of } 3 \text { for STIP years } 2000- \\
\text { 2002. However, adjacent years did not contain a SIP segment with category of } 3 .\end{array}$} \\
\hline Design & 4 & \multicolumn{6}{|c|}{$\begin{array}{l}\text { The prospectus only mentioned substandard and damaged guardrail and no } \\
\text { specific safety problems. The only safety improvements identified (upgrading } \\
\text { existing guardrails) were mandatory corrective measures. }\end{array}$} \\
\hline \multirow[t]{4}{*}{ Expenditures } & \multirow[t]{4}{*}{1} & \multicolumn{6}{|c|}{$\begin{array}{l}\text { The identified safety enhancements accounted for } 22 \% \text { of project construction } \\
\text { costs; } 24 \% \text { was planned. The costs are summarized (in 1,000s): }\end{array}$} \\
\hline & & & Total & Other & Other \% & Safety & Safety \% \\
\hline & & STIP & $\$ 4,512$ & $\$ 3,4290$ & $76 \%$ & $\$ 1,173$ & $24 \%$ \\
\hline & & As-Built & $\$ 2,514$ & $\$ 1,814$ & $72 \%$ & $\$ 701$ & $28 \%$ \\
\hline Performance & 3 & \multicolumn{6}{|c|}{$\begin{array}{l}\text { No target crashes were identified. Fatal and injury A crashes increased from } 1 \text { to } \\
2(100 \%) \text { over the two-year before-after period. }\end{array}$} \\
\hline
\end{tabular}

US26 Hood River Hwy to Pollalie $\mathrm{Cr}$

Mt Hood Hwy MP 73.79-84.93
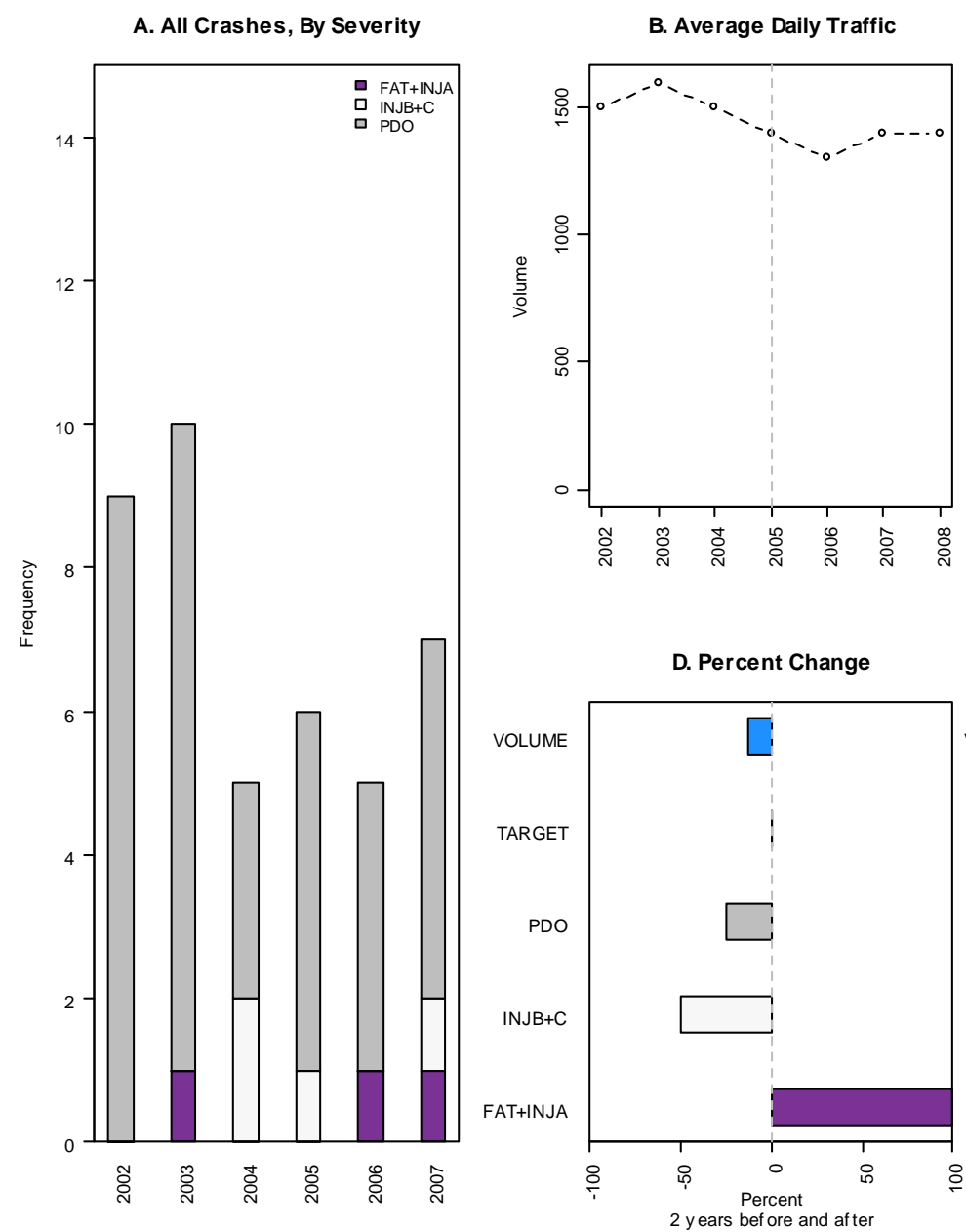

C. Target Crashes:
None

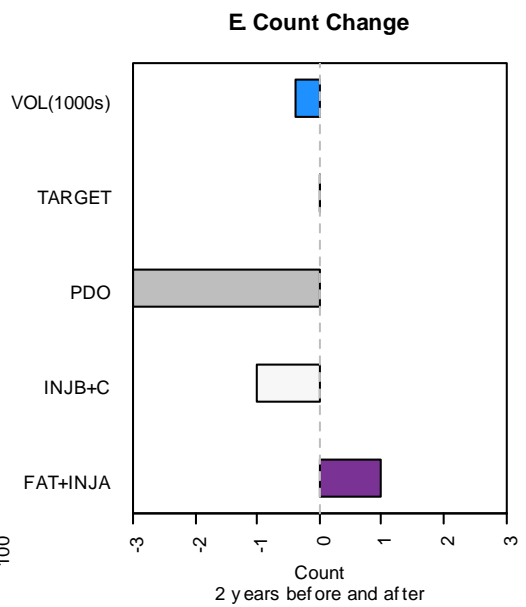

Figure 5.37: Safety Performance, OR 35-Jct Hood River Hwy to Polallie Creek, Key No. 11939 


\subsubsection{OR 35: Long Prairie Rd to Odell Hwy}

\subsubsection{Description}

This 4.5 mile preservation project on OR 35 (Mt. Hood Highway) was constructed in 2005. A summary of the entire project from the project prospectus and STIP project files is shown in Table 5.35. The project area was of mostly rural character and was located in Region 1. A 21\% safety work type was identified in the STIP and prospectus. The project limits contained a segment with a SIP category of 2 . The project did not define the safety deficiencies and the proposed safety solutions were vague. No target crashes were identified. After reviewing the as-built plans and digital video logs the constructed safety improvements included upgrading existing guardrails. These are considered mandatory corrective measures. Before and after photos from the digital video log are shown in Figure 5.38.

Table 5.35: Project Summary, OR 35-Long Prairie Rd to Odell Hwy, Key No. 11940

\begin{tabular}{|c|c|c|c|c|c|}
\hline $\begin{array}{l}\text { Key No. } \\
\text { Contract No. }\end{array}$ & $\begin{array}{l}11940 \\
13098\end{array}$ & Region & 1 & Funding & $\begin{array}{l}\text { Preservation } 79 \% \\
\text { Safety } 21 \%\end{array}$ \\
\hline Highway & 026 Mt. Hood & MP & $91.5-96$ & $\begin{array}{l}\text { Construction } \\
\text { Year }\end{array}$ & 2005 \\
\hline $\begin{array}{l}\text { Estimated } \\
\text { Scope Year }\end{array}$ & 2002 & $\begin{array}{l}\text { SIP } \\
\text { Category } \\
\text { 1999-2001 }\end{array}$ & 2 & $\begin{array}{l}\text { SPIS Score } \\
1999-2001\end{array}$ & $\begin{array}{l}\text { No SPIS scores in } \\
\text { the Top } 15 \%\end{array}$ \\
\hline $\begin{array}{l}\text { ODOT } \\
\text { Problem }\end{array}$ & \multicolumn{5}{|c|}{ The pavement condition will move to a poor rating by 2005 . } \\
\hline $\begin{array}{l}\text { ODOT } \\
\text { Proposed } \\
\text { Solution } \\
\end{array}$ & \multicolumn{5}{|c|}{$\begin{array}{l}\text { MP } 91.5 \text { to 94: } 50 \text { mm inlay travel lanes. Restripe the Odell intersection. Safety } \\
\text { upgrades, i.e. guardrails. }\end{array}$} \\
\hline $\begin{array}{l}\text { Design } \\
\text { Exceptions }\end{array}$ & \multicolumn{5}{|c|}{$\begin{array}{l}\text { Stripe for a 12' NB travel lane instead of 14' at Odell intersection left turn lane. } \\
\text { Below standard shy distance. Standard shy distance is 2' for a 6' shoulder with } \\
\text { guardrail (various locations throughout section). Below standard horizontal curves } \\
\text { and spirals for safe speed design (STA 653+29, 677+10, 753+31, and 771+70). }\end{array}$} \\
\hline $\begin{array}{l}\text { Constructed } \\
\text { Safety } \\
\text { Improvements } \\
\end{array}$ & \multicolumn{3}{|c|}{ Upgrade existing guardrail } & $\begin{array}{l}\text { Target } \\
\text { Crashes }\end{array}$ & None identified \\
\hline \multirow{4}{*}{$\begin{array}{l}\text { Prospectus } \\
\text { Costs (000's) }\end{array}$} & $\mathrm{PE}$ & $\$ 284$ & \multirow{4}{*}{$\begin{array}{l}\text { STIP Costs } \\
\text { (000's) }\end{array}$} & \multirow{4}{*}{$\begin{array}{l}\text { PE } \\
\text { ROW } \\
\text { CON } \\
\text { TOTAL }\end{array}$} & $\$ 284$ \\
\hline & ROW & $\$ 50$ & & & $\$ 58$ \\
\hline & $\mathrm{CON}$ & $\$ 2,843$ & & & $\$ 2,862$ \\
\hline & TOTAL & $\$ 3,177$ & & & $\$ 3,204$ \\
\hline
\end{tabular}



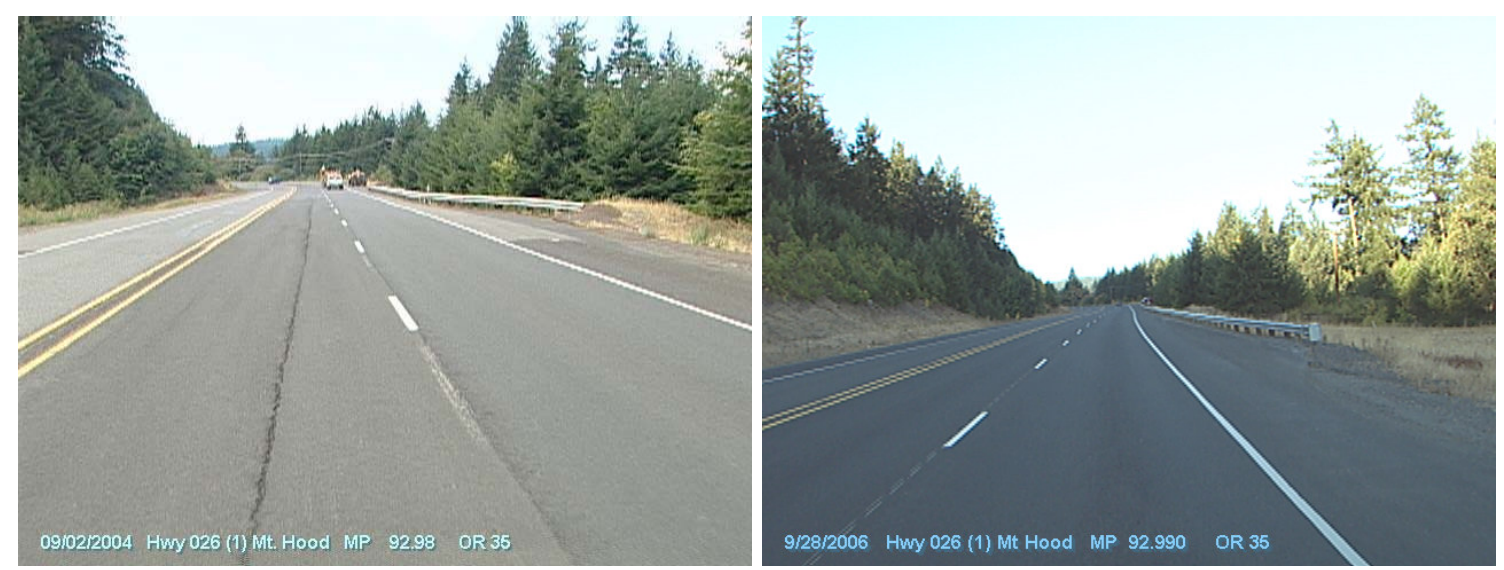

Figure 5.38: Conditions in 2004 (before) and in 2006 (after) showing upgraded guardrail at MP 92.98

\subsubsection{Evaluation}

The project was evaluated according to the criteria for each metric and the results are summarized in Table 5.36. The project did not include a segment with a SIP category of 3 during the estimated scope year (2002) and 2001. However, the 1998, 1999, and 2000 SIP years as well as 2003 and 2004 did include a SIP category 3 segment. Thus, the project was given a funding eligibility score of 1 . Since the upgrade of existing guardrails was a mandatory corrective measure, a design score of 4 was given.

The expenditure analysis found safety related items totaling $\$ 19,000$ and included guardrail Type 2a, terminals, and posts. These expenditures totaled $4 \%$ of the construction costs, much less than the planned STIP safety funding of $21 \%$. Therefore, since it appears that not all of the allocated safety funds were spent, the project was given an expenditure score of 3. It should be noted that the estimated costs from the STIP and prospectus differed substantially from the actual constructed costs ( $\$ 2.8 \mathrm{M}$ to $\$ 1 \mathrm{M})$.

The safety-related data for the project are summarized in Figure 5.39A-E. No target crashes were identified. Over the two-year before to after evaluation period, fatal and injury A crashes increased from 1 to 2 (100\%). All other crash severities and types also increased. Total crashes increased from 3 to 18 , while traffic volumes decreased 10\%. The project was given a safety performance score of 3 (the safety was judged not to have changed much for the fatal and injury A measure - the $100 \%$ is only a count increase of 1). 
Table 5.36: Project Scorecard, OR 35-Long Prairie Rd to Odell Hwy, Key No. 11940

\begin{tabular}{|c|c|c|c|c|c|c|c|}
\hline Metric & Score & \multicolumn{6}{|l|}{ Note } \\
\hline $\begin{array}{l}\text { Funding } \\
\text { Eligibility }\end{array}$ & 1 & \multicolumn{6}{|c|}{$\begin{array}{l}\text { The project contained a segment with a SIP category of 2; however, other years } \\
\text { did include a SIP category } 3 \text { segment so it was eligible for safety funds. }\end{array}$} \\
\hline Design & 4 & \multicolumn{6}{|c|}{$\begin{array}{l}\text { The project did not define the safety deficiencies and the proposed safety } \\
\text { solutions were vague. The constructed safety improvements (upgrading existing } \\
\text { guardrails) were mandatory corrective measures. }\end{array}$} \\
\hline \multirow[t]{4}{*}{ Expenditures } & \multirow[t]{4}{*}{3} & \multicolumn{6}{|c|}{$\begin{array}{l}\text { The identified safety enhancements accounted for } 4 \% \text { of project construction } \\
\text { costs; } 21 \% \text { was planned. The costs are summarized (in 1,000s): }\end{array}$} \\
\hline & & & Total & Other & Other \% & Safety & Safety \% \\
\hline & & STIP & $\$ 2,862$ & $\$ 2,261$ & $79 \%$ & $\$ 601$ & $21 \%$ \\
\hline & & As-Built & $\$ 998$ & $\$ 959$ & $96 \%$ & $\$ 38$ & $4 \%$ \\
\hline Performance & 3 & \multicolumn{6}{|c|}{$\begin{array}{l}\text { No target crashes were identified fatal and injury A crashes increased from } 1 \text { to } \\
2(100 \%) \text { over the two-year before-after period. }\end{array}$} \\
\hline
\end{tabular}

US26 Long Prairie Rd to Odell Hwy

Mt Hood Hwy MP 91.5-96
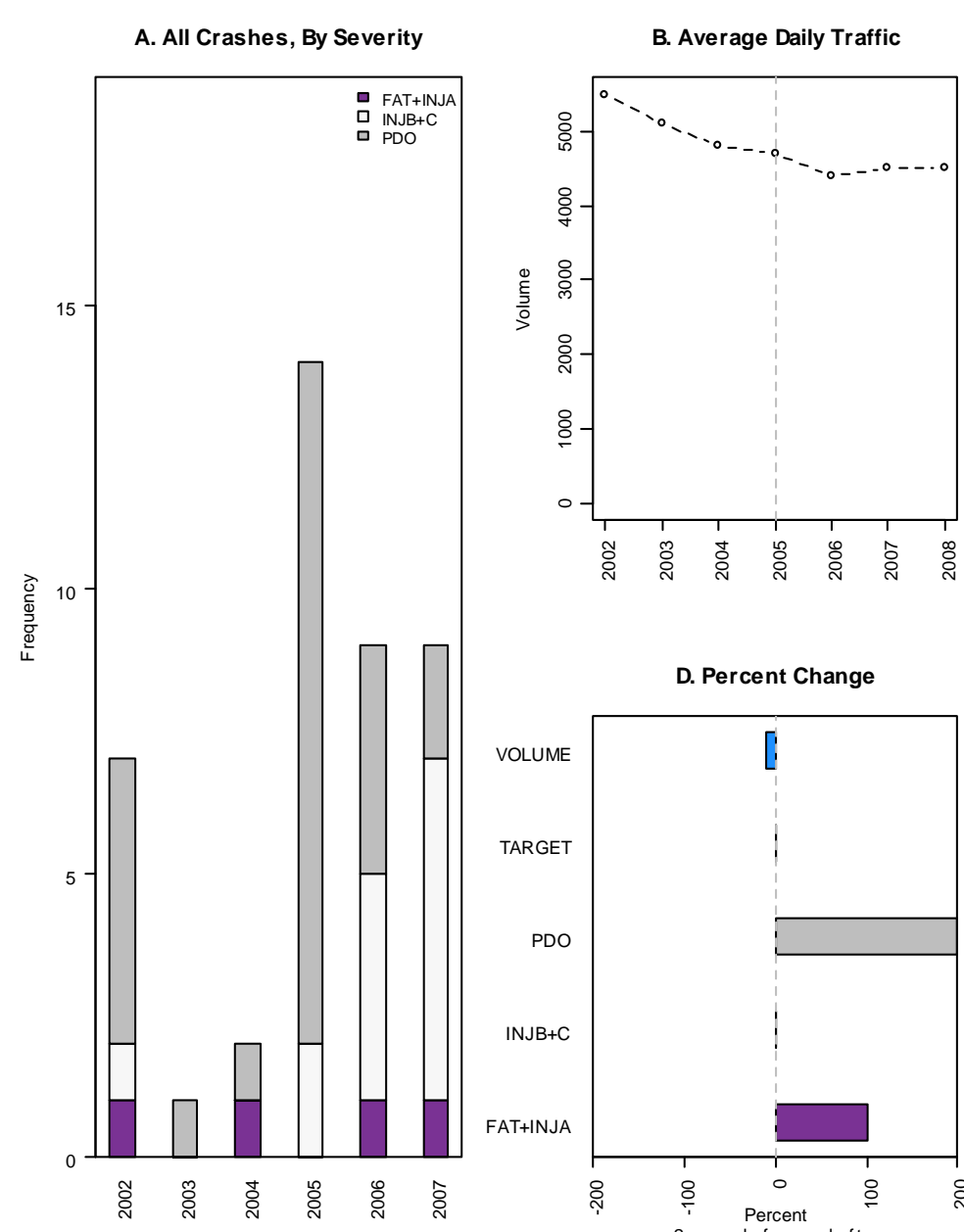

C. Target Crashes:

None

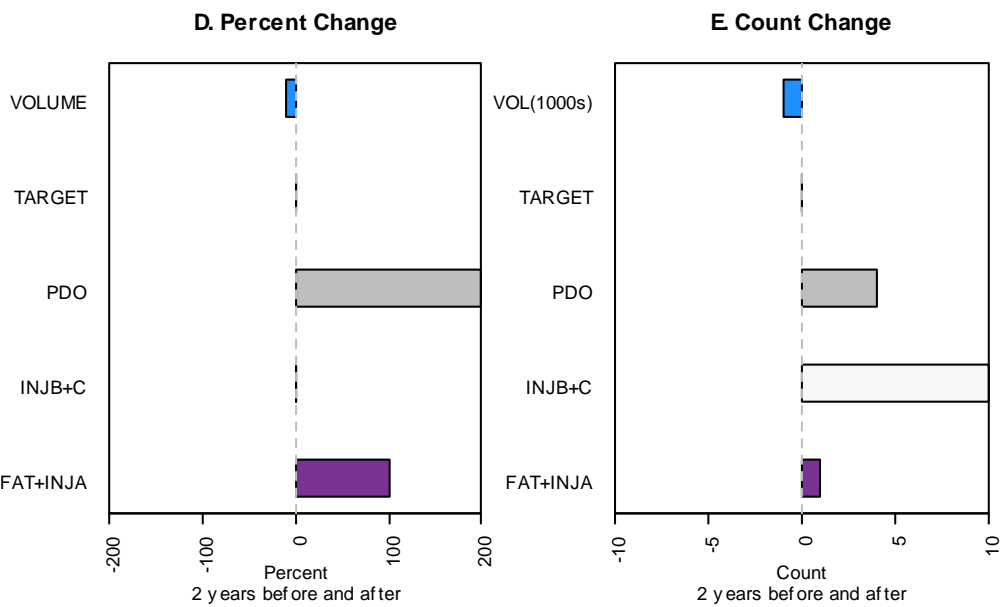

Figure 5.39: Safety Performance, OR 35-Long Prairie Rd to Odell Hwy, Key No. 11940 


\subsubsection{US 26: Jewell Jct to Military Rd}

\subsubsection{Description}

This 4.25 mile preservation project on the US 26 (Sunset Highway) was constructed in 2006. A summary of the entire project from the project prospectus and STIP project files is shown in Table 5.37. The project area was of mostly rural character and was located in Region 1. A 13\% safety work type was identified in the STIP and prospectus. The project limits contained a segment with a SIP category of 4 . The project did not define the safety deficiencies but the proposed safety solutions. After reviewing the as-built plans and digital video logs the constructed safety improvements included shoulder widening, new guardrail flares, and bridge rail replacement. These were considered enhancements. Target crashes were identified as lane-departure (off-roadway) crashes. Before and after photos from the digital video log are shown in Figure 5.40.

Table 5.37: Project Summary, US 26-Jewell Jct to Military Rd, Key No. 12856

\begin{tabular}{|c|c|c|c|c|c|}
\hline $\begin{array}{l}\text { Key No. } \\
\text { Contract No. }\end{array}$ & $\begin{array}{l}12856 \\
13216 \\
\end{array}$ & Region & 1 & Funding & $\begin{array}{l}\text { Preservation } 87 \% \\
\text { Safety } 13 \%\end{array}$ \\
\hline Highway & 047 Sunset & MP & 21.86-26.11 & $\begin{array}{l}\text { Construction } \\
\text { Year }\end{array}$ & 2006 \\
\hline $\begin{array}{l}\text { Estimated } \\
\text { Scope Year }\end{array}$ & 2004 & $\begin{array}{l}\text { SIP } \\
\text { Category } \\
\text { 2001-2003 }\end{array}$ & 4 & $\begin{array}{l}\text { SPIS Score } \\
2001-2003\end{array}$ & $\begin{array}{l}\text { No SPIS score in } \\
\text { the Top } 15 \%\end{array}$ \\
\hline & \multicolumn{5}{|c|}{ Pavement has intermittent patching and sporadic moderate to severe fatigue cracking. } \\
\hline $\begin{array}{l}\text { ODOT } \\
\text { Proposed } \\
\text { Solution }\end{array}$ & \multicolumn{5}{|c|}{$\begin{array}{l}\text { Overlay on US } 26 \text { Sunset Hwy. Project will include minimal shoulder widening and } \\
\text { turn out standardization in areas that have no ROW or environmental impact, new } \\
\text { guardrail flares, and replacement of the bridge rail on two bridge structures (No. } \\
02166 \text { and No. 02164). The Quartz Creek Bridge ice-warning signal system will not } \\
\text { be addressed as part of this pavement project. }\end{array}$} \\
\hline $\begin{array}{l}\text { Design } \\
\text { Exceptions }\end{array}$ & \multicolumn{5}{|c|}{$\begin{array}{l}\text { Vertical alignment at Osweg Slide (MP 22.75) fails to meet 3R requirements. } \\
\text { Shoulder widths are typically 3-4' throughout the section versus 6' standard. Bridge } \\
\text { No. } 02164 \text { at MP } 24.23 \text { has substandard roadway width (26' versus 30' standard) and } \\
\text { deficient bridge rails. Steep cut and fill slopes throughout the project. }\end{array}$} \\
\hline $\begin{array}{l}\text { Constructed } \\
\text { Safety } \\
\text { Improvements }\end{array}$ & \multicolumn{3}{|c|}{$\begin{array}{l}\text { Guardrail and bridge rail, shoulder widening } \\
\text { and turnouts }\end{array}$} & $\begin{array}{l}\text { Target } \\
\text { Crashes }\end{array}$ & $\begin{array}{l}\text { Lane departure (off } \\
\text { roadway) project } \\
\text { limits }\end{array}$ \\
\hline \multirow{4}{*}{$\begin{array}{l}\text { Prospectus } \\
\text { Costs (000's) }\end{array}$} & $\mathrm{PE}$ & $\$ 422$ & \multirow{4}{*}{$\begin{array}{l}\text { STIP Costs } \\
\text { (000's) }\end{array}$} & \multirow{4}{*}{$\begin{array}{l}\text { PE } \\
\text { ROW } \\
\text { CON } \\
\text { TOTAL }\end{array}$} & \begin{tabular}{l|l}
$\$ 422$ \\
\cline { 2 - 2 }
\end{tabular} \\
\hline & ROW & $\$ 27$ & & & $\$ 27$ \\
\hline & CON & $\$ 2,464$ & & & $\$ 2,795$ \\
\hline & TOTAL & $\$ 2,926$ & & & $\$ 3,244$ \\
\hline
\end{tabular}



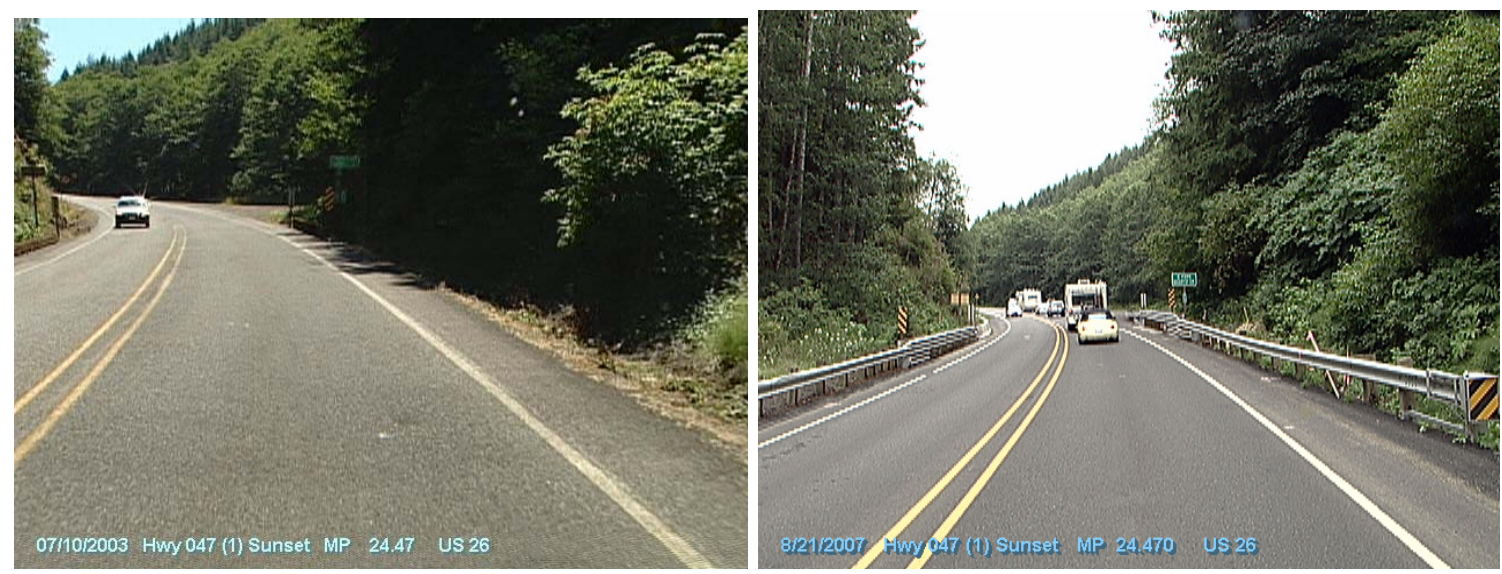

Figure 5.40: Conditions in 2003 (before) and in 2007 (after) showing the upgraded guardrail at Bridge No. 02166 at MP 24.47

\subsubsection{Evaluation}

The project was evaluated according to the criteria for each metric and the results are summarized in Table 5.38. The project included a segment with a SIP category of 4, earning the project a funding eligibility score of 1 . The project did not define the safety deficiencies but the proposed safety solutions (shoulder widening, new guardrail flares, and bridge rail replacement), which were considered enhancements, resulted in a design score of 4 .

In analyzing the project expenditures, the safety related items included guardrail Type 1; guardrail transitions, anchors, endpieces, and terminals; thrie beam steel rail; and asphalt and aggregate for shoulder widening and turnouts. These expenditures totaled $\$ 320,000$; approximately $26 \%$ of the construction costs. The STIP planned a $13 \%$ use of safety funding. Analysis of project expenditures indicated that the allocated safety funds were spent on the identified safety items. Thus, the project was given an expenditure score of 1.

The safety-related data for the project are summarized in Figure 5.41A-E. The project was constructed in 2006 so only one year of after crash data were available for comparison. No safety performance score was given. 
Table 5.38: Project Scorecard, US 26-Jewell Jct to Military Rd, Key No. 12856

\begin{tabular}{|c|c|c|c|c|c|c|c|}
\hline Metric & Score & \multicolumn{6}{|l|}{ Note } \\
\hline $\begin{array}{l}\text { Funding } \\
\text { Eligibility }\end{array}$ & 1 & \multicolumn{6}{|c|}{$\begin{array}{l}\text { The project contained a segment with a SIP category of } 4 \text { and was eligible for } \\
\text { safety funds. }\end{array}$} \\
\hline Design & 2 & \multicolumn{6}{|c|}{$\begin{array}{l}\text { The project did not define the safety deficiencies but the proposed safety } \\
\text { solutions were enhancements. The proposed safety improvements were } \\
\text { shoulder widening, new guardrail flares, and bridge rail replacement. }\end{array}$} \\
\hline \multirow[t]{4}{*}{ Expenditures } & 1 & \multicolumn{6}{|c|}{$\begin{array}{l}\text { The identified safety enhancements accounted for } 26 \% \text { of project construction } \\
\text { costs; } 13 \% \text { was planned. The costs are summarized (in 1,000s): }\end{array}$} \\
\hline & & & Total & Other & Other \% & Safety & Safety \% \\
\hline & & STIP & $\$ 2,795$ & $\$ 2,432$ & $87 \%$ & $\$ 363$ & $13 \%$ \\
\hline & & As-Built & $\$ 2,036$ & $\$ 1,505$ & $74 \%$ & $\$ 531$ & $26 \%$ \\
\hline Performance & NA & \multicolumn{6}{|c|}{ No safety performance score was given; only 1 year of after data was available. } \\
\hline
\end{tabular}

US26 Jewell Jct to Military Rd

Sunset Hwy MP 21.86-26

A. All Crashes, By Severity

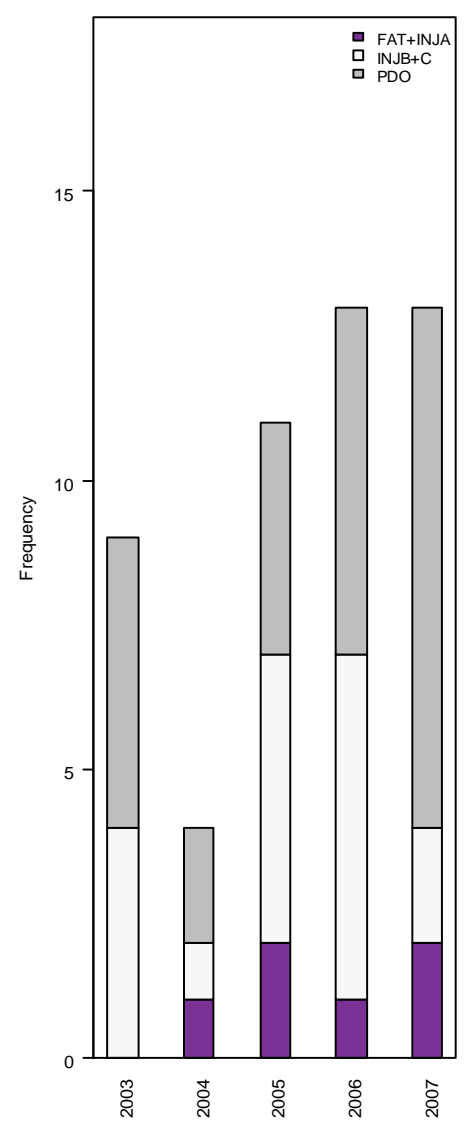

B. Average Daily Traffic

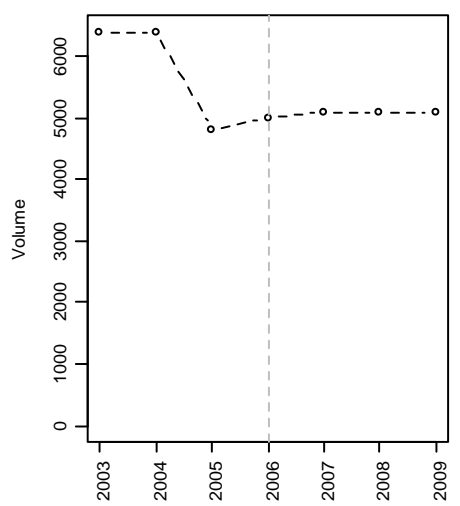

D. Percent Change

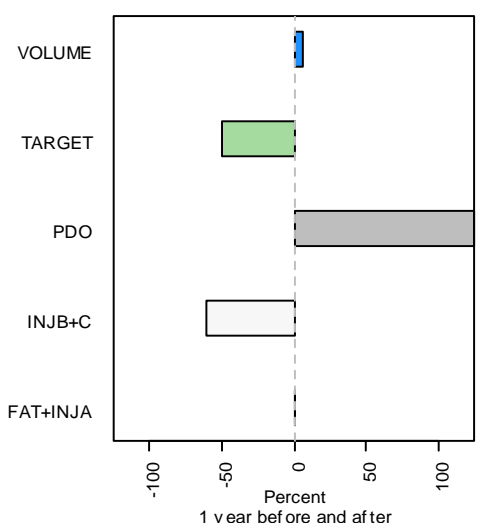

C. Target Crashes:
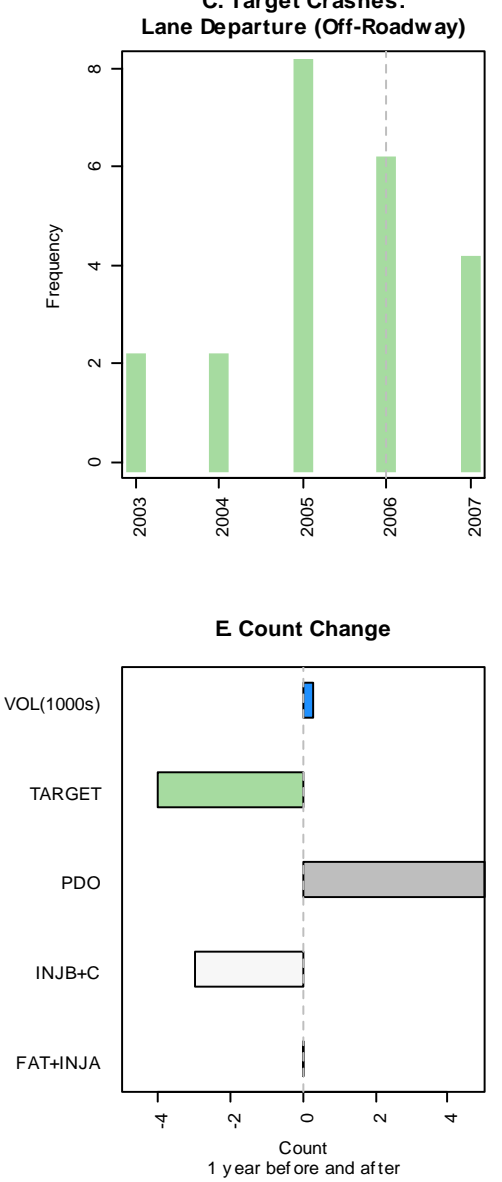

Figure 5.41: Safety Performance, US 26-Jewell Jct to Military Rd, Key No. 12856 


\subsubsection{OR 10: OR 217 to SW Maple Dr}

\subsubsection{Description}

This 0.13 mile preservation project on OR 10 (Beaverton-Hillsdale Highway) was constructed in 2004. A summary of the entire project from the project prospectus and STIP project files is shown in Table 5.39. The project area was of mostly urban character and was located in Region 1. A 44\% safety work type was identified in the STIP and prospectus. The project limits contained a segment with a SIP category of 4 . The project narrative defined the safety deficiencies and described the proposed safety solutions. After reviewing the as-built plans and digital video logs, it was determined that the constructed safety improvements included upgrading the signal at OR 217 and Beaverton-Hillsdale Highway and adding striping to allow a dual left-turn movement. These are considered enhancements. Target crashes were identified as sideswipe crashes from MP 0.99-1.05 (lane widening) and turning, rear-end and sideswipe on the connection 2 from MP 2.1-2.24 (dual left-turn lane). Before and after photos from the digital video log are shown in Figure 5.42. DVL photos are not available on the connection.

Table 5.39: Project Summary, OR 10-OR 217 to SW Maple Dr, Key No. 12905

\begin{tabular}{|c|c|c|c|c|c|}
\hline $\begin{array}{l}\text { Key No. } \\
\text { Contract No. }\end{array}$ & $\begin{array}{l}12905 \\
13048 \\
\end{array}$ & Region & 1 & Funding & $\begin{array}{l}\text { Preservation } 56 \% \\
\text { Safety } 44 \%\end{array}$ \\
\hline Highway & $\begin{array}{l}040 \\
\text { Beaverton- } \\
\text { Hillsdale }\end{array}$ & MP & 0.96-1.09 & $\begin{array}{l}\text { Construction } \\
\text { Year }\end{array}$ & 2004 \\
\hline $\begin{array}{l}\text { Estimated } \\
\text { Scope Year }\end{array}$ & 2003 & $\begin{array}{l}\text { SIP } \\
\text { Category } \\
2000-2002\end{array}$ & \multicolumn{2}{|l|}{4} & $\begin{array}{l}\text { Max: 79.60, MP } \\
0.97 \text { and } 1.05,95- \\
100 \%\end{array}$ \\
\hline $\begin{array}{l}\text { ODOT } \\
\text { Problem }\end{array}$ & \multicolumn{5}{|c|}{$\begin{array}{l}\text { The existing travel lanes under the Highway } 144 \text { (OR 217) over crossing are } \\
\text { substandard (narrow). A safety issue exists where drivers use two lanes on the OR } \\
217 \text { NB off ramp to make a left turn (WB) onto Beaverton Hillsdale Highway, even } \\
\text { though only one lane is signed as a left turn. }\end{array}$} \\
\hline $\begin{array}{l}\text { ODOT } \\
\text { Proposed } \\
\text { Solution }\end{array}$ & \multicolumn{5}{|c|}{$\begin{array}{l}\text { This project will maintain the current number of lanes but widen Beaverton Hillsdale } \\
\text { Highway in the area to create standard lane widths._The OR } 217 \text { NB off ramp signal } \\
\text { will be upgraded to allow dual left turns onto WB Beaverton Hillsdale Highway. }\end{array}$} \\
\hline $\begin{array}{l}\text { Design } \\
\text { Exceptions }\end{array}$ & \multicolumn{5}{|c|}{ None } \\
\hline $\begin{array}{l}\text { Constructed } \\
\text { Safety } \\
\text { Improvements }\end{array}$ & \multicolumn{3}{|c|}{$\begin{array}{l}\text { Upgrade signal to allow dual left turns at OR } \\
217 \text { and Beaverton Hillsdale Hwy }\end{array}$} & $\begin{array}{l}\text { Target } \\
\text { Crashes }\end{array}$ & $\begin{array}{l}\text { Turning, rear end, } \\
\text { and sideswipe }\end{array}$ \\
\hline \multirow{4}{*}{$\begin{array}{l}\text { Prospectus } \\
\text { Costs (000's) }\end{array}$} & \multirow{4}{*}{$\begin{array}{l}\text { PE } \\
\text { ROW } \\
\text { CON } \\
\text { TOTAL }\end{array}$} & $\$ 90$ & \multirow{4}{*}{$\begin{array}{l}\text { STIP Cost } \\
\text { (000's) }\end{array}$} & \multirow{4}{*}{$\begin{array}{l}\text { PE } \\
\text { ROW } \\
\text { CON } \\
\text { TOTAL }\end{array}$} & $\$ 90$ \\
\hline & & & & & $\$ 50$ \\
\hline & & $\$ 900$ & & & $\$ 980$ \\
\hline & & $\$ 990$ & & & $\$ 1,120$ \\
\hline
\end{tabular}



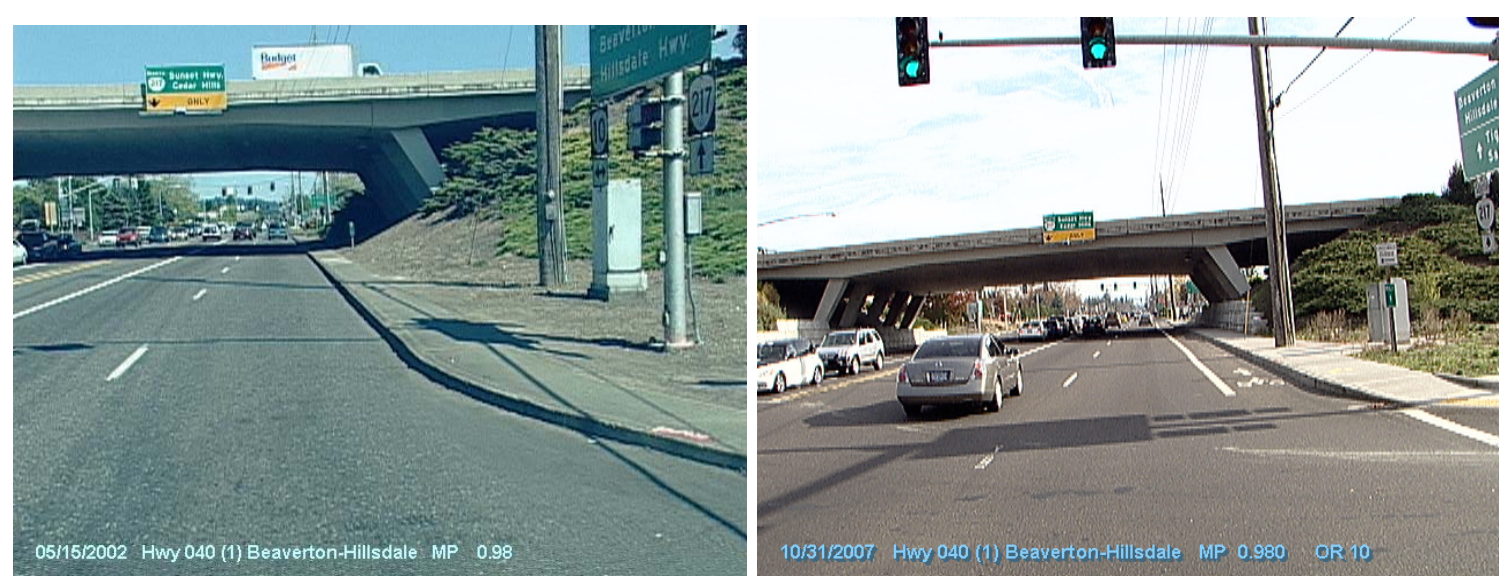

Figure 5.42: Conditions in 2002 (before) and in 2007 (after) showing construction at MP 0.98. Dualleft turn lanes at next connection not shown.

\subsubsection{Evaluation}

The project was evaluated and the results are summarized in Table 5.40. The project included a segment with a SIP category of 4 . The re-striping of lanes and the upgraded signal at OR 217 and Beaverton Hillsdale Highway were considered enhancements. The project received a funding eligibility score of 1 and design score of 1 .

The project expenditures were analyzed, and it was determined that the safety related items included the traffic signal modifications, lane widening, and the dual-left turn lane striping. These expenditures totaled $28 \%$ of the construction costs. The STIP planned a $46 \%$ use of safety funding. Analysis of project expenditures indicated that not all of the allocated safety funds were spent. Thus, the project was given an expenditure score of 3 .

The safety-related data for the project are summarized in Figure 5.43A-E. Target crashes increased from 6 to 9 (50\%) (this includes target crashes for both the lane widening and the addition of the dual-left turn lane). Fatal and injury A crashes increased from 1 to 2 (100\%). Injury B and C crashes also increased within the project limits. However, both of these increases (in terms of count) were small (3 target crashes and 1 fatal and injury A crash). Considering the above observations, the safety performance score given was 3 . 
Table 5.40: Project Scorecard, OR 10-OR 217 to SW Maple Dr, Key No. 12905

\begin{tabular}{|c|c|c|c|c|c|c|c|}
\hline Metric & Score & \multicolumn{6}{|l|}{ Note } \\
\hline $\begin{array}{l}\text { Funding } \\
\text { Eligibility }\end{array}$ & 1 & \multicolumn{6}{|c|}{$\begin{array}{l}\text { The project contained a segment with a SIP category of } 4 \text { and was eligible for } \\
\text { safety funds. }\end{array}$} \\
\hline Design & 1 & \multicolumn{6}{|c|}{$\begin{array}{l}\text { The project narrative defined the safety deficiencies and described the proposed } \\
\text { safety solutions. The safety improvements (restripe lanes and upgrade signal at } \\
\text { OR } 217 \text { and Beaverton Hillsdale Highway) were enhancements. }\end{array}$} \\
\hline \multirow[t]{4}{*}{ Expenditures } & 3 & \multicolumn{6}{|c|}{$\begin{array}{l}\text { The identified safety enhancements accounted for } 28 \% \text { of project construction } \\
\text { costs; } 44 \% \text { was planned. The costs are summarized (in 1,000s): }\end{array}$} \\
\hline & & & Total & Other & Other \% & Safety & Safety \% \\
\hline & & STIP & $\$ 980$ & $\$ 549$ & $56 \%$ & $\$ 431$ & $44 \%$ \\
\hline & & As-Built & $\$ 995$ & $\$ 672$ & $72 \%$ & $\$ 280$ & $28 \%$ \\
\hline Performance & 3 & \multicolumn{6}{|c|}{$\begin{array}{l}\text { Target crashes increased } 50 \% \text { within the project areas where the safety } \\
\text { improvements were constructed. Fatal and injury A crashes increased from } 1 \text { to } \\
2(100 \%)\end{array}$} \\
\hline
\end{tabular}

R217 to SW Maple Dr

Beaverton-Hills dale Hwy MP 0.96-1.09
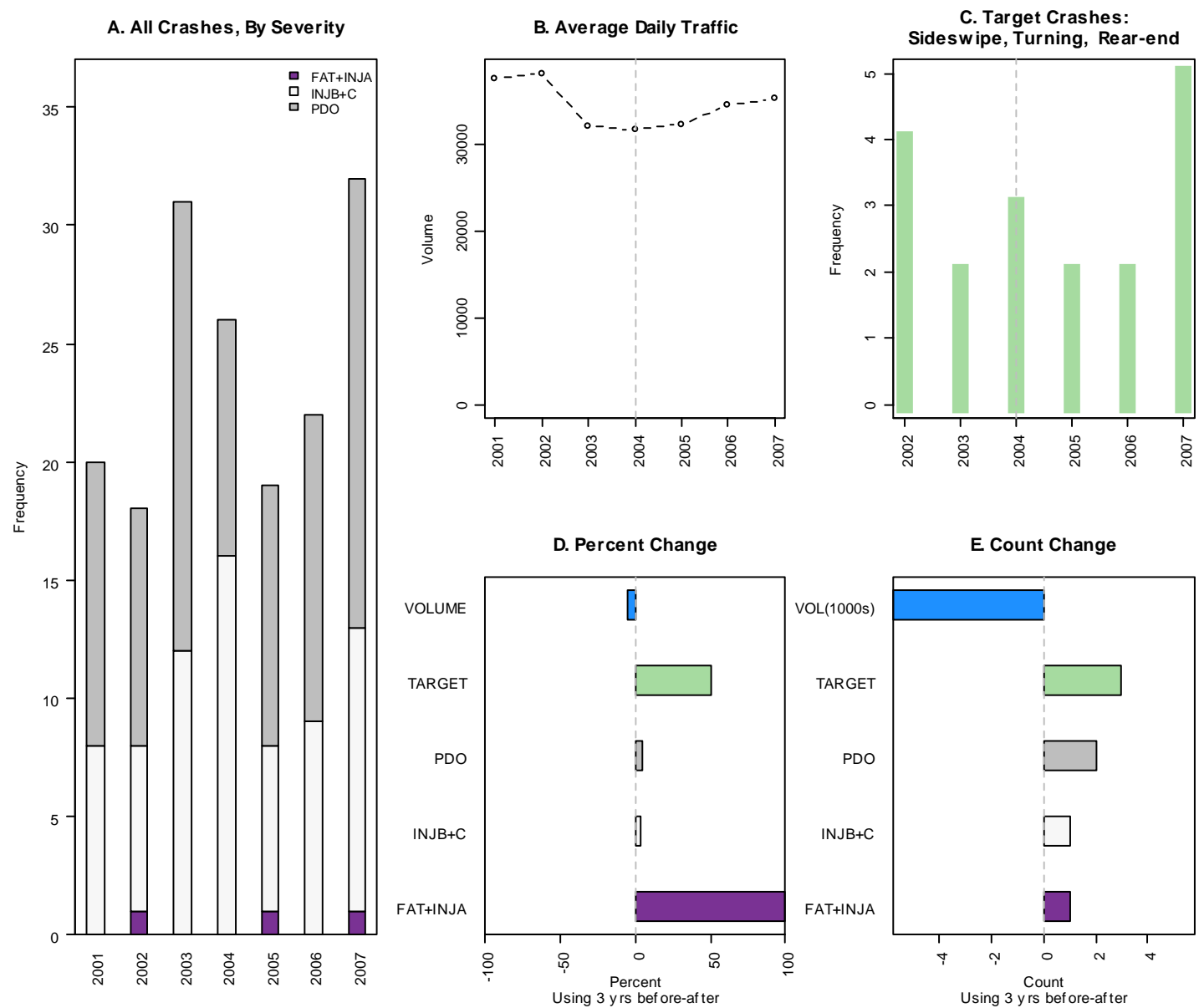

Figure 5.43: Safety Performance, OR 10- OR 217 to SW Maple Dr, Key No. 12905 


\subsubsection{OR 221: Dayton to Salem}

\subsubsection{Description}

This 17.1 mile preservation project on the OR 221 (Salem-Dayton Highway) was constructed in 2006. A summary of the entire project from the project prospectus and STIP project files is shown in Table 5.41. The project area was of mostly rural character and was located in Region 2. A 3\% safety work type was identified in the STIP and prospectus. The project limits contained a segment with a SIP category of 4 . The project did not define the safety deficiencies and the proposed safety solutions were vague. After reviewing the as-built plans and digital video logs, the constructed safety improvements include upgrading existing guardrails. These were considered mandatory corrective measures. No target crashes were identified. Before and after photos from the digital video log are shown in Figure 5.44.

Table 5.41: Project Summary, OR 221-Dayton to Salem, Key No. 13675

\begin{tabular}{|c|c|c|c|c|c|}
\hline $\begin{array}{l}\text { Key No. } \\
\text { Contract No. }\end{array}$ & $\begin{array}{l}13675 \\
13252 \\
\end{array}$ & Region & 2 & Funding & $\begin{array}{l}\text { Preservation 97\% } \\
\text { Safety 3\% }\end{array}$ \\
\hline Highway & $\begin{array}{l}150 \text { Salem- } \\
\text { Dayton }\end{array}$ & MP & $0.49-17.23$ & $\begin{array}{l}\text { Construction } \\
\text { Year }\end{array}$ & 2006 \\
\hline $\begin{array}{l}\text { Estimated } \\
\text { Scope Year }\end{array}$ & 2005 & $\begin{array}{l}\text { SIP } \\
\text { Category } \\
2002-2004\end{array}$ & 4 & $\begin{array}{l}\text { SPIS Score } \\
2002-2004\end{array}$ & $\begin{array}{l}\text { No SPIS scores in } \\
\text { the Top } 15 \%\end{array}$ \\
\hline $\begin{array}{l}\text { ODOT } \\
\text { Problem }\end{array}$ & \multicolumn{5}{|c|}{$\begin{array}{l}\text { The pavement on this section of the Salem-Dayton Hwy is in poor condition. The last } \\
4.7 \text { miles of the project has an old "F" mix wearing surface. Two SPIS sites within } \\
\text { project limits. }\end{array}$} \\
\hline $\begin{array}{l}\text { ODOT } \\
\text { Proposed } \\
\text { Solution }\end{array}$ & \multicolumn{5}{|c|}{$\begin{array}{l}\text { Hwy 150, MP 0.45-17.27, 2” HMAC Wearing Course, 2” HMAC Base Course, 2” } \\
\text { Cold Plane pavement removal. 6” HMAC Base course, 12” Aggregate Base. } \\
\text { Subgrade Geotextile: an estimated 1,000yd2 of surfacing stabilization is needed. } \\
\text { Upgrade bridge rail and guardrail as required. As funding allows address SPIS sites. }\end{array}$} \\
\hline $\begin{array}{l}\text { Design } \\
\text { Exceptions }\end{array}$ & \multicolumn{5}{|c|}{$\begin{array}{l}\text { Retain 11' lanes, striped to edge of narrow pavement, MP 8.8-12.1 and MP } 12.7 \text { to } \\
\text { 15. Retain existing shoulder widths (0-6') for entire section. Retain existing } \\
\text { horizontal alignment, MP 14.8-15.8 (three substandard curves). Retain existing } \\
\text { vertical alignment, MP 11.5. Retain roadside obstacles. }\end{array}$} \\
\hline $\begin{array}{l}\text { Constructed } \\
\text { Safety } \\
\text { Improvements }\end{array}$ & \multicolumn{3}{|c|}{ Upgrade existing guardrail } & $\begin{array}{l}\text { Target } \\
\text { Crashes }\end{array}$ & None identified \\
\hline \multirow{4}{*}{$\begin{array}{l}\text { Prospectus } \\
\text { Costs (000's) }\end{array}$} & \multirow{4}{*}{$\begin{array}{l}\text { PE } \\
\text { ROW } \\
\text { CON } \\
\text { TOTAL }\end{array}$} & $\$ 202$ & \multirow{4}{*}{$\begin{array}{l}\text { STIP Cost } \\
(000 \text { 's) }\end{array}$} & \multirow{4}{*}{$\begin{array}{l}\text { PE } \\
\text { ROW } \\
\text { CON } \\
\text { TOTAL }\end{array}$} & $\$ 202$ \\
\hline & & & & & \\
\hline & & $\$ 4,619$ & & & $\$ 4,619$ \\
\hline & & $\$ 4,821$ & & & $\$ 4,821$ \\
\hline
\end{tabular}




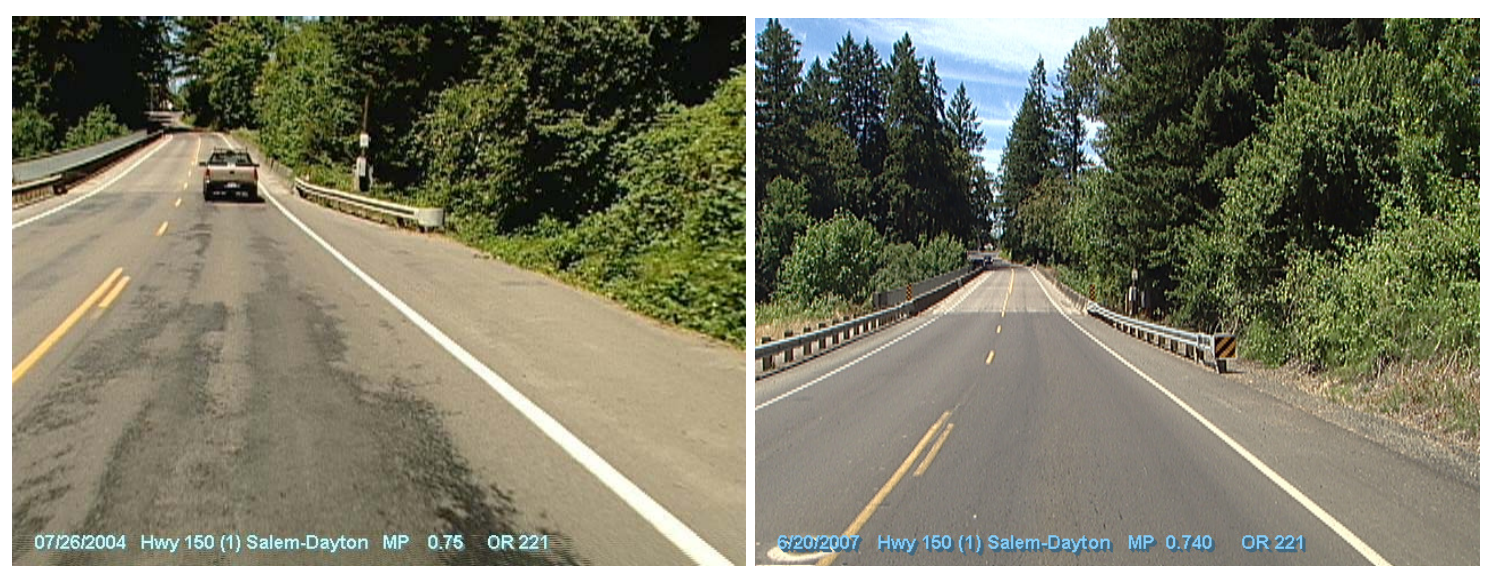

Figure 5.44: Conditions in 2004 (before) and in 2007 (after) showing the upgraded guardrail ends at MP 0.75

\subsubsection{Evaluation}

The project was evaluated according to the criteria for each metric and the results are summarized in Table 5.42. The project contained a SIP segment category of 4. Therefore, the funding score given was a score of 1 . The project did not define the safety deficiencies and the proposed safety solutions were vague. The constructed safety improvements (upgrading existing guardrails) were mandatory corrective measures thus the project was given a design score of 4 .

The project expenditures were analyzed for the mandatory safety corrective measures identified. These safety related items included guardrail Type $2 \mathrm{a}$ and 3 , guardrail anchors, transitions, and terminals totaling $\$ 52,000$, approximately $1 \%$ of the construction costs. The STIP planned a 3\% use of safety funding. Analysis of project expenditures indicated that the allocated safety funds were spent on safety items. Thus, the project was given an expenditure score of 1 .

The safety-related data for the project are summarized in Figure 5.45 A-E. No target crashes were identified. No safety performance score was given because only one year of after construction crash data were available for comparison. In the one year after period, fatal and injury A crashes over the project limits increased by 3 from 2 to 5 (150\%). Moderate and minor injury severity (injury B and C, respectively) crashes decreased while PDO crashes decreased. Traffic volumes were essentially unchanged. 
Table 5.42: Project Scorecard, OR 221-Dayton to Salem, Key No. 13675

\begin{tabular}{|c|c|c|c|c|c|c|c|}
\hline Metric & Score & \multicolumn{6}{|l|}{ Note } \\
\hline $\begin{array}{l}\text { Funding } \\
\text { Eligibility }\end{array}$ & 1 & \multicolumn{6}{|c|}{$\begin{array}{l}\text { The project contained a segment with a SIP category of } 4 \text { and was eligible for } \\
\text { safety funds. }\end{array}$} \\
\hline Design & 4 & \multicolumn{6}{|c|}{$\begin{array}{l}\text { The project did not define the safety deficiencies and the proposed safety } \\
\text { solutions were vague. The constructed safety improvements (upgrading existing } \\
\text { guardrails) were mandatory corrective measures. }\end{array}$} \\
\hline \multirow[t]{4}{*}{ Expenditures } & 1 & \multicolumn{6}{|c|}{$\begin{array}{l}\text { The identified safety enhancements accounted for } 1 \% \text { of project construction } \\
\text { costs; } 3 \% \text { was planned. The costs are summarized (in } 1,000 \mathrm{~s}) \text { : }\end{array}$} \\
\hline & & & Total & Other & Other \% & Safety & Safety \% \\
\hline & & STIP & $\$ 4,619$ & $\$ 4,480$ & $97 \%$ & $\$ 139$ & $3 \%$ \\
\hline & & As-Built & $\$ 4,877$ & $\$ 4,818$ & $99 \%$ & $\$ 59$ & $1 \%$ \\
\hline Performance & NA & \multicolumn{6}{|c|}{ Only 1 year of after available, no safety performance score given. } \\
\hline
\end{tabular}

OR221 Dayton to Salem

Salem-Dayton Hwy MP 0.49-17.23
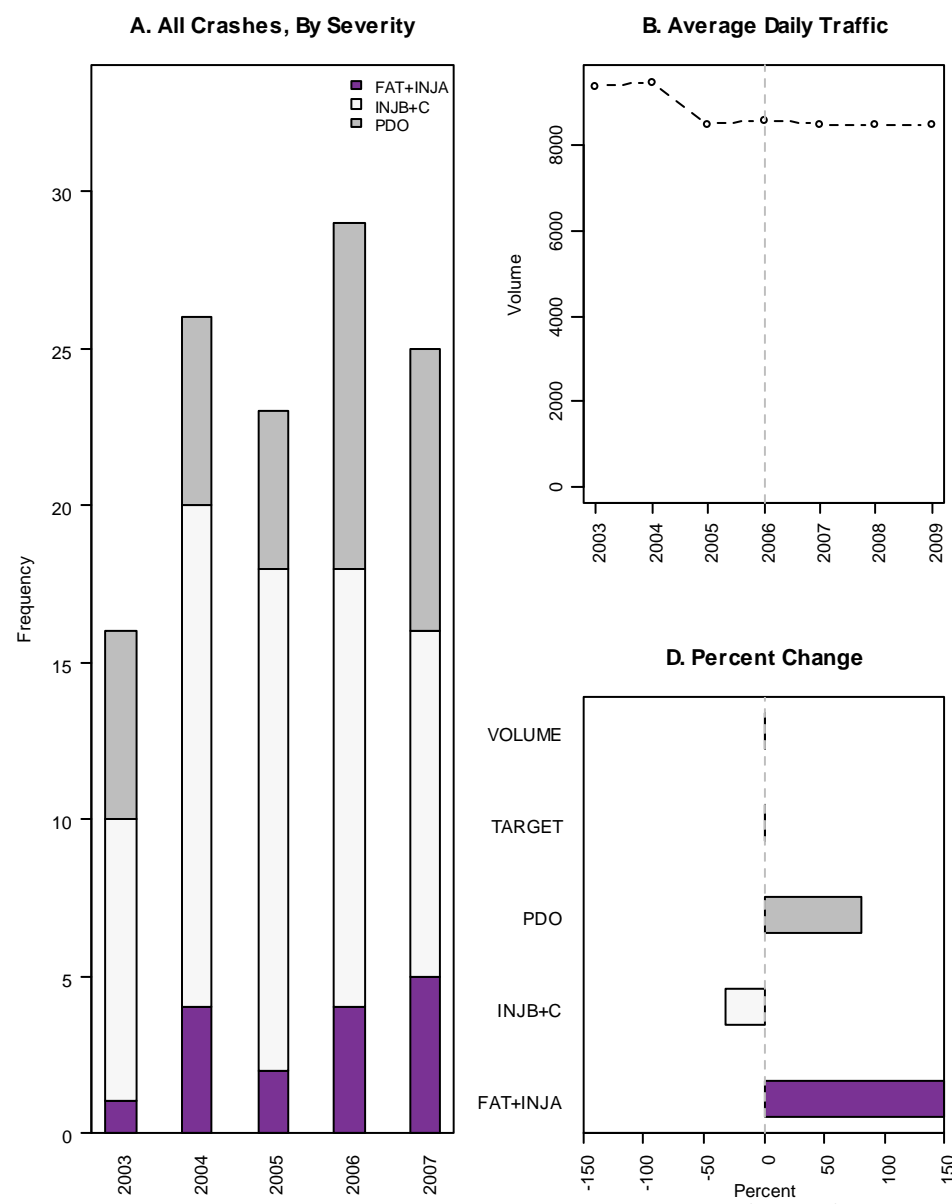

C. Target Crashes: None

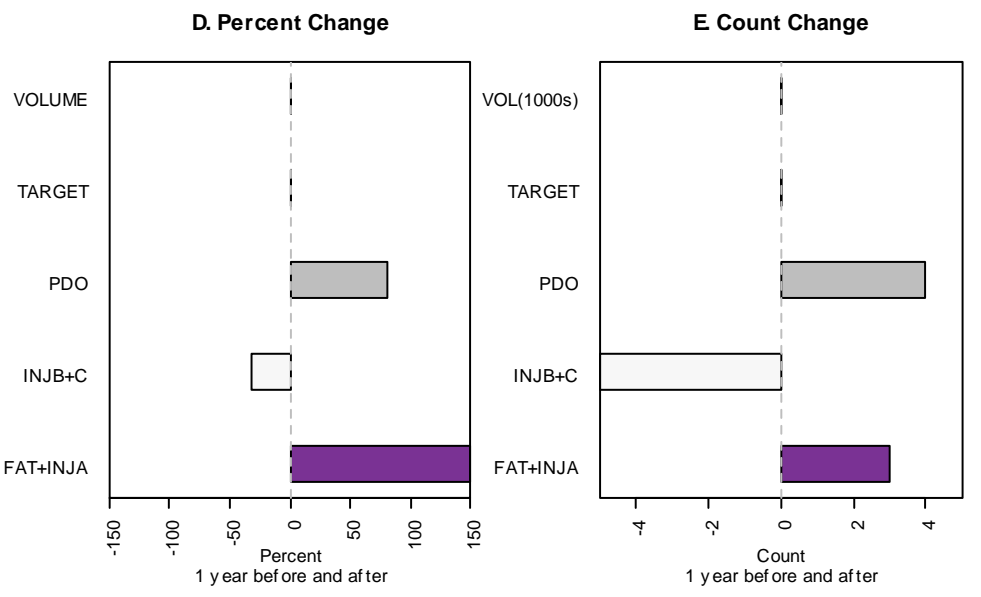

Figure 5.45: Safety Performance, OR 221-Dayton to Salem, Key No. 13675 


\subsubsection{OR 203: WCL La Grande to Union}

\subsubsection{Description}

This 15.8 mile preservation project on OR 203 (La Grande-Baker Highway) was constructed in 2006. A summary of the entire project from the project prospectus and STIP project files is shown in Table 5.43. The project area was of both rural and urban character and was located in Region 5. A 6\% safety work type was identified in the STIP and prospectus. The project limits contained a segment with a SIP category of 2 . The project defined the safety deficiencies and the proposed safety solutions. After reviewing the as-built plans and digital video logs it was determined that the constructed safety improvements included adding new and upgrading existing guardrail and upgrading bridge rails. The addition of new guardrail was considered an enhancement. Additional project improvements (in conjunction with the city of La Grande) improved the Gekeler Lane intersection by reducing the skew to the highway and improved the left turn channelization. Target crashes were identified as lane departure (off-roadway) crashes. Before and after photos from the digital video log are shown in Figure 5.46.

Table 5.43: Project Summary, OR 203-WCL La Grande to Union, Key No. 14127

\begin{tabular}{|c|c|c|c|c|c|}
\hline $\begin{array}{l}\text { Key No. } \\
\text { Contract No. }\end{array}$ & $\begin{array}{l}14127 \\
13208\end{array}$ & Region & 5 & Funding & $\begin{array}{l}\text { Preservation 94\% } \\
\text { Safety 6\% }\end{array}$ \\
\hline Highway & $\begin{array}{l}066 \text { La } \\
\text { Grande-Baker }\end{array}$ & MP & $0-15.8$ & $\begin{array}{l}\text { Construction } \\
\text { Year }\end{array}$ & 2006 \\
\hline $\begin{array}{l}\text { Estimated } \\
\text { Scope Year }\end{array}$ & 2005 & $\begin{array}{l}\text { SIP } \\
\text { Category } \\
\text { 2002-2004 } \\
\end{array}$ & 2 & $\begin{array}{l}\text { SPIS Score } \\
\text { 2002-2004 }\end{array}$ & $\begin{array}{l}\text { No SPIS scores in } \\
\text { the Top } 15 \%\end{array}$ \\
\hline $\begin{array}{l}\text { ODOT } \\
\text { Problem }\end{array}$ & \multicolumn{5}{|c|}{$\begin{array}{l}\text { The roadway surfacing throughout this section of la Grande - Baker Hwy is showing } \\
\text { signs of distress. MP 0-1.28 has sporadic low severity traverse and fatigue cracking. } \\
\text { MP 2.75-7 has extensive low severity transverse and fatigue cracking. MP 7-15.8 has } \\
\text { less stress than the previous locations. Many of the existing guardrails do not comply } \\
\text { with current } 3 R \text { standards and must be replaced or upgraded. Some locations with } \\
\text { roadside hazards will require guardrail installations to enhance safety. There are } 5 \\
\text { bridges on this project that have deficient rails and transitions. }\end{array}$} \\
\hline $\begin{array}{l}\text { ODOT } \\
\text { Proposed } \\
\text { Solution }\end{array}$ & \multicolumn{5}{|c|}{$\begin{array}{l}\text { The proposed solution is to place a 2” HMAC overlay, MP 0-128 and 7-15.8, and a 3: } \\
\text { HMAC overlay MP 2.75-7. Some locations MP 3.32-7, the existing paved shoulders } \\
\text { are deteriorating, requiring a digout and reconstruct. Replace/upgrade existing } \\
\text { guardrail to comply with current standards, and install guardrail at areas as } \\
\text { necessary to improve roadside hazards. Retrofit bridge rails and upgrade transitions. }\end{array}$} \\
\hline $\begin{array}{l}\text { Design } \\
\text { Exceptions }\end{array}$ & \multicolumn{5}{|c|}{$\begin{array}{l}\text { Clear zones: side slopes and utility poles, MP 0.01-1.27, 2.77-15.83 (excluding 4.93- } \\
\text { 5.32,2), and MP 15.65 (Little Creek Structure). Median and lane widths in } \\
\text { channelization areas, MP 4.93 (McAlister Lane) - } 5.32 \text { (EB I-84 Union on/off ramps) } \\
\text { Shy distance for guardrail runs throughout section. }\end{array}$} \\
\hline $\begin{array}{l}\text { Constructed } \\
\text { Safety } \\
\text { Improvements }\end{array}$ & \multicolumn{3}{|c|}{$\begin{array}{l}\text { Added new and upgraded existing guardrail. } \\
\text { Upgrade bridge rails }\end{array}$} & $\begin{array}{l}\text { Target } \\
\text { Crashes }\end{array}$ & $\begin{array}{l}\text { Lane departure } \\
\text { (off roadway) }\end{array}$ \\
\hline \multirow{4}{*}{$\begin{array}{l}\text { Prospectus } \\
\text { Costs (000's) }\end{array}$} & \multirow{4}{*}{$\begin{array}{l}\text { PE } \\
\text { ROW } \\
\text { CON } \\
\text { TOTAL }\end{array}$} & $\$ 315$ & \multirow{4}{*}{$\begin{array}{l}\text { STIP Costs } \\
\text { (000's) }\end{array}$} & \multirow{4}{*}{$\begin{array}{l}\text { PE } \\
\text { ROW } \\
\text { CON } \\
\text { TOTAL }\end{array}$} & \\
\hline & & & & & \\
\hline & & & & & \\
\hline & & & & & \\
\hline
\end{tabular}



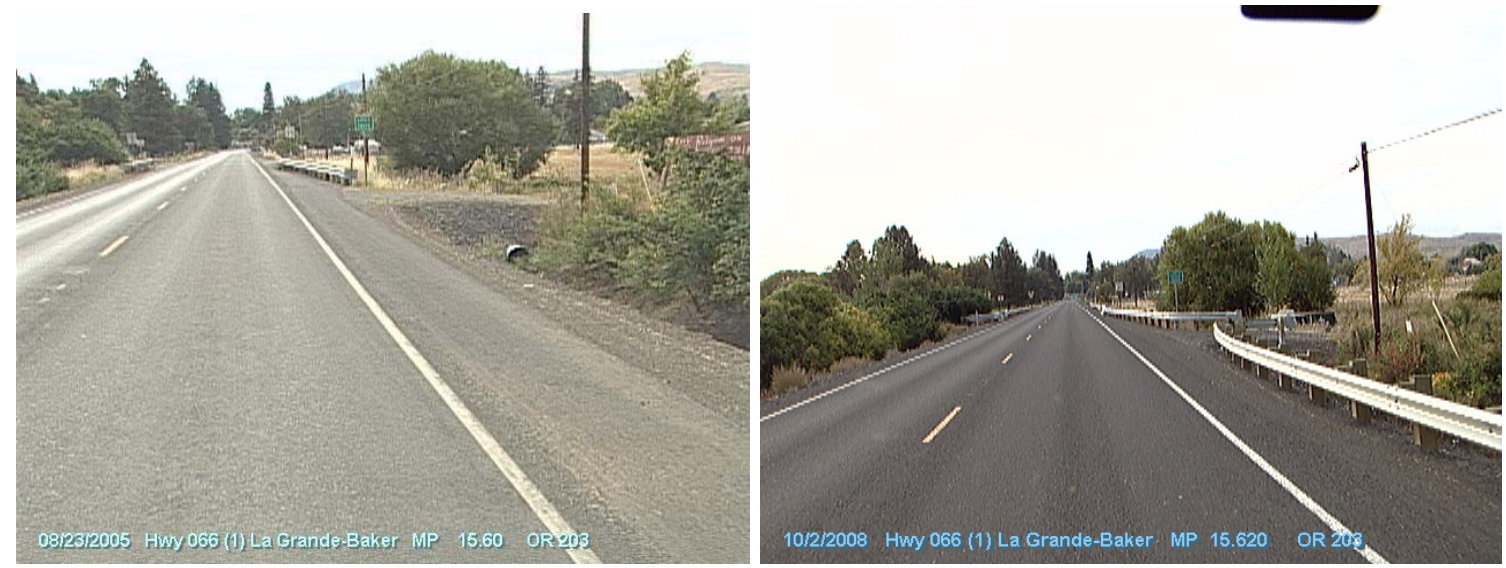

Figure 5.46: Conditions in 2005 (before) and in 2008 (after) showing the upgraded and new guardrail at MP 15.60

\subsubsection{Evaluation}

The project was evaluated according to the criteria for each metric and the results are summarized in Table 5.44. The project contained a segment with SIP category of 2. There was no SIP category of 3 or greater in the any SIP year for this section. As such, the funding eligibility score given was 5 . However, the project defined the safety deficiencies and the proposed safety solutions, upgrading and adding new existing guardrails, were considered enhancements.

In analyzing the project expenditures, the safety related items $(\$ 334,000)$ included guardrail Type 2a, 3, and 4; guardrail anchors, end pieces, transitions, and terminals; concrete rail retrofit; and thrie beam rail retrofit. These expenditures totaled $7 \%$ of the construction costs, which compared well to the STIP planned safety funding of $6 \%$. Analysis of project expenditures indicated that the allocated safety funds were spent on the identified safety items. Thus, the project was given an expenditure score of 1 .

The safety-related data for the project are summarized in Figure 5.47 A-E. Target crashes were identified as lane departure, off-roadway crashes. Because the project only had one year of crash data available in the after period, no safety performance score was given. Considering one year of data before and after construction, target crashes increased; however, when a longer before period was considered, they decreased. Fatal and injury A crashes increased from 0 to 4; crashes of B or C severity increased by 1 , and PDO crashes decreased by 4. 
Table 5.44: Project Scorecard, OR 203-WCL La Grande to Union, Key No. 14127

\begin{tabular}{|c|c|c|c|c|c|c|c|}
\hline Metric & Score & \multicolumn{6}{|l|}{ Note } \\
\hline $\begin{array}{l}\text { Funding } \\
\text { Eligibility }\end{array}$ & 5 & \multicolumn{6}{|c|}{$\begin{array}{l}\text { The project contained a segment with a SIP category of } 2 \text {. There was no SIP } \\
\text { category of } 3 \text { or greater in the SIP year for this section. As such, it is } \\
\text { ineligible for safety funds. }\end{array}$} \\
\hline Design & 2 & \multicolumn{6}{|c|}{$\begin{array}{l}\text { The project defined the safety deficiencies and the proposed safety solutions. } \\
\text { The constructed safety improvements (upgrading and adding new existing } \\
\text { guardrails) were considered enhancements. }\end{array}$} \\
\hline \multirow[t]{4}{*}{ Expenditures } & 1 & \multicolumn{6}{|c|}{$\begin{array}{l}\text { The identified safety enhancements accounted for } 7 \% \text { of project construction } \\
\text { costs; } 6 \% \text { was planned. The costs are summarized (in 1,000s): }\end{array}$} \\
\hline & & & Total & Other & Other \% & Safety & Safety \% \\
\hline & & STIP & $\$ 6,817$ & $\$ 6,408$ & $94 \%$ & $\$ 409$ & $6 \%$ \\
\hline & & As-Built & $\$ 5,642$ & $\$ 5,217$ & $93 \%$ & $\$ 425$ & $7 \%$ \\
\hline Performance & NA & \multicolumn{6}{|c|}{$\begin{array}{l}\text { Only } 1 \text { year of after construction data was available; no safety performance } \\
\text { score given. }\end{array}$} \\
\hline
\end{tabular}

OR203 WCL Lagrande to Union La Grande-Baker Hwy MP 0-15.8

A. All Crashes, By Severity

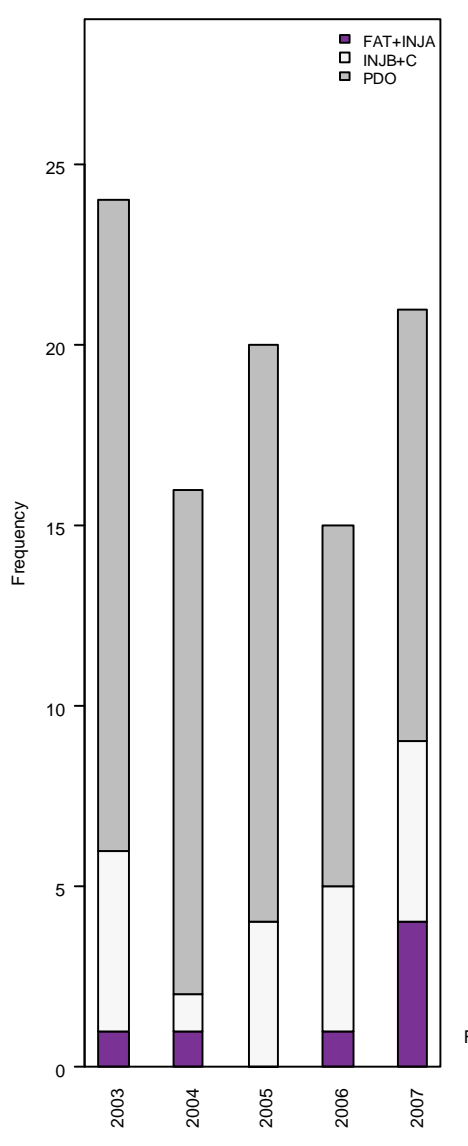

D. Percent Change
C. Target Crashes:
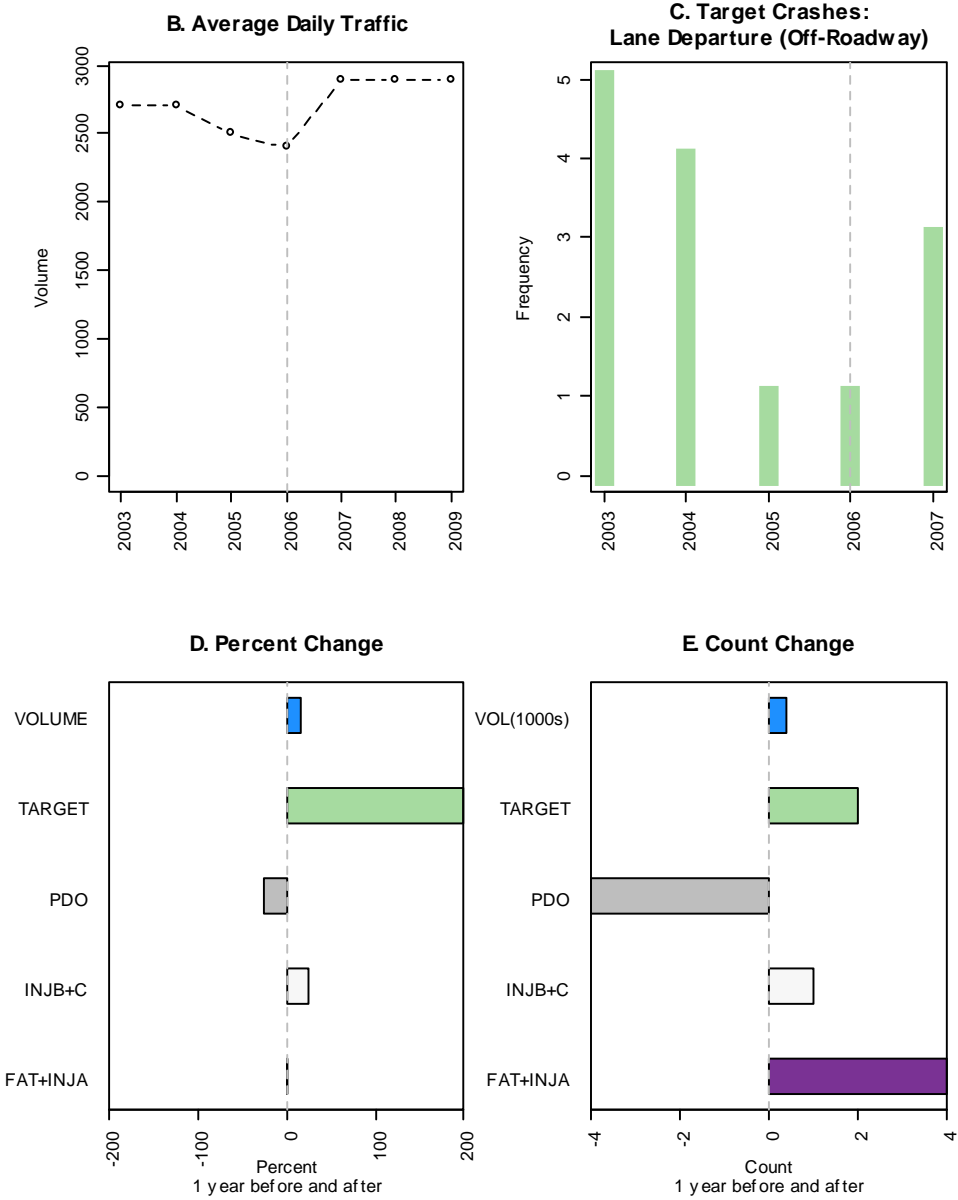

E Count Change

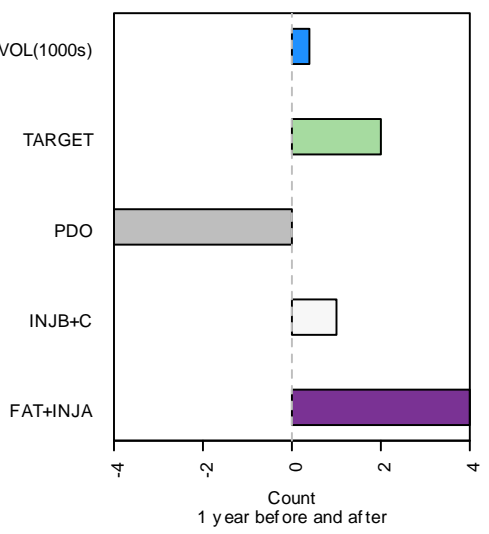

Figure 5.47: Safety Performance, OR 203-WCL La Grande to Union, Key No. 14127 


\subsubsection{US 26: Lindsley Creek to Lower Nehalem Rd}

\subsubsection{Description}

This 20.27 mile preservation project on the US 26 (Sunset Highway) was constructed in 2006. A summary of the entire project from the project prospectus and STIP project files is shown in Table 5.45. The project area was of mostly rural character and was located in Region 2. A 48\% safety work type was identified in the STIP and prospectus. The project limits contained a segment with a SIP category of 3 . The project defined the safety deficiencies and the proposed safety solutions well. After reviewing the as-built plans and digital video logs the constructed safety improvements included upgrading guardrails and realigning Lower Nehalem Road. The realignment was considered enhancements. Target crashes were assumed to be turning and rear-end crashes related to realigning Lower Nehalem Road, closing Woodard Lane access and guardrails) at MP 19.67-19.77. Before and after photos from the digital video log are shown in Figure 5.48 and Figure 5.49 .

Table 5.45: Project Summary, US 26-Lindsley Creek to Lower Nehalem Rd, Key No. 14172

\begin{tabular}{|c|c|c|c|c|c|}
\hline $\begin{array}{l}\text { Key No. } \\
\text { Contract No. }\end{array}$ & $\begin{array}{l}14172 \\
13262\end{array}$ & Region & 2 & Funding & $\begin{array}{l}\text { Preservation 52\% } \\
\text { Safety } 48 \%\end{array}$ \\
\hline Highway & 047 Sunset & MP & $\begin{array}{l}\text { 5-9.79, } \\
19.53-20.27\end{array}$ & $\begin{array}{l}\text { Construction } \\
\text { Year }\end{array}$ & 2006 \\
\hline $\begin{array}{l}\text { Estimated } \\
\text { Scope Year }\end{array}$ & 2005 & $\begin{array}{l}\text { SIP Category } \\
2002-2004\end{array}$ & 3 & $\begin{array}{l}\text { SPIS Score } \\
2002-2004 \\
\end{array}$ & $\begin{array}{l}\text { Max: 50.73, MP } \\
19.6,90-95 \%\end{array}$ \\
\hline $\begin{array}{l}\text { ODOT } \\
\text { Problem }\end{array}$ & \multicolumn{5}{|c|}{$\begin{array}{l}\text { MP 0-5: Missing recessed reflector buttons from original preservation project. MP 5-10: } \\
\text { Deteriorating pavement: BR 03095: Lindsley Creek - Guardrail rated as substandard; } \\
\text { Deck wearing surface rated @ } 3 \text { as “Serious”; BR 06524” North Fork Necanicum River - } \\
\text { Guardrail rated substandard; exterior bent undermining and progressing leaving bridge } \\
\text { unstable at both ends; BR 03099: Little Humbug Creek - Guardrail system rated as } \\
\text { substandard; deck wearing surface rated @ } 5 \text { “Fair”. MP 19.53-20.27 - Lower Nehalem } \\
\text { Road traffic has to access at two intersections due to severe skews. Several rear end } \\
\text { accidents on highway due to sharp horizontal curve. }\end{array}$} \\
\hline $\begin{array}{l}\text { ODOT } \\
\text { Proposed } \\
\text { Solution }\end{array}$ & \multicolumn{5}{|c|}{$\begin{array}{l}\text { Preservation overlay from MP 5-10. BR 03095-Lindsley Creek-remove all AC, inspect } \\
\text { deck and install new membrane waterproofing system/ install new guardrail. BR 06254- } \\
\text { North Fork Necanicum River-drive sheet pile at both ends to slow down the undermining; } \\
\text { retrofit membrane waterproofing system; install new guardrail. } \\
\text { Add recessed reflector buttons from Cannon Beach Junction (HWY 26) to MP } 5 . \\
\text { Realign Lower Nehalem Road using county supplied ROW and rock embankment to a } 90 \\
\text { degree "teed" intersection with Hwy 26. Disconnect and vacate the existing Lower } \\
\text { Nehalem Road and Woodard Lane connections to Hwy 26. Construct turn around } \\
\text { configuration (hammer head or cul-de-sac) along Woodard Lane. Construct an Emergency } \\
\text { Access Only lane from Hwy } 26 \text { along the vacated section of Woodard Lane. Access from } \\
\text { Hwy } 26 \text { is controlled by gate feature. }\end{array}$} \\
\hline $\begin{array}{l}\text { Design } \\
\text { Exceptions } \\
\end{array}$ & \multicolumn{5}{|c|}{ Vertical alignment at MP 5.93} \\
\hline $\begin{array}{l}\text { Constructed } \\
\text { Safety } \\
\text { Improvements } \\
\end{array}$ & \multicolumn{3}{|c|}{$\begin{array}{l}\text { Upgrading guardrails and realigning Lower } \\
\text { Nehalem Road and Woodard Lane }\end{array}$} & $\begin{array}{l}\text { Target } \\
\text { Crashes }\end{array}$ & $\begin{array}{l}\text { Turning, rear end, } \\
\text { and angle MP } \\
19.67-19.77\end{array}$ \\
\hline \multirow{4}{*}{$\begin{array}{l}\text { Prospectus } \\
\text { Costs (000's) }\end{array}$} & \multirow{4}{*}{$\begin{array}{l}\text { PE } \\
\text { ROW } \\
\text { CON } \\
\text { TOTAL }\end{array}$} & $\$ 115$ & \multirow{4}{*}{$\begin{array}{l}\text { STIP Costs } \\
\text { (000's) }\end{array}$} & \multirow{4}{*}{$\begin{array}{l}\text { PE } \\
\text { ROW } \\
\text { CON } \\
\text { TOTAL }\end{array}$} & $\$ 115$ \\
\hline & & $\$ 100$ & & & $\$ 100$ \\
\hline & & $\$ 2,024$ & & & $\$ 2,024$ \\
\hline & & $\$ 2,239$ & & & \\
\hline
\end{tabular}



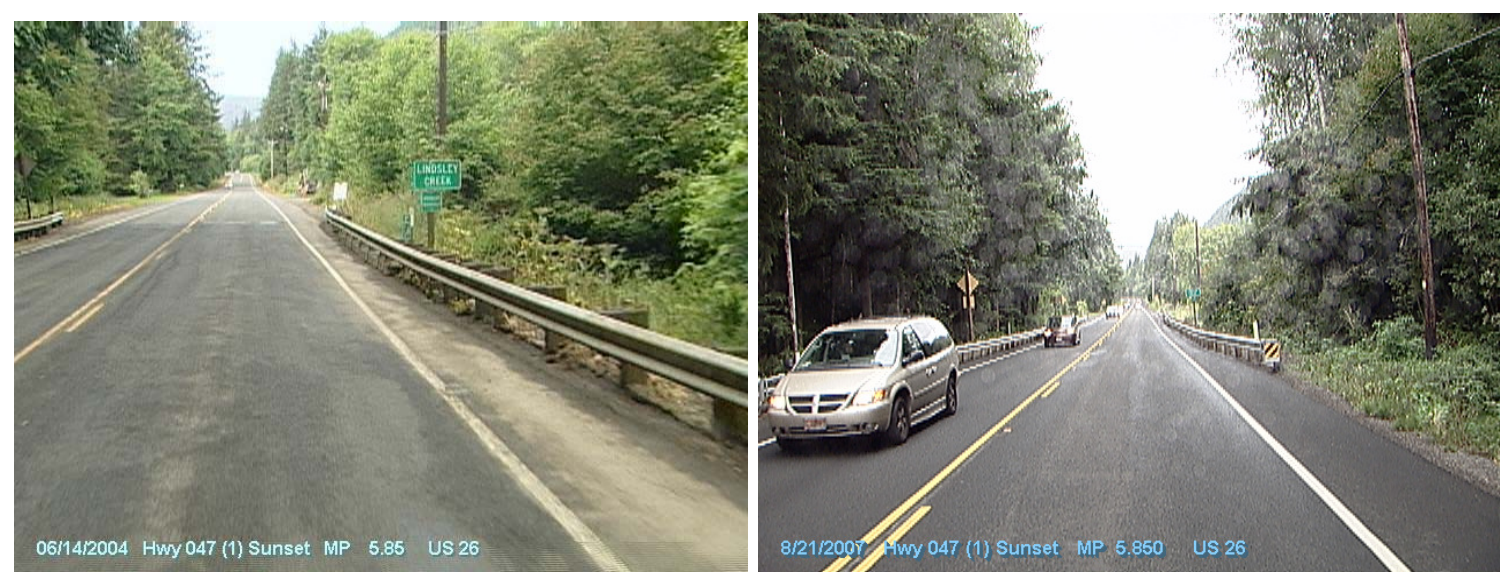

Figure 5.48: Conditions in 2004 (before) and in 2007 (after) showing the upgraded guardrail at Lindsley Creek BR 03095, MP 5.85
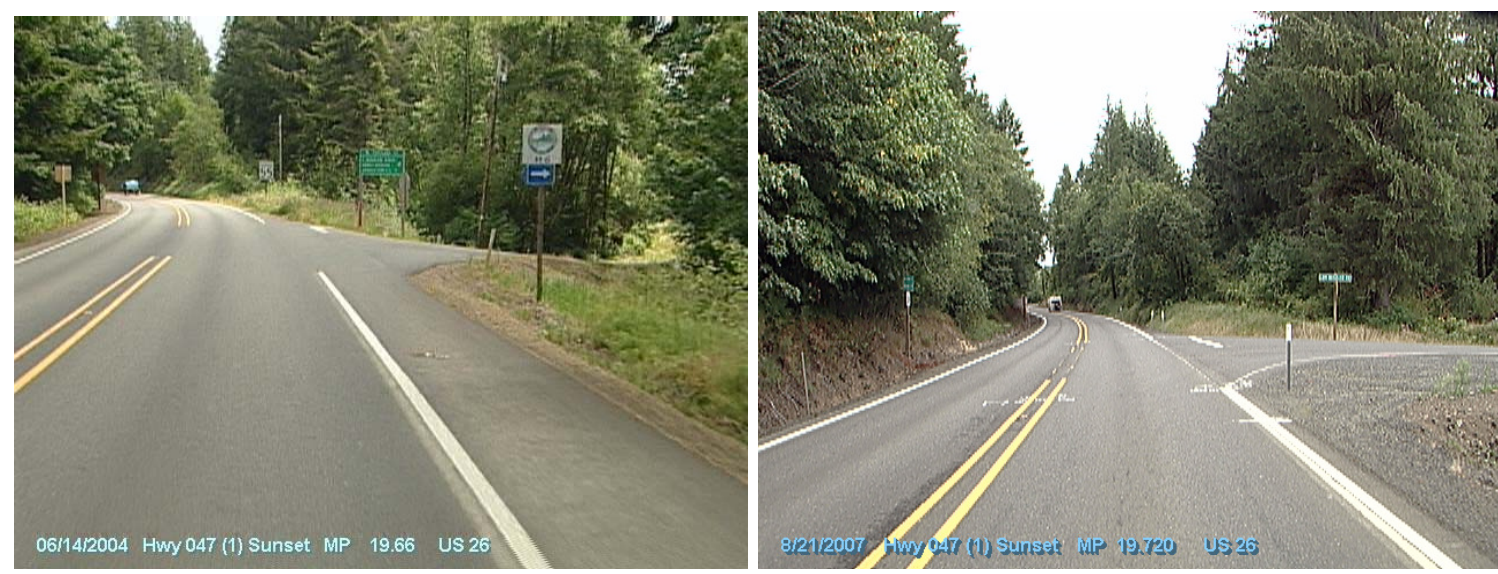

Figure 5.49: Conditions in 2004 and in 2007 (after) showing the Nehalem Road realignment at MP 19.72

\subsubsection{Evaluation}

The project was evaluated and the results are summarized in Table 5.46. The project included a segment with a SIP category of 3, earning the project a funding eligibility score of 1 . The project defined the safety deficiencies and the proposed safety solutions well. The safety improvements (realigning Lower Nehalem Road, closing Woodard Lane access and guardrails) were enhancements. The project was given a design score of 1.

The safety costs for the Nehalem Road realignment and Woodard closure included excavation, subgrade geotextile, subgrade stabilization, riprap, aggregate base, asphalt and sediment fences. Additional safety items included guardrail Type 2a and 3, guardrail transitions and terminals totaling $\$ 243,000,15 \%$ of the construction costs. The STIP planned a $48 \%$ use of safety funding. This analysis of project expenditures indicated that not all of the allocated safety funds were spent. However, it is possible that the actual 
costs to construct the realignment were greater than estimated. The project was given an expenditure score of 3.

The safety-related data for the project are summarized in Figure 5.50 A-E. Target crashes were identified as turning, angle and rear-end near the improved intersection. Only one year of after crash data were available. Target crashes increased by 1 while fatal and injury A crashes decreased by 1 . Because only one year of after data were available, no safety performance score was given.

Table 5.46: Project Scorecard, US 26-Lindsley Creek to Lower Nehalem Rd, Key No. 14172

\begin{tabular}{|c|c|c|c|c|c|c|c|}
\hline Metric & Score & \multicolumn{6}{|l|}{ Note } \\
\hline $\begin{array}{l}\text { Funding } \\
\text { Eligibility }\end{array}$ & 1 & \multicolumn{6}{|c|}{$\begin{array}{l}\text { The project contained a segment with a SIP category of } 3 \text { and was eligible } \\
\text { for safety funds. }\end{array}$} \\
\hline Design & 1 & \multicolumn{6}{|c|}{$\begin{array}{l}\text { The project defined the safety deficiencies and the proposed safety solutions } \\
\text { well. The safety improvements (realigning Lower Nehalem Road and } \\
\text { guardrails) were enhancements. }\end{array}$} \\
\hline \multirow[t]{4}{*}{ Expenditures } & \multirow[t]{4}{*}{3} & \multirow{2}{*}{\multicolumn{6}{|c|}{$\begin{array}{l}\text { The identified safety enhancements accounted for } 15 \% \text { of project } \\
\text { construction costs; } 48 \% \text { was planned. The costs are summarized (in 1,000s): } \\
\begin{array}{rlll}\text { Total } \quad \text { Other } \quad \text { Other } \% \quad \text { Safety Safety } \%\end{array}\end{array}$}} \\
\hline & & & & & & & \\
\hline & & STIP & $\$ 2,024$ & $\$ 1,052$ & $52 \%$ & $\$ 972$ & $48 \%$ \\
\hline & & As-Built & $\$ 2,160$ & $\$ 1,835$ & $85 \%$ & $\$ 325$ & $15 \%$ \\
\hline Performance & NA & \multicolumn{6}{|c|}{$\begin{array}{l}\text { Since only } 1 \text { year of after construction data is available, no safety } \\
\text { performance score given. }\end{array}$} \\
\hline
\end{tabular}



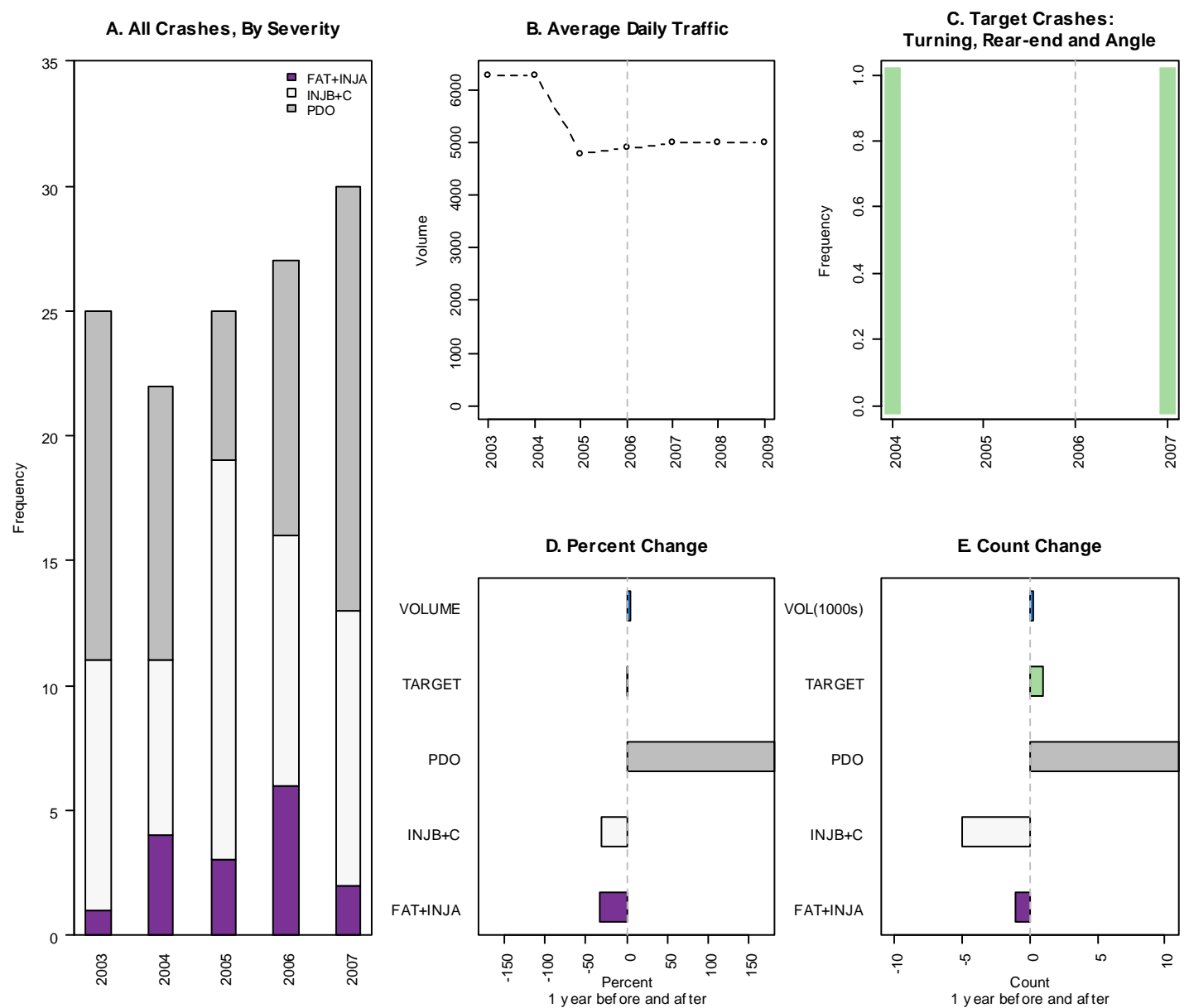

Figure 5.50: Safety Performance, US 26-Lindsley Creek to Lower Nehalem Rd, Key No. 14172

\subsubsection{US 20: Hampton to Glass Butte and Torkelson Rd}

\subsubsection{1 \\ Description}

This 13 mile preservation project on the US 20 (Central Oregon Highway) was constructed in 2007. A summary of the entire project from the project prospectus and STIP project files is shown in Table 5.47. The project area was of mostly rural character and was located in Region 4. A 3\% safety work type was identified in the STIP and prospectus. The project limits contained a segment with a SIP category of 3. The project defined the safety deficiencies and the proposed safety solutions. The proposed safety solution was to close access to US 20 from both Torkelson and Erickson roads. After reviewing the as-built plans, the driveway closure at Torkelson Road was not constructed. However, the construction plans indicate that centerline rumble strips were added from milepost 30-50 (outside the preservation work limits), slope flattening for about 1.7 miles 
at various locations, and durable markings were added for the project limits. Before and after photos from the digital video log are shown in Figure 5.51.

Table 5.47: Project Summary, US 20-Hampton to Glass Butte and Torkelson Rd, Key No. 14189

\begin{tabular}{|c|c|c|c|c|c|}
\hline $\begin{array}{l}\text { Key No. } \\
\text { Contract No. }\end{array}$ & $\begin{array}{l}14189 \\
13332\end{array}$ & Region & 4 & Funding & $\begin{array}{l}\text { Preservation } 97 \% \\
\text { Safety } 3 \%\end{array}$ \\
\hline Highway & $\begin{array}{l}007 \text { Central } \\
\text { Oregon }\end{array}$ & MP & $4.57,62-75$ & $\begin{array}{l}\text { Construction } \\
\text { Year }\end{array}$ & 2007 \\
\hline $\begin{array}{l}\text { Estimated } \\
\text { Scope Year }\end{array}$ & 2005 & $\begin{array}{l}\text { SIP } \\
\text { Category } \\
2002-2004\end{array}$ & $\begin{array}{l}3 \text { with } \\
\text { Torkelson; } 2 \\
\text { without } \\
\text { Torkleson }\end{array}$ & $\begin{array}{l}\text { SPIS Score } \\
2002-2004\end{array}$ & $\begin{array}{l}\text { No SPIS scores in } \\
\text { the Top } 15 \%\end{array}$ \\
\hline $\begin{array}{l}\text { ODOT } \\
\text { Problem }\end{array}$ & \multicolumn{5}{|c|}{$\begin{array}{l}\text { The pavement is shoving and rutting. There are localized areas of delamination and } \\
\text { base failure. There are substandard culvert ends. US20 @ Torkelson: SIP category } 3 . \\
\text { Nine accidents, two fatals since 1996. Eight of the nine involved the west approach } \\
\text { with three resulting in the rear-ending of eastbound traffic stopped waiting to turn } \\
\text { north. The intersection fails to meet OR standards for access management spacing on } \\
\text { a } 55 \text { MPH section of a rural expressway. This intersection is at MP } 4.57 \text { while the } \\
\text { Powell Butte Hwy intersection is at } 4.79 \text {. Disconnecting Torkelson/Erickson would } \\
\text { result in the next intersection being Hamby/Ward Road at MP } 3.56 \text { which would } \\
\text { meet OR Highway Plan spacing standards. }\end{array}$} \\
\hline $\begin{array}{l}\text { ODOT } \\
\text { Proposed } \\
\text { Solution }\end{array}$ & \multicolumn{5}{|c|}{$\begin{array}{l}\text { Millout and inlay with an additional overlay. Upgrade culvert ends as required. Close } \\
\text { access to US20 from both Torkelson and Erickson. Close private access to US20 at } \\
\text { NE corner of intersection and relocate to Erickson. Would require barrier at closed } \\
\text { access. May require R/W purchase for cul-de-sac/hammerhead on closed end of } \\
\text { Torkelson/Erickson. Bear Creek Road, Powell Butte Hwy., Neff Road and } \\
\text { Ward/Hamby Road would provide alternate access to Hwy } 20 \text { once the closure of } \\
\text { Torkelson/Erickson is completed. }\end{array}$} \\
\hline $\begin{array}{l}\text { Design } \\
\text { Exceptions }\end{array}$ & \multicolumn{5}{|c|}{ Substandard shoulders for MP 71.4-74.7. } \\
\hline $\begin{array}{l}\text { Constructed } \\
\text { Safety } \\
\text { Improvements }\end{array}$ & \multicolumn{3}{|c|}{$\begin{array}{l}\text { Centerline rumble strips, slope flattening, and } \\
\text { durable markings. }\end{array}$} & $\begin{array}{l}\text { Target } \\
\text { Crashes }\end{array}$ & None identified \\
\hline \multirow{4}{*}{$\begin{array}{l}\text { Prospectus } \\
\text { Costs (000's) }\end{array}$} & \multirow{4}{*}{$\begin{array}{l}\mathrm{PE} \\
\text { ROW } \\
\text { CON } \\
\text { TOTAL }\end{array}$} & $\$ 250$ & \multirow{4}{*}{$\begin{array}{l}\text { STIP Costs } \\
\text { (000's) }\end{array}$} & \multirow{4}{*}{$\begin{array}{l}\text { PE } \\
\text { ROW } \\
\text { CON } \\
\text { TOTAL }\end{array}$} & $\$ 158$ \\
\hline & & $\$ 50$ & & & $\$ 27$ \\
\hline & & $\$ 6,600$ & & & $\$ 6,714$ \\
\hline & & $\$ 6,900$ & & & $\$ 6,899$ \\
\hline
\end{tabular}
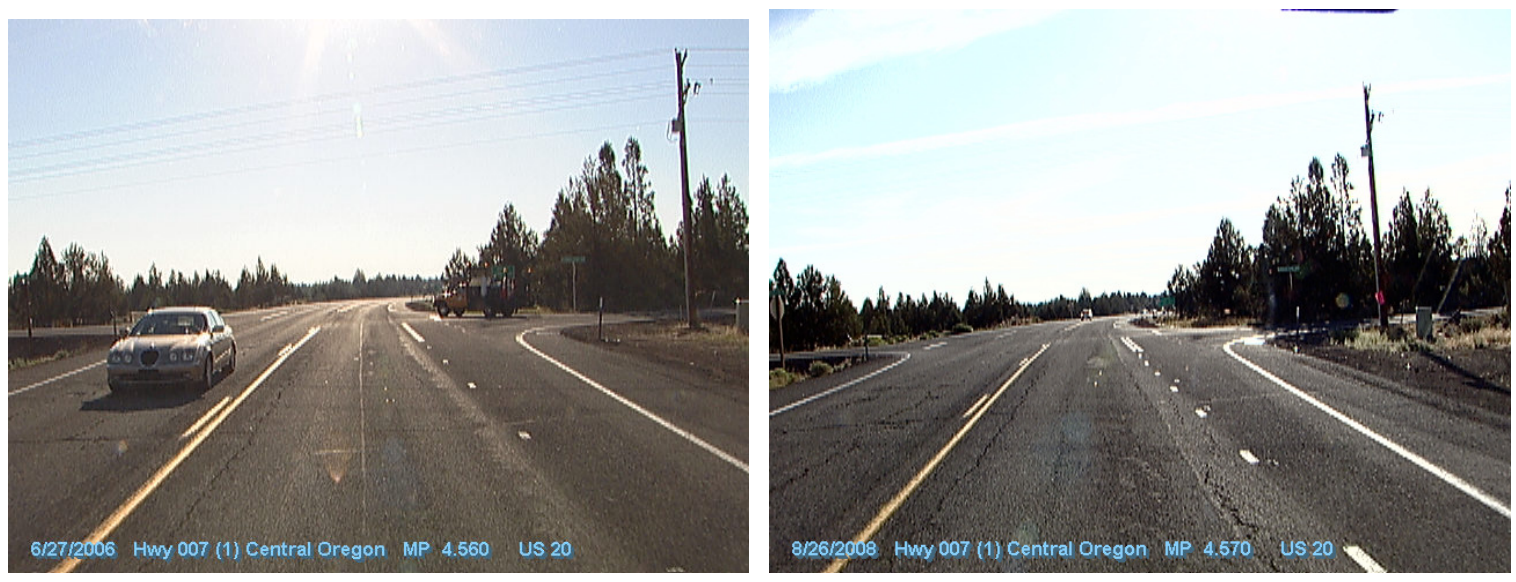

Figure 5.51: Torkelson intersection MP 4.57 in 2006 and 2008 

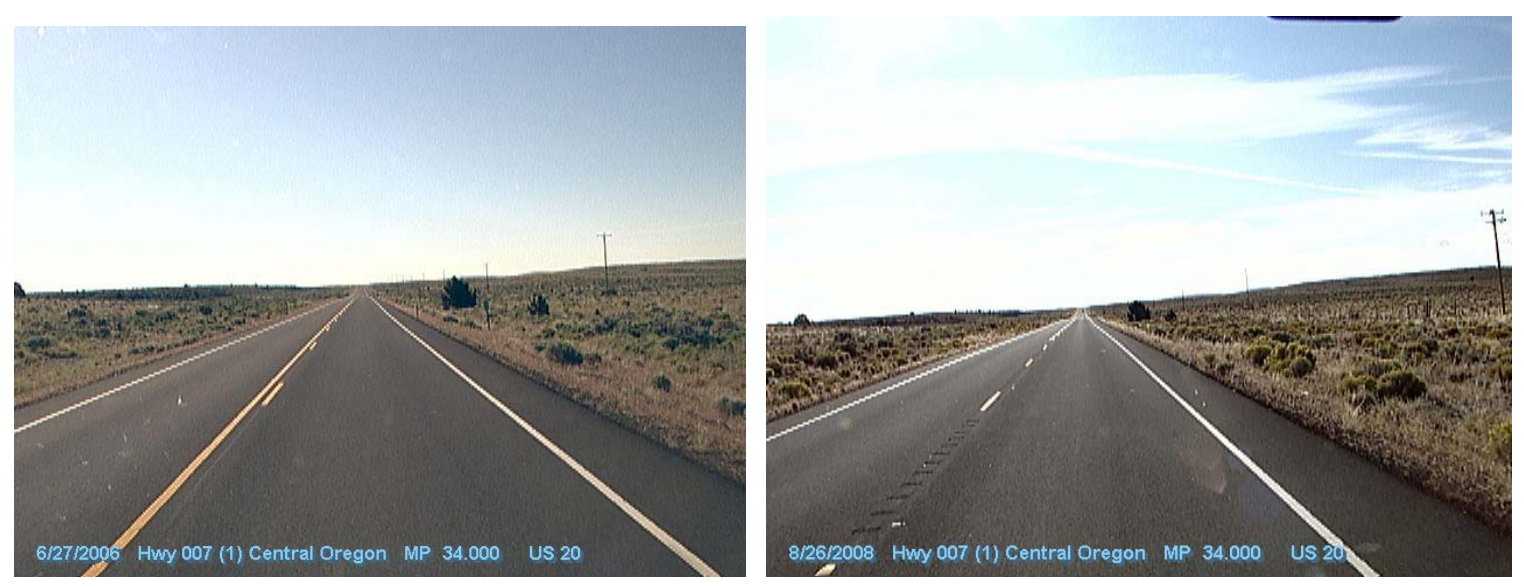

Figure 5.52: Conditions in 2006 and 2008 at MP 34.00 showing the addition of centerline rumble strips.

\subsubsection{Evaluation}

The project was evaluated according to the criteria for each metric and the results are summarized in Table 5.48. As scoped the project did include a SIP category greater than 3 at the Torkelson Road intersection. However, the modifications to be made at the intersection were dropped from the project and the remaining sections of the project do not have a SIP category greater than 3 . Thus, the project was given a funding eligibility score of 5 . The project, however, did include additional safety improvements that could be considered enhancements. The project was given a design score of 1 .

In analyzing the construction expenditures, the identified safety expenditures totaled $6 \%$ of the project construction cost (assuming all of the embankment work was done for slope flattening as appears in the construction plans). The STIP planned a 3\% use of safety funding. Thus, the project was given an expenditure score of 1 . The project was constructed in 2007 so there is no after construction data available currently for the safety performance comparison. No safety score was given. 
Table 5.48: Project Scorecard, US 20-Hampton to Glass Butte and Torkelson Rd, Key No. 14189

\begin{tabular}{|c|c|c|c|c|c|c|c|}
\hline Metric & Score & \multicolumn{6}{|l|}{ Note } \\
\hline $\begin{array}{l}\text { Funding } \\
\text { Eligibility }\end{array}$ & 5 & \multicolumn{6}{|c|}{ The project contained a segment with a SIP category of 2 . } \\
\hline Design & 1 & \multicolumn{6}{|c|}{$\begin{array}{l}\text { The proposed safety improvements (centerline rumblestrips, slope flattening, } \\
\text { and durable markings) were enhancements. }\end{array}$} \\
\hline \multirow[t]{4}{*}{ Expenditures } & 1 & \multicolumn{6}{|c|}{$\begin{array}{l}\text { The identified safety enhancements accounted for } 0 \% \text { of project construction } \\
\text { costs; } 3 \% \text { was planned. The costs are summarized (in 1,000s): }\end{array}$} \\
\hline & & & Total & Other & Other \% & Safety & Safety \% \\
\hline & & STIP & $\$ 6,714$ & $\$ 6,513$ & $97 \%$ & $\$ 201$ & $3 \%$ \\
\hline & & As-Built & $\$ 5,444$ & $\$ 5,137$ & $94 \%$ & $\$ 306$ & $6 \%$ \\
\hline Performance & NA & \multicolumn{6}{|c|}{ No after data available yet } \\
\hline
\end{tabular}

\subsection{CONCLUSIONS}

The results of the project level evaluation are summarized in Table 5.49. The table shows the ODOT region, key number, the actual construction cost (in 1,000s), the estimated safety expenditures (as estimated by the research team, in 1,000s), the expected safety allocation (in percent) from the STIP and the estimated safety expenditures (in percent), and the difference between those (with negative being less safety expenditures than planned). For additional comparisons, the table also shows the maximum SIP category within the project limits and whether or not any specific target crashes were identified. Finally, the table summarizes the scores given for each of the four evaluation metrics. As a reminder, for all scores 1 was considered the "best" and 5 was "worst". Also, the design/expenditure scores should be interpreted together. These scores are color-coded in the green-yellow-red palette for easier visual interpretation of the results in Table 5.49.

These summary data were analyzed in two general ways. First, a basic summary of the results of scores are presented. Second, the interrelationships between scores and project details were investigated.

It was decided that no additional statistical analysis of these summary data would be conducted. In justifying this decision, both the small sample size for the various subcategories (e.g. four projects have a safety performance score of 1) and the subjective, interrelated, nature of the scoring procedure were considered. The researchers felt that there was no basis for a rigorous analysis and that it would not produce meaningful conclusions. 
Table 5.49: SIP Project-level Evaluation Summary

\begin{tabular}{|c|c|c|c|c|c|c|c|c|c|c|c|c|c|}
\hline & & & \multicolumn{5}{|c|}{ Cost Related Items } & & & \multicolumn{4}{|c|}{ Metrics } \\
\hline Key No & 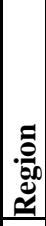 & Project Name & 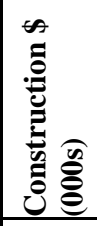 & 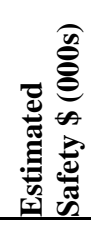 & 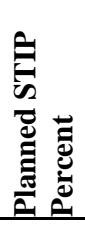 & 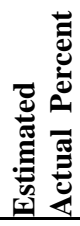 & 茪 & 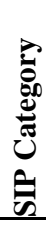 & 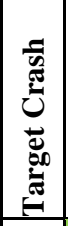 & 里 & 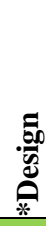 & 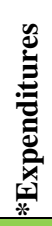 & 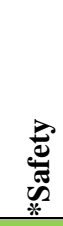 \\
\hline 7101 & 2 & US20 Cox Creek to UPRR & 4,730 & 386 & 7 & 8 & 1 & 5 & Yes & 1 & 1 & 1 & 1 \\
\hline 9841 & 3 & OR42 Winston to I5 & 3,437 & 489 & 30 & 14 & -16 & 4 & Yes & 1 & 2 & 3 & 2 \\
\hline 10349 & 2 & I-105 Willamette to Pacific Hwy & 16,253 & 2,234 & 15 & 14 & -1 & 3 & Yes & 1 & 2 & 1 & 3 \\
\hline 10576 & 1 & US30 Owl Creek & 1,655 & 286 & 39 & 17 & -22 & 2 & Yes & 5 & 2 & 3 & 2 \\
\hline 10665 & 1 & OR212 Rock Creek & 4,773 & 249 & 44 & 5 & -39 & 3 & No & 1 & 1 & 5 & 5 \\
\hline 10666 & 1 & OR10 Beaverton Tigard to MCL & 3,311 & - & 22 & 0 & -22 & 5 & No & 1 & 5 & 5 & 3 \\
\hline 10679 & 1 & OR8 Quince Street to Gaston & 2,879 & 286 & 10 & 10 & 0 & 5 & No & 1 & 4 & 1 & 5 \\
\hline 10680 & 1 & OR8 Minter Br to 117th & 6,874 & 819 & 13 & 12 & -12 & 5 & No & 1 & 4 & 1 & 2 \\
\hline 10731 & 1 & US26 Ross Island to SE50th & 3,213 & 219 & 7 & 7 & 0 & 5 & No & 1 & 2 & 1 & 5 \\
\hline 10748 & 2 & OR6 Tillamook RR to Jordan Cr & 2,942 & - & 2 & 0 & -2 & 2 & No & 3 & 2 & 5 & 3 \\
\hline 10807 & 2 & $\begin{array}{l}\text { OR22 Chemawa Road to N. } \\
\text { Santiam Int. }\end{array}$ & 5,832 & 656 & 12 & 11 & -1 & 4 & Yes & 1 & 2 & 1 & 1 \\
\hline 10817 & 3 & $\begin{array}{l}\text { US101 Nesika Beach to Rogue } \\
\text { River }\end{array}$ & 2,179 & 430 & 40 & 20 & -20 & 2 & No & 5 & 4 & 3 & 5 \\
\hline 11072 & 4 & OR126 Crooked River to Laughlin & 910 & 164 & 18 & 18 & 0 & 4 & Yes & 1 & 1 & 1 & 1 \\
\hline 11125 & 1 & OR211 Hult Rd to Hillockburn & 2,970 & 1,153 & 33 & 39 & 6 & 3 & Yes & 1 & 1 & 1 & 1 \\
\hline 11858 & 2 & OR18 Oldsville Rd to Ash Rd & 2,572 & 126 & 9 & 5 & -4 & 3 & No & 1 & 4 & 3 & 3 \\
\hline 11938 & 1 & US30 Bennett Rd to Laurel Ave & 2,136 & 190 & 19 & 9 & -10 & 4 & No & 1 & 4 & 3 & 5 \\
\hline 11939 & 1 & $\begin{array}{l}\text { US26 Hood River Hwy to Pollalie } \\
\text { Cr }\end{array}$ & 2,514 & 701 & 24 & 28 & 4 & 3 & No & 3 & 4 & 1 & 3 \\
\hline 11940 & 1 & $\begin{array}{l}\text { OR35 Long Prairie Rd to Odell } \\
\text { Hwy }\end{array}$ & 998 & 38 & 21 & 4 & -17 & 2 & No & 1 & 4 & 3 & 3 \\
\hline 12856 & 1 & US26 Jewell Jct to Military Rd & 2,036 & 531 & 13 & 26 & 13 & 4 & Yes & 1 & 2 & 1 & NA \\
\hline 12905 & 1 & OR10 OR217 to SW Maple Dr & 995 & 280 & 44 & 28 & -16 & 4 & Yes & 1 & 1 & 3 & 3 \\
\hline 13675 & 2 & OR221 Dayton to Salem & 4,877 & 59 & 3 & 1 & -2 & 4 & No & 1 & 4 & 1 & NA \\
\hline 14127 & 5 & OR203 WCL Lagrande to Union & 5,642 & 425 & 6 & 7 & 1 & 2 & Yes & 5 & 2 & 1 & NA \\
\hline 14172 & 2 & $\begin{array}{l}\text { US26 Lindseley Cr to Lwr } \\
\text { Nehalem }\end{array}$ & 2,160 & 325 & 48 & 15 & -33 & 3 & Yes & 1 & 1 & 3 & NA \\
\hline 14189 & 4 & US20 Hampton to Glass Butte & 5,444 & 306 & 3 & 6 & 3 & 3 & Yes & 5 & 1 & 1 & NA \\
\hline
\end{tabular}




\subsubsection{Basic Summary}

In Table 5.49, projects are presented in key number order and contain all of the summary information. Recall that for funding and expenditures, only scores of 1,3 or 5 were given and for design only 1, 2, 4 and 5 were given. The score distributions of the four project evaluation metrics are shown in Figure 5.53. Inspection of the project summary table (Table 5.49) and Figure 5.53 can be summarized as follows:

- Funding - The vast majority of projects (18 out of 24) received a score of 1 meaning they contained a SIP category 3 or greater and were eligible for safety funds. Of the six remaining projects, two did have a SIP category of 3 or greater in some SIP year. Four projects did not have any SIP category 3 or greater segments in any years and received a score of 5.

- Design - The majority of projects (15) received an acceptable design score of 1 or 2 . In these projects safety deficiencies were defined and improvements were considered enhancements. A relatively large number of projects (9) did not identify safety features that could be considered enhancements. These projects received poor scores of 4 (8 projects) or 5 (1 project).

- Expenditures - The expenditure score was perhaps the most challenging metric to evaluate. As a reminder, this metric was evaluated independently from the design score so projects could be scored poorly in design but still score well in expenditures. Stated another way, this metric captured the proposed safety expenditures (even if they should not have been eligible for funding under SIP). Overall, 21 of the 24 projects scored acceptably on expenditures (meaning that safety funds were spent as allocated). Thirteen projects had actual expenditures that closely matched planned expenditures and were given a score of 1 ; eight were given scores of 3 . The remaining three projects were given the worst score because no safety items could be identified.

- Safety - Because of limited after construction data, five projects were not given a safety performance score. For the remaining 19 projects, the scores were distributed across all values. Seven projects received a score of 3 indicating "no-change" in safety performance; seven projects receive a score of 1 or 2 meaning that some safety improvement was observed; and five projects received a score of 5 meaning safety was decreased.

A. Funding

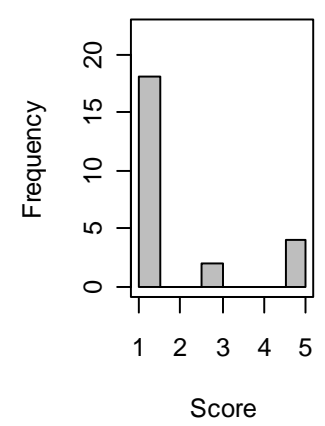

B. Design

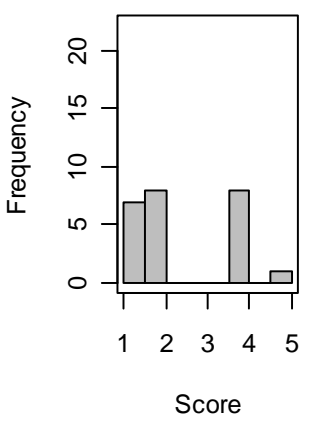

C. Expenditures

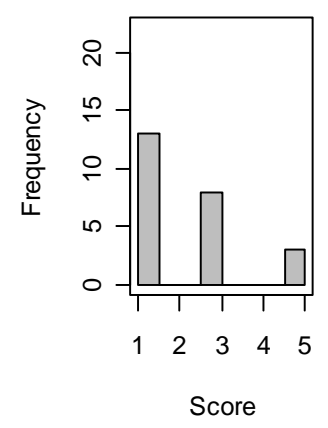

D. Safety

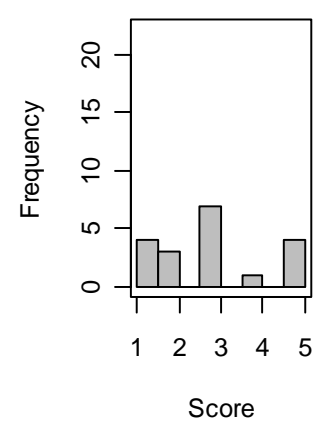

Figure 5.53: Distribution of Evaluation Scores 


\subsubsection{Relationship between Metrics}

As part of the evaluation, it was important to see if there were any apparent patterns relating the project scores and other project-level variables to each other. This analysis was completed by inspection of parallel coordinate plots. For brevity, these plots are not included in this report. The relationship that was observed is presented below in bullet form by metric.

Funding:

- Projects that contained a segment with a SIP category greater than 3 (funding score of 1 ) were not associated with a clear relationship with values in any other metric.

Design:

- In general, there was not a clear pattern for projects with a good design score and improved safety performance. As an example, the project OR 212: Rock Creek, received a design score of 1 for identifying enhancements, however, the primary project improvements were not constructed as originally designed and safety decreased. Another project, OR 10: OR 217 to SW Maple, was constructed as designed, however, the safety problem was not that significant before the improvement, thus resulting in a safety performance score of 3. In contrast, OR 8 Minter Bridge received a poor design score, yet exhibited an improvement in safety.

Expenditures:

- A clear relationship was found between safety performance on projects that had actual expenditures that closely matched planned expenditures. Of the 10 projects scoring 1 for expenditures, seven of them produced safety performance scores of 1 or 3 .

- However, when both expenditure and design metrics are considered together, projects that scored well in both categories also had good safety performance metrics with the exception of US26 Ross Island.

- There did not appear to be any pattern between the total project amount or the estimated safety construction amount and poor expenditures scores.

- A potential red flag was that safety improvements could not be identified on three projects. (Key 10665 OR 212 Rock Creek, Key 10666 OR10 Beaverton, and Key 10748 OR 6 Tillamook). The OR 6 Tillamook was rural with very limited safety work originally planned. It appears the safety work (a beacon) was installed prior to the project's construction. The remaining two projects were urban projects on high-volume arterials. As discussed in their evaluation, the projects probably included some improvements that could be justified as safety expenses (e.g. signal enhancement) but were not explicitly called out.

- A related red flag is that nine of projects appeared to use safety funds to incorporate mandatory items into projects. Some of these projects also appeared to use safety funds to fund durable pavement markings. If no lane departure crashes were identified, the use of safety funds for this improvement was not considered an enhancement. 
Safety:

- The clear pattern was that projects that identified a safety problem (target crashes), and were explicit about a solution for that problem (good design scores), as well as had estimated safety expenditures close to what was planned (expenditures), generally resulted in improved safety performance. In general, these projects were ones that applied the safety funds to specific, directed enhancements.

- Projects that scored poorly in the safety performance metric did not necessarily receive poor scores in other metrics.

\subsubsection{Summary}

In this chapter, mixed preservation-safety projects were evaluated on four metrics: funding eligibility, design, expenditures, and safety with regards to the SIP. The main conclusion is that the best projects in complying with all elements and objectives of the SIP Policy were clear about a safety problem, explicit about a solution for that problem, and constructed the safety element. These projects also exhibited the best performance with regards to safety improvements.

"Compliance" with the funding eligibility and design metrics can easily be monitored if project documentation is improved. Recommendations on how to do this are presented in the final chapter. Systematically monitoring expenditures on an ongoing basis would be more challenging. To extract this information from the existing information system required significant effort and a project-by-project approach. The same improvements in documentation and training that would help the funding and design policy aspects would also improve the likelihood that safety funds are spent as planned (only three projects had expenditure scores of 5 , and one of those (10748-OR6 Tillamook) constructed the planned safety improvement prior to the project). However, until all documentation improvements are implemented it could be worthwhile to review selected projects. Thus, in terms of long term performance measurement, changes in safety on these projects should be the primary metric. 
Page Intentionally Blank 


\subsection{PERFORMANCE MEASURES}

The work performed for the systemic and in particular, the project-based evaluations uncovered the type of information that is needed to review the performance of funded safety projects. This chapter briefly reviews existing Oregon Department of Transportation (ODOT) performance measures, presents some potential measures, and outlines what information is needed to compile useful metrics. Recommendations on how to improve documentation to support the suggested measures are provided in the recommendation section of the following chapter.

In the systematic evaluation (Chapter 4), projects in two Statewide Transportation Improvement Programs (STIPs) with safety funds were evaluated for performance. Projects were evaluated for changes in average total crashes and average fatal and injury A crashes. In Chapter 5, the Safety Investment Program (SIP) was evaluated on four metrics: funding eligibility, design, expenditures, and safety. The conclusions from the chapter suggest that ongoing evaluation of the first three metrics are a matter of improving project documentation and policy and are not suitable as performance measures. As such, only safety-related performance measures are presented in this chapter.

The previous chapters studied historical projects. While policies and procedures have changed over time, the results of this research are still relevant. However, this chapter is focused on transferring the results of the previous two chapters in the context of the current program (the Highway Safety Improvement Program - HSIP).

\subsection{EXISTING PERFORMANCE MEASURES}

Certainly, performance measurement by government transportation agencies is becoming more common, particularly at the state level. Performance measures can be used to communicate with both internal (i.e., decision makers) and external (i.e., public stakeholders) customers and can be based on either quantitative (i.e., crash data) or qualitative (i.e., surveys such as customer orientation) analysis. Without going into significant detail about performance measurement, it is essential that performance measures clearly relate to identified agency or program goals so that decision makers and public constituents can follow investment decisions (Meyer 2002). It is important to distinguish between performance measures at the agency level and those at the program level. Agency level metrics tend to be high-level, while programmatic level measures are more detailed. Ideally, these program measures should feed or match the agency-level metrics.

At the Oregon DOT agency level, 27 key performance measures are summarized in the Service Efforts and Accomplishments Annual Performance Report (SEAP) (ODOT 2007). For brevity, only the first nine measures that speak to overall safety of the transportation system are presented. These measures are:

- Traffic Fatalities: Traffic fatalities per 100 million vehicles miles traveled (VMT).

- Traffic Injuries: Traffic injuries per 100 million vehicles miles traveled (VMT). 
- Safe Drivers: Percent of drivers who drove safely by avoiding traffic violations and accidents during the prior three years.

- Impaired Driving: Percent of fatal traffic accidents that involved alcohol.

- Use of Safety Belts: Percent of all vehicle occupants using safety belts.

- Large Truck At-Fault Crashes: Number of large truck at-fault crashes per million vehicle miles traveled (VMT).

- Rail Crossing Incidents: Number of highway-railroad at-grade incidents.

- Derailment Incidents: Number of train derailments caused by human, track, or equipment error.

- Travelers Feel Safe: Percent of public satisfied with transportation safety.

As discussed in the background chapter of this report, the current (at the time of this report) Federal transportation authorization bill - Safe, Accountable, Flexible, Efficient Transportation Equity Act: A Legacy for Users (SAFETEA-LU) - requires states to develop a Strategic Highway Safety Plan (SHSP). In Oregon, the 2004 Oregon Transportation Safety Action Plan (OTSAP) was amended in 2006 to serve as the Oregon SHSP. The plan identified 14 performance measures, many of them behavioral, which are focused on the overall safety efforts of the Department but still very high-level. For brevity, only those that could be related to an engineering-based project performance are presented.

- Transportation-related deaths per 100,000 population

- Deaths due to motor vehicle crashes per 100 million VMT

- Deaths due to motor vehicle crashes per 100,000 population that is 19 and under

- Total motor vehicle crashes, per 100 million VMT

- Deaths due to alcohol and drug related motor vehicle crashes, per 100 million VMT (.01 BAC or greater.)

The SEAP key measures and the OTSAP performance measures are not necessarily useful at the program level (i.e. the HSIP) and are more suited for aggregate state performance measures. Both documents have fatalities per 100 million VMT in common; the SEAP includes injuries per 100 million VMT. These are the only agency-level measures that are applicable to engineering project improvements.

At the program level, SAFETEA-LU requires that projects funded under the HSIP program are subject to an "Annual Evaluation Report." These projects are defined in the 2006 Amendment to the Oregon Strategic Highway Safety Plan (SHSP) which states that:

"SAFETEA-LU requires that each state establish and implement a program of highway safety projects that is consistent with the requirements of 23 U.S.C. 135(g) Statewide Transportation Improvement Program (STIP). In Oregon a program of SAFETY projects that directly implement the SHSP are scheduled in the STIP, this includes all projects 
funded under Section 148 and includes safety projects from other funding sources as well.”

The projects referred to are the same type of projects that have been evaluated in this research report. This analysis requires a simple report that broadly

“...describes the extent to which the improvements funded under this section contribute to the goals of-- reducing the number of fatalities on roadways; reducing the number of roadway-related injuries; reducing the occurrences of roadway-related crashes; mitigating the consequences of roadway-related crashes; and reducing the occurrences of crashes at railway-highway crossings. 23 U.S.C. 148(g,1,C)"

\subsection{POTENTIAL PERFORMANCE MEASURES}

The mission of ODOT's Highway Safety Program is "to carry out highway safety improvement projects to achieve a significant reduction in traffic fatalities and serious injuries.” Thus, any performance measure should speak directly to this goal and be complimentary with agency-level measures.

In evaluating safety improvement, the primary challenge is an accurate prediction of the expected number of crashes in the after period had no treatment been implemented. After this prediction, a comparison can then be made with the number of crashes that have occurred with the treatment in place. This prediction is challenging because of the influencing factors that must be controlled including traffic conditions, weather, land use, crash reporting levels, and longterm trends.

There are two primary issues associated with this prediction: 1) how to address changes in traffic volume (and other variables), and 2) how to address selection bias. There is a large and growing body of well-done before-after analyses of safety improvements. A detailed discussion of this literature is outside the scope of this chapter but the main issues can be briefly summarized. The interested reader is referred to Hauer (1997) for more information.

It is well-established that exposure (traffic volume) is strongly correlated with motor vehicle crashes. To account for changes in traffic volume, one approach is to use a crash rate for comparison. Rates can be deceiving, however, since changes in either the numerator (crashes) or exposure (miles driven) changes the measure. In effect, the engineering "safety" of a facility or intersection could be unchanged but because of a change in exposure (e.g. higher fuel prices resulting in less travel), the facility is considered "safer" though nothing has actually been improved. However, rates can be useful when comparing similar facilities within similar volume ranges (e.g., state-to-state comparison of rural interstate highways) but are generally not recommended for performance measures.

The selection bias is present because the safety projects were constructed at known safety problem locations. There is a well-established concept of regression-to-the-mean (RTM). In simple terms, this means that high-crash locations tend to return to long-term average performance even without improvements. If not properly accounted for project "success" can be 
overestimated. The influence of RTM can be dampened (but not eliminated) by using longer before-after periods for evaluation (more than three years).

To address both of these issues, the state-of-the-practice is use of safety prediction methods (Safety Performance Functions) to account for volume and other changes and to use an Empirical-Bayes adjustment to account for RTM. These procedures and prediction models (subject to calibration) should be available for many Oregon facilities shortly in the soon to be released Highway Safety Manual (by AASHTO, developed by TRB Task Force for the Development of the Highway Safety Manual). Software to support before and after evaluations should also be available as part of this effort. However, at the time of this report publication, using these methods in measuring the safety program performance would require significant effort.

The primary challenge in systematically evaluating safety improvements is not the methodological issues described previously but the lack of adequate documentation about safety work limits, target crash types and other useful information. To obtain these data the research team had to assemble and review many pieces of information to develop a clear understanding of the project work. While in almost all cases this was successfully done in the project-level evaluation, such effort is not feasible for a systematic evaluation of the program. To effectively evaluate a project the following basic questions need to be addressed:

- What was the identified problem?

- When was this problem investigated?

- What was the proposed solution?

- Where were these improvements to be constructed?

Assuming this information can be obtained (a recommendation to ensure that it is collected is presented in the conclusions chapter), the preferred safety performance measure would be related to target crashes, though it would still be useful to monitor total crashes. Target crashes would be defined as "those accident types, the occurrence of which can be materially affected by the treatment (Hauer 1997)." The recommended performance measures are:

- Change in average target (all severity) crashes per year;

- Change in average target fatal and injury A crashes per year;

- Change in average target injury $\mathrm{B}$ and $\mathrm{C}$ crashes per year;

- Change in average total (all severity) crashes per year;

- Change in average total fatal and injury A crashes per year; and

- Change in average total injury B and C crashes per year.

In various ways, these performance metrics were demonstrated in both the systematic and project-level evaluation chapters. Using crash counts is recommended, not person injury or fatality counts, since multiple occupant crashes could potentially skew results. A three-year minimum is recommended for both the before and after periods. The measures are suitable for long-term monitoring of the program's progress. 
These measures are adaptable to serve different needs:

- Any of these measures could be presented as a percentage change or a frequency (count) change. There are advantages and disadvantages for both communicating to decisionmakers and monitoring project success.

- These measures could be calculated at the project-level then, aggregated by ODOT region, by general type of project, and by road character (urban and rural), by functional class or volume range, by stand-alone or mixed work type projects, or any grouping that provides useful information.

- If a count change is calculated for the program, it could be reported to what extent the safety program is contributing to the ODOT agency-level metrics (i.e. the HSIP program has resulted in a reduction of $X$ crashes which contributed to $Y$ change in the relevant overall state performance measure expressed per VMT exposure).

Prior to the adoption of predictive methods, considerations should be given to characterizing the change in exposure. At the project-level, a rate calculations and comparisons could be appropriate, but performance measures should be expressed as a frequency measure. 
Page Intentionally Blank 


\subsection{CONCLUSIONS AND RECOMMENDATIONS}

The Safety Investment Program (SIP), originally called the Statewide Transportation Improvement Program - Safety Investment Program (STIP-SIP) was adopted by the Oregon Transportation Commission (OTC) in August 1998. In approving the STIP Safety Investment Program, the OTC established the following policies: 1) invest in those segments or locations that have high levels of known fatal and serious injury crashes; and 2) invest in safety countermeasures that show a high benefit-to-cost ratio and target specific problems. Safety projects were to be selected based on high crash locations as identified by the SIP Category and the Safety Priority Index System (SPIS). The SIP Policy was first implemented in the 2000-2003 STIP.

The primary objective of the research was to study the effectiveness of SIP Policy in meeting the goals and objectives of ODOT. To accomplish these objectives, this research evaluated the SIP Policy from the perspective of 1) an overall program for safety improvement projects, 2) a guiding policy when safety improvements are planned as part of other project work, and 3) a component integrated with the highway design procedures for resurfacing, restoration, or rehabilitation (3R) projects. The research included two levels of evaluation; the first evaluation was done as part of the systematic evaluation, while the second was a project-level evaluation. The systematic evaluation used crash data, geographic information systems (GIS) tools, and data from two consecutive STIPs to evaluate the safety investment policy at a comprehensive level. All projects in the target STIP that were funded by safety funds were evaluated for before and after safety performance. In the project-level evaluation, a sample of 24 mixed preservation/safety projects spanning multiple STIP years and all five ODOT regions were evaluated. The evaluation focused on detecting application of the policy in the scoping, design, and construction phases of the project. Finally, a brief review of possible performance measures was conducted based on the results of these two evaluation approaches.

The conclusions of the research and the subsequent recommendations are presented in the next two sections.

\subsection{CONCLUSIONS}

1. The systematic evaluation revealed that, in general, projects where safety funds were used resulted in a net decrease in total crashes as well as fatal and severe injury crashes; however, these benefits were not realized for all locations or all work types. In addition:

- The selection of sites where safety funds were used, in the 2000 to 2003 and the 2002 to 2005 STIPs, sometimes did not occur at locations with recent crash histories.

- Both stand-alone safety projects as well as preservation projects where safety funds were used demonstrated overall reductions in crashes.

- The systematic evaluation provided overall statistics, insights into specific projects, and a tool for additional project-level analysis using the larger dataset. 
2. When safety improvements are planned as part of other projects, there will necessarily be a funding push-pull between safety improvements and other work-types. At the time of its introduction, the SIP served as an approach to improving safety while balancing the need to pave more miles of highway. This balance was to be achieved by allowing more funds to go to pavement preservation by using safety funds for enhancements on highcrash segments and by limiting safety improvements on low crash corridors. The detailed review of the 24 mixed safety-preservation projects highlighted some of the challenges of successfully implementing the SIP Policy. The project-level evaluation concluded that:

- It was clear that the SIP Policy has not been applied consistently to mixed projects. In particular, the variety of design and, to a lesser extent, the funding eligibility scores, highlight the variety of policy interpretations.

- The most important project element to improve safety performance was the specific identification of a safety problem.

- Where estimated safety expenditures were found to closely match the planned safety expenditures, safety performance was more likely to improve.

- Projects that made clear safety problem identification were also likely to have closely matching expenditures.

- Projects that identified "improvements as necessary" in the project prospectus did not result in decreased crashes to the same extent.

3. Safety funds were often used for replacement of existing features and mandatory design items identified in the Highway Design Manual (HDM) which are not allowable safety expenses according to the SIP. From the perspective of this evaluation, there has been a widespread misuse of safety funds.

4. In the project-level evaluation, many documents and information sources were compiled in order to answer the following basic questions:

- What was the identified safety problem?

- When and how adequately was this problem investigated?

- What was the proposed solution?

- Where were these improvements to be constructed?

Not all of these questions could be answered for all projects due to limitations in the documentation maintained on the project from the time it was scoped until the time construction was completed. Consistency in the documentation required and received was found to be an overall issue.

5. In the project level evaluation, many shorter projects were contained within high-rated SIP segments. The project limits did not contain the most significant crash problems but "benefited" by being eligible for safety funds. In addition, the five-mile length introduces challenges in urban areas (large counts). The five-mile fixed length is only useful if the project limits are very close to the SIP segment length. 
6. Adding enhancements or improvements to existing project work makes sense from a financial (less project cost) and safety perspective. The review from the systematic as well as project-level evaluation reveals that this can also be done in a manner that enhances safety.

7. The project level evaluation did not did not find evidence that the SIP policy was a useful design tool in mixed projects or that it was being consistently implemented. It appears that the most visible component of the SIP Policy - the five-mile segment ratings - are now of limited usefulness for the ODOT safety program. Their use as a project identification tool is no longer supported and in our opinion, the five-mile fixed length is only useful if the project limits are very close to the SIP segment length. In the project evaluation, many shorter projects were contained within high-rated SIP segments. The project limits did not contain the most significant crash problem but "benefited" by being eligible for safety funds. In addition, the five-mile length introduces challenges in urban areas (large counts). Given the SIP's rural project roots, this is not unexpected

8. This research was not able to clearly answer the question of whether or not deferring improvements on low-crash segments, in order to invest these safety funds elsewhere, has resulted in an improvement in overall safety.

Overall, this historical evaluation of projects concludes that the SIP Policy was not been applied consistently and in accordance with the original intent of the program. The research found clear gaps; to ameliorate these deficiencies specific recommendations are given in the following section.

\subsection{RECOMMENDATIONS}

1. To make better informed decisions and monitor performance about its investment of safety funds and more effectively evaluate the results, better documentation is needed. This documentation could be named an "investigations report." At a minimum, this documentation can be a stand-alone form but in the long run should be integrated into the project management data systems. The following should be considered:

- It should be consistently included with the region's safety project files or perhaps sent to headquarters or both.

- Some consideration should be given to incorporating guidance in existing project delivery guides or region scoping documents or manuals.

- At a minimum the document should include the following items:

o The year the project was scoped. This is also a missing data element in the project prospectus that would be useful for other policy evaluations. This data element should be added to the project documentation software.

- A summary of the existing crash patterns and trends should be provided in a standard format. The ODOT Crash Data System or other tool could be configured to provide this information for the project limits. 
o Traffic volumes and patterns for the recent history (three years) should be included. A specific roadway classification (e.g. freeway, rural multi-lane, or rural two-lane) should be included.

o If a solution is recommended, the document should identify the types of crashes that are targeted. The target crash type should be defined (in a standard, repeatable manner). The work limits of the safety improvement should be documented in the appropriate format (route number, highway number, mileage type, beginning milepoint, end milepoint, etc).

o Guidance should be provided about when an element is considered projectwide or is a spot treatment. A template could be created to allow the correct parameters (ODOT highway number, milepost, connection, component, direction, etc) to be accurately recorded for each project.

o The report should also include a before construction photo (from the DVL or from a site visit).

o A narrative justification defining the enhancement for which the safety funds will be used.

o An estimated cost for the targeted safety improvement which can be used to calculate a benefit-to-cost ratio.

o The name of the investigator and possibly a review and concurrence by the Region Traffic or Safety Engineer.

This document would serve as the basis for safety performance evaluation, either at the region level or at the program level. There is work currently funded by the Traffic and Roadway Section to produce a Safety Investigations Manual that will be used by region traffic investigators as guidance for safety project investigation and documentation techniques. A form is to be included that is very similar to what is proposed in this recommendation.

With standardized documentation, the agency will find itself in a more advantageous position in litigation if proper documentation and decisions are made.

2. The project-level evaluation found examples where the SIP Policy was not followed. In most cases this was a result of mandatory design elements being identified and funded by the safety funds. There is also evidence that safety problems that were identified by the SIP screening tool were not addressed appropriately when preservation projects were completed. This may partially be due to confusion about the SIP Policy. For these reasons, and to improve Oregon's safety investments, it is recommended that the SIP Policy nomenclature be dropped and its core philosophies (related to design choices on mixed projects and a of reduction serious crashes) be integrated in the existing Highway Safety Program. Discontinue use of the SIP problem identification tool and enhance SPIS to, in addition to identifying safety problem locations by highway and milepoint, identify problem intersections and locations with specific problems such as run off the road crashes, crashes due to excessive speed. To accomplish this, the following actions should be taken: 
- Revise the Highway Design Manual to remove references to the SIP segment ratings.

- $\quad$ Revise the Highway Safety Program Guide to remove references to SIP.

- Identify options for enhancing SPIS to improve its performance as a comprehensive problem analysis tool.

3. The research identified shortcomings of the SIP policy, To support safety investment decisions the following actions should be taken:

- Design the proposed investigations report to require identification of a specific safety problem and solution in order to use safety funds. It is likely that this would also improve the appropriate expenditure of safety funds since the cost of a specific improvement can be accurately estimated.

- Strongly consider wording that makes it clear that the SIP Category for a segment is only a screening tool for a potential safety problem.

- Review and revise the Highway Design Manual (HDM) to strengthen the guidance which identifies the design elements that should be considered mandatory.

- Consider adding a requirement that the use of safety funds on mixed preservation projects is contingent on the investigations report recommended in the documentation section. It should be required that all improvements are explicitly identified and targeted since the project-level evaluation indicated that those projects that did this resulted in the greatest safety improvement.

- Provide some internal training or instruction to project leaders on the SIP policies. These positions often have a high-turnover rate and could benefit from training. A helpful element of this training should provide a safety program process including a flowchart and responsible parties including the Traffic-Roadway Section, Region Traffic, Project Leaders, the STIP Programming Financial Person in the region, and the Construction Project Manager. This would allow all those involved to clearly see their role in the safety program implementation process.

4. One important outcome of this research was the observations made on what data are needed to suitably monitor the performance of the safety program (e.g. performance measurement). The measures recommended for the program level, as presented in Chapter 6, are complimentary to the agency-level metrics. The project level evaluation revealed the usefulness of knowing the project scope date, targeted crashes, and the specific mileposts of an improvement. To do widespread, systematic performance measurement these data are needed. The researchers make the following recommendations for performance measurement:

- No measures should be developed for funding, design, or expenditure metrics. Instead, ODOT should seek to implement the recommendations 1-4 for documentation and policy improvements. If these are successfully implemented such detailed evaluation of projects should not be necessary on a systematic basis. 
However, occasional monitoring of project expenditures should be considered until documentation recommendations are completely implemented. This could involve detailed follow-up with project managers shortly after projects are complete.

- Assuming the necessary documentation is routinely provided in the "investigations report" the following measures are recommended:

o Change in average target (all severity) crashes per year;

o Change in average target fatal and injury A crashes per year;

o Change in average target injury B and $\mathrm{C}$ crashes per year;

o Change in average total (all severity) crashes per year;

o Change in average total fatal and injury A crashes per year; and

o Change in average total injury $\mathrm{B}$ and $\mathrm{C}$ crashes per year.

- In various ways, these performance measures were demonstrated in both the systematic and project-level evaluation chapters. Using crash counts is recommended, not person injury or fatality counts, since multiple occupant crashes could potentially skew results. A three-year minimum is recommended for both the before and after period.

\subsection{SUMMARY}

The primary objective of the research was to study the effectiveness of SIP Policy in meeting the goals and objectives of ODOT. The research accomplished this by thoroughly reviewing the program from both the overall systematic approach and the project-level evaluation. Implementation of the recommendations enumerated above should result in noticeable programmatic and policy improvements. 


\subsection{REFERENCES}

Agent, K.R., J.G. Pigman, and E.R. Green. (2004). Effect of Pavement Resurfacing on Traffic Safety. Research Report KTC-04-02/SPR257-03-1F, Kentucky Transportation Center.

Alaska Department of Transportation and Public Facilities. (2006). Alaska Highway Safety Improvement Program Handbook. $5^{\text {th }}$ edition.

Alabama Department of Transportation. (Accessed Feb. 2007). Alabama 2006 Five Percent Report. http://safety.fhwa.dot.gov/fivepercent/06al.htm.

American Association of State Highway and Transportation Officials (AASHTO). (2001). A Policy on Geometric Design of Highways and Streets.

American Association of State Highway and Transportation Officials (AASHTO). (1977). Geometric Design Guide for Resurfacing, Restoration, and Rehabilitation (RRR) of Highways and Streets.

American Association of State Highway and Transportation Officials (AASHTO). (1996). Roadside Design Guide.

Cleveland, D.E. (1987). Effect of Resurfacing on Highway Safety. State of the Art Report 6:

Relationship Between Safety and Key Highway Features. A Synthesis of Prior Research. Transportation Research Board, National Research Council.

Colorado Safety and Traffic Engineering Branch. (2005) Colorado Highway Safety Improvement Program (HSIP).

Federal Highway Administration (FHWA). (Accessed Feb. 2007). Highway Safety Improvement Program “5 Percent Report” Requirement. http://safety.fhwa.dot.gov/fivepercent/index.htm.

Federal Highway Administration (FHWA). (Accessed Feb. 2007). FHWA Technical Advisory T7570.2, 1994. http://www.fhwa.dot.gov/legsregs/directives /techadvs

/t75702.htm.

Federal Highway Administration (FHWA). (1998). Pavement Preservation: A Road Map for the Future. Ideas, strategies, and techniques for pavement preservation forum, October 26-28,Kansas City, Missouri.

Federal Highway Administration (FHWA). (2005). Safe, Accountable, Flexible, Efficient Transportation Equity Act: A Legacy for Users. A Summary of Highway Provisions. Washington, D.C.

Federal Highway Administration (FHWA). (2006a). SAFETEA-LU Guidance Highway Safety Improvement Program, 23 U.S.C. 148(c)(1)(D) “5 Percent Reports”.

http://safety.fhwa.dot.gov/fivepercent/index.htm (Accessed Feb 2007). Washington D.C.

Federal Highway Administration (FHWA). (2006b). SAFETEA-LU Guidance Highway Safety Improvement Program Reporting Requirements 23 U.S.C. 148(g). Washington, D.C. 
Grile, C., K.M. Hunter-Zaworski, and C.M. Monsere. (2005). Programming Safety Improvements On Pavement Resurfacing, Restoration, And Rehabilitation Projects. Transportation Research Record: Journal of the Transportation Research Board, No. 1922, Transportation Research Board of the National Academies, Washington, D.C., pp 73-78.

Harwood, D.W., E.R.K. Rabbani, K.R. Richard, H.W. McGee, and .L. Gittings. (2003). NCHRP Report 486: Systemwide Impact of Safety and Traffic Operations Design Decisions for 3R Projects. Transportation Research Board of the National Academies, Washington, D.C..

Hauer, E., D. Terry, and M.S. Griffith. (1994). Effect of Resurfacing on the Safety of Two-Lane Rural Roads in New York State. Transportation Research Record 1467, Transportation Research Board, National Research Council, pp 30-37.

Hauer, E. (1997). Observational before-after Studies in Road Safety, Pergamon Press Inc. , Oxford, N.Y.

Iowa State University Center for Transportation Research and Education (Iowa CTRE). (2001). Systematic Identification of High Crash Locations. Iowa Department of Transportation.

Iowa State University Center for Transportation Research and Education (Iowa CTRE). (2002). Evaluation of the Iowa DOT's Safety Improvement Candidate List Process. Iowa Department of Transportation.

Kansas Department of Transportation. (2006). Highway Safety Plan FFY 2007.

Layton, R. D. (1996). An Evaluation of The Safety Priority Index System. Transportation Research Institute at Oregon State University, Prepared for the Oregon Department of Transportation.

Mahoney, K. M., F. Julian, and H. W. Taylor, Jr. (2006). Good Practices: Incorporating Safety Into Resurfacing and Restoration Projects. Report No. FHWA-SA-07-001, Federal Highway Administration, Washington, D.C.

Meyer, M. D. (2002). Measuring System Performance: Key to Establishing Operations as a Core Agency Mission, Transportation Research Board.

Massachusetts Highway Department. (2006). Massachusetts Strategic Highway Safety Plan.

National Cooperative Highway Research Program (NCHRP). (1986). Methods for Identifying Hazardous Highway Element. National Cooperative Highway Research Program Report 128. Transportation Research Board, National Research Council, Washington, D.C..

National Cooperative Highway Research Program (NCHRP). (2001). Impacts of Resurfacing Projects With and Without Additional Safety Improvements. Research Results Digest, Number 255. Transportation Research Board, National Research Council, Washington, D.C.

Oregon Department of Transportation. (2007). ODOT Highway Safety Program Guide. (Accessed September, 2007). http://www.oregon.gov/ODOT/HWY/TRAFFICROADWAY/docs/pdf/ODOT_Safety_Program_Guide_2007.pdf.

Oregon Department of Transportation. (2003). Highway Design Manual. (Accessed April, 2007). http://egov.oregon.gov/ODOT/HWY/ENGSERVICES/

hwy_manuals.shtml\#2003_English_Manual. 
Oregon Department of Transportation. (2007). Service Efforts and Accomplishments Annual Performance Report (SEAP). http://www.oregon.gov/ODOT/CS/PERFORMANCE/index.shtml

Oregon Department of Transportation. (2006). 2006 Amendment One - TSAP http://www.oregon.gov/ODOT/TS/tsap.shtml.

Oregon Department of Transportation. (2004). 2004 Oregon Transportation Safety Action Plan http://www.oregon.gov/ODOT/TS/tsap.shtml.

Sanford, K.L., E.D. Meyer, and H.A. Dameron. (1981). A Cost-Safety Comparison of Illinois Rehabilitation Design Policies. Transportation Research Record 1060, Transportation Research Board, National Research Council, pp 70-74.

Shober, S.E, and D.A. Friedrichs. (1998). Pavement Preservation Strategy. Transportation Research Record 1643, Transportation Research Board, National Research Council, pp 44-53.

Strategic Highway Safety Planning Team. (2003). State of Maryland Strategic Highway Safety Plan.

Tighe, S., L.C. Falls, and J. Morrall. (2001). Integrating Safety with Asset Management Systems. $5^{\text {th }}$ International Conference on Managing Pavements, Seattle, Washington.

Transportation Research Board (TRB). (1987). Special Report 214: Designing Safer Roads: Practices for Resurfacing, Restoration, and rehabilitation. Transportation Research Board, National Research Council, Washington D.C.

Utah Department of Transportation. (2006). Utah Department of Transportation Roadway Safety Improvement Program.

Vermont Agency of Transportation (VTrans). (2004). Highway Safety Improvement Program.

Virginia Department of Transportation. (2006). Highway Safety Improvement Program(HSIP)

Fiscal Year 2007-08.

Zimmerman, K. A., and R. Larson. (2005). Improving Safety as Part of a Pavement Preservation Program. Transportation Research Circular E-C078: Roadway Pavement Preservation. 

APPENDIX A:

ACRONYM LIST 



\begin{tabular}{|l|l|}
\hline AADT & Average Annual Daily Traffic \\
\hline AASHTO & American Association of State Highway Transportation Officials \\
\hline ADT & Average Daily Traffic \\
\hline ARF & Accident Reduction Factor \\
\hline B/C & Benefit-Cost Ratio \\
\hline CTRE & Center for Transportation Research and Education \\
\hline DOT & Department of Transportation \\
\hline EPDO & Equivalent Property-Damage-Only \\
\hline GIS & Geographic Information System \\
\hline FHWA & Federal Highway Administration \\
\hline HSIS & Highway Safety Improvement Program \\
\hline KABCO & $\begin{array}{l}\text { Severity Ranking Scale representing Fatalities (K), Injury Levels } \\
\text { (A, B, \& C), and Property Damage Only (O) }\end{array}$ \\
\hline NCHRP & National Cooperative Highway Research Program \\
\hline ODOT & Oregon Department of Transportation \\
\hline Oregon SIP & Oregon Safety Investment Program \\
\hline SAFETEA-LU & $\begin{array}{l}\text { Safe, Accountable, Flexible, Efficient Transportation Equity Act: } \\
\text { A Legacy for Users }\end{array}$ \\
\hline SHSP & Strategic Highway Safety Plan \\
\hline SIP & Safety Investment Program \\
\hline SPIS & Safety Priority Index System \\
\hline STIP & Statewide Transportation Improvement Program \\
\hline VTrans & Vermont Agency of Transportation \\
\hline
\end{tabular}



APPENDIX B:

OTC MEETING MINUTES, AUGUST 1998 



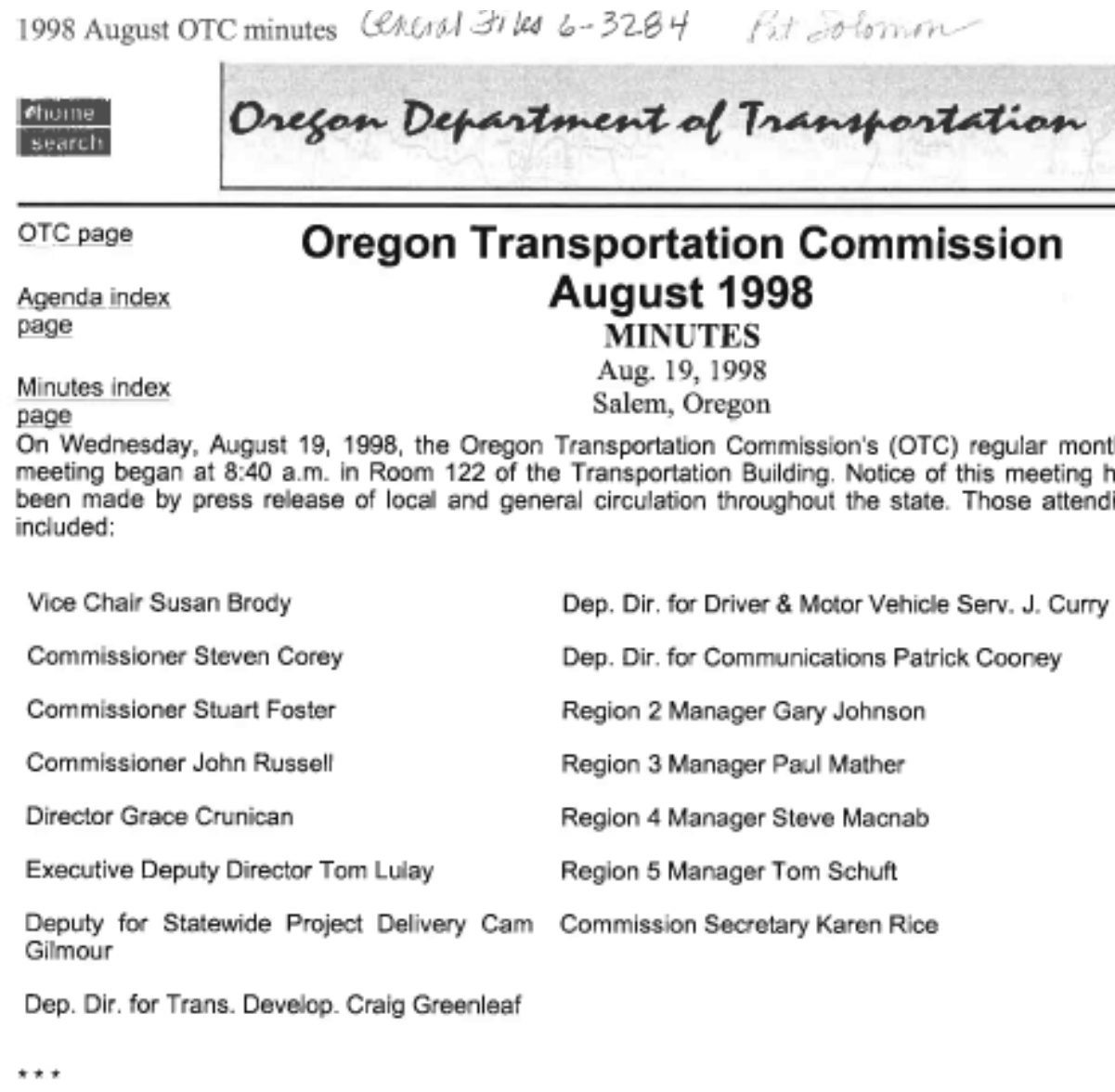

Vice Chair Brody began the regular monthly meeting by confirming the next two Commission meeting dates of:

- Wed., September 9, and Thurs., September 10, in Brookings

- Wed., October 14, in Salem

It was noted that a joint meeting with the Washington State Transportation Commission may be planned for the afternoon of October 14. Because of another commitment, Commissioner Corey indicated he may not be available if the meeting runs late on the day of the 14 th.

Region 3 Manager Paul Mather briefed the Commission on the times of the tour and flight details for the Brookings meeting in September. 


\section{Director Grace Crunican's report:}

- The audit report has been released by Dye Management Group on the Managernent Review of Construction and Maintenance. The Commissioners are encouraged to read the report especially in view of issues raised at the last legislative session about their fole in ODOT operations and management. The report has also been presented to the Efficiency Committee.

- Announced staff changes including the appointment of Cam Gilmour as Deputy for Statewide Project Delivery, appointment of Mike Marsh as Deputy Director of Finance and Administration Operations, and the resignation of Betsy Johnson, Aeronautics manager.

- Thanked commission and staff for the outstanding work that has been accomplished in getting the Highway Plan and STIP work out and ready for staff and the Cornmission.

\section{$\cdots$}

Executive Deputy Director, Tom Lulay, requested approval from the Commission on the funding proposal for the 2000-2003 STIP (Statewide Transportation Improvement Program). The presentation included the new STIP Safety Program, policy assumptions, program funding levels, and regional equity splits. (Additional background material in General Files, Salem.)

\section{STIP Safety Program:}

Steve Macnab gave the commission a brief presentation on the STIP Safety Investment Program and recognized Hank Honeywell (Federal Highway Administration) and his staff for their support and effort to develop a program that meets theirs and our needs. This program formally ties together the safety programs and the preservation programs for now and into the future. Mr. Macnab recognized Larry Christensen, Traffic Safety Section Project Manager for his work on this program.

Commissioner Corey moved to approve the program and the motion was unanimously passed.

\section{Policy Assumptions used in constructing the draft STIP:}

Enhancement Program: Commissioners requested to review the criteria used for project selection and the need to develop specific criteria for Quality Development Objectives. Director Crunican will review agreements we have with local governments. There are a wide range of items, so our proposal of this policy is subject to resolving several issues with them.

Salmon Program: We will continue our commitment at $\$ 3,000,000$ a year.

Immediate Opportunity Fund: ODOT proposed to continue funding level set at $\$ 7$ million a year but

http:/intranet.odot.state.or.us/comm/otc/minutes/1998-08m.htm 


\title{
STIP SAFETY INVESTMENT PROGRAM
}

\section{OTC Presentation}

\author{
August 1998
}

\section{FHWA PARTNERSHIP}

- Recognize the support from FHWA to implement a better way to invest safety dollars.

- FHWA has formally approved their participation in the program. (letter of 7/21/98) 


\section{INTERNAL PARTNERSHIP}

- STARTED IN OCTOBER 97

- TRANSPORTATION SAFETY PROJECT LEADERSHIP

- SECTIONS INVOLVED:

$\rightarrow$ Transportation Safety Section

$\rightarrow$ Traffic Management Section

$\rightarrow$ Roadway Engineering Section

$\rightarrow$ Transportation Data Section

$\rightarrow$ STIP Development Unit

$\rightarrow$ Mapping and Inventory Unit

$\rightarrow$ Oregon State University

\section{ACCOMPLISHMENTS}

- DEVELOPED NEW TOOLS

$\rightarrow$ Highway Segment and Spot Safety Priority Mapping

$\rightarrow$ Automated Information and Analysis Tools

$\rightarrow$ Safety Countermeasure Decision Matrix

- REVISED HIGHWAY DESIGN MANUAL

$\rightarrow 3$-R Standards

$\rightarrow$ Design processes

$\rightarrow$ Exceptions to Standards Process "Pave Mainly" approved by FHWA 7/21/98 


\section{PROGRAM GOAL}

\section{"Reduce the fatality crash rate on the state highway system."}

\section{LINK TO OTHER PLANS}

"Target resources to dangerous routes and locations in cooperation with local and other state agencies." (Oregon Transportation Plan-Action 1G.4 \& Oregon Transportation Safety Action Plan--Action 18)

"6...develop and implement the most cost-effective solutions to high priority safety problems." (Draft Oregon Highway Plan--Action 2F.1) 


\section{PERFORMANCE MEASURE}

- Deaths/100M VMT (OTSAP)

$\rightarrow 1996$ Actual $=1.73 / 100 \mathrm{M}$

VMT

$\rightarrow 2010$ Target $=1.30 / 100 \mathrm{M}$

VMT

\section{KEY POINTS}

- Responds to OTP \& TSAP Goals to Reduce Fatality Crash Rates on State System

- Maximizes Benefits of Safety Investment

- Responds to OTC Direction for a "Pave Mainly" Preservation Program

- Expedites Preservation Contract Delivery

- Reduces Preservation PE Costs 


\section{INVESTMENT STRATEGY}

- Invest in those segments or locations that have high levels of known fatal \& serious injury crashes (see mapping tool)

- Invest in Safety Countermeasures that show a high Benefit/Cost ratio (B/C) and target specific problems

\section{BENEFIT / COST METHODOLOGY}

- Benefits to Society over 10 year period

$\rightarrow$ Vehicle Damage

$\rightarrow$ Medical Costs

$\rightarrow$ Lost Wages

- Cost of Safety Countermeasure

$\rightarrow$ e.g. channelize intersections, widen shoulders, install median barriers

- Selection threshold: $\mathrm{B} / \mathrm{C}>0.8$ 


\section{LINK TO PRESERVATION PROGRAM}

- FIRST INVESTMENT PRIORITIY:

Projects on high priority segments linked to STIP preservation projects.

- SECOND INVESTMENT PRIORITIY:

Stand-alone projects on top-down priority safety segments or spot locations. 
APPENDIX C:

STIP PROJECT SUMMARIES 

Table C.1: 2000 to 2003 STIP Safety Summary

\begin{tabular}{|c|c|c|c|c|c|c|c|c|c|c|c|c|c|}
\hline \multirow[b]{2}{*}{$\begin{array}{c}\text { STIP Key } \\
\text { Number }\end{array}$} & \multirow[b]{2}{*}{$\begin{array}{l}\text { ODOT } \\
\text { Region } \\
\end{array}$} & \multirow[b]{2}{*}{$\begin{array}{l}\text { COUNTY } \\
\text { NUMBER } \\
\end{array}$} & \multirow[b]{2}{*}{$\begin{array}{c}\text { Primary } \\
\text { Worktype }\end{array}$} & \multirow[b]{2}{*}{$\begin{array}{l}\text { Hwy } \\
\text { Num }\end{array}$} & \multirow[b]{2}{*}{$\begin{array}{l}\text { Beginning } \\
\text { Milepoint } \\
\end{array}$} & \multirow[b]{2}{*}{$\begin{array}{c}\text { Ending } \\
\text { Milepoint }\end{array}$} & \multirow[b]{2}{*}{$\begin{array}{l}\text { Const. } \\
\text { Year }\end{array}$} & \multicolumn{3}{|c|}{ Total Crashes } & \multicolumn{3}{|c|}{ Fatal and Severe Crashes } \\
\hline & & & & & & & & $\begin{array}{c}\text { Before } \\
\text { Crashes } \\
\text { per Year }\end{array}$ & $\begin{array}{c}\text { After } \\
\text { Crashes } \\
\text { per Year }\end{array}$ & $\begin{array}{l}\text { Reduction } \\
\text { in Crashes } \\
\end{array}$ & $\begin{array}{c}\text { Before } \\
\text { Crashes } \\
\text { per Year }\end{array}$ & $\begin{array}{c}\text { After } \\
\text { Crashes } \\
\text { per Year }\end{array}$ & $\begin{array}{l}\text { Reduction } \\
\text { in Crashes } \\
\end{array}$ \\
\hline 03407 & 1 & 14 & SAFETY & 281 & 5 & 5.1 & 2003 & 2.50 & 0.67 & 1.83 & 0.13 & 0.00 & 0.13 \\
\hline 04036 & 1 & 03 & SAFETY & 160 & 13.36 & 14.02 & 2002 & 5.29 & 2.50 & 2.79 & 0.14 & 0.25 & $(0.11)$ \\
\hline 04617 & 1 & 03 & SAFETY & 174 & 6.92 & 7.13 & 2001 & 4.50 & 2.60 & 1.90 & 0.17 & 0.00 & 0.17 \\
\hline 06010 & 1 & 34 & SAFETY & 144 & 4.27 & 4.37 & 2003 & 5.63 & 3.00 & 2.63 & 0.50 & 0.00 & 0.50 \\
\hline 07022 & 2 & 36 & PRESRV & 091 & 21.78 & 22.8 & 2000 & 44.40 & 35.33 & 9.07 & 0.00 & 0.50 & $(0.50)$ \\
\hline 07101 & 2 & 22 & PRESRV & 016 & 2 & 12.7 & 2001 & 28.00 & 29.40 & $(1.40)$ & 4.00 & 1.20 & 2.80 \\
\hline 07146 & 1 & 26 & SAFETY & 059 & 0.05 & 1.94 & 2000 & 119.80 & 44.33 & 75.47 & 3.40 & 1.33 & 2.07 \\
\hline 08005 & 1 & 34 & SAFETY & 141 & 2.74 & 2.89 & 2002 & 15.14 & 15.00 & 0.14 & 0.43 & 0.00 & 0.43 \\
\hline 08006 & 1 & 34 & SAFETY & 140 & 2.78 & 2.79 & 2002 & 2.00 & 2.00 & 0.00 & 0.00 & 0.00 & 0.00 \\
\hline 08017 & 5 & 32 & SAFETY & 532 & 0 & 24 & 2002 & 0.00 & 0.00 & 0.00 & 0.00 & 0.00 & 0.00 \\
\hline 08935 & 3 & 10 & SAFETY & 035 & 76.14 & 76.19 & 2000 & 1.00 & 0.67 & 0.33 & 0.20 & 0.00 & 0.20 \\
\hline 08945 & 4 & 18 & SAFETY & 004 & 271 & 271.9 & 2001 & 2.50 & 1.20 & 1.30 & 0.50 & 0.20 & 0.30 \\
\hline 09261 & 2 & 04 & SAFETY & 009 & 28.19 & 28.2 & 2000 & 0.40 & 0.33 & 0.07 & 0.20 & 0.00 & 0.20 \\
\hline 09271 & 2 & 21 & SAFETY & 009 & 156.98 & 156.99 & 2001 & 0.17 & 0.40 & $(0.23)$ & 0.00 & 0.20 & $(0.20)$ \\
\hline 09272 & 2 & 20 & SAFETY & 062 & 0 & 0.24 & 2001 & 3.83 & 3.60 & 0.23 & 0.00 & 0.20 & $(0.20)$ \\
\hline 09274 & 2 & 36 & SAFETY & 140 & 21.85 & 21.92 & 2003 & 4.38 & 3.33 & 1.04 & 0.75 & 1.00 & $(0.25)$ \\
\hline 09276 & 2 & 20 & SAFETY & 200 & 18.07 & 18.1 & 2002 & 0.00 & 0.00 & 0.00 & 0.00 & 0.00 & 0.00 \\
\hline 09278 & 2 & 27 & SAFETY & 039 & 23.85 & 23.86 & 2003 & 1.13 & 2.00 & $(0.88)$ & 0.13 & 0.00 & 0.13 \\
\hline 09294 & 2 & 29 & SAFETY & 009 & 67.3 & 67.69 & 2001 & 1.50 & 0.00 & 1.50 & 0.00 & 0.00 & 0.00 \\
\hline 09296 & 2 & 24 & SAFETY & 081 & 45.24 & 45.25 & 2000 & 4.80 & 3.67 & 1.13 & 0.40 & 0.33 & 0.07 \\
\hline 09358 & 1 & 26 & SAFETY & 068 & 0 & 6.73 & 2000 & 358.60 & 357.50 & 1.10 & 11.00 & 8.17 & 2.83 \\
\hline 09370 & 1 & 03 & SAFETY & 171 & 0 & 5 & 2000 & 117.20 & 100.17 & 17.03 & 3.80 & 3.00 & 0.80 \\
\hline 09386 & 1 & 03 & PRESRV & 171 & 4.83 & 5.37 & 2001 & 49.50 & 38.40 & 11.10 & 1.00 & 0.60 & 0.40 \\
\hline 09390 & 1 & 03 & SAFETY & 003 & 5.1 & 5.9 & 2003 & 10.88 & 10.67 & 0.21 & 1.00 & 0.33 & 0.67 \\
\hline 09391 & 1 & 26 & SAFETY & 064 & 21.1 & 21.1 & 2000 & 1.40 & 0.50 & 0.90 & 0.00 & 0.00 & 0.00 \\
\hline 09394 & 1 & 26 & SAFETY & 123 & 6.18 & 1.38 & 2001 & 0.00 & 0.00 & 0.00 & 0.00 & 0.00 & 0.00 \\
\hline 09407 & 1 & 03 & SAFETY & 081 & 17.4 & 17.9 & 2001 & 9.83 & 7.40 & 2.43 & 1.00 & 0.80 & 0.20 \\
\hline 09733 & 4 & 09 & SAFETY & 004 & 147.55 & 150.48 & 2001 & 8.33 & 6.40 & 1.93 & 1.67 & 0.20 & 1.47 \\
\hline
\end{tabular}




\begin{tabular}{|c|c|c|c|c|c|c|c|c|c|c|c|c|c|}
\hline \multirow[b]{2}{*}{$\begin{array}{l}\text { STIP Key } \\
\text { Number }\end{array}$} & \multirow[b]{2}{*}{$\begin{array}{l}\text { ODOT } \\
\text { Region } \\
\end{array}$} & \multirow[b]{2}{*}{$\begin{array}{l}\text { COUNTY } \\
\text { NUMBER } \\
\end{array}$} & \multirow[b]{2}{*}{\begin{tabular}{|c|} 
Primary \\
Worktype
\end{tabular}} & \multirow[b]{2}{*}{$\begin{array}{l}\text { Hwy } \\
\text { Num }\end{array}$} & \multirow[b]{2}{*}{$\begin{array}{l}\text { Beginning } \\
\text { Milepoint }\end{array}$} & \multirow[b]{2}{*}{\begin{tabular}{|c|} 
Ending \\
Milepoint
\end{tabular}} & \multirow[b]{2}{*}{$\begin{array}{c}\text { Const. } \\
\text { Year }\end{array}$} & \multicolumn{3}{|c|}{ Total Crashes } & \multicolumn{3}{|c|}{ Fatal and Severe Crashes } \\
\hline & & & & & & & & $\begin{array}{c}\text { Before } \\
\text { Crashes } \\
\text { per Year }\end{array}$ & $\begin{array}{c}\text { After } \\
\text { Crashes } \\
\text { per Year }\end{array}$ & $\begin{array}{l}\text { Reduction } \\
\text { in Crashes }\end{array}$ & $\begin{array}{c}\text { Before } \\
\text { Crashes } \\
\text { per Year }\end{array}$ & $\begin{array}{c}\text { After } \\
\text { Crashes } \\
\text { per Year }\end{array}$ & $\begin{array}{l}\text { Reduction } \\
\text { in Crashes }\end{array}$ \\
\hline 09746 & 4 & 09 & MODERN & 004 & 133.5 & 134.9 & 2001 & 23.67 & 26.60 & $(2.93)$ & 1.00 & 1.00 & 0.00 \\
\hline 09940 & 2 & 21 & SAFETY & 009 & 159 & 159.4 & 2000 & 0.80 & 1.00 & $(0.20)$ & 0.40 & 0.00 & 0.40 \\
\hline 10021 & 1 & 26 & SAFETY & 047 & 73.32 & 74.2 & 2002 & 130.86 & 130.00 & 0.86 & 1.71 & 2.00 & $(0.29)$ \\
\hline 10536 & 5 & 23 & SAFETY & 007 & 202 & 203 & 2003 & 1.38 & 1.00 & 0.38 & 0.00 & 0.00 & 0.00 \\
\hline 10537 & 5 & 25 & SAFETY & 320 & 10 & 10.2 & 2001 & 0.00 & 0.00 & 0.00 & 0.00 & 0.00 & 0.00 \\
\hline 10539 & 5 & 30 & SAFETY & 067 & 4.5 & 4.7 & 2000 & 1.80 & 0.33 & 1.47 & 0.20 & 0.00 & 0.20 \\
\hline 10542 & 5 & 23 & SAFETY & 455 & 31.3 & 31.32 & 2001 & 0.67 & 1.00 & $(0.33)$ & 0.50 & 0.00 & 0.50 \\
\hline 10544 & 5 & 30 & SAFETY & 008 & 17.38 & 17.39 & 2001 & 1.00 & 0.20 & 0.80 & 0.33 & 0.00 & 0.33 \\
\hline 10545 & 5 & 31 & SAFETY & 006 & 245 & 250 & 2001 & 7.67 & 13.00 & (5.33) & 0.67 & 0.20 & 0.47 \\
\hline 10546 & 5 & 30 & SAFETY & 008 & 30.62 & 33.32 & 2002 & 12.14 & 12.25 & $(0.11)$ & 1.00 & 1.75 & $(0.75)$ \\
\hline 10547 & 5 & 30 & SAFETY & 333 & 8.71 & 8.72 & 2002 & 0.00 & 0.00 & 0.00 & 0.00 & 0.00 & 0.00 \\
\hline 10548 & 5 & 30 & SAFETY & 054 & 4.83 & 10.77 & 2002 & 55.71 & 37.00 & 18.71 & 2.43 & 1.25 & 1.18 \\
\hline 10573 & 1 & 26 & PRESRV & 002 & 3.92 & 6 & 2000 & 50.00 & 51.17 & $(1.17)$ & 1.00 & 1.17 & $(0.17)$ \\
\hline 10576 & 1 & 05 & PRESRV & 002 & 46.5 & 50.2 & 2001 & 9.33 & 7.20 & 2.13 & 0.67 & 0.20 & 0.47 \\
\hline 10581 & 1 & 26 & SAFETY & 047 & 72.97 & 73.6 & 2000 & 109.60 & 94.00 & 15.60 & 1.80 & 1.00 & 0.80 \\
\hline 10582 & 4 & 18 & SAFETY & 270 & 16.08 & 25.92 & 2003 & 8.63 & 14.33 & (5.71) & 1.25 & 1.33 & $(0.08)$ \\
\hline 10623 & 2 & 27 & MODERN & 039 & 24.2 & 26.9 & 2003 & 4.13 & 2.33 & 1.79 & 1.13 & 0.33 & 0.79 \\
\hline 10634 & 4 & 33 & SAFETY & 004 & 0.91 & 0.98 & 2002 & 1.86 & 1.50 & 0.36 & 0.29 & 0.00 & 0.29 \\
\hline 10635 & 4 & 18 & SAFETY & 004 & 271.94 & 272.59 & 2002 & 3.14 & 1.75 & 1.39 & 0.71 & 0.25 & 0.46 \\
\hline 10664 & 1 & 03 & PRESRV & 171 & 5.37 & 8.13 & 2001 & 62.33 & 58.60 & 3.73 & 3.17 & 2.20 & 0.97 \\
\hline 10665 & 1 & 03 & SAFETY & 174 & 0 & 6.9 & 2001 & 54.00 & 66.20 & (12.20) & 1.67 & 2.80 & (1.13) \\
\hline 10666 & 1 & 34 & PRESRV & 040 & 0.97 & 3.41 & 2001 & 154.50 & 131.40 & 23.10 & 3.00 & 2.80 & 0.20 \\
\hline 10667 & 1 & 03 & SAFETY & 081 & 12.7 & 13.3 & 2001 & 12.17 & 6.80 & 5.37 & 1.00 & 0.40 & 0.60 \\
\hline 10679 & 1 & 34 & PRESRV & 029 & 17.88 & 26.51 & 2003 & 61.38 & 25.00 & 36.38 & 3.38 & 3.00 & 0.38 \\
\hline 10680 & 1 & 34 & PRESRV & 029 & 4.05 & 11.28 & 2002 & 240.57 & 259.25 & (18.68) & 9.29 & 5.00 & 4.29 \\
\hline 10682 & 1 & 34 & SAFETY & 001 & 289.5 & 289.85 & 2002 & 41.14 & 51.75 & (10.61) & 1.00 & 0.50 & 0.50 \\
\hline 10683 & 1 & 34 & SAFETY & 047 & 58.46 & 58.95 & 2002 & 7.43 & 3.25 & 4.18 & 0.43 & 0.50 & $(0.07)$ \\
\hline 10731 & 1 & 26 & PRESRV & 026 & 1.02 & 3.46 & 2003 & 187.38 & 140.33 & 47.04 & 4.38 & 5.33 & $(0.96)$ \\
\hline 10733 & 1 & 05 & SAFETY & 002 & 21.05 & 21.3 & 2003 & 0.00 & 0.33 & $(0.33)$ & 0.00 & 0.00 & 0.00 \\
\hline
\end{tabular}




\begin{tabular}{|c|c|c|c|c|c|c|c|c|c|c|c|c|c|}
\hline \multirow[b]{2}{*}{$\begin{array}{l}\text { STIP Key } \\
\text { Number }\end{array}$} & \multirow[b]{2}{*}{$\begin{array}{l}\text { ODOT } \\
\text { Region }\end{array}$} & \multirow[b]{2}{*}{$\begin{array}{l}\text { COUNTY } \\
\text { NUMBER }\end{array}$} & \multirow[b]{2}{*}{$\begin{array}{c}\text { Primary } \\
\text { Worktype }\end{array}$} & \multirow[b]{2}{*}{$\begin{array}{l}\text { Hwy } \\
\text { Num }\end{array}$} & \multirow[b]{2}{*}{$\begin{array}{l}\text { Beginning } \\
\text { Milepoint }\end{array}$} & \multirow[b]{2}{*}{$\begin{array}{l}\text { Ending } \\
\text { Milepoint }\end{array}$} & \multirow[b]{2}{*}{$\begin{array}{l}\text { Const. } \\
\text { Year }\end{array}$} & \multicolumn{3}{|c|}{ Total Crashes } & \multicolumn{3}{|c|}{ Fatal and Severe Crashes } \\
\hline & & & & & & & & $\begin{array}{c}\text { Before } \\
\text { Crashes } \\
\text { per Year }\end{array}$ & $\begin{array}{c}\text { After } \\
\text { Crashes } \\
\text { per Year }\end{array}$ & $\begin{array}{l}\text { Reduction } \\
\text { in Crashes }\end{array}$ & $\begin{array}{c}\text { Before } \\
\text { Crashes } \\
\text { per Year }\end{array}$ & $\begin{array}{c}\text { After } \\
\text { Crashes } \\
\text { per Year }\end{array}$ & $\begin{array}{l}\text { Reduction } \\
\text { in Crashes }\end{array}$ \\
\hline 10748 & 2 & 29 & PRESRV & 037 & 0.5 & 18 & 2002 & 23.57 & 34.25 & $(10.68)$ & 2.14 & 2.75 & $(0.61)$ \\
\hline 10807 & 2 & 24 & PRESRV & 072 & 0.14 & 7.43 & 2003 & 219.63 & 181.67 & 37.96 & 6.00 & 5.33 & 0.67 \\
\hline 10817 & 3 & 08 & PRESRV & 009 & 320.4 & 327.9 & 2000 & 3.00 & 5.50 & $(2.50)$ & 0.20 & 0.67 & $(0.47)$ \\
\hline 10867 & 1 & 34 & SAFETY & 140 & 0.12 & 0.24 & 2003 & 9.63 & 7.00 & 2.63 & 0.13 & 0.33 & $(0.21)$ \\
\hline 10868 & 1 & 05 & SAFETY & 002 & 57.25 & 57.5 & 2003 & 0.25 & 0.00 & 0.25 & 0.00 & 0.00 & 0.00 \\
\hline 10876 & 3 & 06 & SAFETY & 009 & 240.67 & 244.05 & 2002 & 10.57 & 17.50 & (6.93) & 0.43 & 0.50 & $(0.07)$ \\
\hline 10879 & 3 & 17 & SAFETY & 025 & 7 & 41.69 & 2002 & 54.57 & 66.75 & (12.18) & 6.71 & 9.00 & $(2.29)$ \\
\hline 10880 & 3 & 15 & SAFETY & 271 & 12.61 & 12.62 & 2003 & 2.75 & 1.33 & 1.42 & 0.63 & 0.33 & 0.29 \\
\hline 11060 & 1 & 05 & SAFETY & 002 & 33.02 & 25.77 & 2000 & 0.00 & 0.00 & 0.00 & 0.00 & 0.00 & 0.00 \\
\hline 11069 & 4 & 18 & SAFETY & 020 & 3.6 & 4.55 & 2002 & 27.43 & 22.25 & 5.18 & 1.00 & 0.25 & 0.75 \\
\hline 11072 & 4 & 07 & PRESRV & 041 & 18 & 20.58 & 2001 & 40.67 & 34.20 & 6.47 & 1.67 & 0.60 & 1.07 \\
\hline 11103 & 3 & 06 & OPERAT & 240 & 2.24 & 4.49 & 2000 & 36.80 & 0.50 & 36.30 & 0.80 & 0.00 & 0.80 \\
\hline 11105 & 3 & 17 & SAFETY & 272 & 6.4 & 16 & 2002 & 12.00 & 16.75 & $(4.75)$ & 2.14 & 2.25 & $(0.11)$ \\
\hline 11216 & 3 & 10 & SAFETY & 045 & 39.23 & 49.22 & 2002 & 8.57 & 7.25 & 1.32 & 1.14 & 1.25 & $(0.11)$ \\
\hline 11217 & 3 & 06 & SAFETY & 035 & 4 & 7.8 & 2001 & 6.50 & 11.40 & $(4.90)$ & 0.67 & 1.40 & $(0.73)$ \\
\hline 11218 & 3 & 06 & SAFETY & 035 & 23.4 & 30 & 2002 & 5.43 & 6.50 & (1.07) & 1.29 & 0.75 & 0.54 \\
\hline 11227 & 1 & 34 & PRESRV & 091 & 7.36 & 12.15 & 2000 & 314.00 & 246.50 & 67.50 & 5.20 & 4.50 & 0.70 \\
\hline 11241 & 2 & 20 & SAFETY & 227 & 3.65 & 4.34 & 2001 & 7.00 & 4.20 & 2.80 & 0.33 & 0.60 & $(0.27)$ \\
\hline 11242 & 2 & 20 & SAFETY & 018 & 14.4 & 14.5 & 2000 & 0.60 & 1.17 & $(0.57)$ & 0.20 & 0.17 & 0.03 \\
\hline 11243 & 2 & 24 & SAFETY & 161 & 0.41 & 0.45 & 2001 & 3.00 & 0.80 & 2.20 & 0.00 & 0.00 & 0.00 \\
\hline 11244 & 2 & 03 & SAFETY & 161 & 7.47 & 7.75 & 2001 & 2.83 & 3.60 & $(0.77)$ & 0.50 & 0.60 & $(0.10)$ \\
\hline 11245 & 2 & 36 & SAFETY & 039 & 31.66 & 31.67 & 2000 & 2.60 & 1.83 & 0.77 & 0.80 & 0.33 & 0.47 \\
\hline 11246 & 2 & 04 & SAFETY & 009 & 4.45 & 5.36 & 2001 & 8.50 & 5.80 & 2.70 & 0.17 & 0.20 & $(0.03)$ \\
\hline 11248 & 2 & 21 & SAFETY & 009 & 129.35 & 129.69 & 2002 & 2.14 & 0.75 & 1.39 & 0.00 & 0.00 & 0.00 \\
\hline 11251 & 4 & 18 & SAFETY & 424 & 4.48 & 4.52 & 2000 & 0.00 & 0.00 & 0.00 & 0.00 & 0.00 & 0.00 \\
\hline
\end{tabular}


Table C.2: 2002 to 2005 STIP Safety Summary

\begin{tabular}{|c|c|c|c|c|c|c|c|c|c|c|c|c|c|}
\hline \multirow[b]{2}{*}{$\begin{array}{c}\text { STIP Key } \\
\text { Number }\end{array}$} & \multirow[b]{2}{*}{$\begin{array}{l}\text { ODOT } \\
\text { Region }\end{array}$} & \multirow[b]{2}{*}{$\begin{array}{l}\text { County } \\
\text { Number }\end{array}$} & \multirow[b]{2}{*}{\begin{tabular}{|c|} 
Primary \\
Worktype
\end{tabular}} & \multirow[b]{2}{*}{$\begin{array}{l}\text { Hwy } \\
\text { Num }\end{array}$} & \multirow[b]{2}{*}{$\begin{array}{l}\text { Beginning } \\
\text { Milepoint }\end{array}$} & \multirow[b]{2}{*}{$\begin{array}{l}\text { Ending } \\
\text { Milepoint }\end{array}$} & \multirow[b]{2}{*}{$\begin{array}{l}\text { Const. } \\
\text { Year }\end{array}$} & \multicolumn{3}{|c|}{ Total Crashes } & \multicolumn{3}{|c|}{ Fatal and Severe Crashes } \\
\hline & & & & & & & & $\begin{array}{c}\text { Before } \\
\text { Crashes per } \\
\text { Year }\end{array}$ & $\begin{array}{c}\text { After } \\
\text { Crashes } \\
\text { per Year }\end{array}$ & $\begin{array}{l}\text { Reduction } \\
\text { in Crashes }\end{array}$ & $\begin{array}{c}\text { Before } \\
\text { Crashes } \\
\text { per Year }\end{array}$ & $\begin{array}{c}\text { After } \\
\text { Crashes } \\
\text { per Year }\end{array}$ & $\begin{array}{l}\text { Reduction } \\
\text { in Crashes }\end{array}$ \\
\hline 03407 & 1 & 14 & SAFETY & 281 & 5.0 & 5.1 & 2004 & 2.33 & 1.00 & 1.33 & 0.11 & 0.00 & 0.11 \\
\hline 04036 & 1 & 03 & SAFETY & 160 & 13.4 & 14.0 & 2004 & 5.00 & 3.00 & 2.00 & 0.11 & 0.50 & $(0.39)$ \\
\hline 05329 & 1 & 34 & SAFETY & 047 & 47.5 & 48.5 & 2005 & 3.20 & 0.00 & 3.20 & 0.30 & 0.00 & 0.30 \\
\hline 06010 & 1 & 34 & SAFETY & 144 & 4.3 & 4.4 & 2002 & 5.86 & 2.25 & 3.61 & 0.43 & 0.00 & 0.43 \\
\hline 07101 & 2 & 22 & PRESRV & 016 & 2.0 & 12.8 & 2002 & 29.86 & 32.75 & $(2.89)$ & 4.43 & 1.50 & 2.93 \\
\hline 07146 & 1 & 26 & SAFETY & 059 & 0.1 & 1.9 & 2002 & 110.57 & 24.00 & 86.57 & 3.43 & 0.50 & 2.93 \\
\hline 08005 & 1 & 34 & SAFETY & 141 & 2.7 & 2.9 & 2002 & 15.14 & 15.00 & 0.14 & 0.43 & 0.00 & 0.43 \\
\hline 08006 & 1 & 34 & SAFETY & 140 & 2.3 & 3.0 & 2003 & 4.88 & 3.33 & 1.54 & 0.38 & 0.33 & 0.04 \\
\hline 09261 & 2 & 04 & SAFETY & 009 & 28.2 & 28.2 & 2002 & 0.43 & 0.25 & 0.18 & 0.14 & 0.00 & 0.14 \\
\hline 09271 & 2 & 21 & SAFETY & 009 & 157.0 & 157.0 & 2002 & 0.29 & 0.25 & 0.04 & 0.00 & 0.00 & 0.00 \\
\hline 09274 & 2 & 36 & SAFETY & 140 & 21.9 & 21.9 & 2005 & 4.40 & 3.00 & 1.40 & 0.80 & 0.00 & 0.80 \\
\hline 09276 & 2 & 20 & SAFETY & 200 & 18.5 & 18.5 & 2003 & 0.00 & 0.00 & 0.00 & 0.00 & 0.00 & 0.00 \\
\hline 09278 & 2 & 27 & SAFETY & 039 & 23.8 & 23.9 & 2003 & 1.50 & 2.33 & $(0.83)$ & 0.13 & 0.00 & 0.13 \\
\hline 09358 & 1 & 26 & SAFETY & 068 & 0.0 & 6.7 & 2002 & 365.14 & 336.00 & 29.14 & 10.00 & 9.00 & 1.00 \\
\hline 09393 & 1 & 26 & BRIDGE & 123 & 0.6 & 1.3 & 2003 & 6.38 & 2.00 & 4.38 & 0.38 & 0.33 & 0.04 \\
\hline 09394 & 1 & 26 & SAFETY & 123 & 6.2 & 1.4 & 2002 & 0.00 & 0.00 & 0.00 & 0.00 & 0.00 & 0.00 \\
\hline 09407 & 1 & 03 & SAFETY & 081 & 17.4 & 17.9 & 2002 & 9.57 & 6.75 & 2.82 & 1.00 & 0.50 & 0.50 \\
\hline 09733 & 4 & 09 & SAFETY & 004 & 147.5 & 150.8 & 2002 & 8.14 & 7.00 & 1.14 & 1.43 & 0.25 & 1.18 \\
\hline 10536 & 5 & 23 & SAFETY & 007 & 202.0 & 203.0 & 2004 & 1.22 & 1.50 & $(0.28)$ & 0.00 & 0.00 & 0.00 \\
\hline 10546 & 5 & 30 & SAFETY & 008 & 30.6 & 33.3 & 2003 & 12.50 & 11.33 & 1.17 & 1.25 & 1.67 & $(0.42)$ \\
\hline 10547 & 5 & 30 & SAFETY & 333 & 8.7 & 8.8 & 2002 & 0.29 & 0.00 & 0.29 & 0.00 & 0.00 & 0.00 \\
\hline 10548 & 5 & 30 & SAFETY & 054 & 6.6 & 10.8 & 2002 & 6.00 & 3.50 & 2.50 & 0.71 & 0.50 & 0.21 \\
\hline 10623 & 2 & 27 & SAFETY & 039 & 24.2 & 26.9 & 2004 & 4.44 & 3.00 & 1.44 & 1.00 & 0.50 & 0.50 \\
\hline 10634 & 4 & 33 & SALMON & 004 & 0.9 & 1.0 & 2003 & 1.63 & 1.00 & 0.63 & 0.25 & 0.00 & 0.25 \\
\hline 10635 & 4 & 18 & SAFETY & 004 & 271.9 & 272.6 & 2003 & 0.00 & 0.00 & 0.00 & 0.00 & 0.00 & 0.00 \\
\hline 10665 & 1 & 03 & PRESRV & 174 & 0.0 & 6.9 & 2002 & 55.29 & 64.75 & $(9.46)$ & 1.71 & 3.00 & $(1.29)$ \\
\hline 10666 & 1 & 34 & PRESRV & 040 & 1.0 & 3.4 & 2003 & 147.25 & 128.00 & 19.25 & 2.88 & 2.67 & 0.21 \\
\hline
\end{tabular}




\begin{tabular}{|c|c|c|c|c|c|c|c|c|c|c|c|c|c|}
\hline \multirow[b]{2}{*}{$\begin{array}{l}\text { STIP Key } \\
\text { Number }\end{array}$} & \multirow[b]{2}{*}{$\begin{array}{l}\text { ODOT } \\
\text { Region }\end{array}$} & \multirow[b]{2}{*}{$\begin{array}{l}\text { County } \\
\text { Number }\end{array}$} & \multirow[b]{2}{*}{\begin{tabular}{|c|} 
Primary \\
Worktype
\end{tabular}} & \multirow[b]{2}{*}{$\begin{array}{l}\text { Hwy } \\
\text { Num }\end{array}$} & \multirow[b]{2}{*}{\begin{tabular}{|l} 
Beginning \\
Milepoint \\
\end{tabular}} & \multirow[b]{2}{*}{\begin{tabular}{|c|} 
Ending \\
Milepoint
\end{tabular}} & \multirow[b]{2}{*}{\begin{tabular}{|l} 
Const. \\
Year
\end{tabular}} & \multicolumn{3}{|c|}{ Total Crashes } & \multicolumn{3}{|c|}{ Fatal and Severe Crashes } \\
\hline & & & & & & & & $\begin{array}{c}\text { Before } \\
\text { Crashes per } \\
\text { Year }\end{array}$ & $\begin{array}{c}\text { After } \\
\text { Crashes } \\
\text { per Year }\end{array}$ & $\begin{array}{l}\text { Reduction } \\
\text { in Crashes }\end{array}$ & $\begin{array}{c}\text { Before } \\
\text { Crashes } \\
\text { per Year }\end{array}$ & $\begin{array}{c}\text { After } \\
\text { Crashes } \\
\text { per Year }\end{array}$ & $\begin{array}{l}\text { Reduction } \\
\text { in Crashes }\end{array}$ \\
\hline 10667 & 1 & 03 & SAFETY & 081 & 12.7 & 13.3 & 2002 & 12.14 & 5.75 & 6.39 & 0.86 & 0.50 & 0.36 \\
\hline 10679 & 1 & 34 & PRESRV & 029 & 17.9 & 26.5 & 2004 & 59.00 & 20.50 & 38.50 & 3.11 & 3.00 & 0.11 \\
\hline 10680 & 1 & 34 & PRESRV & 029 & 4.1 & 11.3 & 2002 & 240.57 & 259.25 & $(18.68)$ & 9.29 & 5.00 & 4.29 \\
\hline 10682 & 1 & 34 & SAFETY & 001 & 289.5 & 289.9 & 2002 & 41.14 & 51.75 & $(10.61)$ & 1.00 & 0.50 & 0.50 \\
\hline 10683 & 1 & 34 & SAFETY & 047 & 58.5 & 59.2 & 2002 & 7.57 & 3.75 & 3.82 & 0.43 & 0.50 & $(0.07)$ \\
\hline 10731 & 1 & 26 & PRESRV & 026 & 1.0 & 3.5 & 2004 & 189.67 & 137.00 & 52.67 & 4.44 & 6.00 & $(1.56)$ \\
\hline 10733 & 1 & 05 & SAFETY & 002 & 21.1 & 21.3 & 2004 & 0.00 & 0.50 & $(0.50)$ & 0.00 & 0.00 & 0.00 \\
\hline 10743 & 2 & 20 & SAFETY & 227 & 0.5 & 0.8 & 2002 & 4.43 & 3.50 & 0.93 & 0.00 & 0.00 & 0.00 \\
\hline 10748 & 2 & 29 & PRESRV & 037 & 0.5 & 18.0 & 2002 & 23.57 & 34.25 & (10.68) & 2.14 & 2.75 & $(0.61)$ \\
\hline 10766 & 2 & 02 & PRESRV & 033 & 47.4 & 51.3 & 2002 & 27.29 & 26.75 & 0.54 & 1.43 & 1.75 & $(0.32)$ \\
\hline 10807 & 2 & 24 & PRESRV & 072 & 0.1 & 8.5 & 2004 & 272.44 & 231.00 & 41.44 & 6.67 & 4.50 & 2.17 \\
\hline 10808 & 2 & 20 & PRESRV & 015 & 0.4 & 33.5 & 2004 & 227.89 & 235.00 & $(7.11)$ & 10.22 & 16.00 & (5.78) \\
\hline 10841 & 3 & 15 & MODERN & 001 & 24.0 & 25.0 & 2002 & 6.71 & 14.50 & $(7.79)$ & 0.29 & 1.75 & $(1.46)$ \\
\hline 10867 & 1 & 34 & SAFETY & 140 & 0.1 & 0.2 & 2003 & 9.63 & 7.00 & 2.63 & 0.13 & 0.33 & $(0.21)$ \\
\hline 10868 & 1 & 05 & SAFETY & 002 & 57.3 & 57.5 & 2003 & 0.25 & 0.00 & 0.25 & 0.00 & 0.00 & 0.00 \\
\hline 10869 & 1 & 34 & SAFETY & 047 & 57.1 & 57.2 & 2005 & 2.00 & 5.00 & $(3.00)$ & 0.00 & 0.00 & 0.00 \\
\hline 10876 & 3 & 06 & MODERN & 009 & 240.7 & 244.7 & 2003 & 11.63 & 18.00 & (6.38) & 0.38 & 1.33 & $(0.96)$ \\
\hline 10879 & 3 & 17 & SAFETY & 025 & 7.0 & 41.7 & 2002 & 54.57 & 66.75 & (12.18) & 6.71 & 9.00 & $(2.29)$ \\
\hline 10880 & 3 & 15 & SAFETY & 271 & 12.6 & 12.6 & 2003 & 0.00 & 0.00 & 0.00 & 0.00 & 0.00 & 0.00 \\
\hline 11060 & 1 & 05 & SAFETY & 002 & 33.0 & 25.8 & 2002 & 0.00 & 0.00 & 0.00 & 0.00 & 0.00 & 0.00 \\
\hline 11069 & 4 & 18 & SAFETY & 020 & 3.6 & 4.6 & 2002 & 27.43 & 22.25 & 5.18 & 1.00 & 0.25 & 0.75 \\
\hline 11072 & 4 & 07 & PRESRV & 041 & 18.0 & 20.6 & 2002 & 37.86 & 33.50 & 4.36 & 1.57 & 0.75 & 0.82 \\
\hline 11125 & 1 & 03 & PRESRV & 161 & 20.9 & 28.7 & 2002 & 8.86 & 8.50 & 0.36 & 1.14 & 1.00 & 0.14 \\
\hline 11243 & 2 & 24 & SAFETY & 161 & 0.4 & 0.5 & 2002 & 2.71 & 0.00 & 2.71 & 0.00 & 0.00 & 0.00 \\
\hline 11244 & 2 & 03 & SAFETY & 161 & 7.5 & 7.8 & 2002 & 3.00 & 4.25 & $(1.25)$ & 0.43 & 0.75 & $(0.32)$ \\
\hline 11248 & 2 & 21 & SAFETY & 009 & 129.4 & 129.7 & 2003 & 1.88 & 1.00 & 0.88 & 0.00 & 0.00 & 0.00 \\
\hline 11799 & 2 & 22 & SAFETY & 016 & 12.8 & 14.9 & 2005 & 75.20 & 42.00 & 33.20 & 2.30 & 1.00 & 1.30 \\
\hline 11800 & 2 & 24 & SAFETY & 081 & 34.4 & 34.8 & 2003 & 3.88 & 3.00 & 0.88 & 0.50 & 0.33 & 0.17 \\
\hline 11801 & 2 & 24 & SAFETY & 072 & 7.5 & 7.5 & 2004 & 4.44 & 8.00 & (3.56) & 0.00 & 0.00 & 0.00 \\
\hline
\end{tabular}




\begin{tabular}{|c|c|c|c|c|c|c|c|c|c|c|c|c|c|}
\hline \multirow[b]{2}{*}{$\begin{array}{c}\text { STIP Key } \\
\text { Number }\end{array}$} & \multirow[b]{2}{*}{$\begin{array}{l}\text { ODOT } \\
\text { Region }\end{array}$} & \multirow[b]{2}{*}{$\begin{array}{l}\text { County } \\
\text { Number }\end{array}$} & \multirow[b]{2}{*}{\begin{tabular}{|c|} 
Primary \\
Worktype
\end{tabular}} & \multirow[b]{2}{*}{$\begin{array}{l}\text { Hwy } \\
\text { Num }\end{array}$} & \multirow[b]{2}{*}{$\begin{array}{l}\text { Beginning } \\
\text { Milepoint }\end{array}$} & \multirow[b]{2}{*}{\begin{tabular}{|c|} 
Ending \\
Milepoint
\end{tabular}} & \multirow[b]{2}{*}{$\begin{array}{l}\text { Const. } \\
\text { Year }\end{array}$} & \multicolumn{3}{|c|}{ Total Crashes } & \multicolumn{3}{|c|}{ Fatal and Severe Crashes } \\
\hline & & & & & & & & \begin{tabular}{|c|} 
Before \\
Crashes per \\
Year \\
\end{tabular} & $\begin{array}{c}\text { After } \\
\text { Crashes } \\
\text { per Year }\end{array}$ & $\begin{array}{l}\text { Reduction } \\
\text { in Crashes }\end{array}$ & $\begin{array}{c}\text { Before } \\
\text { Crashes } \\
\text { per Year }\end{array}$ & $\begin{array}{c}\text { After } \\
\text { Crashes } \\
\text { per Year }\end{array}$ & $\begin{array}{l}\text { Reduction } \\
\text { in Crashes } \\
\end{array}$ \\
\hline 11802 & 2 & 20 & SAFETY & 015 & 3.7 & 3.8 & 2004 & 6.67 & 6.50 & 0.17 & 0.33 & 0.00 & 0.33 \\
\hline 11803 & 2 & 22 & SAFETY & 210 & 0.3 & 1.8 & 2005 & 23.70 & 31.00 & $(7.30)$ & 1.50 & 0.00 & 1.50 \\
\hline 11804 & 2 & 02 & SAFETY & 033 & 51.0 & 51.1 & 2005 & 5.90 & 6.00 & $(0.10)$ & 0.20 & 1.00 & $(0.80)$ \\
\hline 11805 & 2 & 20 & SAFETY & 091 & 121.1 & 121.2 & 2004 & 14.56 & 12.50 & 2.06 & 0.33 & 0.50 & $(0.17)$ \\
\hline 11806 & 2 & 24 & SAFETY & 081 & 34.8 & 35.2 & 2003 & 4.00 & 4.00 & 0.00 & 0.50 & 0.00 & 0.50 \\
\hline 11807 & 2 & 04 & SAFETY & 047 & 19.5 & 20.3 & 2005 & 2.30 & 2.00 & 0.30 & 0.40 & 0.00 & 0.40 \\
\hline 11824 & 5 & 31 & SAFETY & 006 & 270.9 & 271.3 & 2003 & 2.38 & 2.67 & $(0.29)$ & 0.38 & 0.00 & 0.38 \\
\hline 11825 & 5 & 31 & SAFETY & 066 & 4.5 & 4.7 & 2005 & 0.00 & 0.00 & 0.00 & 0.00 & 0.00 & 0.00 \\
\hline 11858 & 2 & 36 & PRESRV & 039 & 40.4 & 50.1 & 2005 & 27.80 & 36.00 & $(8.20)$ & 3.20 & 3.00 & 0.20 \\
\hline 11903 & 4 & 16 & SAFETY & 053 & 108.2 & 109.0 & 2004 & 1.00 & 0.00 & 1.00 & 0.44 & 0.00 & 0.44 \\
\hline 11915 & 1 & 14 & SAFETY & 281 & 0.9 & 0.9 & 2003 & 2.63 & 0.33 & 2.29 & 0.25 & 0.00 & 0.25 \\
\hline 11926 & 1 & 26 & SAFETY & 002 & 13.9 & 13.9 & 2002 & 0.00 & 0.00 & 0.00 & 0.00 & 0.00 & 0.00 \\
\hline 11927 & 1 & 26 & SAFETY & 061 & 0.4 & 0.6 & 2003 & 1.63 & 3.67 & (2.04) & 0.13 & 0.00 & 0.13 \\
\hline 11928 & 1 & 03 & SAFETY & 026 & 21.0 & 21.2 & 2004 & 3.56 & 2.50 & 1.06 & 0.56 & 0.50 & 0.06 \\
\hline 11929 & 1 & 34 & SAFETY & 102 & 88.0 & 88.2 & 2004 & 6.11 & 4.50 & 1.61 & 0.56 & 1.00 & $(0.44)$ \\
\hline 11930 & 1 & 03 & SAFETY & 026 & 53.5 & 54.3 & 2004 & 7.11 & 5.50 & 1.61 & 0.67 & 0.00 & 0.67 \\
\hline 11931 & 1 & 34 & SAFETY & 140 & 5.5 & 5.6 & 2004 & 6.56 & 2.50 & 4.06 & 0.67 & 0.00 & 0.67 \\
\hline 11938 & 1 & 05 & PRESRV & 002 & 21.1 & 25.8 & 2004 & 9.11 & 17.00 & $(7.89)$ & 0.67 & 0.50 & 0.17 \\
\hline 11939 & 1 & 14 & PRESRV & 026 & 73.8 & 84.9 & 2005 & 7.90 & 5.00 & 2.90 & 0.20 & 1.00 & $(0.80)$ \\
\hline 11940 & 1 & 14 & PRESRV & 026 & 91.5 & 96.0 & 2005 & 5.40 & 9.00 & $(3.60)$ & 0.80 & 1.00 & $(0.20)$ \\
\hline 11943 & 1 & 34 & SAFETY & 140 & 4.6 & 5.0 & 2005 & 3.10 & 2.00 & 1.10 & 0.30 & 0.00 & 0.30 \\
\hline 11967 & 1 & 03 & SAFETY & 026 & 52.5 & 53.0 & 2005 & 3.70 & 2.00 & 1.70 & 0.20 & 0.00 & 0.20 \\
\hline 12018 & 3 & 15 & SAFETY & 022 & 0.0 & 0.0 & 2002 & 0.00 & 0.00 & 0.00 & 0.00 & 0.00 & 0.00 \\
\hline 12022 & 4 & 18 & SAFETY & 021 & 0.0 & 0.0 & 2003 & 0.00 & 0.00 & 0.00 & 0.00 & 0.00 & 0.00 \\
\hline 12024 & 4 & 28 & SAFETY & 042 & 0.0 & 0.0 & 2003 & 0.50 & 2.00 & $(1.50)$ & 0.00 & 0.00 & 0.00 \\
\hline 12047 & 4 & 16 & SAFETY & 016 & 87.0 & 87.3 & 2002 & 1.00 & 1.50 & $(0.50)$ & 0.00 & 0.00 & 0.00 \\
\hline 12150 & 1 & 26 & SAFETY & 059 & 1.9 & 3.1 & 2004 & 105.44 & 0.00 & 105.44 & 1.89 & 0.00 & 1.89 \\
\hline 12158 & 1 & 03 & SAFETY & 171 & 4.8 & 5.4 & 2005 & 45.30 & 52.00 & $(6.70)$ & 0.80 & 0.00 & 0.80 \\
\hline 12286 & 2 & 24 & SAFETY & 140 & 0.0 & 0.0 & 2002 & 0.71 & 0.00 & 0.71 & 0.00 & 0.00 & 0.00 \\
\hline
\end{tabular}




\begin{tabular}{|c|c|c|c|c|c|c|c|c|c|c|c|c|c|}
\hline \multirow[b]{2}{*}{$\begin{array}{c}\text { STIP Key } \\
\text { Number }\end{array}$} & \multirow[b]{2}{*}{$\begin{array}{l}\text { ODOT } \\
\text { Region }\end{array}$} & \multirow[b]{2}{*}{$\begin{array}{l}\text { County } \\
\text { Number }\end{array}$} & \multirow[b]{2}{*}{\begin{tabular}{|c|} 
Primary \\
Worktype
\end{tabular}} & \multirow[b]{2}{*}{$\begin{array}{l}\text { Hwy } \\
\text { Num }\end{array}$} & \multirow[b]{2}{*}{$\begin{array}{l}\text { Beginning } \\
\text { Milepoint }\end{array}$} & \multirow[b]{2}{*}{\begin{tabular}{|c|} 
Ending \\
Milepoint
\end{tabular}} & \multirow[b]{2}{*}{$\begin{array}{l}\text { Const. } \\
\text { Year }\end{array}$} & \multicolumn{3}{|c|}{ Total Crashes } & \multicolumn{3}{|c|}{ Fatal and Severe Crashes } \\
\hline & & & & & & & & \begin{tabular}{|c|} 
Before \\
Crashes per \\
Year \\
\end{tabular} & $\begin{array}{c}\text { After } \\
\text { Crashes } \\
\text { per Year }\end{array}$ & $\begin{array}{l}\text { Reduction } \\
\text { in Crashes }\end{array}$ & $\begin{array}{c}\text { Before } \\
\text { Crashes } \\
\text { per Year } \\
\end{array}$ & $\begin{array}{c}\text { After } \\
\text { Crashes } \\
\text { per Year }\end{array}$ & $\begin{array}{l}\text { Reduction } \\
\text { in Crashes } \\
\end{array}$ \\
\hline 12292 & 1 & 03 & SAFETY & 160 & 0.0 & 0.5 & 2003 & 28.63 & 21.67 & 6.96 & 0.50 & 0.00 & 0.50 \\
\hline 12368 & 2 & 04 & SAFETY & 009 & 28.2 & 28.2 & 2002 & 0.00 & 0.00 & 0.00 & 0.00 & 0.00 & 0.00 \\
\hline 12499 & 5 & 30 & SAFETY & 333 & 8.7 & 8.8 & 2002 & 0.29 & 0.00 & 0.29 & 0.00 & 0.00 & 0.00 \\
\hline 12525 & 2 & 20 & PRESRV & 015 & 0.4 & 33.5 & 2004 & 0.00 & 0.00 & 0.00 & 0.00 & 0.00 & 0.00 \\
\hline 12580 & 2 & 22 & SAFETY & 210 & 0.4 & 1.2 & 2003 & 12.88 & 15.00 & $(2.13)$ & 1.50 & 0.33 & 1.17 \\
\hline 12670 & 2 & 36 & OP-SSI & 091 & 25.8 & 37.7 & 2006 & 145.73 & na & na & 4.82 & na & na \\
\hline 12726 & 3 & 10 & SAFETY & 073 & 0.1 & 0.1 & 2003 & 5.88 & 0.00 & 5.88 & 0.25 & 0.00 & 0.25 \\
\hline 12727 & 3 & 17 & SAFETY & 272 & 0.2 & 0.2 & 2003 & 0.00 & 0.00 & 0.00 & 0.00 & 0.00 & 0.00 \\
\hline 12734 & 3 & 15 & MODERN & 272 & 34.7 & 35.2 & 2005 & 5.00 & 1.00 & 4.00 & 0.70 & 0.00 & 0.70 \\
\hline 12854 & 1 & 34 & PRESRV & 144 & 0.0 & 6.4 & 2006 & 232.45 & na & na & 4.55 & na & na \\
\hline 12855 & 1 & 03 & PRESRV & 081 & 3.1 & 9.0 & 2006 & 184.18 & na & na & 7.00 & na & na \\
\hline 12859 & 1 & 26 & SAFETY & 026 & 7.2 & 7.9 & 2006 & 34.82 & na & na & 0.91 & na & na \\
\hline 12871 & 1 & 03 & PRESRV & 161 & 16.4 & 20.9 & 2006 & 10.27 & na & na & 1.64 & na & na \\
\hline 12872 & 1 & 03 & PRESRV & 171 & 0.0 & 4.4 & 2007 & na & na & na & na & na & na \\
\hline 12876 & 1 & 03 & SAFETY & 160 & 3.9 & 4.3 & 2007 & na & na & na & na & na & na \\
\hline 12905 & 1 & 03 & SAFETY & 040 & 1.0 & 1.1 & 2003 & 27.75 & 26.00 & 1.75 & 0.50 & 0.33 & 0.17 \\
\hline 13031 & 2 & 24 & SAFETY & 081 & 39.1 & 39.1 & 2005 & 2.70 & 1.00 & 1.70 & 0.20 & 0.00 & 0.20 \\
\hline 13038 & 4 & 18 & SAFETY & 004 & 271.9 & 272.6 & 2003 & 2.88 & 1.67 & 1.21 & 0.75 & 0.00 & 0.75 \\
\hline 13077 & 1 & 34 & SAFETY & 047 & 44.7 & 45.5 & 2003 & 2.75 & 2.00 & 0.75 & 0.13 & 0.33 & $(0.21)$ \\
\hline 13080 & 2 & 36 & SAFETY & 091 & 39.0 & 39.0 & 2003 & 0.75 & 0.33 & 0.42 & 0.00 & 0.00 & 0.00 \\
\hline 13081 & 2 & 20 & SAFETY & 018 & 8.2 & 8.2 & 2003 & 0.13 & 0.00 & 0.13 & 0.00 & 0.00 & 0.00 \\
\hline 13082 & 2 & 22 & SAFETY & 081 & 30.7 & 30.7 & 2003 & 0.00 & 0.00 & 0.00 & 0.00 & 0.00 & 0.00 \\
\hline 13086 & 2 & 02 & SAFETY & 091 & 91.2 & 91.2 & 2003 & 1.38 & 0.00 & 1.38 & 0.13 & 0.00 & 0.13 \\
\hline 13087 & 2 & 36 & SAFETY & 039 & 43.0 & 43.0 & 2003 & 0.88 & 0.33 & 0.54 & 0.13 & 0.00 & 0.13 \\
\hline 13088 & 3 & 10 & SAFETY & 231 & 23.9 & 23.9 & 2003 & 0.00 & 0.00 & 0.00 & 0.00 & 0.00 & 0.00 \\
\hline 13089 & 4 & 19 & SAFETY & 019 & 138.3 & 138.4 & 2003 & 0.13 & 0.33 & $(0.21)$ & 0.00 & 0.33 & $(0.33)$ \\
\hline 13090 & 5 & 23 & SAFETY & 005 & 266.7 & 266.7 & 2003 & 0.00 & 0.00 & 0.00 & 0.00 & 0.00 & 0.00 \\
\hline 13100 & 2 & 21 & SAFETY & 009 & 0.0 & 0.0 & 2003 & 0.00 & 0.00 & 0.00 & 0.00 & 0.00 & 0.00 \\
\hline 13111 & 2 & 24 & SAFETY & 081 & 34.4 & 35.2 & 2005 & 8.10 & 1.00 & 7.10 & 0.80 & 0.00 & 0.80 \\
\hline
\end{tabular}




\begin{tabular}{|c|c|c|c|c|c|c|c|c|c|c|c|c|c|}
\hline \multirow[b]{2}{*}{$\begin{array}{l}\text { STIP Key } \\
\text { Number }\end{array}$} & \multirow[b]{2}{*}{$\begin{array}{l}\text { ODOT } \\
\text { Region }\end{array}$} & \multirow[b]{2}{*}{$\begin{array}{l}\text { County } \\
\text { Number }\end{array}$} & \multirow[b]{2}{*}{\begin{tabular}{|c|} 
Primary \\
Worktype
\end{tabular}} & \multirow[b]{2}{*}{$\begin{array}{l}\text { Hwy } \\
\text { Num }\end{array}$} & \multirow[b]{2}{*}{$\begin{array}{l}\text { Beginning } \\
\text { Milepoint }\end{array}$} & \multirow[b]{2}{*}{$\begin{array}{c}\text { Ending } \\
\text { Milepoint }\end{array}$} & \multirow[b]{2}{*}{$\begin{array}{l}\text { Const. } \\
\text { Year }\end{array}$} & \multicolumn{3}{|c|}{ Total Crashes } & \multicolumn{3}{|c|}{ Fatal and Severe Crashes } \\
\hline & & & & & & & & \begin{tabular}{|c|} 
Before \\
Crashes per \\
Year \\
\end{tabular} & $\begin{array}{c}\text { After } \\
\text { Crashes } \\
\text { per Year }\end{array}$ & $\begin{array}{l}\text { Reduction } \\
\text { in Crashes }\end{array}$ & $\begin{array}{c}\text { Before } \\
\text { Crashes } \\
\text { per Year }\end{array}$ & $\begin{array}{c}\text { After } \\
\text { Crashes } \\
\text { per Year }\end{array}$ & $\begin{array}{l}\text { Reduction } \\
\text { in Crashes } \\
\end{array}$ \\
\hline 13233 & 1 & 26 & SAFETY & 003 & 0.0 & 0.0 & 2004 & 0.00 & 0.00 & 0.00 & 0.00 & 0.00 & 0.00 \\
\hline 13237 & 4 & 18 & SAFETY & 020 & 0.0 & 0.0 & 2004 & 0.00 & 0.00 & 0.00 & 0.00 & 0.00 & 0.00 \\
\hline 13238 & 5 & 32 & SAFETY & 010 & 0.0 & 0.0 & 2004 & 0.67 & 0.00 & 0.67 & 0.00 & 0.00 & 0.00 \\
\hline 13265 & 2 & 20 & SAFETY & 229 & 0.0 & 1.0 & 2004 & 0.44 & 0.00 & 0.44 & 0.22 & 0.00 & 0.22 \\
\hline 13280 & 2 & 24 & SAFETY & 162 & 1.5 & 2.8 & 2004 & 29.67 & 21.00 & 8.67 & 0.78 & 0.00 & 0.78 \\
\hline
\end{tabular}


APPENDIX D:

STIP PROJECT SUMMARIES 

Table D.1: Summary of Selected Projects

\begin{tabular}{|c|c|c|c|c|c|c|c|c|c|c|}
\hline \multirow[b]{2}{*}{$\begin{array}{l}\text { Key } \\
\text { Number }\end{array}$} & \multirow[b]{2}{*}{ Region } & \multirow[b]{2}{*}{ Project Name } & \multirow{2}{*}{$\begin{array}{c}\text { ODOT } \\
\text { Highway } \\
\text { No } \\
\end{array}$} & \multirow[b]{2}{*}{ Highway Name } & \multicolumn{2}{|c|}{ Project Milepost } & \multirow[b]{2}{*}{$\begin{array}{l}\text { Construction } \\
\text { Year }\end{array}$} & \multirow[b]{2}{*}{$\begin{array}{l}\text { Target Crash } \\
\text { Type }\end{array}$} & \multicolumn{2}{|c|}{ Target Milepost } \\
\hline & & & & & From & To & & & From & To \\
\hline 07101 & 2 & US20 Cox Creek to UPRR & 16 & Santiam & 2 & 12.8 & 2002 & $\begin{array}{l}\text { Turn and Rear- } \\
\text { end }\end{array}$ & 9.77 & 9.87 \\
\hline 10576 & 1 & US30 Owl Creek & 92 & $\begin{array}{l}\text { Lower } \\
\text { Columbia River }\end{array}$ & 46.5 & 50.2 & 2001 & $\begin{array}{l}\text { Lane Departure } \\
\text { (All) }\end{array}$ & 46.5 & 50.2 \\
\hline 10665 & 1 & OR212 Rock Creek & 174 & $\begin{array}{l}\text { Clackamas- } \\
\text { Boring }\end{array}$ & 0 & 6.9 & 2001 & $\begin{array}{l}\text { Turning and Rear- } \\
\text { End }\end{array}$ & 0 & 6.9 \\
\hline 10666 & 1 & $\begin{array}{l}\text { OR10 Beaverton Tigard to } \\
\text { MCL }\end{array}$ & 40 & $\begin{array}{l}\text { Beaverton- } \\
\text { Hillsdale }\end{array}$ & 0.97 & 3.41 & 2001 & None & 0.97 & 3.41 \\
\hline 10679 & 1 & $\begin{array}{l}\text { OR8 Quince Street to } \\
\text { Gaston }\end{array}$ & 29 & Tualatin Valley & 17.88 & 26.51 & 2004 & None & 17.88 & 26.51 \\
\hline 10680 & 1 & OR8 Minter Br to 117th & 29 & Tualatin Valley & 4.05 & 11.28 & 2002 & None & 4.05 & 11.28 \\
\hline 10731 & 1 & $\begin{array}{l}\text { US26 Ross Island to } \\
\text { SE50th }\end{array}$ & 26 & Mt Hood & 1.02 & 3.46 & 2004 & None & 1.02 & 3.46 \\
\hline 10748 & 2 & $\begin{array}{l}\text { OR6 Tillamook RR to } \\
\text { Jordan Cr }\end{array}$ & 37 & Wilson River & 0.5 & 18 & 2002 & None & 1.75 & 1.85 \\
\hline 10807 & 2 & $\begin{array}{l}\text { OR22 Chemawa Road to } \\
\text { N. Santiam Intchg }\end{array}$ & 72 & Salem & 0.14 & 8.46 & 2004 & $\begin{array}{l}\text { Rear and } \\
\text { Sideswipe }\end{array}$ & 7.92 & 8.46 \\
\hline 10817 & 3 & $\begin{array}{l}\text { US101 Nesika Beach to } \\
\text { Rogue River }\end{array}$ & 9 & Oregon Coast & 320.4 & 327.9 & 2000 & None & 320.4 & 327.9 \\
\hline 11072 & 4 & $\begin{array}{l}\text { OR126 Crooked River to } \\
\text { Laughlin }\end{array}$ & 41 & Ochoco & 18 & 20.5 & 2002 & Turn and Angle & 19.7 & 19.8 \\
\hline
\end{tabular}




\begin{tabular}{|c|c|c|c|c|c|c|c|c|c|c|}
\hline \multirow[b]{2}{*}{$\begin{array}{l}\text { Key } \\
\text { Number }\end{array}$} & \multirow[b]{2}{*}{ Region } & \multirow[b]{2}{*}{ Project Name } & \multirow{2}{*}{$\begin{array}{c}\text { ODOT } \\
\text { Highway } \\
\text { No } \\
\end{array}$} & \multicolumn{3}{|c|}{ Project Milepost } & \multirow[b]{2}{*}{$\begin{array}{l}\text { Construction } \\
\text { Year } \\
\end{array}$} & \multirow[b]{2}{*}{$\begin{array}{l}\text { Target Crash } \\
\text { Type }\end{array}$} & \multicolumn{2}{|c|}{ Target Milepost } \\
\hline & & & & Highway Name & From & To & & & From & To \\
\hline 11125 & 1 & $\begin{array}{l}\text { OR211 Hult Rd to } \\
\text { Hillockburn }\end{array}$ & 161 & $\begin{array}{l}\text { Woodburn- } \\
\text { Estacada }\end{array}$ & 20.89 & 28.7 & 2002 & $\begin{array}{l}\text { Lane Departure } \\
\text { (Off-Roadway) }\end{array}$ & 20.89 & 28.7 \\
\hline 11858 & 2 & $\begin{array}{l}\text { OR22 Oldsville Rd to Ash } \\
\text { Rd }\end{array}$ & 39 & Salmon River & 40.37 & 50.1 & 2005 & None & 40.37 & 50.1 \\
\hline 11938 & 1 & $\begin{array}{l}\text { US30 Bennett Rd to Laurel } \\
\text { Ave }\end{array}$ & 92 & $\begin{array}{l}\text { Lower } \\
\text { Columbia River }\end{array}$ & 21.1 & 25.79 & 2004 & None & 21.1 & 25.79 \\
\hline 11939 & 1 & $\begin{array}{l}\text { US26 Hood River Hwy to } \\
\text { Pollalie Cr }\end{array}$ & 26 & Mt Hood & 73.79 & 84.93 & 2005 & None & 73.79 & 84.93 \\
\hline 11940 & 1 & $\begin{array}{l}\text { OR35 Long Prairie Rd to } \\
\text { Odell Hwy }\end{array}$ & 26 & Mt Hood & 91.5 & 96 & 2005 & None & 91.5 & 96 \\
\hline 12856 & 1 & $\begin{array}{l}\text { US26 Jewell Jct to } \\
\text { Military Rd }\end{array}$ & 47 & Sunset & 21.86 & 26 & 2006 & $\begin{array}{l}\text { Lane Departure } \\
\text { (Off-Roadway) }\end{array}$ & 21.86 & 26 \\
\hline 13675 & 2 & OR221 Dayton to Salem & 150 & Salem-Dayton & 0.49 & 17.23 & 2006 & None & 0.49 & 17.23 \\
\hline 14127 & 5 & $\begin{array}{l}\text { OR203 WCL Lagrande to } \\
\text { Union }\end{array}$ & 66 & $\begin{array}{l}\text { La Grande- } \\
\text { Baker }\end{array}$ & 0 & 15.8 & 2006 & $\begin{array}{l}\text { Lane Departure } \\
\text { (Off-Roadway) }\end{array}$ & 0 & 15.8 \\
\hline 14172 & 2 & $\begin{array}{l}\text { US26 Lindseley Cr to Lwr } \\
\text { Nehalem }\end{array}$ & 47 & Sunset & 5 & 20.7 & 2006 & $\begin{array}{l}\text { Turn, Rear-end, } \\
\text { and Angle }\end{array}$ & 19.67 & 19.77 \\
\hline 14189 & 4 & $\begin{array}{l}\text { US20 Hampton to Glass } \\
\text { Butte }\end{array}$ & 7 & Central Oregon & 4.49 & 75 & 2007 & None & 62 & 75 \\
\hline 12905 & 1 & $\begin{array}{l}\text { OR10 OR217 to SW } \\
\text { Maple Dr }\end{array}$ & 40 & $\begin{array}{l}\text { Beaverton- } \\
\text { Hillsdale }\end{array}$ & 0.96 & 1.09 & 2004 & Sideswipe & 0.99 & 1.05 \\
\hline 12905 & 1 & $\begin{array}{l}\text { OR10 OR217 to SW } \\
\text { Maple Dr }\end{array}$ & 144 & $\begin{array}{l}\text { Beaverton- } \\
\text { Tigard }\end{array}$ & 2 & 2.1 & 2004 & $\begin{array}{l}\text { Turning, Rear-end } \\
\text { and Sideswipe }\end{array}$ & 2 & 2.1. \\
\hline
\end{tabular}




\begin{tabular}{|c|c|c|c|c|c|c|c|c|c|c|}
\hline \multirow[b]{2}{*}{$\begin{array}{l}\text { Key } \\
\text { Number }\end{array}$} & \multirow[b]{2}{*}{ Region } & \multirow[b]{2}{*}{ Project Name } & \multirow{2}{*}{$\begin{array}{c}\text { ODOT } \\
\text { Highway } \\
\text { No } \\
\end{array}$} & \multicolumn{4}{|c|}{ Project Milepost } & \multirow[b]{2}{*}{$\begin{array}{l}\text { Target Crash } \\
\text { Type }\end{array}$} & \multicolumn{2}{|c|}{ Target Milepos } \\
\hline & & & & Highway Name & From & To & $\begin{array}{l}\text { Construction } \\
\text { Year }\end{array}$ & & From & To \\
\hline 09841 & 3 & OR42 Winston to I5 & 35 & $\begin{array}{l}\text { Coos Bay- } \\
\text { Roseburg }\end{array}$ & 73.2 & 77.2 & 2002 & $\begin{array}{l}\text { Turn and Rear- } \\
\text { end }\end{array}$ & 75.72 & 75.82 \\
\hline 09841 & 3 & OR42 Winston to I5 & 35 & $\begin{array}{l}\text { Coos Bay- } \\
\text { Roseburg } \\
\end{array}$ & 73.2 & 77.2 & 2002 & $\begin{array}{l}\text { Turn and Rear- } \\
\text { end }\end{array}$ & 76.22 & 76.32 \\
\hline 10349 & 2 & $\begin{array}{l}\text { I-105 Willamette to Pacific } \\
\text { Hwy }\end{array}$ & 227 & $\begin{array}{l}\text { Eugene- } \\
\text { Springfield }\end{array}$ & 0.89 & 3.95 & 2005 & $\begin{array}{l}\text { Rear and } \\
\text { Sideswipe }\end{array}$ & 1.21 & 1.53 \\
\hline 10349 & 2 & $\begin{array}{l}\text { I-105 Willamette to Pacific } \\
\text { Hwy }\end{array}$ & 227 & $\begin{array}{l}\text { Eugene- } \\
\text { Springfield }\end{array}$ & 0.89 & 3.95 & 2005 & $\begin{array}{l}\text { Rear and } \\
\text { Sideswipe }\end{array}$ & 2.35 & 3.09 \\
\hline
\end{tabular}


Table D.2: Summary of SIP Category Ratings by Project

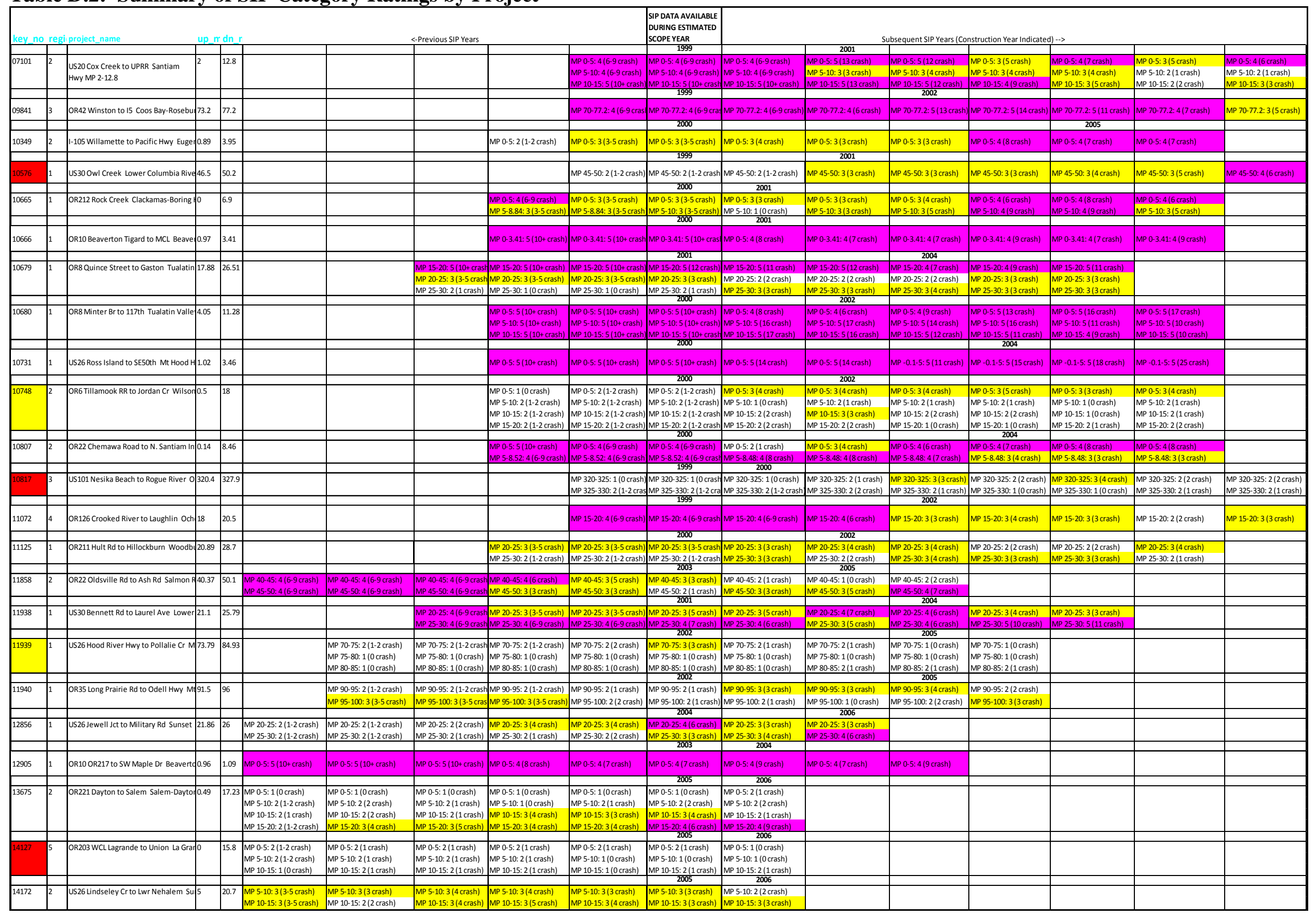

D-4 